\title{
Jean-Guy Vaillancourt
}

Sociologue, département de sociologie, Université de Montréal

(1982)

\section{Mouvement écologiste, énergie et environnement}

\section{Essais}

\section{d’écosociologie}

Un document produit en version numérique par Jean-Marie Tremblay, bénévole,

Professeur sociologie au Cégep de Chicoutimi

Courriel: jean-marie_tremblay@uqac.ca

Dans le cadre de "Les classiques des sciences sociales"

Site web: http://classiques.uqac.ca/

Une bibliothèque fondée et dirigée par Jean-Marie Tremblay, sociologue

Une collection développée en collaboration avec la Bibliothèque

Paul-Émile-Boulet de l'Université du Québec à Chicoutimi

Site web: http://bibliotheque.uqac.ca/ 


\section{Politique d'utilisation de la bibliothèque des Classiques}

Toute reproduction et rediffusion de nos fichiers est interdite, même avec la mention de leur provenance, sans l'autorisation formelle, écrite, du fondateur des Classiques des sciences sociales, Jean-Marie Tremblay, sociologue.

Les fichiers des Classiques des sciences sociales ne peuvent sans autorisation formelle:

- être hébergés (en fichier ou page web, en totalité ou en partie) sur un serveur autre que celui des Classiques.

- servir de base de travail à un autre fichier modifié ensuite par tout autre moyen (couleur, police, mise en page, extraits, support, etc...),

Les fichiers (.html, .doc, .pdf., .rtf, .jpg, .gif) disponibles sur le site Les Classiques des sciences sociales sont la propriété des Classiques des sciences sociales, un organisme à but non lucratif composé exclusivement de bénévoles.

Ils sont disponibles pour une utilisation intellectuelle et personnelle et, en aucun cas, commerciale. Toute utilisation à des fins commerciales des fichiers sur ce site est strictement interdite et toute rediffusion est également strictement interdite.

L'accès à notre travail est libre et gratuit à tous les utilisateurs. C'est notre mission.

Jean-Marie Tremblay, sociologue

Fondateur et Président-directeur général, LES CLASSIQUES DES SCIENCES SOCIALES. 
Cette édition électronique a été réalisée Jean-Marie Tremblay, bénévole, professeur de soins infirmiers retraitée de l'enseignement au Cégep de Chicoutimi

Courriel: jean-marie_tremblay@uqac.ca

à partir du livre de :

Jean-Guy Vaillancourt,

Mouvement écologiste, énergie et environnement. Essais d'écosociologie.

Montréal : Les Éditions coopératives Albert Saint-Martin, 1982, 262 pp. Collection : "Pratiques sociales".

L’auteur est sociologue au département de sociologie de l’Université de Montréal.

[Autorisation formelle accordée, le 10 mai 2005 par M. Jean-Guy Vaillancourt de diffuser ce livre dans Les Classiques des sciences sociales.]

g. Courriel : jean.guy.vaillancourt@umontreal.ca

Polices de caractères utilisée :

Pour le texte: Times New Roman, 12 points.

Pour les citations : Times New Roman 12 points.

Pour les notes de bas de page : Times New Roman, 12 points.

Édition électronique réalisée avec le traitement de textes Microsoft Word 2004 pour Macintosh.

Mise en page sur papier format : LETTRE (US letter), 8.5’’ x 11'’)

Édition numérique réalisée le 17 juillet 2008 à Chicoutimi, Ville de Saguenay, province de Québec, Canada. 


\section{Jean-Guy Vaillancourt}

Sociologue, département de sociologie, Université de Montréal

\section{Mouvement écologiste, énergie et environnement. Essais d'écosociologie}

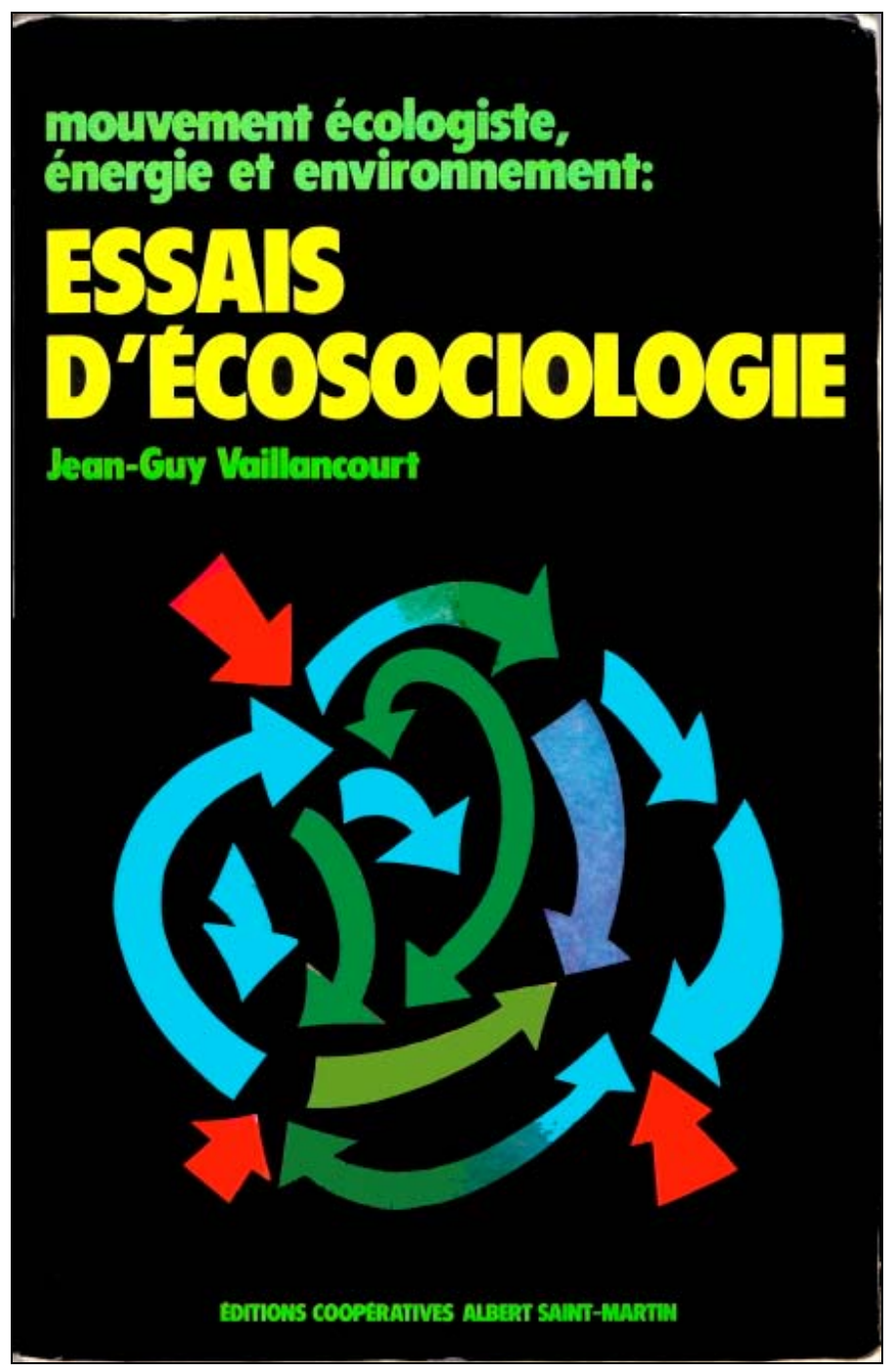

Montréal : Les Éditions coopératives Albert Saint-Martin, 1982, 262 pp. Collection: "Pratiques sociales". 


\section{Table des matières}

Quatrième de couverture

Introduction

\section{Première partie. Descriptions et analyses}

Chapitre 1. “Lettre à un militant anti-nucléaire.” Texte publié dans la revue Possibles, vol. 2, no 4, été 1978, p. 99-100.

Chapitre 2. "Décentralisation et démocratie de participation ." Texte inédit présenté sous forme de causerie à la Conférence du Rassemblement des citoyens de Montréal sur les conseils de quartier en octobre 1977, et révisé en 1978.

Chapitre 3. $\quad$ Question nationale et mouvement écologique.” Texte à paraître dans les Actes du colloque de Cérisy de 1979.

Chapitre 4. " “Le mouvement contre l'énergie nucléaire en Europe de l'Ouest.” Communication présentée au Congrès annuel du Council for European Studies, à Washington D.C. en octobre 1980, et publiée sous une forme révisée dans la revue Our Generation, vol. 15, no 2, 1982, p. 14-24.

$\underline{\text { Introduction }}$

Les origines du nucléaire et de l'opposition anti-nucléaire

La France

La Grande-Bretagne et l'Irlande

L'Allemagne de l'Ouest

L'Autriche

La Suisse, la Hollande et la Belgique

Les pays scandinaves

L'Espagne

L'Italie

$\underline{\text { Conclusion }}$ 
Chapitre 5. "Évolution, diversité et spécificité des associations écologiques québécoises.” Texte publié dans la revue Sociologie et Sociétés, vol. 13, no 1, avril 1981, p. 81-98.

Introduction

Origine et développement des associations écologiques québécoises

Unité et diversité du mouvement écologique québécois

Spécificité et originalité des associations écologiques québécoises

Tableau 1. Les idéologies écologiques

Chapitre 6. "Les Québécois ont-ils besoin du nucléaire ?.” Texte publié dans le bulletin De toute urgence, août 1981, vol. XII, no 2, p. 231-243.

Chapitre 7. "Le mouvement écologiste et anti-nucléaire face aux gouvernements.” Texte présenté au 2e Colloque sur la réforme et le changement en administration publique, Montréal les 27-28-29 avril 1982.

Introduction

L'évolution de la lutte anti-nucléaire

Pour un débat public sur l'énergie

La Semaine de l'énergie

Une promesse électorale...

La nouvelle régionalisation de la lutte

Le débat public sur l'énergie au niveau fédéral

Conclusion

Chapitre 8. “Le mouvement écologiste québécois des années 80.” Texte à paraître dans Changer de société, Serge Proulx et Pierre Vallières (sous la direction de), Québec-Amérique, Montréal, 1982. 


\section{Deuxième partie. Interventions et prises de position}

Chapitre 1. "Localisation de lignes de transport d'énergie.” Texte publié dans le Rapport du Comité d'experts sur l'environnement : analyse méthodologique, Direction Environnement, Hydro-Québec, Projet Canton Mousseau-Chénier, Montréal, janvier 1976 ; et reproduit dans le Mémoire pour le rejet du projet de ligne électrique de 735 $K w$ dans la région de Saint-Jean-de-Matha, mémoire du Comité des citoyens de Saint-Jean-de-Matha, Saint-Jean-de-Matha, 14 février 1978, p. 122-135.

Chapitre 2. "Le manifeste écologique et la croissance du mouvement au Québec.” Texte publié dans la revue Our Generation, vol. 13, no 4, automne 1979, p. 5-7.

Chapitre 3. "Manifeste écologique du Regroupement écologique québécois." Texte terminé le 22 novembre 1978, et distribué sous forme de pamphlet.

Introduction

Qui sont les écologistes?

Les problèmes et leur cause

Une société écologique

Plan d'action

Conclusion

Chapitre 4. "La politique québécoise de conservation de l'énergie.” Texte publié dans Le Devoir, 10 février 1981, p. 9-10.

Chapitre 5. "Le débat public sur l'énergie aura-t-il lieu .” Texte publié dans la revue Possibles, vol. 5, no 3-4, 1981, p. 277-288.

Chapitre 6. "Pour un débat public sur l'énergie.” Texte publié dans Le Devoir, le 5 octobre 1981, p. 14.

Chapitre 7. “Contre l'énergie nucléaire.” Texte présenté par l'Alliance Tournesol et le Regroupement pour la surveillance du nucléaire, publié dans Le Devoir, 23 novembre 1981, p. 7.

Chapitre 8. "Les interventions du groupe Écologie humaine d'Hydro-Québec." Texte publié dans L'Intervention sociale : Actes du colloque an- 
nuel de l'ACSALF, (sous la direction de Micheline Renaud-Mayer et Alberte Le Doyen), Éditions coopératives Albert Saint-Martin, Montréal, 1982, p. 245-255.

Chapitre 9. “L'électricité et le nucléaire.” Texte publié dans La Presse, 6 mai 1982, p. A7.

Chapitre 10. "Pourquoi prendre les risques de Gentilly II ? .” Texte publié dans Le Devoir, 14 juin 1982, p. 13 et 14.

\section{Troisième partie.} Perspectives critiques

Chapitre 1. “L'encerclement selon Barry Commoner.” Texte publié dans la revue Études internationales, vol. 5, no 1, mars 1974, p. 168-170.

Chapitre 2. "Pierre Dansereau, écologiste humain.” Texte publié dans la Revue canadienne de sociologie et d'anthropologie, vol. 13, no 3, août 1976, p. 365-368.

Chapitre 3. "La crise de l'énergie et les conflits mondiaux pour le pouvoir et la richesse.” Texte publié dans la revue Études internationales, vol. 7, no 3, septembre 1976, p. 481-483.

Chapitre 4. "Le nucléaire militaire et le nucléaire civil.” Texte publié dans la revue Études internationales, vol. 10, no 1, mars 1979, p. 200-201.

Chapitre 5. "Présentation du numéro spécial sur « Écologie sociale et mouvements écologiques ».” Texte publié dans la revue Sociologie et Sociétés, vol. 13, no 1, avril 1981, p. 3-11.

Chapitre 6. "Société de gaspillage, société de conservation et écosociété : des scénarios à la demi-douzaine.” Texte publié dans L'Environnement, vol. 8, no 2, mai 1981, p. 8.

Chapitre 7. "Relations industrielles et changements technologiques dans les mines de l'INCO.” Texte à paraître dans la Revue canadienne de sociologie et d'anthropologie, vol. 19, no 3, octobre-novembre 1982.

\section{BIBLIOGRAPHIE}


Aux militants et militantes écologistes et anti-nucléaires du Québec et à ma fille Véronique. 


\section{Mouvement écologiste, énergie et environnement. Essais d'écosociologie. \\ Quatrième de couverture}

$\underline{\text { Retour à la table des matières }}$

Le lecteur trouvera ici une série très diversifiée d'écrits marqués à la fois par la conjoncture et par les exigences souvent contradictoires d'une sociologie qui se veut à la fois objective et engagée dans les luttes sociales et politiques.

Cet ensemble touche le domaine de la sociologie de l'environnement, un secteur nouveau de la sociologie que l'on pourrait aussi appeler l'« écosociologie ». Celle-ci, par analogie avec la biosociologie et la psychosociologie, se situe au confluent de la sociologie et de l'écologie, mais en parlant du point de vue de la sociologie plutôt que de celui de l'écologie, contrairement à l'écologie humaine et à l'écologie sociale qui font plutôt le cheminement inverse.

Plusieurs des textes ont été écrits en équipe avec des écologistes militants. Ils ont tous été rédigés entre l'été 1972 et l'été 1982, soit les dix années qui se sont écoulées entre les deux grandes conférences de l'ONU sur l'environnement, celle de Stockholm en 1972 et celle de Nairobi en 1982. Ces dix années constituent une période cruciale en ce qui concerne la prise de conscience généralisée de la détérioration écologique de la biosphère.

Nous espérons que ces textes pourront en aider plusieurs à mieux comprendre l'une des questions les plus brûlantes actuellement pour l'avenir et la survie de l'humanité. 


\section{Mouvement écologiste, énergie et environnement.}

Essais d'écosociologie.

\section{Introduction}

Ce livre contient un ensemble de 25 essais, articles, et compte-rendus d'ouvrages, que j'ai rédigés, seul ou en collaboration, dans le domaine de la sociologie de l'environnement, un secteur nouveau de la sociologie que l'on pourrait aussi appeler « l'écosociologie ». Celle-ci, par analogie avec la biosociologie et la psychosociologie, se situe au confluent de la sociologie et de l'écologie, mais en partant du point de vue de la sociologie plutôt que de celui de l'écologie, contrairement à l'écologie humaine et à l'écologie sociale qui font plutôt le cheminement inverse. Plusieurs des textes qui suivent ont été produits depuis 1979, à mon retour d'une année sabbatique consacrée surtout à l'étude du mouvement écologiste et des questions énergétiques au Québec et en France. Quelques-uns ont été écrits en équipe avec des écologistes militants, entre autres, un jeune biologiste-sociologue formé en Acadie et en France, Ronald Babin. Ils ont tous été rédigés entre l'été 1972 et l'été 1982, donc durant ces dix dernières années, période durant laquelle j'ai enseigné l'écologie humaine et la sociologie de l'environnement à l'Université de Montréal, ainsi qu'à l'Université Bishops de Lennoxville (1976) et à l'Université du Québec à Chicoutimi (1980 et 1981).

Les dix années qui se sont écoulées entre les deux grandes conférences de l'ONU sur l'environnement, celle de Stockholm en 1972 et celle de Nairobi en 1982, constituent une période cruciale en ce qui concerne la prise de conscience 
généralisée de la détérioration écologique de la biosphère. Il m'a semblé qu'il serait utile, et peut-être

10 Mouvement écologiste, énergie et environnement

même intéressant, de regrouper en une anthologie la plupart des écrits que j'ai produits durant cette période sur la crise de l'environnement et sur les problèmes énergétiques, ainsi que sur le mouvement écologiste et le mouvement antinucléaire. J'ai l'impression que ces textes, dont la plupart ont déjà été publiés (parfois dans des endroits difficiles d'accès pour le lecteur profane et pour l'étudiant, voire même pour le militant écologiste et pour le sociologue patenté), pourront en aider plusieurs à mieux comprendre l'une des questions les plus brûlantes actuellement pour l'avenir et la survie de l'humanité. Je n'ai pas la prétention d'avoir tout couvert avec ces essais dans ce domaine en pleine expansion qu'est l'écosociologie, mais j'ai le ferme espoir d'avoir abordé assez de questions importantes avec assez d'acuité et de simplicité pour que le lecteur puisse sortir avec une intelligence enrichie et une conscience aiguisée de l'étude de ce petit livre.

Les 25 textes que je livre ici ont été regroupés en trois parties. Dans la première, les textes sont pour la plupart plus substantiels, plus descriptifs et plus analytiques que dans les deux autres. La deuxième partie du livre comprend surtout des textes de lutte, d'action et d'intervention. Tous les écrits que j'ai produits en collaboration avec les militants d'Alliance Tournesol et du Regroupement pour la surveillance du nucléaire, pour Le Devoir et pour La Presse, ont été inclus dans cette section. Enfin, la troisième partie du livre contient les recensions critiques d'ouvrages que j'ai publiées dans le domaine de l'écosociologie depuis une dizaine d'années.

Dans chacune des trois sections, j'ai décidé de présenter les textes selon l'ordre chronologique de leur rédaction ou de leur parution, à quelques exceptions près, parce qu'il m'a semblé qu'il serait artificiel de les classer par thèmes ou selon une autre logique. De plus, je n'ai pas retouché les textes déjà publiés, sauf pour en raccourcir un et pour supprimer une bibliographie redondante, afin de leur préserver toute leur saveur et toutes leurs faiblesses originales. Ainsi, le lecteur pourra mieux comprendre l'évolution des phénomènes que j'ai observés et commentés, et 
aussi l'évolution de ce que j'ai pensé en écosociologie, spécialement sur les thèmes de l'énergie et du mouvement écologiste que j'ai privilégiés dans mes écrits, dans mon enseignement, et dans mon action depuis le début des années 70. Cet ordre de présentation et d'exposition comporte toutefois un désavantage pour le lecteur : les premières choses que j'ai écrites dans ce domaine sont en général des documents moins intéressants que les textes un peu plus étoffés que j'ai produits depuis quelques années.

introduction 11

Le lecteur qui voudra parer à cet inconvénient pourra toujours commencer la lecture de chaque section en commençant par la fin et en remontant le cours du temps jusqu'aux écrits les plus anciens.

Lorsque j'ai commencé à enseigner au département de sociologie de l'Université de Montréal en septembre 1969, j'avais été engagé pour enseigner la sociologie des organisations et la sociologie de la religion. J'ai donc d'abord donné des cours dans ces deux domaines ainsi que des cours d'introduction à la sociologie et de théorie sociologique. Mais comme il y avait à ce moment-là plusieurs professeurs dans le département qui étaient intéressés à enseigner la sociologie des religions, j'ai proposé à mes collègues et à mon directeur de département de laisser tomber ce cours dans ma charge et de réactiver plutôt un cours appelé « écologie humaine » qui était au programme mais qui ne se donnait plus depuis quelque temps.

L'écologie humaine n'était pourtant pas dans mes aires de spécialisation, bien que j'aie été sensibilisé à ces questions dès 1962 par un cours d'Hervé Carrier en sociologie urbaine, et par mes lectures et mes activités à Berkeley entre 1965 et 1969. N'est-ce pas à Berkeley en effet, à la radio communautaire KPFA, que SPR Charter a fait ses célèbres conférences qui ont conduit à la publication d'un des meilleurs livres d'écologie humaine ${ }^{1}$, que la célèbre bataille du People's Park a eu lieu, et que les « contre-culturels » et les « politicos » et d'obscurs professeurs et

1 SPR Charter, Man on Earth : A Preliminary Evaluation of the Ecology of Man, préface d'Aldous Huxley, New York, Grove Press Inc., 1962. 
leurs étudiants jetaient les bases de la nouvelle écologie sociale et de l'écologie politique radicale. Je me souviens d'avoir été fortement marqué à ce moment-là par le livre de Shepard et McKinley intitulé The Subversive Science : Essays Toward an Ecology of $\mathrm{Man}^{2}$, une anthologie qui regroupait ce qui avait été écrit de plus intéressant et de plus radical dans ce domaine.

J'ai donc donné le cours d'écologie humaine au département de sociologie de l'Université de Montréal en 1970, en 1972, en 1974 et en 1976. Mes recensions des livres de Commoner, de Dansereau et de Tanzer datent de cette période. Quand je suis revenu d'année sabbatique au début de 1979, j'ai changé le titre et l'orientation du cours et j'ai commencé à faire davantage de sociologie de l'environnement, centrant un peu plus mon attention sur les groupes et les mouvements écologistes.

Le premier texte de l'ouvrage (I-1) est une lettre à un militant anti-nucléaire qui fut écrite juste avant mon départ pour la France en 1978, et quelques mois après la création de l'Alliance Tournesol, le regroupement des militants antinucléaires québécois francophones.

12 Mouvement écologiste, énergie et environnement

Le document qui suit sur la décentralisation et la démocratie de participation (I-2), est le texte d'un exposé que j'ai fait en octobre 1977 à la conférence du Rassemblement des citoyens de Montréal sur les conseils de quartiers. Ce texte a été révisé à la fin de 1978, mais il n'avait pas encore été publié. Le troisième texte (I3) est la communication que j'ai présentée au Colloque de Cérisy en 1979, un colloque sur les mouvements sociaux organisé par Alain Touraine. Comme Touraine venait à ce moment-là de terminer sa recherche sur le mouvement anti-nucléaire en France, et que le manuscrit de son livre sur ce sujet était déjà terminé ${ }^{3}$, il fut beaucoup question des groupes écologistes et anti-nucléaires durant le colloque. L'essai suivant (I-4) sur le mouvement anti-nucléaire européen entre 1970 et 1980

2 Paul Shepard and Daniel McKinley, The Subversive Science Essays toward an Ecology of Man, Boston, Houghton Mifflin Company, 1969.

3 Alain Touraine, Z. Hegedus, F. Dubet, M. Wieviarka, La Prophétie antinucléaire, Paris, Seuil, 1980. 
a d'abord été présenté en octobre 1980 à Washington à un congrès d'européanistes, puis il a été révisé et publié en anglais dans la revue Our Generation durant l'été 1982.

En avril 1981, paraissait le numéro spécial de la revue Sociologie et Sociétés que j'ai consacré au thème «Écologie sociale et mouvements écologiques ». J'ai reproduit ici, extrait de ce numéro, mon article sur les associations écologiques québécoises (I-5), article fort bien accueilli par la plupart des écologistes ${ }^{4}$. Le texte sur l'idéologie des groupes anti-nucléaires québécois (I-6) a été présenté au 6e colloque du Conseil québécois de l'environnement qui a eu lieu à l'UQÀM en novembre 1980 et qui portait sur le thème des besoins. Cet essai a été publié dans la revue du CQE, De toute urgence, et doit paraître sous peu dans le volume des Actes du colloque de 1980.

Le texte suivant (I-7), écrit en collaboration avec Ronald Babin, est notre contribution à la session «mouvements écologiques » de l'atelier « organisations et mouvements sociaux » que j'ai organisé et animé lors du 2e Colloque sur la réforme et le changement en administration publique du Groupe de recherche en administration publique. Enfin, le dernier texte de la première partie (I-8), est une analyse que je viens de terminer sur le mouvement écologiste tel qu'il se développe à l'heure actuelle. Il paraîtra bientôt dans un ouvrage collectif sur les nouvelles pratiques culturelles, ouvrage qui sera publié au début de l'automne 1982 sous la direction de Serge Proulx et de Pierre Vallières.

La seconde partie du livre s'ouvre avec mon rapport sur la localisation des lignes de transport d'énergie (II-1) qui a été présenté à l'intérieur d'un comité d'ex-

4 Benoît Boutin, « L'Écologie sociale, ce fleuve obscur », Le Devoir, 22 août 1981, p. 11.

Gilbert Tarrab, «L'Écologie sociale », bulletin de l'ACSALF, vol. 4, no 1, février 1982, p. 36-39, reproduit en partie dans La Presse, 20 février 1982, p. C5.

André Delisle, «Écologie sociale et mouvements écologiques », QuébecScience, vol. 20, no 6, février 1982, p. 54.

Voir aussi les remarques de Jean-Pierre Rogel, Un Paradis de la pollution, p. 126-128 et le compte rendu de Michel Maldague, dans De toute urgence, vol. 12, no 2, août 1981, p. 296. 
perts appelé à évaluer la ligne Canton Mousseau-Chénier pour le compte d'HydroQuébec. Je décris plus loin dans un autre texte qui porte sur les interventions d'Hydro-Québec (II-8), le contexte dans lequel cet article a été écrit et publié.

\section{Introduction 13}

Ma présentation du manifeste des écologistes québécois (II-2) a été publiée en anglais dans la revue Our Generation. J'ai cru bon de l'inclure ici, et de la faire suivre du texte du manifeste lui-même (II-3), bien que je n'aie pas participé de façon très active à la rédaction finale du manifeste. Je considère que ce manifeste est un document collectif d'une grande importance, comme l'ont souligné d'ailleurs les quatre rédacteurs de la revue Our Generation dans leurs commentaires publiés dans le même numéro de cette revue, juste après ma présentation et le manifeste lui-même.

Début 1981, un petit groupe de militants d'Alliance Tournesol et du Regroupement pour la surveillance du nucléaire, dont je faisais partie, a publié dans Le Devoir un article sur la politique de conservation de l'énergie (II-4). Ce texte est suivi ici d'un essai que j'ai écrit pour la revue Possibles sur la semaine de l'énergie organisée par le Front commun pour un débat public sur l'énergie (II-5). Les deux articles, suivants (II-6 et II-7), publiés dans Le Devoir à l'automne 1981, sont le fruit d'un travail fait en collaboration avec des militants de l'Alliance Tournesol et du Regroupement pour la surveillance du nucléaire. Quant à mes commentaires sur «Les interventions du groupe écologie humaine d'Hydro-Québec » (II-8), c'est une communication faite au congrès de 1981 de l'ACSALF, dans le contexte d'une session sur les interventions en écologie humaine. L'article qui suit, sur l'électricité et le nucléaire (II-9), est le fruit d'une collaboration qui se poursuit toujours avec des militants anti-nucléaires. Il est paru dans La Presse le 6 mai 1982. Il fait partie de la série d'articles que nous avions publiés l'année précédente dans Le Devoir. Nous avons décidé de le présenter cette fois-ci à La Presse afin de rejoindre un nouveau public. Enfin le dernier texte de cette deuxième partie du livre (II-10), a été publié dans Le Devoir du 14 juin 1982, ainsi que dans La Presse et dans The Gazette. 
Les comptes rendus critiques d'ouvrages d'écosociologie constituent le troisième type d'essais que j'ai cru bon d'inclure dans ce livre. Celui sur Commoner (III-1) établit de façon explicite le lien entre le capitalisme et la crise de l'environnement. Commoner est un homme bien connu. Il est actuellement l'un des écologistes les plus prestigieux et les plus engagés au plan international. Il fut le candidat présidentiel du People's Party aux élections américaines de 1980 et il demeure l'un des écologistes les plus écoutés dans le monde entier. Ma critique de l'ouvrage La Terre des hommes et le paysage intérieur de Pierre Dansereau (III-2), tente de faire ressortir les aspects sociologiques de l'oeuvre de ce grand écologiste québécois. Je me situe ici dans une perspective d'écologie politique radicale,

14 Mouvement écologiste, énergie et environnement

comme c'est le cas dans l'article suivant sur la crise de l'énergie telle que vue par Michael Tanzer (III-3). L'ouvrage de Tanzer, comme ceux de Commoner et de Dansereau, n'ont pas perdu de leur actualité et semblent même avoir eu des accents quelque peu prophétiques, quand on les lit à la lumière de ce qui s'est passé dans le domaine de l'écologie depuis leur parution. Quant à la brève recension de deux livres qui suit ces trois comptes rendus, elle illustre l'intérêt accru de ma part pour la question importante du nucléaire civil et militaire au moment où le mouvement anti-nucléaire québécois était en voie de formation et de consolidation.

J'ai inclus dans cette dernière section un texte qui n'est pas à proprement parler une recension, mais plutôt une présentation d'ouvrage (III-5). En effet, j'ai reproduit ici la présentation du numéro spécial de la revue Sociologie et Sociétés, que j'avais composée pour décrire l'évolution de l'écologie humaine et sociale, et de la sociologie de l'environnement. J'y ai supprimé le bref sommaire de chacun des dix articles du numéro. L'article sur les scénarios imaginés par le professeur Valaskakis et son groupe GAMMA (III-6), est une version légèrement remaniée, pour le journal L'Environnement de la SVP, d'une recension du livre La Société de conservation que j'avais publiée quelques mois plus tôt dans la Revue canadienne de science politique ${ }^{5}$. Enfin, le dernier essai est une recension d'ouvrage qui sera

$5 \quad$ Revue canadienne de science politique, vol. XIV, no 4, décembre 1981, p. 824-827. 
publiée sous peu. Les mines sont un des secteurs les plus importants des ressources naturelles, dont l'épuisement constitue l'un des points critiques de la crise de l'environnement. Ma critique en somme fort chaleureuse de l'excellent livre de Wallace Clement sur l'industrie minière (III-7), déborde les cadres de l'écosociologie mais s'y rattache quand même puisqu'il s'agit des relations de travail et des changements technologiques dans un secteur où les problèmes d'environnement et de santé, et de sécurité des travailleurs, sont au premier plan.

En somme, le lecteur trouvera ici une série très diversifiée d'écrits marqués à la fois par la conjoncture et par les exigences souvent contradictoires d'une sociologie qui se veut à la fois objective et engagée dans les luttes sociales et politiques. Je n'ai pas la prétention de livrer ici un opus ciselé et définitif, mais plutôt les jalons d'un cheminement personnel à travers l'écosociologie contemporaine. J'ai l'espoir que ces textes pourront être de quelque utilité aux militants et aux chercheurs qui sont de plus en plus avides d'information et de direction dans le domaine de l'écologie et de l'environnement, et qu'ils contribueront à combler quelque peu le large fossé qui existe encore entre l'université et la société, entre la recherche et l'action.

\section{Introduction 15}

En ce qui me concerne, j'ai l'intention de continuer à travailler en écosociologie, parce que j'ai bien conscience qu'une fois que l'on s'engage dans des questions aussi vitales que celles qui sont traitées dans ce livre, il est bien difficile de s'en dégager. L'avenir de la vie sur notre petite planète, sur ce que certains écologistes ont appelé «le vaisseau spatial Terre » est tellement fragile et précaire depuis quelques décennies que l'on ne peut plus se fermer les yeux, les oreilles et la bouche une fois qu'on les a ouverts.

En terminant, je voudrais remercier tous les militants écologistes et environnementalistes qu'il m'a été donné de connaître, avec lesquels j'ai travaillé depuis plus de cinq ans, et dont j'ai pu admirer le dévouement inlassable et la ténacité à toute épreuve. Je leur dédie ce livre, dont les droits d'auteur, s'il y en a, seront partagés à part égale entre l'Alliance Tournesol et le Conseil québécois de l'environnement. 
Mouvement écologiste, énergie et environnement.

Essais d'écosociologie.

\section{Première partie}

\section{Descriptions et analyses}

Retour à la table des matières 


\title{
Mouvement écologiste, énergie et environnement.
}

Essais d'écosociologie.

Première partie . Descriptions et analyses

\section{Chapitre 1}

\section{Lettre à un militant anti-nucléaire}

Texte publié dans la revue Possibles, vol. 2, no 4, été 1978, p. 99-100.

\author{
par Jean-Guy Vaillancourt
}

\section{$\underline{\text { Retour à la table des matières }}$}

Cher Michel,

J'ai bien reçu ta lettre, dans laquelle tu m'informes de la création à Sherbrooke d'un centre de documentation sur le nucléaire et sur les énergies alternatives, pour notre région des Cantons de l'Est. Tu me demandes de t'envoyer une liste des plus importants journaux anti-nucléaires ayant une perspective internationale, ainsi qu'un bilan de mes recherches sur le mouvement anti-nucléaire mondial et une bibliographie sur le nucléaire et les alternatives douces. Comme je pars dans quelques jours pour Paris, et que je n'ai pas encore réussi à me relever complètement de la pire grippe de ma vie, ma première réaction est de t'envoyer une petite note disant que je te ferai parvenir tout cela à mon retour, d'autant plus que j'ai à peine commencé à rédiger un petit article sur le mouvement anti-nucléaire québécois que j'ai promis à la revue Possibles. En y pensant bien, je me rends compte qu'il est aussi important d'acquiescer à ta demande avant mon départ que de terminer cet article. Mieux encore, peut-être puis-je faire d'une pierre deux coups, et suggérer à Possibles de publier cette lettre à un jeune militant que je considère 
comme l'un des plus solides et des mieux articulés parmi ceux qui se battent pour une société écologique en territoire québécois. J'ajouterai à ce que tu me demandes un peu d'information sur la petite histoire du jeune mouvement écologique anti-nucléaire québécois, car je crains que si personne n'écrit ces choses à ce moment-ci, nous oublierons comment est né ce mouvement. J'espère donc que cette lettre contribuera un peu à la construction d'un mouvement décentralisé d'action et d'information sur le nucléaire et ses alternatives au Québec, en aidant notre groupe des Cantons de l'Est à organiser sa banque d'information et en informant les lecteurs de Possibles de ce qui se passe au plan de la lutte anti-nucléaire pour qu'eux aussi puissent s'y impliquer activement.

Il y a deux dates importantes à retenir dans la brève histoire du mouvement anti-nucléaire au Québec, le 22 octobre 1977 et le 12 février 1978. Le 22 octobre eut lieu la plus grande manifestation anti-nucléaire sur le sol québécois. Le 12 février, c'est le jour de fondation de l'Alliance Tournesol, une coalition des groupes anti-nucléaires québécois. Le 12 février dernier, lors du week-end de formation intensive sur le nucléaire convoqué par le Comité écologique anti-nucléaire aux Ateliers d'Éducation populaire, au 350 rue Boucher à Montréal, les participants ont donné naissance à un véritable mouvement écologique anti-nucléaire. Tu te rappelles sans doute qu'au début du bref exposé que j'ai fait sur le mouvement anti-nucléaire international, j'ai insisté sur le fait que l'enjeu du nucléaire est à la fois très local (ce sont d'abord les gens de la région de Trois-Rivières, de Lotbinière et Grondines, qui sont affectés), mais que c'est aussi un problème qui touche tous les Québécois et tous les habitants de la planète. Même si les Français, les Allemands, les Américains, les Ontariens sont encore plus embarqués dans le nucléaire que nous, je pense qu'il faut d'abord connaître notre propre mouvement ici au Québec, ainsi que notre establishment nucléaire québécois, canadien et américain, plutôt que de trop nous attarder sur ce qui se passe loin de chez nous. Nous avons quand même beaucoup à apprendre des autres expériences, surtout de celle de l'Ontario puisque c'est là que l'Énergie atomique du Canada, une compagnie du fédéral, en collaboration avec Hydro-Ontario, a le plus développé de projets de centrales semblables à celles que nous avons au Québec. Le mouvement anti-nucléaire ontarien est surtout actif au plan des publications et de la représentation auprès du gouvernement et de la Commission Porter. Des groupes comme Probe (43 Queen's Park Crescent East, Toronto et 53 rue Queen, bureau 54, Ot- 
tawa) et CANDU (Box 342, Goderich, Ontario) sont deux des groupes les plus dynamiques en Ontario, et il est possible d'obtenir d'eux beaucoup d'information sur la filière canadienne CANDU. Il existe aussi un journal anti-nucléaire dans les Maritimes qui s'appelle Nuclear Reaction (25 cents l'exemplaire, en écrivant àMary Keith, 17 Sunset Drive, Saint-Jean, Nouveau-Brunswick).

Pour ce qui est des livres canadiens, le plus utile à mon avis est celui de Fred H. Knelman, Nuclear Energy, the Unforgiving Technology, (Hurtig, Edmonton, 1976), que Solange Vincent, une des Québécoises les mieux informées sur le nucléaire est en train de traduire en français. Je te recommande aussi trois petits livres publiés par Info-Earth (P.O. Box 138, Station B, Ottawa) : The Nuke Book à 2,95 \$, The Sun Book à 2,50 \$ et The Wind Book à 2,50 \$. Info-Earth a aussi une liste d'autres publications sur le nucléaire et les alternatives douces.

Je mentionne ces groupes et ce matériel canadien, car c'est la filière CANDU (réacteur à uranium naturel et à eau lourde) qu'il nous faut surtout connaître ici au Québec, bien plus que les filières américaines ou européennes. Les vendeurs du nucléaire, l'establishment nucléaire qui agit au Québec, est le même qui opère en Ontario. Tout ne s'arrête pas avec Hydro-Québec, loin de là. Le complexe gouvernemental industriel qui colporte le nucléaire au Québec est un establishment américano-canadien. Le gouvernement fédéral y joue un rôle très important, de même que les membres importants de l'Association nucléaire canadienne comme Canatom.

Le groupe anti-nucléaire canadien le mieux connu est le Regroupement pour la surveillance nucléaire / Coalition for Nuclear Responsability (2010 rue Mackay, Montréal), une vaste coalition formée en 1975 par de nombreux groupes préoccupés par les dangers de l'énergie nucléaire. La section francophone (québécoise) de cet organisme a été très active depuis trois ans. Son mémoire sur J'énergie, présenté à la Commission parlementaire des Ressources naturelles du Québec, le 11 février 1977, comprend une large section sur le nucléaire au Québec qui constitue une excellente introduction à cette question.

Un autre groupe très important et très dynamique, et aussi ancien que le Regroupement pour la surveillance du nucléaire, est le Comité de protection de l'en- 
vironnement de Lotbinière, formé en 1975 pour empêcher la construction d'une centrale nucléaire à Lotbinière. Ce groupe s'occupe d'information auprès de la population, surtout au niveau local, et attaque régulièrement les politiques pronucléaires d'Hydro-Québee. Il a présenté lui aussi au début de 1977 à la Commission Joron un excellent mémoire intitulé : Centrales nucléaires : aventure technique coûteuse, dangereuse et inutile. C'est ce même groupe qui reprochait environ un an plus tard au gouvernement de retarder la publication d'un rapport du Conseil consultatif de l'environnement sur le manque de normes sécuritaires à l'usine d'eau lourde de La Prade, rapport qui exigeait une halte dans la construction pour améliorer ces normes.

En février 1977, le Conseil québécois de l'environnement que dirige le professeur Maldague a aussi présenté un mémoire qui demandait un moratoire suspendant tout recours à l'électro-nucléaire. STOP, Sauvons Montréal, SVP, ainsi que quelques individus, soumirent aussi des mémoires exigeant la mise au ban du nucléaire.

Plusieurs groupes écologiques québécois, et surtout la Société pour vaincre la pollution (SVP), sont actifs depuis quelques années dans la lutte contre l'énergie nucléaire. Le 3 mars 1976, par exemple, la SVP organisait une projection du film américain Lovejoy's Nuclear War, et un panel suivi d'une discussion avec des experts et des militants. C'est le comité Énergie-Environnement de la SVP qui a publié en 1975 (et réédité à la fin de 1976) la brochure intitulée : Tout ce que vous aimeriez ne pas savoir sur l'énergie nucléaire et que l'on ne voudrait pas non plus vous dire (64 pages). Ce document contient une bonne bibliographie. Le journal L'Environnement de la SVP (C.P. 65, Place d'Armes, Montréal) publie beaucoup d'informations sur le nucléaire dans chacun de ses numéros depuis quelque temps. En collaboration avec d'autres groupes écologiques (le Comité Ste-Croix de Lotbinière et celui de Grondines, le Mouvement pour l'agriculture biologique, le Monde à bicyclette, Contact-Conservation, Projet banque d'information, le Groupe écologique Maisonneuve, le Regroupement québécois pour la protection de l'environnement, Sauvons Montréal, STOP, la Librairie populaire d'Alma, et j'en oublie peut-être), la SVP a aidé à donner naissance au mouvement écologique anti-nucléaire québécois l'été dernier. En effet, au mois d'août 1977, un comité d'action formé de représentants de ces groupes a décidé de se réunir pour organi- 
ser une manifestation à Gentilly à l'automne, suite à une suggestion venant du groupe très dynamique des militants de Trois-Rivières, qui voulaient aussi créer un regroupement des forces anti-nucléaires québécoises. (Je te recommande de faire circuler dans la région l'excellent petit tract À propos du Nucléaire, préparé par Ross Lessard et l'extraordinaire Dédé la Terreur.)

C'est donc dire que le Front commun qui fut mis sur pied par ces militants ne fut pas une structure imposée d'en haut par un seul groupe, mais plutôt une coalition souple issue des protestations de groupes bien enracinés dans leur milieu. À mesure que les membres de ces groupes s'informent et s'activent, ils découvrent la nature des intérêts politiques et économiques qui jouent à la roulette russe avec l'avenir de la planète et qui essaient de garder en vie avec l'aide des fonds publics une industrie qui se meurt, et ils deviennent de plus en plus politisés et intéressés à connaître davantage les ramifications de cette industrie nucléaire et ses liens avec les gouvernements.

Au Québec, en 1966, les autorités d'Hydro-Québec avaient accepté de participer à la construction d'un réacteur expérimental avec l'Énergie atomique du Canada Limitée à Gentilly. Gentilly I a commencé à opérer en 1972, mais dut fermer ses portes pendant deux ans. En 1973, une deuxième centrale, propriété d'HydroQuébec, fut mise en chantier (Gentilly Il), et l'année suivante l'EACL décida de construire une usine d'eau lourde à La Prade pour alimenter les centrales en eau lourde. Selon les projets d'Hydro-Québec, il y a de 30 à40 centrales nucléaires de prévues le long du Saint-Laurent, au coût de 51 milliards de dollars environ et Gentilly I devait servir uniquement à fournir de l'électricité à l'usine de La Prade. Durant l'été de 1972, on décida de construire Gentilly III, qui devait être terminée avant 1990. Avec le récent moratoire du gouvernement du Québec, il semble que pour l'instant seulement ces trois centrales verront le jour, mais pour les militants de l'anti-nucléaire, ce sont là trois centrales de trop. Au mois d'août l'an dernier, c'est contre tous ces projets et contre le faux moratoire qui s'annonçait (le gouvernement du Québec s'est engagé avec Ottawa à acheter suffisamment d'eau lourde pour alimenter cinq centrales) que les groupes écologiques avaient décidé de se liguer. 
Le 20 septembre 1977, le Front commun anti-nucléaire, regroupant une quinzaine d'organismes québécois, fut lancé simultanément à Montréal, Alma et TroisRivières, en solidarité avec la lutte entreprise dans plusieurs autres pays, lutte qui s'organise de plus en plus sur une base politique et pas seulement sur une base morale.

La déclaration de principe distribuée en conférence de presse le 20 septembre insistait sur la nécessité, à cause des dangers encourus, de dire non au nucléaire, d'arrêter toute activité de production d'eau lourde et d'énergie nucléaire sur le sol québécois, d'aider la recherche sur les alternatives douces et sur l'application des principes de la conservation, et enfin de financer une campagne d'information sur ces sujets. Le but du mouvement n'était pas seulement d'obtenir un moratoire mais de faire rayer de la carte Gentilly 1 et Gentilly Il, ainsi que l'usine de La Prade, et d'amorcer la création d'une société écologique autogérée et décentralisée. Le Front commun n'hésita pas à s'attaquer de front aux «marchands du nucléaire » et à sommer les gouvernements à Ottawa et à Québec de cesser leur complicité avec cette « industrie de la mort ».

Le 5 octobre, le Front commun organisa une « Journée anti-nucléaire » au Cégep Maisonneuve, où l'on trouve l'un des groupes écologiques anti-nucléaires les plus actifs à Montréal.

La principale activité du Front commun fut de préparer une grande manifestation à Gentilly. Celle-ci eut lieu le 22 octobre 1977. Malgré le froid et les grands vents qui soufflaient dans la plaine, cette première grande manifestation antinucléaire sur le sol québécois fut un franc succès. Près de huit cents personnes firent à pied ou à bicyclette le trajet entre le centre du village de Gentilly et les installations d'eau lourde et de production électronucléaires. Les manifestants déposèrent devant une des usines une espèce de cercueil symbolisant un contenant de déchets nucléaires. De retour au village, ils passèrent la soirée à s'informer, à discuter et à fêter, dans une atmosphère de grande curiosité intellectuelle et de convivialité.

Suite à cette manifestation du 22 octobre, une nouvelle étape fut franchie un mois plus tard, le 19 novembre, quand une cinquantaine de personnes du Front 
commun anti-nucléaire se réunirent à Montréal pour faire le point et relancer la lutte. Les écologistes présents formèrent un Comité écologique anti-nucléaire et mirent en branle un processus pour créer un regroupement des écologistes québécois au printemps. Entre-temps, le Comité écologique anti-nucléaire se réunit à diverses reprises, en décembre et en janvier, publia une lettre-manifeste aux 6 millions de Québécois, et décida de travailler à structurer (de façon très souple et décentralisée) un vaste mouvement anti-nucléaire québécois. Grâce au travail acharné d'une douzaine de militants, le comité organisa une session intensive de formation (avec films, vidéo, conférences, discussion, table de documentation) sur la filière nucléaire canadienne.

Cette session très importante eut lieu les 11 et 12 février à Montréal, et réunit une centaine de personnes de tous les coins du Québec intéressées à acquérir une connaissance Plus Poussée des aspects techniques, politiques et économiques du nucléaire. Le dimanche 12 février 1978 est une journée importante pour le mouvement anti-nucléaire québécois, car c'est ce jour-là, vers la fin de l'après-midi, que fut créée ] Alliance Tournesol, un mouvement écologique anti-nucléaire décentralisé basé sur des cellules locales autonomes reliées entre elles autour de centres régionaux. L'Alliance Tournesol a maintenant un local (1375 rue MarieAnne à Montréal) et les éléments d'une banque d'information. À Montréal, depuis le 9 mars dernier et à tous les jeudis soirs par la suite, à 20 heures, au Vidéographe (1604, rue Saint-Denis), l'Alliance organise des soirées d'information sur le nucléaire pour toute la population, en se servant de vidéos. Il y a aussi des sessions sur le nucléaire et les alternatives qui sont organisées dans les Cégeps par des militants de l'Alliance Tournesol, et par des membres d'autres groupes comme les Amis de la Terre dont la section québécoise vient d'être fondée par l'écologiste Michel Jurdant de Québec.

Il y aura d'autres activités anti-nucléaires et pro-solaires ce printemps et surtout cet été, dans différentes régions du Québec. Le but de l'Alliance Tournesol se propose de dénoncer le faux moratoire décrété par le gouvernement québécois sous la pression du chantage que fait le gouvernement fédéral en faisant miroiter des emplois et des octrois. De plus, il exige le rejet pur et simple de l'option nucléaire, c'est-à-dire l'arrêt de toute nouvelle construction de centrale et des études concernant le choix de sites futurs, ainsi que la fermeture de l'usine de La Prade et 
des centrales de Gentilly. Il y aura d'autres manifestations comme celle du 22 octobre dernier.

De façon plus positive, l'Alliance Tournesol demande la mise sur pied d'un vaste programme de recherches appliquées dans le domaine des énergies douces et renouvelables. Plusieurs des membres de l'Alliance participeront au congrès de regroupement des écologistes québécois qui a été annoncé pour la mi-avril. De plus, ils organiseront des célébrations pour la fête du Soleil au début de mai, et continueront à informer la population sur les dangers du nucléaire et sur la nécessité de développer des alternatives moins coûteuses et moins périlleuses à tous points de vue.

Je n'insisterai pas ici sur ces dangers du nucléaire, ni sur les bienfaits qui découleraient de l'utilisation d'une technologie appropriée, car ça nous conduirait trop loin. Je n'ai pas le temps non plus pour le moment de décrire le mouvement écologique anti-nucléaire au plan international, ni l'industrie nucléaire et les rapports qu'elle entretient avec les gouvernements. Ce sera pour une autre fois. J'ai préféré insister ici sur les premiers balbutiements du mouvement anti-nucléaire québécois, car c'est à partir de ce mouvement que tout le reste s'éclaire. Pour terminer, cher Michel, il me reste à te donner quelques informations sur les livres et les journaux anti-nucléaires les plus importants, au plan international, pour la banque d'information de Sherbrooke et pour ceux qui voudraient parfaire leur formation dans ce domaine.

En français, il existe maintenant beaucoup de livres, mais je te recommande les suivants qui me semblent les plus utiles :

1. Jean-Pierre Colson, Le Nucléaire sans les Français. Qui décide? Qui profite ? Paris, Maspéro, 1977.

2. $\quad$ Les Amis de la Terre, L'Escroquerie nucléaire, Lutter/Stock, 2, 1975.

3. Pierre Samuel, Le Nucléaire en question, Paris, Éditions Entente, 1977.

4. $\quad$ Michel Bosquet (André Gorz), Écologie et politique, Paris, Seuil, 1978.

5. Syndicat CFDT de l'Énergie atomique, L'Électro-nucléaire en France, Paris, Seuil, 1975. 
6. Dominique Pignon et al., Questions sur le nucléaire, Paris, Éditions Christian Bourgois, 1975.

7. René Dumont, L'Utopie ou la mort, Paris, Seuil, 1974.

8. Didier Anger, Chronique d'une lutte, Paris, Jean-Claude Simoën, 1977.

9. Laurent Samuel, Guide pratique de l'écologiste, Paris, Christian Bourgois, 1977.

10. Claude-Marie Vadros, L'Écologie, histoire d'une subversion, Paris, Syros, 1977.

11. Jean-Claude Ribes, Pourquoi les écologistes font-ils de la politique?, Paris, Seuil, 1978.

12. Brice Lalonde et Dominique Simonnet, Quand vous voudrez, Paris, Pauvert, 1977.

Quant aux revues en langue française en plus de Mainmise et de quelques autres revues et journaux québécois, qui ont des articles de temps en temps et qu'il serait utile d'avoir ou de pouvoir consulter, je suggère les suivantes :

1. Le Sauvage, 12, rue du Mail, 75002, Paris.

2. Écologie, 12, rue Neuve du Patis, 45200 Montargis, France.

3. La Gueule ouverte, B.P. 26, 71800 La Clayette, France.

4. Politique-Hebdo.

5. Le Nouvel Observateur.

6. Sciences et Vie.

Descriptions et analyses 27

En anglais, il y a quelques journaux et bulletins de liaison qui ont une perspective internationale et qui pourraient être utiles aux militants québécois. Voici les principaux (les items 2 et 3 sont les meilleurs) :

1. Critical Mass. Journal, Box 1538, Washington DC 20013.

2. The Dutch Link, LEK, 2e Weteringplantsorig, Amsterdam, Hollande.

3. Nuclear Opponents, Citizens Energy Council, Box 285, Allendale, N.J. 07401. 
4. People and Energy, CEP, 1413 K Street, N.W., 8th floor, Washington, DC 20005.

5. Clamshell Alliance News, 62 Congress St., Portsmouth, N.H. 03801.

6. EARS, 2234 Colfax, Denver, Colorado 80206.

7. Not Man Apart, Friends of the Earth, 429 Commercial St., San Francisco, 94111.

8. Environment, P.O. Box 755, Bridgetown, Missouri 63044.

Voilà ! J'espère que cette longue lettre te sera utile, et que tu ne seras pas froissé si jamais la revue Possibles accepte de la publier. J'espère que vous avez réussi à sortir tout votre bois avec Anna votre belle jument noire, et que l'eau d'érable coulera à flot dans vos chaudières ce printemps. J'essaierai d'aller vous rendre visite dans la petite vallée à mon retour d'Europe. À ce moment-là, je pourrai t'en dire plus long sur le mouvement anti-nucléaire international. À bientôt,

Jean-Guy 


\section{Mouvement écologiste, énergie et environnement.}

Essais d'écosociologie.

Première partie . Descriptions et analyses

\section{Chapitre 2 \\ "Décentralisation et démocratie de participation."}

Texte inédit présenté sous forme de causerie à la Conférence du Rassemblement des citoyens de Montréal sur les conseils de quartier en octobre 1977, et révisé en 1978.

\section{par Jean-Guy Vaillancourt}

Mon exposé comprendra deux volets. J'aimerais d'abord décrire brièvement le cheminement historique et la poussée mondiale récente vers la décentralisation et la démocratie de participation au plan socio-économique et politique. Ensuite je donnerai quelques exemples concrets de cette tendance telle qu'elle s'est manifestée récemment dans les luttes urbaines dans divers pays. La première partie constituera donc une espèce de toile de fond théorique et historique pour éclairer certains développements qui ont lieu présentement au plan de la lutte pour démocratiser la ville et pour transformer la politique municipale. La première partie, je l'aborderai surtout en tant que sociologue des organisations intéressé par l'autogestion et par les coopératives de production, et comme sociologue de l'environnement préoccupé par la crise écologique actuelle et engagé spécialement dans la lutte contre l'énergie nucléaire et dans la recherche sur les associations et groupes qui travaillent pour ou contre le nucléaire et ses alternatives. Quant à la seconde partie de mon expose, je me baserai sur des lectures, des contacts et des recher- 
ches, et aussi sur des expériences que j'ai vécues depuis mes années de militant étudiant à Berkeley durant les années soixante jusqu'à mon travail actuel comme échevin du quartier 4 à Dunham.

Lorsque l'on parle de la préoccupation croissante pour la décentralisation et la démocratie à la base, je pense qu'il faut d'abord faire une distinction entre avant et après 1968, qui me semble être l'année où ces idées ont vraiment réussi à s'étendre et à s'implanter de façon massive et solide dans les pays capitalistes avancés. C'est à peu près à ce moment-là qu'une certaine convergence a commencé à se dessiner parmi des gens venus de traditions, d'horizons et de situations très différents vers un type de socialisme démocratique et autogestionnaire, contre l'usurpation du pouvoir par des bureaucrates et par des technocrates.

En France par exemple, depuis 1968, on trouve un intérêt croissant pour l'autogestion et pour le socialisme non bureaucratique dans tout l'éventail de la gauche et de l'extrême-gauche. Aux États-Unis, où l'on parle plutôt de «selfmanagement » et de " démocratie industrielle », et où les ambiguïtés sont parfois considérables comme j'ai pu le constater il y a quelques années à une conférence internationale sur le «self-management » tenue à l'Université Cornell, (certains types d'écoles de business-administration confondent self-management et les techniques un peu plus sophistiquées de relations humaines dans l'industrie), il y a aussi maintenant une vague de fond en faveur de l'autogestion et pour la véritable participation à la base, qui ne manque pas de surprendre quiconque prend la peine de se pencher sur la question. Là, comme ailleurs, bien entendu, beaucoup de gens confondent la pseudo-participation et la cogestion d'une part, et le vrai contrôle ouvrier et l'autogestion d'autre part.

Avant 1968, pour bien des gens, les questions de décentralisation, d'autogestion, de contrôle ouvrier et populaire, de démocratie de participation étaient des questions abstraites qui s'étaient posées concrètement il y a plus d'un siècle, lors des révolutions européennes de 1848, mais qui avaient perdu de leur mordant et de leur importance et étaient devenues quelque peu oiseuses et même sensiblement dépassées. Pour ces gens, la Commune de Paris de 1871 avait constitué la fin de la belle époque des révolutionnaires utopiques et anarchisants ouverte par la révolution française de 1789 et le printemps des peuples de 1848, plutôt qu'un 
temps fort et une étape additionnelle mais non ultime dans la longue et difficile marche vers la véritable démocratie populaire, vers un socialisme libertaire et autogéré.

Les diverses percées dans la direction d'un socialisme vraiment démocratique, après l'échec de 1848 et la défaite de la Commune de Paris, ne furent pas une épopée des plus glorieuses. Échecs et demi-échecs s'enchaînèrent sans relâche. On songe par exemple au peu de succès des travailleurs pour établir des coopératives ouvrières de production, aux défaites politiques des socialismes et des syndicalismes de toutes sortes. Ainsi, le relatif oubli dans lequel avaient sombré, jusqu'à ces dernières années, les idées hardies et les expériences avortées des guild socialists anglais, des syndicalistes français, des Industrials Workers of the World américains est un bon indice de l'acceptation généralisée, pour plus d'un siècle, d'une perspective pessimiste quant aux chances de succès de la démocratie de participation.

Les gens se sont satisfaits de demi-mesures limitées, quoiqu'importantes, comme l'extension graduelle et mesurée du droit de vote, au moyen duquel ils pouvaient tout au plus intervenir de façon non décisive dans l'attribution du pouvoir politique à l'une ou l'autre aile de la bourgeoisie. C'est Carlos Marighella qui écrivait, avec une légère pointe d'exagération, sans doute, que : «Les élections ne sont rien d'autre qu'un thermomètre que la classe dominante utilise pour évaluer le niveau de conscience du peuple ».

Les soi-disant démocraties libérales ont élargi un peu l'aire de la liberté, dans la plupart des cas, mais quand le pouvoir de la bourgeoisie est menacé, elles basculent facilement vers le fascisme. En temps normal, elles demeurent quand même des simulacres de la véritable démocratie de participation, car le pouvoir de la classe dominante s'y cache toujours derrière le mythe de la souveraineté populaire et de la primauté de la nation (voyez par exemple comment on excuse facilement les crimes des policiers de l'État sous prétexte qu'ils veillent à la sécurité nationale) et derrière ce mécanisme qui fausse tout le jeu démocratique, à savoir la remise complète du pouvoir à des élus et à des experts. Quand le pouvoir réel se sent tant soit peu menacé, il met en branle toutes sortes de mécanismes de contrôle pour maintenir son emprise tout en essayant de conserver sa légitimité, y compris 
le lavage de cerveau, le soudoyage, le chantage et même la violence. Il faut donc essayer d'étendre l'emprise des forces socialistes et démocratiques avec autant de souplesse, d'intelligence et de détermination qu'en mettent nos ennemis pour asseoir leur domination.

La révolution russe n'aurait jamais eu lieu sans cette immense volonté populaire d'une transformation radicale dans la façon dont l'autorité était exercée dans la Russie des Tsars. Les conseils ouvriers surgirent d'abord durant la révolution russe de 1905, et ils fonctionnèrent brièvement comme des comités de grève conjoints des syndicats et des partis politiques, avant d'être écrasés par le tsar. Les conseils ouvriers ressurgirent en pleine force en février 1917, au moment où Lénine clamait encore que tout le pouvoir devait aller aux soviets et que le contrôle ouvrier était la seule façon d'éviter le désastre économique. Les conseils ouvriers géraient les entreprises et élisaient des délégués aux soviets, ces comités populaires opérant au niveau local, régional et central qui supplantèrent le gouvernement provisoire après octobre 1917.

Malheureusement, les conseils ouvriers furent remplacés par des inspecteurs désignés par en haut, et les syndicats puis les Conseils régionaux et suprêmes de l'Économie nationale, les Conseils des commissaires du peuple et finalement le Bureau politique du Parti communiste usurpèrent les pouvoirs des soviets. Après la guerre, l'opposition ouvrière, qui tentait de sauver le contrôle et la participation des ouvriers face au pouvoir grandissant de l'appareil bureaucratique de l'État et du Parti, fut écrasée à son tour par les bolchéviques devenus fascinés par le pouvoir de l'État, et par le taylorisme et le fordisme, et désireux de solidifier le régime communiste dans leur pays.

Dans un article publié en 1966 dans le premier numéro de la revue française Autogestion, Duvignaud affirme que Georges Gurvitch, le sociologue proudhonien qui avait participé dans sa jeunesse aux soviets ouvriers de Petrograd, disait que Trotsky et Staline avaient réussi à convaincre Lénine que l'autogestion ouvrière nuisait à la production. Quoi qu'il en soit de cette complexe inter-influence entre Lénine, Trotsky et Staline, sur cette question, il demeure que le pouvoir en URSS a pris assez rapidement une orientation autoritaire. Staline, vers la fin des années 20, supprima les derniers vestiges du contrôle ouvrier et créa un système 
politique et économique basé sur des principes opposés aux idéaux du socialisme démocratique, et au lieu du dépérissement de l'État, il y eut plutôt son rendurcissement et l'élargissement de son emprise sur la société civile.

Le mouvement des conseils ouvriers qui, sous l'influence de la révolution russe d'octobre 1917, avait surgi un peu partout en Europe, en Hongrie, en Allemagne, en Italie, en Autriche, en Pologne, en Norvège, en Angleterre et en Suisse, ne survécut pas à la montée fulgurante du fascisme et du nazisme, et à la réorientation du communisme dans une direction autoritaire. Il y eut même des expériences intéressantes en Asie, annonciatrices de transformations révolutionnaires subséquentes, en Chine et en Indochine par exemple, ce qui montre bien qu'une révolution est un changement qui se prépare sur une très longue période de temps et qui ne peut pas s'improviser.

C'est surtout en Espagne que l'autogestion ouvrière et paysanne a réussi à s'implanter tant soit peu comme organisation de classe. À Barcelone, les travailleurs prirent le contrôle des usines, des services publics, du transport urbain, et les dirigèrent avec efficacité selon un mode de gestion anarcho-syndicaliste. Mais l'expérience se résolva rapidement par un échec total à cause de son isolement en Espagne même, et aussi à cause de l'opposition farouche des fascistes, des bourgeois, et des staliniens. La dictature de Franco mit donc fin à une des expériences les plus intéressantes de démocratie ouvrière et de participation populaire. Quand la plupart des autres dictatures fascistes disparurent avec la fin de la Seconde Guerre mondiale, la guerre froide rendit très difficile la renaissance d'un socialisme autogéré. Ce sont des formes de socialisme étatique, de social-démocratie, de démocratie-chrétienne, ou des régimes tout à fait à droite qui s'établirent un peu partout dans le monde.

Mais une autre rupture importante s'opéra en 1948 quand la Yougoslavie prit ses distances vis-à-vis de l'URSS et de son modèle bureaucratique et centralisateur, et tenta d'établir dans l'entreprise et dans la société yougoslave l'autogestion ouvrière et la démocratie de participation. L'expérience yougoslave, malgré ses limites évidentes, eut une influence considérable, et continue d'exercer encore aujourd'hui une attraction surprenante. Certains pays africains, comme l'Algérie et la Tanzanie par exemple, tentèrent eux aussi, a la suite de la Yougoslavie et avec 
plus ou moins de succès eux aussi, de créer un socialisme où la participation ouvrière et paysanne constituerait un contrepoids au parti unique et à la centralisation administrative et politique.

Après la mort de Staline, les Hongrois, les Polonais, puis les Tchèques se révoltèrent dans un effort pour établir des conseils ouvriers et un régime socialiste démocratique mais là aussi ce fut un échec, car l'URSS, légitimée et aidée en cela par les grenouillages des Américains, s'y opposa par la force et obligea ces pays à rester dans son orbite.

Les années 50 et le début des années 60 représentent donc une période plutôt calme pour la montée du socialisme autogéré. Par ailleurs, la naissance d'une nouvelle gauche, que $\mathrm{C}$. Wright Mills saluait déjà dans sa fameuse lettre ouverte à la Nouvelle gauche au début des années 60, laissait poindre l'espoir d'un renouveau. Peu à peu, l'autogestion est redevenue la principale revendication de la Nouvelle gauche, des écologistes et des socialistes libertaires. Après les contestations des Noirs et des étudiants américains, ce fut la grève générale de mai 1968 en France qui, à cet égard, fut l'occasion d'un réveil brutal de la part de ceux qui croyaient terminé le temps des grandes contestations en faveur de la démocratie autogestionnaire. À côté de Marx et d'Engels, et même un peu contre eux, Rousseau, Fourier, Owen, Blanc, Proudhon, Bakounine et Kropotkine, de même que Kollontaï, Pannekoek, Korsch et Gramsci, redevenaient d'actualité. On s'aperçut alors qu'entre 1871 et 1968, malgré les nombreuses défaites et certains reculs, le socialisme autogestionnaire était resté vivant, et qu'il s'affirmait maintenant plus fortement que jamais.

Constatant la faillite du capitalisme libéral devenu capitalisme de monopole d'État, et du socialisme étatique devenu de plus en plus une dictature sur le prolétariat plutôt que le gouvernement des travailleurs et qui semble jouer le même rôle intermédiaire entre le capitalisme et le socialisme véritable que le despotisme centralisateur des monarques plus ou moins éclairés a joué autrefois entre le féodalisme et le capitalisme bourgeois, insatisfaits des formes courantes de négociation collective, de consultation tripartite et de pseudo-participation, les travailleurs, les étudiants, plusieurs autres groupes opprimés, et divers nouveaux mouvements sociaux ont décidé de miser sur l'autogestion et sur la démocratie directe pour 
essayer d'en arriver à pouvoir décider eux-mêmes, dans toutes les sphères de leur vie, de leurs idéaux, de leurs intérêts et de leur avenir.

Le plus surprenant, ce n'est pas tellement que le socialisme autogestionnaire ait subi tant de défaites entre 1848 et 1968, mais que malgré toutes ces défaites, les vagues nouvelles se soient faites plus fortes et plus étendues. Le passage de l'antiquité au féodalisme, de même que la transition du féodalisme au capitalisme, se sont opérés sur de très longues périodes après toutes sortes de tentatives plus ou moins heureuses et souvent avortées. Il ne faut donc pas s'attendre à ce que, à peine un siècle après la Commune de Paris et les premiers soubresauts révolutionnaires des classes ouvrière et populaire, celles-ci réussissent à établir un système mondial de démocratie industrielle et de socialisme autogestionnaire d'un seul coup et rapidement. L'important, c'est que, malgré certains reculs, la situation globale s'améliore et que les nouveaux cycles représentent un progrès par rapport aux cycles précédents.

Il y a eu, bien sûr, des petites victoires partielles et essentiellement ambiguës, des réformes qui comme autrefois la semaine de cinq jours de travail et le suffrage universel, représentent des efforts de cooptation de la part des gouvernements et des capitalistes autant que des pas en avant pour une démocratie autogestionnaire : je pense aux mécanismes de consultation établis dans les pays scandinaves, en Autriche, en Angleterre, en Belgique, en France, et à la fameuse co-détermination allemande. Ce ne sont pas encore là des expériences d'autogestion, mais parfois des petites réformes de ce genre peuvent conduire à des transformations plus profondes et plus radicales. Mais les véritables amorces de changements substantiels sont apparues depuis 1968, depuis le foisonnement surprenant des nouveaux conflits urbains et des mouvements sociaux qu'ils charrient, et qui sont devenus, bien plus que les recherches et les combines des experts et des planificateurs, les véritables moteurs des transformations urbaines. Pensons par exemple aux luttes des femmes, des associations de protection des consommateurs, aux revendications des écologistes et des étudiants.

La grève générale en France en mai 1968 représente sans contredit un des moments forts de cette poussée récente vers un renouveau des idéaux du socialisme de participation. Malgré certains légers reculs depuis une dizaine d'années 
dans certains pays, je pense qu'il s'est fait beaucoup de chemin dans ce domaine, tant au plan de la diffusion et de l'acceptation des idées qu'au plan des expériences concrètes. Mai 68 a sans doute aussi donné naissance et vigueur à certaines tendances marxistes autoritaires, mais 10 ans après, on constate un essoufflement et même un rejet croissant de ces tendances, ce qui n'est pas le cas pour l'autogestion.

Il était peut-être inévitable que les premières révolutions socialistes, en URSS, en Chine, à Cuba, se fassent sur un mode un peu plus discipliné, que leurs dirigeants aient peur de lâcher un peu trop de lest, et que plusieurs autres révolutions n'aboutissent pas du tout, étant donné la puissance du système capitaliste mondial. Mais à mesure que la sphère d'autonomie du socialisme mondial augmente, surtout dans les pays industriellement plus avancés, il est souhaitable et probable qu'il commencera à montrer un visage plus humain et plus démocratique. L'idée de Gramsci, selon laquelle ce n'est pas seulement un parti qu'il faut, mais une coalition entre les syndicats, les conseils de quartiers et d'usines, et un parti ouvrier capable de travailler avec d'autres forces et partis progressistes, a fait du chemin et a contribué à la naissance et au développement de la tendance socialiste antiautoritaire qu'on retrouve aujourd'hui dans divers mouvements sociaux d'avantgarde, ainsi que chez les eurocommunistes, les socialistes de gauche, les marxistes du Tiers-monde, et même dans plusieurs groupes d'extrême-gauche et de sociauxdémocrates.

Dans les pays capitalistes avancés, il ne faut pas s'imaginer que l'autogestion, surtout dans l'entreprise industrielle, s'instaurera rapidement, sans la nationalisation et la socialisation des principaux moyens de production. L'échec de la plupart des coopératives ouvrières de production et des quasi-coopératives de production est là pour nous le montrer, ce qui ne veut pas dire qu'il ne faut jamais essayer de mettre de telles entreprises modèles sur pied, surtout dans certains secteurs culturels par exemple, où la marge de liberté est moins étroite. C'est à mon avis en partie en édifiant dans le ventre même de l'ancienne société certaines expériences progressistes authentiques, même si elles sont limitées, comme c'est le cas pour le coopératisme, qu'on commence à construire la société nouvelle, et qu'on montre qu'il est possible et souhaitable de se désaliéner et de s'approprier véritablement. 
Voyons donc maintenant brièvement certaines de ces expériences concrètes, de ces amorces de socialisme à visage humain, qui manifestent la vitalité de ce courant autogestionnaire qui s'affirme de plus en plus dans le monde.

La contestation des années 68-70 a conduit à une impasse, que certains groupes comme le FLQ, le Weather Underground, les Tupamaros, les terroristes allemands, japonais et palestiniens, poussés dans certains cas par la provocation policière, ont tenté de surpasser par des bombes, des détournements d'avions et des prises d'otages. D'autres, et je pense par exemple, pour ne reprendre que le cas des États-Unis, aux Panthères noires d'Oakland en Californie, à certains radicaux de Berkeley, de Ann Arbor, de Madison au Wisconsin, se sont tournés vers la politique au plan municipal. Plusieurs sont allés travailler à la base, dans les écoles, les usines et les syndicats, dans des associations de locataires ou des coopératives populaires, dans les groupes écologiques de gauche préoccupés surtout à l'heure actuelle par la lutte contre le nucléaire, après avoir lutté pour des People's Parks et pour de l'air et de l'eau non pollués.

En Angleterre, les gens de l'Institute for Workers' Control, très actifs dans la gauche du parti travailliste, publient beaucoup de livres et de pamphlets sur l'autogestion ainsi qu'un bulletin et une revue A Journal of International Studies consacrée à la démocratie industrielle. Ils sont particulièrement engagés dans la lutte pour la démocratie syndicale et le contrôle ouvrier, et ils tentent de redonner plus de vitalité démocratique à l'important mouvement du « Town and Country Planning ».

En France, au plan de l'entreprise, la communauté Boismondau, et l'usine de montres LIP, qui vit toujours, constituent, chacune à sa façon, deux exemples frappants de cette poussée frappante vers l'autogestion et le socialisme. En fait, une revue qui s'appelle précisément Autogestion et socialisme, le CERES (Centre d'études de recherches et d'éducation socialistes), la maison d'édition François Maspéro, à différents niveaux, représentent trois pôles intéressants pour ce qui est de la recherche et des publications sur l'autogestion en France et dans le monde. L'autogestion en régime capitaliste se heurte à des difficultés presque insurmontables, mais il est peut-être possible de commencer à en introduire des éléments au plan politique, surtout municipal, pour pouvoir arriver à offrir un contrepoids au 
pouvoir centralisateur et technocratique de l'État et de sa bureaucratie, pour que les nationalisations et la planification socialistes se fassent le plus démocratiquement possible lorsque le socialisme réussira à renverser le capitalisme. Les recherches sociologiques montrent que le désir de participation et d'autogestion est généralisé. Ce n'est pas pour rien que ceux qui détiennent le pouvoir et qui veulent le conserver font tellement appel à la pseudo-participation, et font tellement semblant d'être prêts à partager leur pouvoir, mais sans vraiment le partager effectivement.

C'est peut-être en Italie que des expériences concrètes peuvent être intéressantes pour nous ici au Québec. La stratégie de la gauche, en Italie comme en France, a été de prendre le pouvoir à la base, dans les villes, et d'y montrer comment il est possible de fonctionner démocratiquement et efficacement. Qui n'a pas entendu parler des expériences de Bologne et de Grenoble, où il y a des conseils de quartiers consultatifs, et où la gauche a partiellement réussi, en autant que c'est possible sur un plan aussi limité que le plan municipal, à faire la preuve de son sérieux administratif, en respectant la démocratie de base, et des visées sociales de gauche. Là, comme ailleurs, bien sûr, il y a encore des problèmes considérables, mais qui pourrait nier qu'il s'y est fait un travail extraordinaire par les gens à la base, pour prendre leurs affaires en main.

L'Italie constitue sans doute le point chaud des luttes urbaines et ouvrières en Europe. Les groupes de gauche y prolifèrent. Les luttes y sont complexes et dures et pas toujours limitées aux usines, mais s'étendent au logement et au transport publie. De 1969 à aujourd'hui, on occupe des logis, on refuse de payer une partie du prix du transport et des autres services publics comme le téléphone, l'électricité, le gaz ; c'est ce qu'on appelle les auto-réductions. On réduit soi-même et collectivement son loyer, ses impôts, les tarifs des services lorsque l'État les augmente. Pour lutter contre la hausse du prix des aliments, les gens de Pise ont organisé eux-mêmes un Marché rouge. À Rome, un Centre de santé rouge a été créé pour assurer des soins gratuits. Dans son petit livre sur les Luttes urbaines, Manuel Castels décrit avec finesse la structure interne d'un mouvement social urbain de lutte contre la « rénovation-déportation » dans la ville de Paris. Les gens veulent garder leurs logements, leurs quartiers, leur ville, leur vie, contre les profiteurs qui 
détruisent des logements tout à fait valables pour les remplacer par des immeubles neufs aux loyers inabordables. Castels consacre aussi un chapitre entier à

l'expérience du FRAP à Montréal de 1969 à 1972. Le FRAP n'existe plus, mais sans lui, aurait-on aujourd'hui le RCM qui a des chances de remporter la victoire aux prochaines élections municipales de Montréal avec un programme de démocratie à la base et de réorganisation des services à la population.

Comme Paris en 1870 était le maillon faible en Europe, Montréal me semble être aujourd'hui un maillon faible en Amérique du Nord. A partir de la mi-mars 1871, le peuple de Paris s'empare du pouvoir dans les quartiers et à l'Hôtel de Ville, puis les ouvriers se mettent en branle pour instaurer l'autogestion dans certaines entreprises. Mais l'appareil d'État et l'armée se reconstituent à Versailles, et reprennent le contrôle. Ici, si le RCM prend le pouvoir, il faudra s'attendre à ce que la classe dominante, qui n'arrive même pas à accepter la prise du pouvoir par le PQ à Québec, fasse tout en son pouvoir pour l'empêcher de bien gérer la ville, de démocratiser la vie, et de commencer à faire dépérir l'État. À ce moment-là, il faudra être vigilant pour ne pas subir une défaite semblable à celle qu'a subie la Commune de Paris.

Concluons. Un vaste mouvement international est en train de se développer sous nos yeux, dont j'ai essayé de vous décrire certains éléments. Je pense que j'en ai dit suffisamment jusqu'ici pour indiquer l'importance grandissante que prennent les revendications pour la participation à la base et pour l'autogestion. Mais qu'estce que cela a à faire avec le RCM et les conseils de quartiers. A mon avis, le RCM et ses diverses positions, par exemple celle sur les conseils de quartiers représente précisément, à la suite du travail des comités de citoyens, du FRAP et des CAP, un effort sérieux et réaliste parmi quelques autres au Québec actuellement, pour faire naître ici un socialisme vraiment démocratique et autogestionnaire. Et même si la gestion anti-hiérarchique est importante, il ne faut pas oublier qu'à côté de la liberté, il y a l'égalité et la fraternité. Il faut abolir à la fois l'hétérogestion et la misère. Il ne faut pas seulement répondre à l'aliénation par l'autogestion, il faut aussi remplacer l'exploitation par la révolution.

Ce ne sera pas pour demain, ça ne viendra pas tout d'un coup un soir de mai ou d'octobre, mais il faut faire des pas concrets, même si ce sont des petits pas 
pourvu que ce soient des pas dans la bonne direction. Par exemple, avoir des assemblées municipales ouvertes au public et qu'elles aient lieu à des dates fixes. Que l'information y soit donnée et que les décisions ne soient pas prises en secret, que les citoyens et leurs associations aient droit de regard et de parole.

Ce sont des choses élémentaires mais essentielles. Le contrôle de la police et des dépenses inutiles est particulièrement important. Aussi la demande d'un représentant par quartier plutôt que de trois est fondamentale. Il faut aussi démystifier l'autorité et le pouvoir, et faire en sorte que la démocratie soit la plus directe possible. Que les élus soient près de la base, révocables plus facilement et obligés de rendre des comptes de leur action aux gens de leur quartier, à des assemblées de rues ou de bloc, à des associations populaires locales. Cela peut sembler des petites choses, mais c'est avec des petites choses comme ça que ça commence. L'appétit vient en mangeant.

Ne manquons pas le train à cause de nos querelles intestines et de notre dogmatisme, apprenons à collaborer avec des gens qui ne pensent pas exactement comme nous, mais qui militent eux aussi dans le syndicalisme, dans le coopératisme, en politique ou dans des associations de toutes sortes. Un exemple entre mille. Pour beaucoup de gens, le Monde à bicyclette et la Rive-Sud à bécane sont des groupes rigolos pas sérieux, mais si on y pense vraiment, ce sont là des mouvements extrêmement importants dont les potentialités révolutionnaires (pour ne pas dire vélorutionnaires) devraient être évidentes à toute personne de gauche dont l'intelligence n'est pas ankylosée. Par une stratégie de revendications tactiques et plus transitoires, qui illustrent déjà ce que pourrait être la société de demain, on arrivera plus sûrement au but que si on attend pour la perfection avant d'agir, ou si on favorise le pire dans l'espoir futile d'accélérer les choses. 
Mouvement écologiste, énergie et environnement.

Essais d'écosociologie.

Première partie . Descriptions et analyses

\section{Chapitre 3}

\section{"Question nationale et mouvement écologique.”}

Texte à paraître dans les Actes du colloque de Cérisy de 1979.

par Jean-Guy Vaillancourt

$\underline{\text { Retour à la table des matières }}$

Je dirai d'abord quelques mots sur la relation qui s'est développée entre la sociologie québécoise et les mouvements sociaux au Québec. Ensuite je traiterai du rapport entre nationalisme, formations politiques et ces mouvements. Je terminerai par quelques mots sur le mouvement écologique québécois. La partie centrale de mon exposé s'inspire d'un article écrit en collaboration avec Pauline Vaillancourt pour l'Australian and New Zealand Journal of Sociology en 1978.

La sociologie n'a vraiment pris son essor au Québec qu'au début des années soixante, durant la révolution tranquille. La plupart des sociologues québécois sont depuis ce temps assez proches du mouvement nationaliste, du mouvement ouvrier, des divers nouveaux mouvements sociaux québécois et de la tendance modernisatrice et progressiste du pouvoir politique québécois. Ceci n'a jamais posé trop de problèmes puisque, dans la société dépendante qu'est le Québec, la distance entre ces acteurs sociaux n'est pas trop grande, étant donnée l'existence 
d'un adversaire commun puissant à droite, aux États-Unis, au Canada et même au Québec.

La majorité des sociologues québécois tente de s'engager dans des recherches utiles au peuple québécois, au mouvement ouvrier et aux divers mouvements sociaux populaires dans leur effort de clarification des enjeux de leur action et de connaissance de l'adversaire. Deux tendances principales se dessinent dans leurs recherches : un petit nombre croit qu'il faut surtout centrer l'attention sur la classe dominante, les politiques sociales de l'État, les mécanismes de contrôle, les rapports de domination et d'exploitation ; d'autres, plus nombreux, font des recherches sur la question nationale, le mouvement ouvrier, le syndicalisme, le mouvement des femmes, les groupes, les expériences coopératives et communautaires. Pour moi, je crois qu'il ne faut pas se limiter à la recherche sur les mécanismes de pouvoir mais étudier aussi les mouvements : il y a, en effet, une recherche sur le pouvoir qui profite au pouvoir, il y a une recherche sur les mouvements qui peut les éclairer et les aider.

Bien entendu, ces sociologues essaient de garder leur indépendance vis-à-vis des divers mouvements : ils se veulent engagés mais analystes objectifs et refusent le rôle d'idéologues partisans ou de voyeurs. Certains réussissent à garder une certaine distance critique envers les divers groupes et travaillent à briser les particularismes à l'intérieur d'un même mouvement, par exemple entre les syndicats, et au rapprochement entre les différents mouvements sociaux eux-mêmes. Ainsi Fernand Dumont et Marcel Rioux ont tenté de développer, chacun à leur façon, un socialisme québécois, un nationalisme progressiste. Le cm le plus typique est celui du sociologue ou de la sociologue qui étudie le mouvement ouvrier ou la question nationale, qui milite pour le socialisme ou l'indépendance (ou pour les deux), et qui essaie de montrer comment ces deux luttes se conjuguent entre elles et avec celles des autres mouvements sociaux : tel est le cas de la revue Possibles, des Cahiers du Socialisme. On trouvera aussi dans Sociologie et sociétés des articles ayant une préoccupation militante. Par ailleurs, le Centre de formation populaire compte bon nombre de sociologues et de politicologues qui produisent des textes utiles aux militants (surtout ouvriers) et organisent des sessions de formation. Au Regroupement des écologistes québécois, un comité comprenant des sociologues 
a travaillé sur les points possibles de rencontre entre mouvement écologique, mouvement syndical, et groupes communautaires.

Attardons-nous donc un peu maintenant sur la question fondamentale pour la gauche québécoise et pour les sociologues québécois du rapport entre la question nationale, les partis politiques, et les mouvements sociaux populaires. D'abord, le nationalisme québécois n'est pas un concept univoque : des classes et des groupes sociaux différents ont donné naissance à des sous-types variés de nationalisme dont les deux principaux sont sans doute le nationalisme conservateur et le nationalisme progressiste. Ce dernier s'est développé surtout après 1960, entre autres raisons à cause de la modernisation dans l'économie et l'éducation, du recul démographique et politique du ait français, et du retour des conservateurs au pouvoir à Ottawa à la fin des années cinquante. C'est le long de cet axe conservateurprogressiste que les sociologues québécois placent les autres types de nationalisme. La synthèse que Léon Dion fait à partir des ouvrages de Marcel Rioux (La Question du Québec), et de Gilles Bourque et Nicole Laurin-Frenette aboutit à distinguer quatre types de nationalisme qui sont apparus successivement au Québec : les nationalisme conservateur, libéral, social-démocrate et socialiste. La distinction entre les deux derniers types est significative dans le contexte actuel, puisque le Parti québécois, qui se veut le porte-parole du nationalisme québécois, refuse l'option socialiste, se proclame social-démocrate et contient beaucoup d'éléments libéraux. Nous pourrions ajouter une cinquième catégorie, le nationalisme d'extrême-gauche, et le portrait serait complet.

Bien qu'il n'y ait pas adéquation parfaite entre les classes sociales au Québec et les différents types de nationalisme, on peut dire que le nationalisme conservateur et le nationalisme libéral sont surtout le fait de la bourgeoisie, et de la petite bourgeoisie traditionnelle, tandis que les trois types de nationalisme de gauche sont plutôt celui de la nouvelle petite bourgeoisie et de la classe ouvrière. Certains sociologues comme Marcel Fournier ont bien montré que le PQ recrute beaucoup parmi ceux qui, comme les enseignants, les fonctionnaires, et les journalistes, travaillent en français et ont donc un intérêt matériel à ce que le Québec soit un État français indépendant ou plus autonome. 
Mais pour caractériser la position des divers groupes politiques et mouvements sociaux québécois sur la question nationale, il ne suffit pas de montrer auquel de ces cinq types de nationalisme ils se rattachent. En effet, les modèles classificatoires évolutionnistes basés sur l'orientation socio-économique ou sociopolitique ne nous disent rien sur le degré de radicalisme du nationalisme luimême : il faut donc opérationaliser celui-ci sur un axe plus proprement culturel ou politico-constitutionnel ; le nationalisme peut en effet être défini de façon très variée : attachement à une langue, une culture, une histoire, des institutions, un territoire, un groupe ethnique, voire le besoin d'opprimer, ou d'être libéré d'une oppression.

La distinction entre nationalisme des oppresseurs et nationalisme des opprimés, ou entre différents types de nationalisme de droite ou de gauche ne suffit pas à rendre compte de l'état des choses. Perpendiculairement au premier, il faut construire un second axe pour jauger l'intensité des attitudes nationalistes sur les nombreux traits constitutifs du nationalisme que nous venons d'évoquer. Faute de pouvoir inclure tous les aspects mentionnés ci-haut dans l'élaboration de notre grille, nous la construirons sur la position vis-à-vis de l'indépendance politique, qui symbolise assez bien le nationalisme au Québec.

On peut alors distinguer cinq positions importantes actuellement : d'abord l'indépendantisme, c'est-à-dire l'option pour la souveraineté politique complète de la nation et de l'État québécois ; puis la « souveraineté-association » (c'est la position du PQ) ; ensuite la thèse des « deux nations » et deux États associés, c'est-àdire celle de l'auto-détermination du Québec dans une nouvelle confédération des deux nations fondatrices ; puis le «fédéralisme renouvelé », avec statut spécial pour le Québec, c'est-à-dire avec beaucoup plus d'autonomie dans une nouvelle fédération; enfin le fédéralisme actuel, avec peut-être un peu plus de pouvoirs pour le Québec (en somme, le statu quo, peut-être légèrement modifié).

En croisant cet axe avec l'axe socio-économique, nous obtenons vingt-cinq capes classificatoires ; il faut bien préciser qu'il y a dans la réalité des chevauchements, mais le tableau a l'avantage de nous aider à comprendre l'évolution des idéologies nationalistes au Québec, la position des divers groupes et mouvements sur la question nationale, les luttes sociales, économiques et politiques, ainsi que 
les alliances et compromis qu'ils établissent entre eux. Je vous épargne la mise en cage des groupes et associations actuels pour faire plutôt un survol historique à l'aide de ce tableau.

Chez les Patriotes de 1837-38, le nationalisme est beaucoup plus libéral que conservateur, et passablement radical sur la question de l'indépendance nationale. Mais, plus tard, très peu de Québécois remettront la Confédération de 1867 en question. Par la suite, l'idéologie dominante a été longtemps un nationalisme conservateur et nettement fédéraliste. Durant le long règne de Duplessis (en gros, de la fin des années trente à celle des années cinquante) l'Union nationale use d'un nationalisme très modéré au plan politique et constitutionnel et accepte malgré tout le cadre confédératif existant. Dans les années quarante, nous voyons émerger un nationalisme plus libéral (à l'Action libérale nationale, au Bloc populaire, et plus tard au journal Le Devoir). Durant les années cinquante, on assiste à une étonnante montée du mouvement ouvrier et syndical et à la création d'un éphémère Parti social-démocrate (1955), à des grèves importantes et à une certaine baisse du nationalisme. Mais le Parti libéral au pouvoir à Québec de 1960 à 1966 est à la fois plus nationaliste et moins conservateur que l'UN de Duplessis. C'est alors qu'on commence à parler de la Nation québécoise, de l'État québécois. Au début des années soixante commence à poindre un nationalisme plus radical sur l'indépendance et la question ouvrière, dans le mouvement étudiant, le monde ouvrier, la nouvelle petite bourgeoisie ; il s'exprime dans la Revue socialiste, dans PartiPris, puis dans les revues Socialisme et Révolution québécoise, avec une certaine tension entre socialisme et nationalisme. En 1967, René Lévesque quitte les libéraux, après qu'ils eurent éliminé de ce parti la nouvelle petite bourgeoisie nationaliste de gauche et furent défaits par une Union nationale devenue plus nationaliste. Lévesque et ses partisans s'unissent avec les indépendantistes de gauche du Rassemblement pour l'Indépendance nationale et les indépendantistes de droite du Regroupement national pour former le Mouvement Souveraineté-Association. Le FLQ se manifeste en 1963, le Parti socialiste québécois était né cette même année et avait créé un comité de coordination des mouvements de gauche en 1965 ; il disparaît en 1967, brisé par la question nationale. En 1968, le MSA devient le Parti québécois qui en 1970 obtient 24\% des voix, en 1973, 30\%, en 1976, 41\% et le pouvoir. Tout en maintenant son option souveraineté-association, le PQ penche vers un type de social-démocratie à la suédoise, même si plusieurs de ses leaders 
restent proches du néo-libéralisme. Cependant, pour gagner son référendum et garder le pouvoir, il est maintenant tenté de diluer ces deux options tandis que le Parti libéral essaie de reprendre des voix au PQ en se dotant d'un leader qui prône un conservatisme moins rigide que celui de Robert Bourassa et un fédéralisme renouvelé. Ce nouveau leader libéral, Claude Ryan, est l'ancien directeur du Devoir.

Par ailleurs, le Crédit social reste le parti le plus conservateur, avec une aile nationaliste et une aile fédéraliste ; l'Union nationale, en voie de disparition aussi est plus conservatrice mais moins fédéraliste que le Parti libéral. Le Nouveau parti démocratique reconnaît du bout des lèvres le droit du Québec à l'autodétermination, mais il s'oppose à la promotion active de celle-ci, ce qui en fait tout au plus un parti social-démocrate prônant un fédéralisme renouvelé ; sur la question nationale, la position des principaux groupes marxistes léninistes (La Ligue, En lutte, et le PCC (ML » est identique à celle du NPD.

Le Parti communiste du Québec qui comme le NPD est une petite section peu autonome d'un parti pancanadien exige la reconnaissance de deux nations et le droit à l'autodétermination pour le Québec. Il propose la création d'un État canadien bi-national et d'une nouvelle confédération canadienne. Les trotskystes de la Ligue ouvrière révolutionnaire, préconisent l'indépendance du Québec sous l'impulsion de la classe ouvrière.

Actuellement, le PQ se trouve débordé non seulement sur le plan social par des groupes et des partis de gauche, mais aussi sur la question nationale ellemême, par les trotskystes, par un petit groupe marxiste-léniniste (le Parti des Travailleurs, qui publie le journal Choc), par le mouvement syndical et ouvrier (ou du moins une partie de ces mouvements), et par les militants qui gravitent autour du Centre de formation populaire, militants indépendantistes et socialistes qu'on retrouve aussi dans le mouvement de solidarité internationale et d'appui aux luttes de libération nationale (Solidarité Québec/Amérique latine, Comité Québec-Chili, Développement et Paix), chez les chrétiens progressistes et dans les mouvements qui tournent autour de la défense du consommateur et l'élaboration de nouvelles pratiques communautaires. Les militantes des mouvements féministes aussi sont souvent socialistes et indépendantistes ; de la fondation du Front de libération des 
femmes en 1969 à la création du Regroupement des femmes québécoises en 1978 par des ex-péquistes, le mouvement des femmes a été aux prises avec des tensions internes concernant la question de l'indépendance puis de la lutte des classes, et les relations avec les mouvements ouvrier et nationaliste sont aujourd'hui encore au centre des débats, mais les préoccupations explicites sont beaucoup plus les garderies, le logement, le nom des femmes, les questions du viol et de la brutalité.

L'arrivée du PQ au pouvoir a entraîné dans les mouvements populaires le déclin de la question nationale et l'ouverture d'un front plus politique et d'une stratégie d'alliance entre ces mouvements : la revue Temps Fou par exemple parle de réunir socialisme, féminisme, écologie contre l'autoritarisme, les hiérarchies de pouvoir, et la centralisation.

Enfin, quelques mots sur le mouvement écologique et anti-nucléaire ; il existe des groupes assez dynamiques, réunis pour la plupart dans le Front commun pour un débat public sur l'énergie, l'Alliance Tournesol (Mouvement anti-nucléaire et pour les alternatives) et le Regroupement pour la surveillance du nucléaire. On retrouve des militants anti-nucléaires dans la Société pour vaincre la pollution, le Monde à bicyclette, le Mouvement pour l'agriculture biologique, les groupes de recyclage, le Conseil québécois de l'environnement, etc.

Il y a assez peu de contacts entre le mouvement syndical et le mouvement anti-nucléaire, bien que certains écologistes tentent des rapprochements actuellement en centrant leur action sur des préoccupations plus directes pour les travailleurs, comme la santé, la sécurité, les horaires, le logement, les énergies alternatives, l'expansion des services publics, etc.

Il y a dans le mouvement anti-nucléaire un débat sur l'adversaire (marchands de nucléaire ou technocrates du gouvernement). La non-violence, les thèmes de l'État policier et de la peur, opposés à ceux de l'écosociété, sont également présents, avec ceux de la politique énergétique et du style de développement. Sur les politiques énergétiques, en particulier, le mouvement exige un débat publie. Il insiste sur la nécessité de bâtir un autre type de société (une écosociété) ; mais au Québec, ni la politique nucléaire, ni par conséquent le mouvement anti-nucléaire ne sont très dynamiques. Par ailleurs, le Front commun pour un débat public sur 
l'énergie est en train d'amorcer un nouveau départ pour la lutte écologique antinucléaire, et peut-être, à plus long terme, pour le combat contre la technocratie. 


\section{Mouvement écologiste, énergie et environnement. \\ Essais d'écosociologie.}

Première partie . Descriptions et analyses

\section{Chapitre 4}

\section{Le mouvement contre l'énergie nucléaire en Europe de l'Ouest}

Communication présentée au Congrès annuel du Council for European Studies, à Washington D.C. en octobre 1980, et publiée sous une forme révisée dans la revue Our Generation, vol. 15, no 2, 1982, p. 14-24.

\section{par Jean-Guy Vaillancourt *}

\section{Introduction}

\section{$\underline{\text { Retour à la table des matières }}$}

Bien qu'il ne soit apparu que depuis dix ans environ, le mouvement contre l'énergie nucléaire est l'un des mouvements sociaux les plus importants parmi ceux qui se sont développés en Europe de l'Ouest depuis 1960.

Le sociologue français Alain Touraine et son équipe, ainsi que des intellectuels et des écologistes comme Michel Bosquet/André Gorz et Brice Lalonde, croient que la lutte anti-nucléaire représente les débuts d'un nouveau mouvement social en opposition au pouvoir ascendant de la technocratie, et qu'il pourrait très bien devenir le mouvement social central de la société post-industrielle naissante, l'équivalent de ce qu'ont été le mouvement ouvrier du 19e et du début du 20e siè-

Je tiens à remercier François Benoît et Chantal McAviney qui m'ont aidé à faire la traduction française du texte original anglais. 
cles, et le mouvement pour les libertés civiles dans la société mercantiliste. Le mouvement anti-nucléaire est particulièrement important, en dépit de sa faiblesse et de sa désorganisation actuelle, parce qu'il constitue la première manifestation d'une lutte pour l'orientation de la société et parce qu'il soulève la question de contrôle social du mode de développement et des moyens de production, et conteste les bases de la société programmée, ses outils, ses règles, sa logique économique et ses processus de planification. Le mouvement anti-nucléaire représenterait donc une résistance politique aux maîtres de l'appareil de gestion et de production qui créent et orientent les besoins de la population et lui imposent une politique dangereuse et indésirable de développement. Lorsque les militants antinucléaires acceptent ce point de vue sur leur action, comme ce fut le cas pour le groupe d'intervention de Paris dans la recherche d'Alain Touraine sur le nucléaire, la lutte anti-nucléaire n'est plus conçue comme une défense étroite d'un territoire, une lutte pour la démocratie locale, une peur contre-culturelle des irradiations ni même une bataille contre l'État ou le capitalisme, mais comme un puissant mouvement social en plein essor qui tient compte bien entendu de quelques-uns des éléments cités plus haut, mais qui va plus loin que cela en s'opposant à la domination des technocrates qui essaient d'imposer leur vision de l'avenir au nom de la nécessité économique et de la rationalité technologique. En d'autres mots, le mouvement anti-nucléaire européen, en France du moins, pourrait être la force politique et sociale naissante qui va s'opposer aux politiques énergétiques de l'État militaro-industriel et qui proposera un contreprojet d'un type de développement énergétique et social autogéré et convivial. Trois des récents livres de Touraine, $L a$ Prophétie anti-nucléaire, La Mort d'une gauche et L'Après-socialisme exposent ces idées, le premier sur la base d'une recherche/intervention menée avec son équipe, les deux autres sur la base d'une analyse polémique de la crise du socialisme actuel ${ }^{6}$.

Dans le présent article je m'inspirerai de cette hypothèse, mais mon approche sera descriptive bien plus qu'analytique. En cela je respecte l'idée de Francis Bacon qui disait que les études scientifiques devraient d'abord et avant tout se préoc-

6 Alain Touraine, Z. Hegedus, F. Dubet, M. Wieviorka, La Prophétie antinucléaire, Paris, Seuil, 1980 ; Alain Touraine, Mort d'une gauche, Paris, Galilée, 1979 ; Alain Touraine, L'Après-socialisme, Paris, Grasset, 1980. 
cuper d'histoire naturelle et de classification. Avant d'expliquer et d'interpréter, il me semble qu'il faut en effet établir les faits et comprendre ce qui se passe en mettant de l'ordre dans ces faits.

Je porterai d'abord mon attention sur les origines et les significations du mouvement anti-nucléaire en Europe de l'Ouest. J'essaierai ensuite de reconstruire historiquement le développement de l'opposition à l'énergie nucléaire dans certains pays européens, particulièrement en France, en Grande-Bretagne, en Allemagne, en Autriche et dans les pays scandinaves, puisque c'est dans ces pays que l'énergie nucléaire a vu son développement le plus imposant. J'examinerai ensuite les objectifs, les stratégies, les tactiques et les problèmes d'organisation du mouvement anti-nucléaire en vue d'identifier les différences et les ressemblances entre les différents pays pour voir si les idées de Touraine s'appliquent dans d'autres pays européens que la France. Les travaux de Dorothy Nelkin et Michael Pollack ${ }^{7}$, les pionniers dans ce travail de comparaison, ainsi que les écrits publiés par le mouvement anti-nucléaire lui-même, par les journaux et par les spécialistes des sciences sociales, m'ont été très utiles dans la préparation du présent essai.

\section{Les origines du nucléaire et de l'opposition anti-nucléaire}

$\underline{\text { Retour à la table des matières }}$

Le mouvement anti-nucléaire européen prend racine, comme en Amérique du Nord, dans le mouvement pacifiste des années 50, dans le mouvement étudiant des années 60 et dans le mouvement écologique plus général des années 70 . Le mouvement anti-nucléaire européen a aussi été grandement influencé par le mouvement anti-nucléaire américain qui a débuté quelque temps auparavant. On doit cependant mentionner que le mouvement européen a aussi eu, surtout ces dernières années, un certain impact sur le mouvement américain lui-même. Le mouvement anti-nucléaire est en quelque sorte le produit de l'agitation des années 60, un

7 Dorothy Nelkin et Michael Pollack, The Atom Besieged, Cambridge, Mass., M.I.T. Press, 1981. 
mouvement dans lequel plusieurs des militants étudiants radicaux de la nouvelle gauche ont trouvé un débouché pour continuer leur lutte pour un changement de société. Mais il s'agit également de quelque chose de tout à fait nouveau qui a fleuri parmi les chercheurs, parmi la jeunesse et parmi les groupes locaux sensibilisés à la crise écologique et à la détérioration de l'environnement.

Hiroshima, Nagasaki, les expériences de la bombe « $\mathrm{A}$ » et de la bombe « $\mathrm{H}$ » après la Seconde Guerre mondiale ont ouvert la boîte de Pandore de l'énergie atomique. Dans le but de stopper la prolifération des armes nucléaires et leur expérimentation, un mouvement international a été lancé par des citoyens et des chercheurs sensibilisés au problème des retombées radioactives. Tout a commencé le 11 janvier 1952 lorsque dix personnes décidèrent d'occuper les escaliers devant le War Office à Londres. Le 9 juillet 1955, Albert Einstein et Bertrand Russell publièrent un manifeste contre la guerre. C'est d'ailleurs Russell qui fut le grand inspirateur de la Campagne pour le désarmement nucléaire qui fut lancée à Londres en 1958. Cette campagne a connu son apogée en 1961 avec l'occupation de Trafalgar Square par 50000 personnes, occupation pendant laquelle Russell fut arrêté en même temps que 32 personnes. Certains des militants pacifistes du mouvement pour bannir la bombe furent pendant quelque temps favorables à la campagne en faveur de l'Atome pour la Paix que le président Eisenhower entreprit en 1953 pour essayer de montrer au monde que malgré la guerre froide, les ÉtatsUnis étaient un pays pacifique. L'idée derrière cette campagne était de démontrer qu'il était économiquement et politiquement rentable de mettre en valeur les aspects positifs de l'instrument de destruction atomique. L'énergie nucléaire, disaiton, produira tellement d'électricité qu'il sera inutile d'en calculer les coûts. Beaucoup d'opposants aux essais nucléaires et à la bombe crurent pour un temps qu'une réorientation de l'usage militaire vers un usage civil de l'atome serait la meilleure façon d'atteindre leurs buts. La première conférence internationale sur l'usage pacifique de l'atome, qui eut lieu en 1955 illustre bien cette sérieuse méprise. Paradoxalement, l'opposition à l'énergie nucléaire vint de certaines personnes qui avaient justement été les plus ardents partisans de celle-ci lorsqu'on la percevait encore comme une alternative humaine à l'usage militaire de l'atome. Cependant, petit à petit, le mouvement pacifiste et une partie importante de la communauté scientifique devinrent réfractaires à l'usage de l'énergie nucléaire même pour des buts non-militaires, étant donné que les problèmes de la prolifération et des radia- 
tions n'étaient toujours pas résolus. La production d'électricité par la fission de l'atome fut bientôt perçue par plusieurs comme presque aussi dangereuse que les utilisations militaires de l'arme atomique.

Dans la plupart des cas, que ce soit en Europe ou aux États-Unis, la lutte antinucléaire a débuté sous la forme d'une lutte pour la protection de l'environnement, menée par des communautés locales appuyées par des jeunes écologistes et des chercheurs préoccupés par le manque de contrôle sérieux dans la gestion des déchets nucléaires. La lutte s'est d'abord centrée sur les dangers inhérents à une production massive de substances radio-actives, sur la possibilité d'accidents et sur les problèmes qu'occasionne la présence d'une installation nucléaire dans les environs. Cette lutte n'était pas politique dans le sens usuel que l'on donne à ce terme ; elle était en effet plus culturelle que politique ou sociale. Il y a eu une certaine continuité entre la révolte des jeunes des années 60 et le mouvement écologiste anti-nucléaire. Des militants étudiants comme Brice Lalonde, Rudi Dutschke et Daniel Cohn-Bendit sont passés du mouvement étudiant et pacifiste aux luttes écologistes anti-nucléaires durant les années 70. En Europe, comme aux ÉtatsUnis, les hippies et particulièrement les «politicos » de la précédente décennie devinrent l'aile grisonnante du mouvement anti-nucléaire. Les dangers et les coûts, ainsi que les conséquences politiques et sociales d'une telle option ont activé la formation d'une opposition visant l'arrêt par le gouvernement des programmes commencés au début des années 70. Ces opposants veulent que l'on mise sur les économies d'énergie, sur une meilleure utilisation des sources d'énergie fossile existantes et sur l'utilisation de différents types de nouvelles énergies d'origine solaire.

Les programmes de développement de l'énergie nucléaire du début des années 70 ont reçu un appui inattendu suite à la crise de l'énergie de 1973. Ainsi en 1979, il y avait dans le monde 222 centrales nucléaires réparties dans environ 50 pays dont 15 étaient également exportateurs de technologie nucléaire. La plupart de ces centrales étaient situées aux États-Unis (72) et dans les pays de l'Est (43, dont 32 en URSS). Les autres étaient situées au Japon (22), en Grande-Bretagne (18), en France (15), en Allemagne de l'Ouest (11), au Canada (9), en Suède (6), en Italie (4), en Suisse (4), en Belgique (3), en Inde (3), en Espagne (3), en Finlande (2), en Hollande (2) et à Taiwan. Selon un rapport publié en 1980 à Stockholm, la Corée 
du Sud, l'Argentine et le Pakistan en ont également une. Près du tiers de toutes les centrales nucléaires au monde sont donc situées en Europe occidentale ${ }^{8}$.

En fait de puissance nucléaire, calculée en milliers de mégawatts, les ÉtatsUnis viennent au premier rang, avec $41 \%$ de la puissance mondiale, suivis par le Japon (11\%) et l'URSS (9\%). Viennent ensuite la France (8\%), la GrandeBretagne (7\%) et l'Allemagne de l'Ouest (7\%). Le Canada a 4\% de cette puissance, la Suède 3\%, la Suisse 2\% et les autres pays, majoritairement européens $2 \%{ }^{9}$. On le voit d'après ces chiffres, les pays de l'Europe de l'Ouest sont de très importants producteurs d'énergie nucléaire ${ }^{10}$. Comme ils ont peu d'énergie fossile et peu d'hydro-électricité, plusieurs d'entre eux se sont sentis obligés de se tourner vers l'énergie nucléaire. Ils ont tous eu à faire face à de l'opposition de la part des militants anti-nucléaires. Examinons donc la situation des mouvements antinucléaires dans quelques-uns de ces pays.

\section{La France}

$\underline{\text { Retour à la table des matières }}$

Nous commencerons par la France, puisque ce pays a le programme nucléaire le plus imposant en Europe de l'Ouest. Dès 1985, les centrales nucléaires fourniront 65\% de l'énergie produite en France. Mais ce pays a aussi un mouvement anti-nucléaire dynamique et bien organisé. L'opposition à l'énergie nucléaire en France a fait son apparition quand un groupe d'individus s'est opposé à l'utilisation militaire de l'énergie atomique et aux tests atomiques entrepris par la France et les États-Unis. L'Association pour la protection contre les rayons ionisants (APRI) fut fondée en 1971 par un enseignant du nom de Jean Pignero. Celui-ci militait depuis 1956 contre les radiations atomiques et il avait fondé, en 1962, l'Associa-

$8 \quad$ Le Devoir, 20 février 1980.

$9 \quad$ Nuclear News, 2, 1980, et Nucleonics Week, 28 août 1980, cités dans «It's About Time ", Abalone Alliance Newspaper, August 1980, p. 5.

10 Les pays du marché commun reçoivent un peu plus de $10 \%$ de leur électricité des centrales nucléaires. Il y a une couple d'années, on prévoyait que ce pourcentage serait de $40 \%$ en 1985. 
tion contre le danger radiologique 11 . Mais c'est en Alsace, en 1970, que le mouvement anti-nucléaire français a vraiment pris son essor, avec la création du Comité pour la sauvegarde de Fesselheïm et de la plaine du Rhin (CSFR). Des fermiers et des villageois, de même que des chercheurs et des écologistes radicaux, décidèrent de s'opposer à la pollution industrielle et au danger nucléaire représenté par le réacteur de Fesselheim. Une manifestation pacifique, la première manifestation anti-nucléaire en Europe, eut lieu le 12 avril 1971, avec 1500 participants. Les membres du CSFR entreprirent des démarches judiciaires pour arrêter la construction du réacteur, mais ils perdirent leur procès au début de 1975. À côté des gens de la région préoccupés par leur sécurité, nous retrouvons des jeunes, des gauchistes et surtout des anarchistes et des socialistes libertaires influencés par les événements de Mai 68. C'est de ce courant que le mouvement écologiste français a reçu une bonne partie de son dynamisme. Des leaders étudiants, comme Brice Lalonde, devinrent, dans les années qui suivirent, des figures dominantes dans le mouvement écologiste et anti-nucléaire. De la Sorbonne à Malville, il y a continuité, tout comme il y a eu continuité en Californie entre le « Free Speech Movement » de Sproule Plaza en 1964, et I'Abalone Alliance against Nuclear Power d'aujourd'hui.

La section française des Amis de la Terre, fondée en 1971, a été dès le début très active contre l'énergie nucléaire. Un journaliste de Charlie-Hebdo, Pierre Fournier, a beaucoup contribué lui aussi à la création du mouvement antinucléaire français. Il a été un des organisateurs de la manifestation et de l'occupation au site de Bugey en 1971 et de la marche du 16 octobre entre Bugey et Lyon. C'est également lui qui, en 1972, fonda la première revue écologique antinucléaire La Gueule ouverte.

Les scientifiques (par exemple, les gens du groupe et de la revue Vivre et Survivre), ainsi que les groupes déjà existants d'écologistes et de fervents de la nature, vinrent se joindre au mouvement en 1972. À la fin de cette année-là, une grande campagne fut lancée pour obtenir un moratoire sur les programmes nucléaires.

11 Voir, entre autres, le texte de Martine Chaudron et Yves Le Pape, « Le mouvement écologique dans la lutte anti-nucléaire »in F. Fagnagi et A. Nicolon, Nucléopolis, Paris, Presses Universitaires de Grenoble, 1979. 
On y retrouva plus de 100 groupes et plus de 100000 personnes. Ceux-ci exigeaient un moratoire sur l'énergie nucléaire et la fin des tests nucléaires dans le Pacifique.

En 1973, une agence de presse écologique fut créée à Montargis et l'important magazine Le Nouvel Observateur lança un mensuel écologique ayant pour titre Le Sauvage. Par contre, la crise énergétique de 1973 donna un nouvel élan aux forces pro-nucléaires. Un ambitieux programme d'énergie nucléaire fut annoncé en 1974 par le Premier ministre Messmer : sept nouveaux réacteurs devaient être bâtis au rythme de un par année. Cette décision eut pour effet de renforcer l'unité des écologistes français quant à l'enjeu nucléaire, de susciter la création de nouveaux groupes anti-nucléaires et de convaincre l'écologiste René Dumont de poser sa candidature aux élections à la présidence de la République. La campagne présidentielle de 1974 contribua donc à la dissémination de l'information écologique et anti-nucléaire à travers toute la France. En remportant presque 3\% des votes, Dumont réussit à donner à l'écologie, et indirectement à la position anti-nucléaire, une légitimité et une importance accrues.

En France, le PCF et les deux plus importants partis politiques de la droite, les Gaullistes en particulier, sont favorables au développement de l'énergie nucléaire. Par ailleurs, le PSU et plusieurs membres du Parti socialiste ont pris position en faveur d'un moratoire sur le nucléaire. Sont aussi anti-nucléaires certains petits groupes d'extrême-gauche, ainsi que quelques éléments des Petits partis du centre ${ }^{12}$. Des travailleurs dans le domaine de l'énergie nucléaire, affiliés à la CFDT, publièrent en 1974 une série de dépliants (qui parurent sous forme de livre en 1975 sous le titre L'Électro-nucléaire en France) contre le programme de Messmer. En mai 1975, la CFDT exigea un moratoire de trois ans sur la construction des centrales nucléaires.

L'été et l'automne de 1974, ainsi que le début de 1975, furent particulièrement mouvementés en ce qui concerne les actions et les publications anti-nucléaires.

12 Dorothy Nelkin et Michael Pollack, «Political Parties and the Nuclear Energy Debate in France and Germany », Comparative Politics, January 1980, p. 131-133. 
Environ 400 scientifiques, dont beaucoup de physiciens, publièrent une lettre ouverte mettant en garde contre les dangers du programme énergétique de Messmer. Vers la fin de 1975, 4000 autres scientifiques ajoutèrent leur signature au document. Certains de ces scientifiques publièrent un dépliant intitulé « Les Risques et dangers du programme électro-nucléaire » et créèrent le Groupement des scientifiques pour l'information sur l'énergie nucléaire (GSIEN). Ce groupe se mit alors à publier la revue La Gazette nucléaire et à organiser des débats publics à travers tout le pays.

C'est durant l'année 1975 que l'on peut constater le démarrage décisif du mouvement anti-nucléaire dans les diverses régions de France, en particulier en Bretagne et dans le sud-ouest. Les manifestations se firent de plus en plus fréquentes et les participants de plus en plus nombreux. Des comités anti-nucléaires surgirent un peu partout en France, surtout dans les régions désignées pour recevoir des installations nucléaires. Malville et La Hague devinrent des symboles pour les forces d'opposition au nucléaire. Plusieurs attaques à la bombe eurent lieu contre les installations nucléaires en 1975, à mesure que les forces de l'extrême-gauche commencèrent à s'intéresser à la question. Les débats s'envenimèrent et les attaques s'intensifièrent en 1976. L'atmosphère joyeuse que l'on avait remarquée en 1971 à Bugey fut remplacée par un esprit de confrontation et une convergence entre les différentes tendances et orientations actives dans la lutte anti-nucléaire. La grève de trois mois en 1976 à La Hague, qui visait principalement àarrêter le transfert de la centrale à l'entreprise privée mais qui avait aussi comme préoccupation majeure la santé et la sécurité des travailleurs, fut très importante puisqu'elle permit le rapprochement entre les travailleurs et la population locale. Le surgénérateur devint le point de mire cette année-là, et de nombreuses manifestations eurent lieu à Malville. Les tactiques préférées des militants devinrent la désobéissance civile et l'action directe, bien que la participation aux élections fut aussi considérée comme importante.

Le 31 juillet 1977, à Malville, un jeune instituteur fut tué et une centaine d'autres personnes furent blessées lorsque 5000 policiers firent face à 60000 manifestants opposés au premier surgénérateur commercial français. Plusieurs adversaires du nucléaire venus d'autres pays d'Europe participèrent également à cette manifestation de Malville. Le Parti socialiste et la CFDT refusèrent finalement d'y parti- 
ciper par peur de la violence de la part des extrémistes de gauche qui avaient orienté l'événement vers une confrontation directe avec l'État et la police. Une période de découragement suivit ce 31 juillet sanglant à Malville. La frustration mena, d'un côté à l'apathie, et de l'autre à la violence. Le nombre de manifestations diminua considérablement, mais il y eut cinq attaques à la bombe sur les installations nucléaires de l'État français, le 20 novembre 1977. Les élections législatives de mars 1978, par ailleurs, furent un échec pour les forces anti-nucléaires. Les candidats écologiques reçurent seulement $2,14 \%$ des votes, ce qui est de beaucoup inférieur à ce qu'ils avaient obtenu dans les diverses élections de 1977.

Par contre, après l'incident de Three Mile Island aux États-Unis, il y eut un certain empressement de la part du gouvernement français pour l'accélération de son programme nucléaire. On a pu constater aussi un regain d'activités de la part des militants s'opposant à ce programme. Dans les deux années qui suivirent, la lutte devint plus politique que culturelle et il y eut un plus grand effort de déployé pour établir une liaison entre les militants anti-nucléaires et les autres mouvements sociaux progressistes, particulièrement les travailleurs et les femmes. Un effort fut aussi fait pour la convergence avec des groupes politiques ainsi qu'avec d'autres mouvements anti-nucléaires européens. Une rencontre internationale de militants anti-nucléaires eut lieu à La Hague les 28 et 29 juin 1980, afin surtout d'attirer l'attention sur les implications de l'addition prévue de trois nouvelles usines de retraitement de déchets radioactifs dans cette ville. Les principales revendications qui surgirent furent les suivantes : 1) non au prolongement du programme de La Hague, 2) non à l'utilisation du plutonium pour des fins civiles et militaires, 3) non à la technologie des surgénérateurs, 4) non à l'augmentation de la répression contre les mouvements anti-nucléaires ${ }^{13}$. Les Amis de la Terre et la CFDT formèrent une alliance en vue d'appuyer une pétition anti-nucléaire. Cette " pétition nationale pour une politique énergétique différente », est basée sur l'acceptation des nouvelles voies offertes par l'énergie douce.

Les États généraux sur le nucléaire civil et militaire qui ont eu lieu en mars 1982 à Valence-d'Agen près du site de Golfech ont amorcé une nouvelle orientation de la lutte anti-nucléaire, c'est-à-dire l'alliance entre écologistes et pacifistes.

13 WISE-World Information Service on Energy, vol. 2, no 4, May-June 1980. 
C'est là le développement actuel le plus significatif en France, de même que dans la plupart des autres pays d'Europe.

La réorientation de la lutte anti-nucléaire vers la participation électorale après la précédente période de confrontation ne porta pas fruit. Et comme dans le système français il y a peu de possibilité d'entreprendre des actions légales efficaces de la part des citoyens comme c'est le cas en Allemagne ou aux États-Unis, (même si cela a été essayé), le mouvement anti-nucléaire français se retrouve dans une impasse. Le mouvement anti-nucléaire en France s'éloigne présentement de l'action culturelle pour s'orienter vers des liens ou une participation avec les forces syndicales et politiques de gauche. Touraine et ses collègues croient que l'avenir de ce mouvement social réside dans sa capacité de dépasser l'intervention culturelle et politique pour s'orienter vers un type de lutte de classe contre la montée de la technocratie, une lutte qui maintiendrait la suprématie du mouvement social sur toute activité politique. Le mouvement social anti-technocratique est déjà présent dans la lutte anti-nucléaire mais elle est incapable de poursuivre son action puisque nous ne sommes qu'au début du développement de cette lutte ${ }^{14}$. Si l'on fait une comparaison avec le mouvement ouvrier, c'est un peu comme si l'on se trouvait encore dans la première moitié du 19e siècle.

\section{La Grande-Bretagne et l'Irlande}

$\underline{\text { Retour à la table des matières }}$

Il y avait 33 centrales nucléaires en opération en Grande-Bretagne en 1980. Elles produisaient 12\% de l'électricité de la Grande-Bretagne, c'est-à-dire 4\% de son énergie totale. La première centrale britannique, qui fut aussi la première centrale commerciale au monde, commença à produire en 1950. D'autres on été ajoutées graduellement au cours des années qui suivirent. Pour éviter de provoquer des débats, on ajoutait souvent un deuxième réacteur à une centrale déjà en opération.

14 Alain Touraine et al., La Prophétie anti-nucléaire, Paris, Seuil, 1980, p. 316-319. 
La naissance tardive du mouvement britannique contre l'énergie nucléaire s'explique probablement par l'existence durant les années 60 d'un mouvement anti-bombe important centré uniquement sur les aspects militaires du nucléaire. Mais une fois le lien entre les utilisations militaires et civiles compris au milieu de 1970, le mouvement contre les centrales nucléaires connut une croissance rapide.

Le rapport de la Commission Flower, remis le 26 septembre 1976, recommandait fortement la remise à plus tard de l'expansion de l'énergie nucléaire en Grande-Bretagne. Par contre, le gouvernement décida de construire deux nouveaux réacteurs et d'agrandir l'usine de retraitement à Windscale. Le point de mire de l'opposition depuis 1976 a été Windscale, ainsi que le réacteur projeté de Torness en Écosse. Il y a eu de nombreuses pétitions, des marches pacifiques, des pressions politiques, des interventions légales et une forte participation aux mécanismes de consultation établis par le gouvernement, tout cela dans le but de mettre fin aux divers volets du programme nucléaire. À cause du peu de succès de ces méthodes, le mouvement s'est tourné, ces dernières années, vers l'action directe non violente et cela malgré le fait que le mouvement lui-même dans son ensemble paraît s'affaiblir et devenir moins militant que les mouvements équivalents sur le continent.

Les forces anti-nucléaires en Grande-Bretagne ont eu tendance à fonctionner comme groupe de pression plutôt que comme un mouvement social radical. Comme elles ont eu peu de succès dans leurs efforts pour bloquer le développement du nucléaire, elles semblent maintenant chercher désespérément de nouvelles façons de s'oppose à l'énergie nucléaire. Le mouvement a trouvé un certain appui dans le Parti libéral et chez les gens de gauche, qu'ils soient ou non à l'intérieur du Parti travailliste. À cause de la difficulté de créer de nouveaux partis politiques dans le système électoral à majorité simple de type britannique, le parti écologiste The Green Alliance n'a pas eu beaucoup de succès au plan électoral.

En 1978, le gouvernement fit une enquête publique sur l'expansion de l'usine de retraitement de Windscale. Ces audiences publiques de Windscale furent un point tournant pour le mouvement. Les militants anti-nucléaires se rendirent alors compte qu'il était pratiquement inutile de passer par les voies officielles. Ils for- 
mèrent donc sous le nom de Torness Alliance un réseau de groupes semblables aux coalitions et aux alliances anti-nucléaires nord-américaines.

En avril 1978, à l'instigation des Amis de la Terre, 12000 personnes vinrent à Londres pour manifester contre le plan visant à utiliser Windscale pour le retraitement de déchets japonais. Le mois suivant, SCRAM, Scottish Campaign to Resist the Atomic Menace, a rallié 5000 personnes, dont plusieurs venaient de l'extérieur de la Grande-Bretagne, pour une marche et une occupation festive à Torness. Une deuxième occupation de ce genre eut lieu à Torness en mai 1979, avec la présence de 10000 manifestants. Quelques-uns réussirent àpénétrer à l'intérieur du site et à causer des dommages considérables. La manifestation de mai 1980 au même endroit attira moins de participants qu'en 1978 et 1979, mais les manifestants utilisèrent des tactiques encore plus militantes. Il y eut quelques arrestations.

Le gouvernement conservateur de Margaret Thatcher veut une expansion des facilités nucléaires et projette la construction d'un nombre de nouveaux réacteurs pouvant aller jusqu'à 20, d'ici à la fin du siècle. L'opposition à ces plans se retrouve dans un mouvement large qui a pris un nouvel essor à la suite de l'accident de Three Mile Island et à cause de la publicité concernant Torness. Le mouvement semble maintenant être tiraillé dans des directions opposées, entre d'une part l'action violente directe (sabotage et occupation) et d'autre part les pressions symboliques de groupe et l'électoralisme.

Au niveau organisationnel, le mouvement oseille entre une tendance qui privilégie l'action politique organisée de groupes écologiques bien structurés, et une tendance pacifiste, anarchiste et libertaire fonctionnant par groupes d'affinités. Toutefois, il y a un effort sérieux de fait par certains militants anti-nucléaires pour lier leur cause avec celle du mouvement ouvrier, SERA, Socialist Environment and Resources Association, par exemple, travaille de pair avec les délégués d'ateliers dans les usines pour faire opposition à l'énergie nucléaire. La perspective internationale est présente aussi, de même que la question régionale qui joue un rôle assez important bien que rarement mentionné dans de nombreux pays européens, puisque les centrales nucléaires sont souvent construites dans des régions éloignées des centres hautement urbanisés et à forte densité démographique. Il y a peut-être moins de fermiers menacés par le nucléaire en Grande-Bretagne, mais 
les nationalistes écossais (tout comme les nationalistes bretons ou basques) sont actifs parce qu'ils voient l'invasion du nucléaire sur leur territoire comme un autre signe de l'oppression coloniale de la part du gouvernement central et de ses technocrates.

Il y a aussi beaucoup d'opposition à l'énergie nucléaire en Irlande. Le gouvernement prévoyait un complexe nucléaire à Carnsore Point, mais il semble maintenant que l'Irlande n'aura pas de centrale nucléaire, et cela surtout à cause du rôle crucial joué par les syndicats dans la lutte anti-nucléaire de ce pays ${ }^{15}$. En Irlande à l'heure actuelle, la lutte est maintenant centrée sur les mines d'uranium, qui constituent toujours une menace même si les plans de réacteurs ont été mis de côté pour le moment.

\section{L'Allemagne de l'Ouest}

Retour à la table des matières

L'Allemagne de l'Ouest est une des grandes puissances mondiales dans le domaine de l'énergie nucléaire. Ses quatorze centrales nucléaires génèrent $12 \%$ de son électricité. Il y a neuf autres centrales en construction et presque autant au stade de la planification pour 1990. L'Allemagne de l'Ouest est aussi le troisième plus important pays exportateur de nucléaire, après les États-Unis et l'URSS. L'Afrique du Sud, l'Argentine et surtout le Brésil, qui projette l'achat de 63 réacteurs pour l'an 2000, sont parmi les pays qui ont reçu l'aide de l'Allemagne de l'Ouest dans ce domaine. Il n'est donc pas surprenant que le programme nucléaire allemand ait été accusé par des militants anti-nucléaires d'avoir donné refuge à des ex-nazis déterminés à promouvoir l'hégémonie de l'Allemagne dans le monde.

Le mouvement anti-nucléaire allemand a débuté en 1971 lorsque le gouvernement a annoncé qu'il construirait un réacteur à Breisach. L'opposition des citoyens de la région força le gouvernement à abandonner Breisach comme empla-

15 Voir le rapport de Petra Kelly sur la République de l'Irlande, dans Anna Gyorgy and friends, No Nukes. Everyone's Guide to Nuclear Power, Boston, South End Press, 1979, p. 330-332. 
cement possible. Celui-ci opta alors pour Wyhl, bien que la communauté agricole locale fût également très opposée au projet. En février 1975, la controverse de Wyhl a atteint son sommet : une manifestation de 28000 personnes s'y déroula. Jeunes militants écologistes, fermiers et vignerons marchèrent ensemble jusqu'à l'emplacement choisi pour la centrale nucléaire. Malgré les 3000 policiers présents, ils prirent possession du site. Quelques-uns participèrent à une occupation symbolique qui dura neuf mois, ce qui obligea le gouvernement à abandonner son projet de construction de la centrale.

Le 13 novembre 1976, plus de 30000 personnes manifestèrent sur le site du réacteur de Brokdorf, et 3000 d'entre elles essayèrent vainement d'occuper les lieux. Une occupation similaire fut tentée à Grohnde en mars 1977 et plusieurs autres manifestations eurent lieu à Brokdorf et Grohnde cette même année. Des participants furent blessés et arrêtés. En septembre, dans une grande manifestation pacifique, 60000 personnes s'opposèrent au projet de construction de deux surgénérateurs de 300 mégawatts à Kalkar par l'Allemagne en coopération avec la France, la Belgique, la Hollande et la Grande-Bretagne. Malgré le harcèlement et malgré l'arrestation de 150 individus par les 4500 policiers présents, il n'y eut pas de sérieux incidents et aucun effort ne fut entrepris pour occuper les lieux. Après Kalkar, on s'efforça de trouver des moyens de pression autres que des manifestations, par exemple la participation aux élections et les recours en justice.

Le mouvement anti-nucléaire allemand est l'un des mieux organisés et des plus disciplinés des mouvements anti-nucléaires européens, et avec le mouvement français, il exerce un rôle clef à l'intérieur du mouvement européen en général. En 1977, avec les mouvements anti-nucléaires de huit autres pays du marché commun (et l'Autriche), il contribua à la création d'un réseau d'informations antinucléaires européen et il collabora avec eux à la décision de présenter des candidats sous la bannière écologique aux élections européennes. Au niveau national, les Allemands ont créé une coalition écologique « verte » qui a remporté plusieurs sièges aux élections locales de Berlin et d'Hambourg en 1978, à Brême en 1979 et à Bade-Wurtemberg en 1980.

Le 16 mai 1979, le gouvernement retarda temporairement l'implantation d'une usine d'entreposage et de retraitement de déchets nucléaires de 6 milliards de dol- 
lars à Gorleben en Basse-Saxe, qui était devenue l'objet d'une nouvelle controverse. Le 14 décembre de la même année, 100000 personnes marchèrent dans Bonn pour demander la fermeture des réacteurs ouest-allemands et le 3 mai 1980, le débat fut relancé par l'occupation symbolique du site de Gorleben et la création de la République libre du Wentland. Après 33 jours, le chancelier Schmidt dépêcha 10000 policiers pour évacuer les 3000 Wentlanders. Un vaste mouvement émergea immédiatement dans toute l'Allemagne contre la répression exercée par les autorités, qui est devenue une caractéristique importante de la lutte en Allemagne. De plus en plus, les militants anti-nucléaires voient leurs libertés civiles menacées et ils sont souvent considérés par les détenteurs du pouvoir socio-économique et politique comme de dangereux terroristes.

Les « initiatives des citoyens » ont réussi à obtenir un ralentissement du programme nucléaire. Les groupes environnementaux ont maintenant une douzaine de projets nucléaires de bloqués grâce à des procès en justice, ce qui serait impossible en France. À cause de la répression des militants par le gouvernement, la lutte contre l'énergie nucléaire reste très ardue. Il y a certains appuis de la part de groupes féministes et religieux, des organisations de jeunes sociaux-démocrates et des associations de médecins, mais les syndicats ouvriers et les dirigeants du Parti social-démocrate ont pris position en faveur de l'énergie nucléaire, bien qu'ils ne l'aient pas fait aussi fortement que les dirigeants de la démocratie chrétienne.

Le développement du programme nucléaire allemand est actuellement bloqué par des contraintes légales, mais il est possible que le chancelier Schmidt réussisse à faire disparaître quelques-unes de ces barrières. Si cela arrivait, il y aurait un grave risque que l'on voit surgir une nouvelle vague d'opposition qui pourrait même impliquer des actions terroristes. Pour l'instant cependant, c'est la lutte des pacifistes contre les armes nucléaires qui accapare l'attention des anti-nucléaires. 


\section{L'Autriche}

$\underline{\text { Retour à la table des matières }}$

Même si l'Agence internationale de l'énergie atomique est située en Autriche, ce pays ne figure pas au nombre des plus gros pays producteurs européens d'énergie nucléaire. Il n'existe en fait qu'une seule centrale en Autriche, celle-ci ayant été acceptée en 1968 sans aucune opposition. Mais cette centrale a de bonnes chances aujourd'hui d'avoir été en quelque sorte tuée dans l'oeuf ou, tout au plus, d'être la seule à être éventuellement mise en opération dans ce pays. En 1973, la construction d'une deuxième centrale fut fortement dénoncée, d'abord par des médecins, puis par des biologistes et des environnementalistes. En 1975, une pétition de 60000 noms s'opposa au projet de construction de cette seconde centrale. En 1977, Salzbourg fut l'hôte de la conférence internationale pour un avenir non nucléaire. L'année suivante, la première centrale nucléaire d'Autriche, une centrale de 700 mégawatts ayant coûté 750 millions de dollars, devait entrer en opération à Swentendorf. Toutefois son ouverture fut stoppée par un référendum antinucléaire qui eut lieu le 15 novembre 1978, après une dure campagne de trois ans orchestrée par une coalition nationale appelée l'Initiative anti-nucléaire autrichienne. La participation dans un débat public lancé par le gouvernement en 1976 porta finalement ses fruits. Même si les dépenses des militants de l'anti-nucléaire furent 200 fois moindres que celles de l'industrie nucléaire et des entreprises d'électricité, les anti-nucléaires gagnèrent le référendum avec 50,47\% des votes. Les forces pro-nucléaires, qui comprennent le syndicat de la construction entre autres, essaient maintenant de renverser les résultats du vote de 1978 en proposant un nouveau référendum. Quels que soient les résultats de ce nouveau référendum, la décision prise en 1978 ne peut être changée que par une majorité des 2/3 au Parlement. Il est donc tout à fait probable que l'Autriche n'adoptera pas une position pronucléaire, même si les forces anti-nucléaires perdent dans un nouveau référendum. Le mouvement anti-nucléaire autrichien insiste sur le danger que représentent les déchets radioactifs, pour lequel il n'existe pas de solution permanente, et aussi sur les risques de prolifération. À ces raisons s'ajoute le fait que les pays voisins comme l'Allemagne de l'Ouest et la Tchécoslovaquie projettent de 
bâtir leurs centrales près des frontières avec l'Autriche, qui est le seul pays européen à avoir rejeté l'énergie nucléaire par un vote populaire majoritaire. Si les forces anti-nucléaires gagnent ce second référendum, celles-ci se tourneront probablement vers l'extérieur pour s'opposer à la construction de centrales nucléaires sur leurs frontières par l'Allemagne de l'Ouest et la Tchécoslovaquie.

\section{La Suisse, la Hollande et la Belgique}

\section{$\underline{\text { Retour à la table des matières }}$}

En Suisse, il y a maintenant quatre centrales nucléaires en opération et trois à cinq autres centrales sont projetées. Le mouvement anti-nucléaire y est bien implanté et une large proportion de la population y participe. Il existe aussi à l'intérieur de ce mouvement une aile plus radicale. Dès 1975, il y eut plusieurs manifestations, ainsi que des grèves de la faim et des occupations de sites, contre le programme d'énergie atomique suisse (à Kaiserhugst, Goesgen, Aarau et Liebstadt) organisées par les militants anti-nucléaires, les fermiers et les citadins. En 1977, les anti-nucléaires l'emportèrent par 3 à 1 dans un référendum sur le nucléaire à Bâle. Le gouvernement décida alors de ne pas construire de nouvelles centrales avant d'avoir tenu un nouveau référendum national sur la question. Ce référendum national eut lieu en février 1979. La question portait sur un droit de veto qu'auraient eu les communautés locales, quant à l'édification des centrales. Les anti-nucléaires perdirent par la faible marge de $51,2 \%$ à $48,8 \%$, mais en mai, le gouvernement institua de sévères contrôles concernant l'énergie nucléaire.

En Hollande, en 1973, il y avait déjà deux centrales nucléaires en opération. Le mouvement anti-nucléaire démarra cette année-là avec le Mouvement pour stopper Kalkar puis ensuite avec une demande de moratoire faite par des scientifiques et des environnementalistes. Le mouvement anti-nucléaire hollandais est aujourd'hui puissant et internationaliste. Les sondages démontrent que la majorité de la population hollandaise est anti-nucléaire. Les Chrétiens démocrates avaient inclus dans leur programme une phrase concernant les dangers du nucléaire, mais une fois élus, ils investirent de façon importante dans URENCO, un consortium anglais-hollandais-allemand qui projette la production d'uranium enrichi grâce à 
une nouvelle technologie de séparation centrifuge. Les socialistes, qui sont dans l'opposition, ont officiellement pris position en faveur de la fermeture des deux centrales nucléaires du pays. Le Parti radical, une petite formation membre de la coalition gouvernementale est aussi anti-nucléaire, et de fait exerce une pression de l'intérieur pour s'opposer à l'expansion du nucléaire et à la vente de réacteurs à l'Afrique du Sud. Le 18 octobre 1980, un front commun formé de 60 à 70 groupes de militants anti-nucléaires manifestait à Dodewaard pour demander la fermeture de la centrale. Il s'agit là d'une radicalisation de l'action commencée le 4 mars 1978, lors d'un rassemblement international de 40000 personnes tenu à Almeno près de la frontière allemande. Cette manifestation eut lieu à l'usine d'uranium enrichi d'URENCO où l'on doit produire assez de carburant pour fournir « tout le système nucléaire du nord-ouest de l'Europe pour le reste du siècle et même pour pouvoir vendre une partie de la production au Brésil 16 ».

Plus de 25\% de la production électrique de la Belgique est d'origine nucléaire. Il n'y a présentement que quelques centrales en opération, mais on est en train d'en construire et d'en projeter d'autres. En 1978, un accident eut lieu à la centrale de Thihange, propriété conjointe de la Belgique et de la France, et 80 personnes furent contaminées. Cet accident accéléra le développement du mouvement antinucléaire belge. Ainsi, le 1er octobre 1978, deux référendums municipaux sur le nucléaire obtenaient un «non » catégorique à l'établissement d'une centrale.

\section{Les pays scandinaves}

$\underline{\text { Retour à la table des matières }}$

En Scandinavie, même si l'on peut dire que le mouvement anti-nucléaire est fort et qu'il a récolté un certain succès partout, la situation n'est visiblement pas la même dans tous les pays. La Norvège est un cas vraiment à part, puisque l'on ne retrouve dans ce pays aucun réacteur nucléaire ni aucun projet pour en établir. Il semble bien qu'il n'y en aura d'ailleurs jamais, la population et le gouvernement étant fermement opposés à tout développement de l'énergie nucléaire.

16 Nuclear Opponents, 27 février 1978, p. 3, col. 2. 
Au Danemark, la situation est quelque peu différente. Le gouvernement avait d'abord décidé la construction de 15 centrales mais il a décidé en février 80 de remettre ces projets aux calendes grecques. Cette victoire, le mouvement antinucléaire l'a obtenue grâce à la très grande implication de ses militants qui ont formé un mouvement décentralisé de 200 groupes. Celui-ci a tenu des manifestations très imposantes, il a maintenu un bon contact avec les syndicats et il a orchestré une importante campagne d'éducation populaire. Une brochure antinucléaire d'une très grande qualité a été distribuée dans tous les foyers du pays. L'accent a été mis sur le développement d'une politique énergétique ne faisant pas appel au nucléaire. Un effort important est mis sur une campagne destinée à tous les niveaux de la société et visant à générer des expériences locales faisant appel aux énergies douces. Le Danemark, tout comme la Norvège, ne rentrera probablement jamais dans l'ère nucléaire.

La Suède, par contre, y est entrée très tôt et essaie maintenant de s'en sortir. La situation de ce pays est, en fait, fort complexe. En 1976, la Suède avait déjà cinq réacteurs en opération, cinq en construction et on en planifiait trois de plus. Le gouvernement social-démocrate prévoyait que ces 13 réacteurs produiraient 40\% de l'énergie électrique du pays vers 1985, mais une opposition généralisée, animée par un mouvement anti-nucléaire bien organisé, s'opposa à un plus grand développement de l'énergie nucléaire. Cette résistance s'organisa très tôt et fut encouragée par un lauréat du prix Nobel de physique Hannes Alfven, lorsque cet ancien partisan d'un usage civil de l'énergie nucléaire se prononça publiquement contre le nucléaire. Le premier ministre social-démocrate d'alors, Olaf Palme, fut défait par Thorbjoern Fallding, du Parti du centre, à cause de ses prises de positions pro-nucléaires. Lorsque la coalition gouvernementale (formée du Parti libéral, du Parti conservateur et du Parti du centre) donna son accord à la construction d'un deuxième réacteur à Barsebaeck, la réponse ne se fit pas attendre. Le 10 septembre 1977, 15000 partisans anti-nucléaires défilèrent en signe de protestation. En 1978, des différends portant sur l'énergie nucléaire provoquèrent la chute du gouvernement de coalition, le premier gouvernement suédois non-socialiste en 44 ans. À l'intérieur de la coalition, les Partis conservateur et libéral étaient en faveur de l'énergie nucléaire tandis que le petit Parti du centre dirigé par Fallding était contre. On évita adroitement la question à l'élection de 1979 en s'entendant sur la 
tenue d'un référendum au mois de mars 1980. La même coalition revint au pouvoir, toujours aussi divisée qu'auparavant. Le 8 juin 1980, le parlement suédois vota l'arrêt de la construction de tous les nouveaux réacteurs. On décida de tenir un référendum pour décider du sort des nouveaux réacteurs et de ceux déjà en opération. Le 26 août de la même année se tenait une manifestation contre le nucléaire qui réunissait 50000 personnes.

Le référendum du mois de mars 1980 donna 18,7\% des votes à l'option pronucléaire des Partis conservateur et libéral, qui proposaient que les six centrales déjà construites ou en voie de l'être viennent s'ajouter aux six réacteurs déjà en fonctionnement. L'option défendue par le Parti social-démocrate, qui demandait également l'ajout de ces six réacteurs mais qui prévoyait leur mise hors-service graduelle, récolta 39,3\% du vote, alors que l'option foncièrement anti-nucléaire des Partis écologiste, centriste et communiste (qui demandaient le démantèlement de toutes les installations d'ici 1990) reçut 38,6\% du suffrage populaire.

Les résultats concrets de ce référendum furent la limitation à12 du nombre de réacteurs du programme nucléaire, un moratoire sur tous les nouveaux réacteurs, mais également une mise au rancart de toutes les centrales d'ici 15 ou 25 ans. La Suède a de graves problèmes avec le recyclage des déchets puisque le contrat avec les installations françaises de La Hague couvre le recyclage des déchets de huit réacteurs pour une période de dix ans alors que le programme nucléaire actuel implique la production de déchets pour douze réacteurs pour une période de 25 ans. C'est ainsi que certains réacteurs devront demeurer inactifs même s'ils sont opérationnels.

En Suède, comme dans les autres pays européens, le mouvement antinucléaire a contribué à faire éclater la dichotomie habituelle entre la droite et la gauche. Tous les partis ont perdu des appuis à cause de leur position pronucléaire. Le Parti social-démocrate de Suède a perdu le pouvoir en grande partie à cause de cela. Bien que le Parti du centre soit clairement le seul parti antinucléaire en Suède, on trouve encore des militants anti-nucléaires dans chacun des autres partis politiques et ils constituent en cela un danger pour chacun de ceux-ci. 
Les six réacteurs suédois en opération produisent à eux seuls 25\% de toute l'électricité du pays, soit 7\% de toute son énergie. Per capita, il s'agit là du plus important programme au monde. D'un autre côté, on constate des expériences prometteuses dans ce pays dans le domaine de la conservation de l'énergie et dans celui des énergies nouvelles. La Suède n'est pas sortie de l'âge nucléaire, mais elle entre quand même dans l'ère des énergies douces. L'attention se déplace donc de l'énergie nucléaire vers une politique énergétique davantage orientée vers l'avenir.

La Finlande a, pour sa part, quatre centrales nucléaires et il est question qu'elle en achète une cinquième à l'URSS. Cette dernière centrale aurait une capacité de production de 1000 mégawatts. On a distribué, en février 1980, environ 200000 copies d'un journal de quatre pages contre ce dernier projet de centrale. Le 15 mars, un défilé était organisé à Helsinki et 5000 personnes y participaient. Il s'agissait là d'une première en Finlande. On comptait parmi les organisateurs de cette manifestation les sections jeunesse de la plupart des partis politiques, tous les mouvements écologistes, l'association étudiante nationale, de même qu'un important groupe de pacifistes et plusieurs associations féministes.

Comme en Irlande, une des préoccupations majeures du mouvement antinucléaire finlandais est la question de l'extraction d'uranium, qui est d'ailleurs devenue un enjeu important pour le mouvement anti-nucléaire international. C'est pourquoi une conférence a eu lieu en juillet 1980 à Bessines en France dans le but d'échanger des informations sur ce problème de l'extraction de l'uranium.

\section{L'Espagne}

\section{$\underline{\text { Retour à la table des matières }}$}

Le mouvement anti-nucléaire espagnol a fait son premier coup d'éclat en 1972 avec une pétition de 150000 signatures. Ces personnes s'opposaient à la construction d'une installation nucléaire à Lemoniz en pays basque. À la suite de cette pétition, 200000 personnes participaient le 14 juillet 1972 à la manifestation de Bilbao contre le programme gouvernemental de construction de 12 centrales nucléaires sur la côte basque. En septembre de la même année, 600000 personnes 
manifestaient conte la construction d'un réacteur Westinghouse à Lemoniz tandis que 100000 défilaient à Saragosse dans une marche anti-nucléaire.

Le 8 avril 1978, des bombes détruisaient les pylônes électriques de la compagnie ayant le contrat de construction d'un réacteur nucléaire à Bilbao. Le 1er septembre 1979, 96 maires de villages marchaient en compagnie de 25000 personnes à Badajoz en protestation contre l'intention gouvernementale de construire deux réacteurs nucléaires dans la région.

L'Espagne a pour les 20 prochaines années l'un des programmes nucléaires les plus imposants de toute l'Europe. On prévoit en effet 30 nouveaux réacteurs pour cette période. Mais l'Espagne a également eu les plus grosses manifestations de tous les pays du monde. Il faut préciser que l'enjeu nucléaire est ici lié de près à la question régionale; plusieurs installations sont prévues dans des régions où les sentiments séparatistes sont forts, ce qui explique probablement la résistance si grande à la politique énergétique du gouvernement central. De fait, lorsque le régionalisme s'allie au sentiment anti-nucléaire, on se retrouve devant un mouvement social très puissant.

\section{L'Italie}

$\underline{\text { Retour à la table des matières }}$

L'Italie a, pour sa part, quatre centrales qui fournissent environ 2,5\% de la production énergétique du pays. En 1977, le gouvernement dévoila des projets pour l'ajout de 10 autres centrales, mais il rencontre depuis ce temps, une opposition grandissante de la part des jeunes gauchistes, des radicaux et des groupes écologistes. Le 30 mars 1977, 7000 personnes tinrent une manifestation à Montaltodi contre les projets nucléaires du gouvernement dans cette région. Le minuscule mais dynamique Parti radical a été le fer de lance de cette opposition, jouant le rôle d'un parti écologique. Aux élections pour le parlement européen, les candidats écologistes danois et italiens ont été les seuls à être élus, bien que certains candidats élus dans d'autres pays sous des bannières de partis non-écologistes, étaient eux aussi contre l'énergie nucléaire. À l'heure actuelle, le mouvement anti- 
nucléaire italien est légèrement divisé sur la pertinence de demander un référendum, l'objection majeure étant qu'il vaut mieux ne pas avoir de référendum, que d'en avoir un et de le perdre.

\section{Conclusion}

$\underline{\text { Retour à la table des matières }}$

Le survol de ces quelques pays nous donne certaines indications sur la façon dont s'est déroulée la lutte anti-nucléaire en Europe occidentale durant les dix dernières années. Il est difficile, sans aller dans les détails, de dégager les particularités de chaque mouvement mais il est néanmoins possible d'identifier les points communs, en dépit des inévitables différences. L'objectif majeur du mouvement anti-nucléaire, comme de la plupart des autres nouveaux mouvements sociaux, comme le mouvement des femmes ou le mouvement des étudiants, ne semble pas être la prise de contrôle de l'État, par la violence ou par la voie électorale, dans le but de mieux exercer le pouvoir ou de supprimer celui-ci, mais bien de changer la réalité sociale, en commençant par le quotidien. On semble viser, à travers les actions concrètes et les différentes luttes, à éliminer plusieurs des causes de l'oppression, de la centralisation et du productivisme. Les buts semblent limités et spécifiques plutôt que généraux et universels. Ainsi, les anti-nucléaires centrent leur attention sur l'innovation culturelle, les conflits sociaux et les luttes politiques au sens large du terme, plutôt que sur l'intervention économique de l'État et sur les batailles électorales seulement. Ces luttes ont, bien sûr, une coloration politique certaine, non pas à la manière des jacobins, des léninistes ou des fabiens, mais davantage selon une ligne libertaire et anarchiste.

Puisque les tactiques et les stratégies, en opposition aux objectifs, ont toujours été importantes pour les militants anti-nucléaires, les moyens ne peuvent pour eux qu'illustrer et servir les fins et non pas être justifiés par elles. Les buts sont implicites dans la manière de les atteindre. Puisque les buts et les objectifs ont évolué au fil des années, on peut noter également un léger changement dans les tactiques et les stratégies, une évolution graduelle de celles-ci. On trouve cependant beaucoup de variété à l'intérieur des différents mouvements. Le mouvement écologi- 
que, y compris son aile anti-nucléaire, valorise la diversité et ne cherche pas à reproduire la structure unitaire, hiérarchisée d'un parti politique. En fait, ce qui apparaît comme des dilemmes et des oppositions n'est souvent rien d'autre que la « coexistence pacifique » de plusieurs tactiques, stratégies et modèles d'organisation. L'existence d'une grande diversité de groupes, d'activités et de stratégies est vue comme un actif et non comme un passif. Néanmoins on note effectivement une légère évolution vers une plus grande politisation et un plus grand militantisme du mouvement anti-nucléaire, ces récentes années en Europe de l'Ouest.

Au début, on organisait surtout des pétitions, de la publicité, des défilés pacifiques, du lobbying, de la participation à des commissions d'enquête, des manifestations non violentes, des «teach-in », des débats, ainsi que des contestations judiciaires ; mais petit à petit, les actions devinrent plus radicales. On fit appel à la désobéissance civile, à l'occupation des sites et aux affrontements violents. À mesure que le mouvement a grossi, on a pu noter un déplacement vers une activité électorale plus intense. L'idée sous-jacente à ce dernier type d'action est qu'il vaut mieux agir soi-même que de proposer et de faire campagne pour que d'autres agissent pour nous. On ne s'oppose pas seulement de plus en plus à l'énergie nucléaire mais également à la politique nucléaire de l'État et des technocrates, par la force lorsque c'est nécessaire, par d'autres moyens lorsque C'est possible et désirable. On ne rejette pas seulement un genre de technologie mais bien un modèle de développement. La lutte est orientée vers une bataille pour le contrôle de la production dans un type différent de société. Il s'agit donc d'un projet de libération et d'un projet de modernisation intégrés l'un à l'autre et non pas d'une peur dépassée de la technologie moderne.

La création de partis écologistes et la tenue d'un nombre important de référendums où les gens mettent de côté les loyautés traditionnelles, semblent indiquer que Touraine n'a pas tort lorsqu'il souligne l'importance de l'enjeu nucléaire et lorsqu'il définit les luttes anti-nucléaires comme le signe avant-coureur des luttes à venir entre les technocrates et la population assujettie.

Les technocrates voient le développement de l'énergie nucléaire comme un champ idéal pour la programmation de besoins artificiels. Le mouvement antinucléaire rejette ce type de développement, cette mentalité de la croissance pour 
la croissance sans égards aux conséquences, et il met de l'avant un contre-modèle basé sur l'équilibre, la décentralisation et la convivialité. Quant à la façon d'implanter ce modèle, il n'y a pas de moyen privilégié mais une multitude d'activités innovatrices et radicales. Les anti-nucléaires de l'Europe de l'Ouest dépassent la simple défense contre-culturelle ou réformiste, et proposent un type d'action militante orientée vers la création d'un type de société plus démocratique en opposition à l'ordre politique et social existant basé sur la centralisation. Les forces antinucléaires ont élargi le débat sur les politiques énergétiques, elles ont également créé des partis politiques ou des coalitions élargies qui incluent d'autres mouvements sociaux. Ainsi un effort est fait pour rejoindre les syndicats, pour trouver des intérêts communs avec les autres mouvements sociaux progressistes en vue de dépasser l'action basée sur le court terme et de travailler conjointement à la construction du type de société que l'on veut laisser aux générations futures. La collaboration avec les syndicats a commencé sur la base de la santé et de la sécurité des travailleurs, mais de plus en plus aussi sur le genre et le nombre d'emplois à créer et à maintenir et sur le type de société à bâtir. Des points de convergence similaires ont été trouvés avec les conservationistes, les féministes, les cyclistes, les groupes de défense des consommateurs, etc.

On note également une internationalisation de la lutte anti-nucléaire depuis quelques années. Les militants anti-nucléaires vont au-delà des alliances nationales et des coalitions locales, pour former une sorte d'Internationale assez informelle qui a ses publications, ses rencontres et ses leaders en Amérique du Nord et en Europe occidentale. Les questions de la prolifération, des problèmes frontaliers et de la coopération des «nucléocrates » de différents pays ont aidé à cette internationalisation de la lutte. On constate cette internationalisation dans les dernières élections européennes et dans la création d'agences de nouvelles internationales concernant le nucléaire comme le Worid Information Service on Energy, WISE.

La question nucléaire divise les familles, les communautés, les pays et dans le cas de la Suède surtout, les partis politiques traditionnels. Dans ce dernier pays, le gouvernement est tombé deux fois à cause du nucléaire et, lors du référendum de 1979, cette question a provoqué un réalignement conjoncturel étrange : chacun des trois partis de la coalition au pouvoir appuyait une option différente et les deux partis de l'opposition de gauche appuyaient deux options différentes. Mais la 
politisation de la question nucléaire dans plusieurs pays d'Europe de l'Ouest ne signifie pas l'abandon par le mouvement anti-nucléaire de la lutte sociale au profit des manoeuvres politiques partisanes. La tendance dans certains cas semble être de changer les partis, ceux de la gauche en particulier, et de les débarrasser de leur tendance productiviste et centralisatrice plutôt que de les remplacer par de nouveaux partis. Les élections sont donc vues comme des moyens d'écologiser les partis et la population en général au moyen de la publicité et par des coalitions circonstancielles. Le but principal semble être de faire discuter et débattre du sujet par la population afin d'engager cette dernière à devenir active et participante dans la définition et la satisfaction de ses besoins réels. Les objectifs demeurent simples, précis et ponctuels plutôt que globaux, à l'emporte-pièce et trop ambitieux. Il s'agit d'une lutte contre les pouvoirs et non pas pour s'emparer du pouvoir. Le pouvoir que l'on recherche est surtout un pouvoir local et décentralisé. Les militants anti-nucléaires engagent cette bataille en alliance et en collaboration avec les autres mouvements sociaux progressistes et les autres mouvements politiques démocratiques contre les technocrates du secteur privé et public. Il est peut-être un peu tôt pour dire « adieu au prolétariat » comme l'a dit André Gorz ${ }^{17}$, ou pour annoncer avec Touraine que nous sommes déjà dans l'après-socialisme 18 et qu'une certaine gauche est morte ${ }^{19}$, mais nous allons certainement dans cette direction non seulement en France, mais également ailleurs en Europe de l'Ouest et un peu partout dans le monde. Cet essai n'est peut-être pas une confirmation concluante de ces théories mais il nous permet, je crois, de voir que ce qu'ont dit Touraine et Gorz à propos de la France a également beaucoup de pertinence pour les pays voisins. Des études comme celle de Touraine dans d'autres pays et dans d'autres contextes et davantage d'études comparatives comme celle de Nelkin et Pollack 20 feront avancer d'un grand pas la connaissance et l'étude de cet important phénomène. Elles aideront le mouvement anti-nucléaire à mieux se connaître lui-même et à mieux orienter son action.

17 André Gorz, Adieu au prolétariat, Paris, Galilée, 1980.

18 Alain Touraine, L'Après-socialisme, Paris, Grasset, 1980.

19 Alain Touraine, Mort d'une gauche, Paris, Galilée, 1979.

20 Dorothy Nelkin et Michael Pollack, op. cit. 
Mouvement écologiste, énergie et environnement.

Essais d'écosociologie.

Première partie . Descriptions et analyses

\section{Chapitre 5}

"Évolution, diversité et spécificité des associations écologiques québécoises : de la contre-culture et du conservatisme à l'environnementalisme et à l'écosocialisme."

Texte publié dans la revue Sociologie et Sociétés, vol. 13, no 1, avril 1981, p. 8198.

\section{par Jean-Guy Vaillancourt}

\section{Introduction}

$\underline{\text { Retour à la table des matières }}$

Il existe fort peu de descriptions et d'analyses sociologiques des associations écologiques québécoises. À part quelques mémoires de maîtrise et divers rapports financés par des organismes gouvernementaux, qui traitent d'aspects restreints du sujet ou qui sont des répertoires bien plus que des études sociologiques, et à part quelques articles épars dans des revues et des journaux qui abordent tangentiellement ces sujets, il n'y a presque rien de publié, et très peu de choses d'écrites ${ }^{21}$.

21 Voir, par exemple, le mémoire de Louise Boileau, Étude de deux mouvements écologiques : SVP et STOP, mémoire de M.Sc. en sociologie, Département de sociologie, Université de Montréal, 1975, ainsi que Le Citoyen protège son environnement, publié en septembre 1974 par la Société pour vaincre la pollution (101 pages) et mes trois brefs articles : «Lettre à un militant anti-nucléaire », Possibles, vol. 2, no 4, été 1978, p. 99-110 ; « The Ecology Manifesto and the Growth of the Movement in Quebec », Our Generation, vol. 13, n04, automne 1979, p. 5-7 et « Le débat public sur l'énergie aura-t-il lieu ? », Possibles, vol. 5, no 3, 1981. 
Et pourtant, les écologistes québécois sont très actifs et très visibles, et ils s'expriment beaucoup depuis quelques années ${ }^{22}$. Aussi, plusieurs spécialistes des sciences sociales considèrent-ils que le mouvement écologique québécois, surtout son aile la plus radicale, représente un phénomène de plus en plus important au Québec. Par exemple, le dernier chapitre du livre La Conjoncture au Québec au début des années 80, écrit par quatre militants socialistes qui sont aussi des spécialistes des sciences sociales, se termine par une section sur le Front écologique qui clôt sur les interrogations suivantes :

Mais en fait, les revendications écologiques ne posent-elles pas un problème gigantesque au capitalisme, particulièrement dans la conjoncture de crise structurelle actuelle du système (modernisation, dépenses, recyclage, etc.) ? Jusqu'à quel point la problématique écologique ne constitue-t-elle pas ces années-ci un front privilégié pour affaiblir le capitalisme ? D'autre part, en jonction avec des organisations inscrites dans une lutte sociale plus globale (syndicale et politique), le mouvement écologique ne pourrait-il pas apporter aux militants syndicaux et politiques une vision nouvelle plus large de la société à construire ? Une société dans laquelle la conservation de la vie, la qualité de la vie ne seraient pas des expressions creuses, une société critique face au productivisme, à l'idéologie de la croissance ${ }^{23}$.

22 En plus de ce qui s'écrit dans des journaux et des revues qui s'intéressent à l'occasion aux thèmes environnementaux (Le Devoir, La Presse, Le Soleil, Perspectives, Québec Science, Le Temps Fou, Focus, Possibles, Our Generation), il existe au moins une douzaine de publications spécifiquement écologiques ayant un bon tirage au Québec, dont les plus importantes sont sans doute le journal L'Environnement de la Société pour vaincre la pollution (SVP), De toute urgence du Conseil québécois de l'environnement (C.Q.E.), Forêt conservation publié par les Clubs 4-H et l'Association forestière québécoise, Vers une ville nouvelle du Monde à bicyclette (MAB), Transitions du Regroupement pour la surveillance du nucléaire (RSN), Le Noyau publié par une commune en Gaspésie, Informations, des Ami(e)s de la Terre de Québec, et la toute nouvelle revue Biosphère, publiée par le Biocreux.

23 Marielle Désy, Marc Ferland, Benoît Lévesque et Yves Vaillancourt, La Conjoncture au Québec au début des années 80 : les enjeux pour le mouvement ouvrier et populaire, Librairie socialiste de l'Est du Québec, Rimouski, 1980, p. 185. De même, la dernière phrase de l'introduction de l'excellente anthologie de Boismenu, Mailhot et Rouillard sur l'histoire récente du Québec, constitue une semblable mise en lumière de l'importance des associations écologiques québécoises. En effet, les auteurs, qui sont de jeunes historiens très au fait de l'évolution actuelle du Québec, y font l'affirmation sui- 
Du point de vue descriptif, une des choses les plus intéressantes que je connaisse sur l'aile progressiste du mouvement écologique québécois est la série de treize cahiers de transcriptions d'une série d'émissions radiophoniques présentées à Radio-Canada durant l'été de l'année 1980 par le, réalisateur Denis Boucher, avec l'aide de l'écologiste André Delisle ${ }^{24}$. Ces treize émissions ont exploré le monde des écologistes québécois et tenté de décrire certaines de leurs expériences et de leurs réalisations dans les domaines suivants : les communautés rurales, les énergies douces, l'agriculture biologique, le recyclage, les coopératives alimentaires, les entreprises communautaires, les médias, l'autoconstruction et l'artisanat, l'alimentation naturelle, le mouvement écologique, les lieux d'échanges, les initiatives de sensibilisation, et l'écosociété. Ces 173 pages d'interviews et de commentaires nous livrent une image plutôt fidèle de ce qu'il y a de plus dynamique parmi les associations écologiques québécoises actuelles. Des militants écologistes bien connus comme Michel Bélair (coauteur du Répertoire québécois des outils planétaires ${ }^{25}$ ) François Tanguay (cofondateur de la nouvelle revue Biosphère), Clément Boulanger (du Mouvement d'agriculture biologique), Michel Jurdant (des Ami(e)s de la Terre de Québec, auteur du livre Les Insolences d'un écologiste 26), Thérèse Dumesnil (journaliste écologiste à Perspectives et auteur d'un livre tout récent sur Pierre Dansereau), Christian Ouellette (du Groupe de ressources en autoconstruction et en écologie), Michel Belleau (des Ami(e)s de la Terre de Québec), Roger Julien (de l'Alliance Tournesol) et Pierre Lacombe (de la SVP) principal organisateur du Front commun pour un débat public sur l'énergie entre autres, y sont interviewés sur leurs expériences et leurs opinions, de telle

vante: "Malgré l'étonnante force de récupération du contexte nordaméricain, certaines expériences d'autosuffisance communautaire, l'établissement d'un réseau de regroupements coopératifs d'alimentation et le développement d'un mouvement anti-nucléaire constituent certes le fondement d'une critique de la production et de la morale dominantes » (Gérard Boismenu, Laurent Mailhot et Jacques Rouillard, Le Québec en textes, Montréal, Boréal Express, 1980, p. 24).

24 L'Écologie, espace de vie, Service des transcriptions et dérivés de la radio, Montréal, Maison de Radio-Canada, 1980.

25 Christian Allegre et al., Le Répertoire québécois des outils planétaires, vol. 1, Montréal, Les Éditions alternatives Ltée, 1977.

26 Michel Jurdant, Les Insolences d'un écologiste, édition revue et augmentée, Montréal, Boréal Express, 1981. 
sorte que l'ensemble des témoignages rapportés constitue un document indispensable pour connaître l'évolution récente et la diversité actuelle du mouvement écologique québécois.

L'intérêt grandissant pour les associations écologiques est encore trop récent pour avoir donné lieu à des études approfondies à leur sujet, mais d'ici quelques années, grâce aux recherches en cours et aux thèses et mémoires qui sont en train d'être rédigés, l'on peut prévoir qu'il y en aura, surtout si beaucoup de travaux sont réalisés sur des groupes particuliers et sur des aspects bien délimités de la question. En attendant, je crois qu'il peut être utile, à partir des études que je poursuis sur le mouvement écologique québécois au moyen d'interviews, d'observation participante et d'une analyse de la production intellectuelle et de l'action de ce mouvement, de donner ici une idée d'ensemble de son origine et de son développement, ainsi que de sa configuration actuelle et de sa spécificité par rapport au mouvement écologique dans d'autres pays comme la France et les États-Unis.

\section{Origine et développement des associations écologiques québécoises}

$\underline{\text { Retour à la table des matières }}$

La prise de conscience de l'importance de la conservation et de la nécessité de lutter contre les nuisances et contre la pollution de l'air et de l'eau n'a pas débuté brusquement au Québec au cours des années soixante, comme certains sont parfois portés à le croire. Nous avons eu au Québec l'équivalent de l'action des pêcheurs à la ligne et des conservationnistes qui sont respectivement à l'origine du mouvement écologique en France et aux États-Unis ${ }^{27}$. Songeons, par exemple,

27 Claude Fischer, «Le mouvement écologique et ses contradictions », Preuves, no 19, automne 1974, p. 6-21. C.M. Vadrot, «Les mouvements écologiques », dans J.-P. Charbonneau et al., Encyclopédie de l'écologie, Paris, Larousse, 1977, p. 454. D.E. Morrisson, K.E. Hornback et W.K. Warner, « The Environmental Movement : Some Preliminary Observations and Predictions ", dans W. Burch, N. Cheek and L. Taylor (édit.), Social Behavior, Natural Resources and the Environment, New York, Harper and Row, 1972, p. 259-279. Caroll Pursell, From Conversation to Ecology, The Develop- 
au Cercle des jeunes naturalistes, aux sociétés de protection de la faune, aux groupes de randonnée dans la nature, aux Clubs 4-H, à l'Association forestière québécoise, aux gens qui gravitent autour du Jardin et de l'Institut botanique de Montréal, à certaines associations savantes comme la Société de géographie de Québec, fondée en 1878, la Société linnéenne de Québec, la Société canadienne d'histoire naturelle et d'autres sociétés membres de l'ACFAS, au rayonnement considérable du Frère Marie-Victorin, puis de Pierre Dansereau, le premier véritable écologiste québécois, dont la renommée est internationale et dont l'influence a commencé à se faire sentir au Québec durant les années cinquante 28 . Ici donc, comme ailleurs, on trouve les précurseurs du mouvement écologique actuel chez les fervents de la nature et chez les spécialistes de la botanique et de la biologie. De plus, à la fin des années cinquante, il existait déjà plusieurs associations de riverains de lacs désireux de conserver leur milieu dans son état naturel, et des groupes de scientifiques et d'étudiants qui s'insurgeaient contre les dangers des explosions nucléaires pour des raisons de santé et de protection de l'environnement. Les comités de citoyens mis sur pied à partir de 1963 ont été eux aussi des précurseurs des groupes écologiques, étant donné leur préoccupation avec les problèmes de logement et de santé. De même, certaines associations de protection des consommateurs font figure de précurseurs du mouvement écologique.

Le premier règlement adopté au Canada contre la pollution de l'air fut voté en 1872 à Montréal. En 1931, la ville de Montréal créa une division d'inspection pour l'élimination de la fumée, à l'intérieur du Service des travaux publics et, en 1950, le Conseil municipal vota un règlement plus général contre la pollution de l'atmosphère. En 1966, la ville adopta un nouveau règlement plus sévère qui ame-

ment of Environmental Concern, New York, Thomas Crowell, 1973. Allan Schnaiberg, The Environment, From Surplus to Scarcity, New York, Oxford University Press, 1980.

28 Le livre de Thérèse Dumesnil, Pierre Dansereau, l'écologiste aux pieds nus, Montréal, Nouvelle Optique, 1981, constitue une excellente introduction à l'oeuvre de Dansereau. De son Biogeography (New York, Ronald Press, 1957) à la série de films éducatifs qu'il est en train de faire sur l'écologie pour le ministère de l'Environnement du Québec, ce dernier n'a pas cessé de jouer un rôle clef dans le développement de l'écologie au Québec. 
na la fermeture de 1800 incinérateurs privés ${ }^{29}$. C'est donc dire que les pressions des citoyens contre la pollution de l'air, qui se manifestent aujourd'hui dans la lutte pour fermer l'incinérateur Des Carrières à Montréal ne datent pas d'hier. Sur le plan provincial, le gouvernement du Québec mit sur pied en 1958 un Comité de pollution des eaux, qui fut remplacé en 1961 par la Régie d'épuration des eaux. À partir de 1966, le gouvernement organisa une Division du génie sanitaire sous la direction de Tony Lesauteur. Là encore la pression des citoyens y est pour quelque chose, bien qu'alors il n'existait pas encore de véritable groupe écologique se définissant comme tel.

Comme aux États-Unis et en France, c'est surtout à partir de 1968 qu'on passe d'un conservationnisme très modéré et peu organisé à un environnementalisme réformateur porté par des groupes plus revendicateurs. Le mouvement écologique démarre vraiment en 1970 avec la publication du premier et unique numéro de la revue Écologie-Québec par des gens faisant partie du Centre d'information sur la pollution de l'environnement, avec la création de la SVP et de son équivalent anglophone STOP (Society to Overcome Pollution), avec la fondation de Survivre (une association de scientifiques pour la survie de l'homme et de la vie), des Citoyens pour la responsabilité sociale dans la science (pour lutter contre la pollution de la Union Carbide à Beauharnois), et du Conseil québécois pour l'environnement ${ }^{30}$. En 1971, c'est le groupe Sauvons Montréal, puis l'Association des espaces verts. qui sont fondés. Dans presque tous ces groupes, dans lesquels plusieurs universitaires sont impliqués, l'idéologie n'est plus une espèce de conservationnisme de droite, mais plutôt un environnementalisme réformiste luttant contre

29 L'Assainissement de l'air dans l'T̂le de Montréal, 1872-1980, Montréal, Communauté urbaine de Montréal, Service de l'assainissement de l'air et de l'inspection des aliments, 1980, p. 28-30.

30 À la suite d'un symposium sur la conservation tenu à Montréal en novembre 1969, il avait été décidé de créer un Conseil québécois pour la conservation des ressources naturelles. Un an plus tard, le Conseil québécois de l'environnement était fondé à un congrès tenu au Jardin botanique de Montréal. Le C.Q.E. publie depuis dix ans une revue écologique de qualité De toute urgence, et organise des symposiums sur des thèmes environnementaux. (Michel Maldague, «Le Conseil québécois de l'environnement à l'aube d'une nouvelle décennie », De toute urgence, vol. XI, no 3, 1981, p. 335341.) 
la pollution et le gaspillage des ressources. Un certain militantisme commence même à poindre à l'intérieur de certains de ces groupes qui rejoignent un public de plus en plus large, surtout parmi les jeunes. Il y a aussi toute une série de petits groupes environnementalistes locaux qui naissent, et qui vivent, parfois seulement le temps d'une lutte ou d'une subvention, mais qui ont quand même, grâce aux mass média, un impact considérable dans la population et auprès des gouvernements. Durant l'été de 1970, la SVP et STOP sont responsables d'un pavillon écologique à Terre des Hommes. Avec l'arrivée au pouvoir du gouvernement libéral de Robert Bourassa (qui en décembre 1970 nomme Victor C. Goldbloom responsable de la qualité de l'environnement), et surtout après les événements d'octobre 1970, un mouvement communautaire rural à forte tendance écologique commence à se développer parmi les contre-culturels. Mainmise (surtout après quelques années de publication), le Répertoire québécois des outils planétaires et le vaste réseau des coopératives d'alimentation naturelle, expriment assez bien cette tendance contre-culturelle orientée vers le communautarisme rural qui se développe peu à peu à côté d'une tendance contre-culturelle plus individualiste.

À partir de 1971, l'attention de la plupart des groupes environnementalistes urbains se centre sur les diverses formes de pollution de l'air et de l'eau, sur la protection du Saint-Laurent (projet « Un fleuve, un pare »), sur l'aménagement de l'espace urbain, sur les transports publics, et sur la critique de la société de consommation. Par exemple, la SVP prépare en 1971 des mémoires sur la fluoration de l'eau, sur le traitement des eaux usées, et sur l'autoroute Est-Ouest. Le livre de Chaput et Lesauteur, Dossier pollution, et le numéro spécial de la revue Crîtère sur l'environnement expriment bien les préoccupations environnementalistes de cette période ${ }^{31}$. En mars 1971, le gouvernement du Québec regroupe la Régie des eaux du Québec et la Direction générale des équipements et de l'hygiène du milieu, pour former les Services de protection de l'environnement, avec un budget de 4 millions pour 1971, de 12 millions pour 1972, et de 17 millions pour 1973 32. C'est à la fin de 1972 que la loi sur la qualité de l'environnement -est

31 Marcel Chaput et Tony Lesauteur, Dossier pollution, Montréal, Éditions du Jour, 1971 ; Critère, no 5, janvier 1972.

32 De 17 millions de dollars qu'il était encore en 1976, ce budget augmente à 71 millions en 1980 ; le nombre de fonctionnaires est passé de 540 à 1200, 
sanctionnée à Québec par le gouvernement Bourassa à la suite de pressions de la part des groupes écologiques. Ce même gouvernement qui tente de projeter une image de défenseur de l'environnement, est fortement critiqué en avril 1973 par le Comité de défense de la Baie James, pour avoir lancé le «projet du siècle » à la Baie de James dans le but de fournir l'énergie nécessaire à une usine d'enrichissement d'uranium requise pour la production d'énergie nucléaire ${ }^{33}$.

Vers la fin de 1973, avec la crise du pétrole, c'est la question de l'énergie qui passe à l'avant-scène, puis, presque simultanément, la question des ressources alimentaires. L'analyse des environnementalistes commence alors à se radicaliser et on voit naître à ce moment-là au Québec une véritable écologie politique. Avec la crise économique qui s'amorce, c'est la société capitaliste industrielle et sa logique productiviste centrée sur le profit plutôt que sur les besoins réels des gens qui est de plus en plus attaquée. Les projets de société de conservation et même d'écosociété, l'autonomie des communautés naturelles, l'anti-productivisme, la qualité de la vie et les problèmes de simple survie sont des questions qui prennent une importance centrale. La SVP, avec son journal l'Environnement et ses divers comités, s'attaque à ces nouveaux problèmes, tout en continuant à lutter contre la pollution de l'air et de l'eau, et demeure un des groupes les plus dynamiques du mouvement écologique québécois. En 1974, deux groupes voient le jour, le Mouvement pour l'agriculture biologique, et les Ami(e)s de la Terre de Québec, qui expriment bien les nouvelles préoccupations. Cette même année, il y a aussi un premier effort de rassemblement des divers groupes écologiques québécois, avec l'organisation d'une Semaine de l'environnement, qui est suivie de la fondation du Regroupement québécois pour l'environnement (RQPE). Ce regroupement réunit un ensemble hétéroclite de fervents de la nature d'une part, d'environnementalistes et de militants écologiques d'autre part, ce qui rend son existence assez précaire dès le début.

En 1975, la question nucléaire commence aussi à devenir une préoccupation majeure. Le Regroupement pour la surveillance du nucléaire est formé à Montréal

tandis que le nombre de poursuites annuelles contre les pollueurs est passé de 100 environ à près de 800 durant ces mêmes quatre années.

33 Ce groupe avait publié peu de temps après sa fondation le livre La Baie James, c'est grave, grave, grave..., Montréal, Éditions québécoises, 1972. 
en juillet 1975, pour répondre à ce problème. Le RSN est un groupe pancanadien qui tire ses origines

des inquiétudes concernant la prolifération des armes atomiques suite à l'explosion par l'Inde d'une bombe atomique créée grâce à l'achat d'une centrale CANDU par ce pays. Le RSN regroupe au début environ 45 associations de toutes les régions du Canada. Maintenant, ce nombre s'élève à plus de 200 groupes. Au plan local, le Comité de protection de l'environnement de Sainte-Croix de Lotbinière est créé en 1975 pour empêcher la construction d'une centrale nucléaire sur le territoire de cette municipalité. Le Comité énergie de la SVP, grâce surtout à sa brochure très bien documentée sur les dangers du nucléaire Civil ${ }^{34}$, prend l'initiative dans ce nouveau combat en s'opposant au nucléaire pour des raisons de sécurité, et à cause des coûts économiques et sociaux élevés de cette option. En mai 1976, il y a un nouvel effort pour relancer le RQPE, avec les États généraux de l'environnement. De nombreux groupes sont présents à la rencontre, mais la tentative de regroupement échoue finalement, non par manque d'intérêt mais parce que les groupes convoqués ont des préoccupations trop différentes les unes de autres. Chacun préfère oeuvrer seul ou avec des groupes semblables au plan idéologique. Les groupes ne semblent pas intéressés non plus à perdre une partie de leur autonomie au profit d'une fédération ou d'un regroupement.

De 1970 à 1976, il y a donc un nombre imposant de groupes environnementalistes oeuvrant au Québec qui, malgré la faiblesse de leurs moyens et la précarité de leur existence, sont très actifs et très dynamiques, grâce à l'engagement de leurs membres et surtout de leurs dirigeants, à cause aussi de la prise de conscience croissante d'une bonne partie de la population québécoise au sujet des problèmes environnementaux. Ces groupes sont surtout formés de jeunes gens ayant une orientation politique de gauche libertaire. Ils arrivent parfois à exister et à subsister grâce au bénévolat et aux contributions des membres, et avec l'aide de subventions gouvernementales pour des projets de conservation d'énergie ou d'éducation écologique ${ }^{35}$.

34 Tout ce que vous aimeriez ne pas savoir sur l'énergie nucléaire et que l'on ne voudrait pas non plus vous dire, Montréal, SVP, 1974, 70 p.

35 Le dossier Le Citoyen protège son environnement, par exemple, qui fut produit par la SVP, est le fruit d'un tel projet : il constitue un répertoire de plus 
L'année 1977 a été l'année du grand redémarrage du mouvement écologique québécois. Ce nouvel essor est dû en bonne partie à l'influence de la conjoncture internationale dans le domaine de l'énergie. Hydro-Québec avait alors des plans grandioses qui prévoyaient la construction de 35 centrales nucléaires au Québec. Lors de la Commission parlementaire des ressources naturelles sur l'énergie en février 1977, plusieurs groupes présentent des mémoires attaquant l'option pronucléaire du gouvernement. Le Regroupement pour la surveillance du nucléaire, dans un document préparé par Dorothy Henaut, Dorothy Rosenberg et Gordon Edwards, demande que le gouvernement ne construise pas Gentilly III, à cause des problèmes techniques, économiques et moraux impliqués dans cette option, et dont certains, disent-ils, « apparaissent tout à fait insolubles ». Ce groupe affirme que le Québec n'a pas besoin d'énergie nucléaire, puisque la demande réelle en énergie diminue et que le Québec possède d'abondantes réserves hydroélectriques qui, avec une stratégie rationnelle de conservation et d'exploitation de sources d'énergie renouvelables, pourront satisfaire les besoins québécois en électricité pour bien au-delà de 50 ans. Dans son mémoire à la même Commission parlementaire, la SVP insiste sur les dangers et les coûts du nucléaire, et sur les avantages de la conservation et du recyclage, de l'utilisation des ressources renouvelables et des technologies douces, de la recherche, de la décentralisation et de l'autosuffisance énergétique. La SVP demande aussi un moratoire sur l'implantation de centrales nucléaires au Québec, et lance l'idée d'un vaste débat public sur l'énergie. Parmi les nombreux autres groupes et individus qui présentent des mémoires, celui qui semble avoir eu le plus d'influence sur le gouvernement est probablement le Conseil québécois de l'environnement, puisque c'est dans une perspective très proche de celle de sa demande de moratoire sur l'électronucléaire que Québec a par la suite mis de l'avant son propre projet de moratoire.

d'une centaine de groupes et d'actions environnementalistes ayant vu le jour au Québec avant l'été de 1974. 


\section{Unité et diversité du mouvement écologique québécois}

$\underline{\text { Retour à la table des matières }}$

Après cette Commission parlementaire de février 1977, un besoin nouveau de regroupement anti-nucléaire se fait sentir parmi les groupes écologiques plus radicaux. Suite à des rencontres qui ont lieu durant l'été, un Front commun antinucléaire regroupant une quinzaine d'organismes québécois est lancé simultanément, le 20 septembre 1977, à Montréal, à Alma et à Trois-Rivières. On y retrouve la SVP, le Projet banque d'information, Contact-Conservation, le Groupe écologique Maisonneuve, le Monde à bicyclette, STOP, le Mouvement pour l'agriculture biologique, Sauvons Montréal, et plusieurs groupes locaux comme les Protons de Trois-Rivières, les comités de protection de l'environnement de Grondines et de Sainte-Croix de Lotbinière, la Librairie coopérative d'Alma, etc. Ces groupes organisent une manifestation anti-nucléaire, la première au Québec, à Gentilly le 22 octobre 1977, et environ 800 personnes y participent. Après le succès de cet événement, une cinquantaine de personnes du FCAN se réunissent, le 19 novembre, pour organiser la poursuite de la lutte anti-nucléaire. Elles forment le Comité écologique anti-nucléaire, et mettent en marche un processus pour créer une coalition anti-nucléaire québécoise permanente et pour tenter de mettre sur pied un nouveau regroupement écologique québécois plus dynamique, plus militant et plus souple que celui qui existait toujours, mais qui ne réussissait pas à vraiment démarrer. Ce Comité écologique anti-nucléaire publie au début de 1978 une lettre manifeste aux 6 millions de Québécois. Celle-ci reprend les thèmes soulevés dans la déclaration de principe du 20 septembre et dans les documents de la SVP et du RSN à la Commission parlementaire de février, mais avec une insistance particulière sur le gaspillage des ressources et sur la nécessité de l'information anti-nucléaire au Québec. Ensuite, les Il et 12 février 1978, le Comité organise une session de formation à Montréal. Les cent personnes présentes décident sur place de créer l'Alliance Tournesol, un mouvement écologique anti-nucléaire décentralisé, basé sur des cellules locales autonomes, reliées entre elles autour de centres régionaux. L'Alliance Tournesol est depuis ce temps, grâce surtout au tra- 
vail de quelques permanents bénévoles appuyés par de nombreux autres militants, la plaque tournante de l'activité anti-nucléaire chez les francophones du Québec. Il serait trop long d'analyser ici toute la production et toutes les actions de cette association : lettres aux élus et aux journaux, conférences de presse, manifestations, bulletin de liaison, vidéo, diaporama, programme à Radio Centre-Ville, conférences, sessions d'information, banque d'information avec livres, films, revues et documents, etc. Ce travail s'est fait de façon continue, malgré de petits problèmes d'organisation dûs en bonne partie au manque de ressources financières et à de légères différences d'idéologie et de personnalité qu'on retrouve dans beaucoup d'associations volontaires de ce genre.

En juin 1978, au Lac Saint-Joseph près de Québec, lors d'une fin de semaine mémorable, une grande rencontre de groupes et d'individus a lieu pour réaliser le second volet de la décision du 19 novembre 1977, c'est-à-dire la création d'un nouveau regroupement des écologistes québécois. Environ 180 groupes écologiques et plusieurs centaines d'individus y ont été invités pour former un vaste regroupement décentralisé et pour élaborer un manifeste écologique ${ }^{36}$. Non sans difficulté, un regroupement est effectivement créé, sur une base régionale, mais le projet de manifeste amorcé à partir d'une vaste consultation est mis de côté, faute de temps, et la rédaction finale est reportée à plus tard. Grâce en partie au travail préliminaire entrepris par Michel Jurdant et les Ami(e)s de la Terre de Québec, la section montréalaise du Regroupement produit finalement un manifeste quelque temps après. Ce manifeste est publié dans le bulletin du Mouvement pour l'agri-

36 C'est dans les termes suivants que les organisateurs présentaient le but de la rencontre : « Ce colloque sera les assises d'un grand Mouvement écologique kébécois (à baptiser), décentralisé niais unifié dont le but sera de créer une force socio-politique qui révolutionnera globalement et radicalement la société productiviste, hiérarchique et destructrice dans laquelle nous vivons, en contestant les choix et les valeurs sous-jacentes de son orientation actuelle et en proposant des alternatives d'une société écologique en harmonie avec l'écosphère de la planète Terre. Les chapitres locaux de ce mouvement pourront canaliser l'activité des aspirants soit vers les groupes écologiques déjà existants, soit vers le développement d'un chapitre local ou régional qui favorisera la polyvalence des préoccupations écologiques selon les priorités locales et/ou nationales. » 
culture biologique, et il est généralement bien accueilli dans le milieu des militants écologistes québécois en automne de l'année 1978 et en 197937.

À la réunion du 20 janvier 1979 de la section montréalaise du Regroupement, les représentants des quatorze groupes présents mettent sur pied un comité de radio pour s'occuper d'un programme d'une heure par jour sur l'écologie, à Radio Centre-Ville. Les principaux groupes écologiques montréalais prennent chacun une heure par semaine ou par deux semaines pour mettre la population au courant de divers aspects de l'écologie politique. Il y a aussi un Comité du journal, qui publie le journal Ecoville, un comité sur les alternatives pour promouvoir le recyclage et la conservation, un comité pour la fondation d'un café écologique, et un comité du 1er mai pour coordonner la participation des écologistes à la fête des travailleurs. Le Comité du manifeste, son mandat terminé, prépare un mémoire sur la santé et la sécurité des travailleurs pour la Commission parlementaire sur la loi 17, dans le but de rapprocher la lutte écologique de la lutte des travailleurs. Le regroupement fonde aussi un café écologique, La Vie douce, sur la rue SaintDenis près de la rue Mont-Royal. L'orientation à donner à ce café est l'occasion d'une scission importante à l'intérieur du Regroupement de Montréal en 1980 entre une tendance plus conservatrice et plus contre-culturelle qui s'intéresse surtout à développer La Vie douce comme restaurant écologique, et une autre tendance plus politique et plus radicale qui aurait voulu en faire un centre actif de la lutte écologique. Les tenants de cette dernière tendance démissionnent du Regroupement de Montréal pour enfin se retrouver à la SVP et au Front commun pour un débat public sur l'énergie. Les groupes plus stables et les mieux établis, comme la SVP, le Regroupement pour la surveillance du nucléaire, Sauvons Montréal, STOP, le Monde à bicyclette, le Mouvement pour l'agriculture biologique, et les divers groupes de récupérateurs de papier et de verre avaient déjà commencé d'ailleurs, depuis le début de 1980, à l'instigation de la SVP, à prendre leurs distances vis-à-vis du Regroupement et à se réunir sur une base de fronts communs sur des luttes précises, dans le genre de la lutte amorcée durant l'été de 1979 sur la question du débat public sur l'énergie. Ce Front commun pour un débat public sur

37 Voir les quatre commentaires de ce manifeste publiés dans Our Generation, vol. 13, n04, automne 1979, p. 13-22, ainsi que la présentation que j'en ai faite (p. 5-7). 
l'énergie regroupe maintenant près de 50 associations qui réclament du gouvernement la tenue d'un grand débat public sur l'ensemble de la question énergétique. C'est la SVP, la plus importante des organisations écologiques québécoises, qui est le fer de lance de ce Front commun qui constitue la principale activité des écologistes radicaux en ce début de 1981. L'Alliance Tournesol y participe aussi, tout en collaborant surtout de façon étroite avec le Regroupement pour la surveillance du nucléaire, par exemple dans la préparation d'une prise de position conjointe sur le livre «Une stratégie pour la décennie 80 » d'Hydro-Québec, prise de position qui a été publiée dans Le Devoir du 11 février 1981. Le Front commun pour un débat public sur l'énergie, qui a organisé un excellent colloque et une grande semaine sur l'énergie à l'Université du Québec à Montréal du 16 au 22 février 1981, a refusé d'aller présenter un mémoire à la Commission parlementaire, en invoquant la futilité d'une telle participation. En effet, cela n'aurait servi qu'à légitimer les politiques anti-écologiques d'Hydro-Québec en matière d'énergie. Les groupes faisant partie du Regroupement des récupérateurs à la source ont accepté de leur côté de participer aux journées de concertation sur la récupération et le recyclage organisées à la mi-février 1981 par le ministère de l'Environnement. Il faut dire que ces groupes de récupérateurs sont un peu dépendants pour leur financement et leurs opérations de la bonne volonté des divers paliers de gouvernement, ce qui a pour effet de les pousser dans une orientation conservationniste - environnementaliste et contre-culturelle communautaire plutôt que vers l'écologie politique et l'éco-socialisme. Le grand problème des associations écologiques québécoises demeure toujours celui du financement de leurs activités, et de la dépendance qui risque de découler vis-à-vis des instances gouvernementales à cause de ce problème, surtout en ce qui concerne le loyer des locaux, le salaire des permanents et les autres dépenses inhérentes à toute action auprès du public (publications, déplacements, recherches, etc.). Malgré ces difficultés, plusieurs de ces groupes ont non seulement un local et des militants bénévoles presque permanents, mais certains ont aussi un bulletin, un journal ou une revue qu'ils diffusent avec des tirages assez impressionnants.

Depuis un an environ, deux problèmes écologiques mobilisent beaucoup d'attention et suscitent la création de quelques nouveaux groupes et comités : ce sont 
le problème des déchets toxiques et celui des pluies acides ${ }^{38}$. Ces deux problèmes contribuent aussi à la radicalisation du mouvement écologique, car ils permettent d'identifier la grande entreprise privée comme étant principalement responsable de la pollution et de la détérioration écologique. Ils font comprendre les mécanismes par lesquels la grande entreprise refile les coûts sociaux de la production à la collectivité tout en gardant les profits pour elle. La radicalisation du mouvement écologique québécois s'est exprimée aussi tout récemment par la création par un groupe de femmes d'un courant écoféministe parmi les écologistes du Québec. Ce courant est en train de tenter d'opérer une convergence entre le mouvement féministe et le mouvement écologique. Une alliance du même type s'amorce aussi actuellement entre les écologistes et le mouvement ouvrier, à travers le Comité Environnement et pollution mis sur pied à la suite du Sommet populaire de 1980 organisé par le Conseil central de Montréal de la CSN ${ }^{39}$, et à travers l'intérêt apporté à l'écologie par deux groupes socialistes démocratiques en voie de formation au Québec, le Comité des 100 et le Regroupement des militants socialistes. De même, le récent colloque sur l'autogestion organisé à l'Université de Montréal par la revue Possibles et le colloque organisé à l'UQÀM par ceux qui ont publié le livre L'Impasse ${ }^{40}$, ont accordé une place importante au point de vue des groupes écologiques québécois. Il y a quelques années, dans de tels groupes et de tels rassemblements, il n'était question que du mouvement des travailleurs et du mouvement nationaliste, et parfois du mouvement des femmes, alors qu'aujourd'hui, il y est beaucoup question aussi du mouvement écologique.

En somme, on peut dire qu'à côté des autres mouvements sociaux québécois, un véritable mouvement écologique est en train de se développer au Québec. Ce mouvement écologique comprend des associations conservationnistes plutôt mo-

38 Jean-Pierre Bonhomme, « Les citoyens s'intéressent de plus en plus à l'environnement », La Presse, 3 janvier 1981, p. A5.

39 La CSN s'intéresse depuis quelque temps à la lutte contre la pollution. Voir par exemple la brochure préparée par le syndicat des employés de Standard Chemical, en collaboration avec le CLSC Beauharnois-Valleyfîeld et le Service du génie industriel de la CSN, La Pollution par le mercure à Beauharnois. La Stanchem, principal pollueur, CSN, mai 1977, 30 pages.

40 Nicole Laurin-Frenette et Jean-François Léonard, L'Impasse. Enjeux et perspectives de l'après-référendum, Montréal, Éditions Nouvelle Optique, 1980. 
dérées (la plupart des 550 associations qui font partie de la Fédération des associations pour la protection de l'environnement des lacs (FAPEL), des associations environnementalistes anti-pollution qui essaient de protéger la nature par des suggestions de réformes au plan individuel et collectif, et des associations d'écologistes politiques, comme celles dont nous avons surtout parlé ci-dessus). Depuis quelques années, j'ai réussi à recenser au-delà de cent associations québécoises importantes représentant ces trois différentes tendances idéologiques à l'intérieur du mouvement écologique. Si à ces trois tendances écologiques on ajoute une quatrième tendance (qui n'est pas vraiment écologique), le pseudoconservationnisme et le pseudo-environnementalisme réactionnaires, et si on met ces quatre tendances, qui se situent sur le plan socio-politique, en parallèle avec quatre tendances semblables qu'on trouve au plan contre-culturel, on obtient la classification représentée au tableau 1.

Comme de raison, ce ne sont pas là huit types purs auxquels on peut identifier définitivement tous les membres d'une association, mais plutôt huit idéal-types obtenus par le croisement d'un axe contre-culturel - socio-politique avec un axe droite - gauche. Les types II-III-IV, et 2-3-4 peuvent être compris comme faisant partie du mouvement écologique québécois, bien que, à proprement parler, seuls IV et 4 devraient probablement être considérés comme étant des positions écosocialistes 41 .

41 Je n'insiste pas beaucoup sur les quatre catégories au plan contre-culturel. Comme pour les tendances au plan socio-politique, il y en a trois qui ont émergé successivement et qui sont " écologiques » : a) l'idéologie contreculturelle de droite (II), centrée sur la bouffe, la musique, le hippisme californien, idéologie idéaliste et néo-libérale individualiste qui se développe au Québec à partir de 1967-1968, et qu'exprime très bien Mainmise au début ; b) l'idéologie contre-culturelle réformiste et utopique (III), qui commence vers 1971, mais qui devient importante surtout en 1975 et après, avec l'essor du communautarisme rural visant l'autosuffisance. Mainmise vers la fin, le réseau d'alimentation naturelle, la revue Le Noyau représentent bien cette tendance ; c) l'idéologie contre-culturelle radicale ou le courant social alternatif qui s'exprime dans des revues comme Le Temps Fou (1978) et Biosphère (1980) et dans des groupes comme les deux MAB. Cette idéologie n'est pas très éloignée de l'écologie politique, avec cette différence que c'est une idéologie qui rejette la politique traditionnelle et les luttes pour le pouvoir. Ses tenants sont des socialistes libertaires plus près des anarchistes que des socialistes ; $d$ ) enfin, comme sur le plan socio-politique, il y a une posi- 


\section{Tableau 1. Les idéologies écologiques}

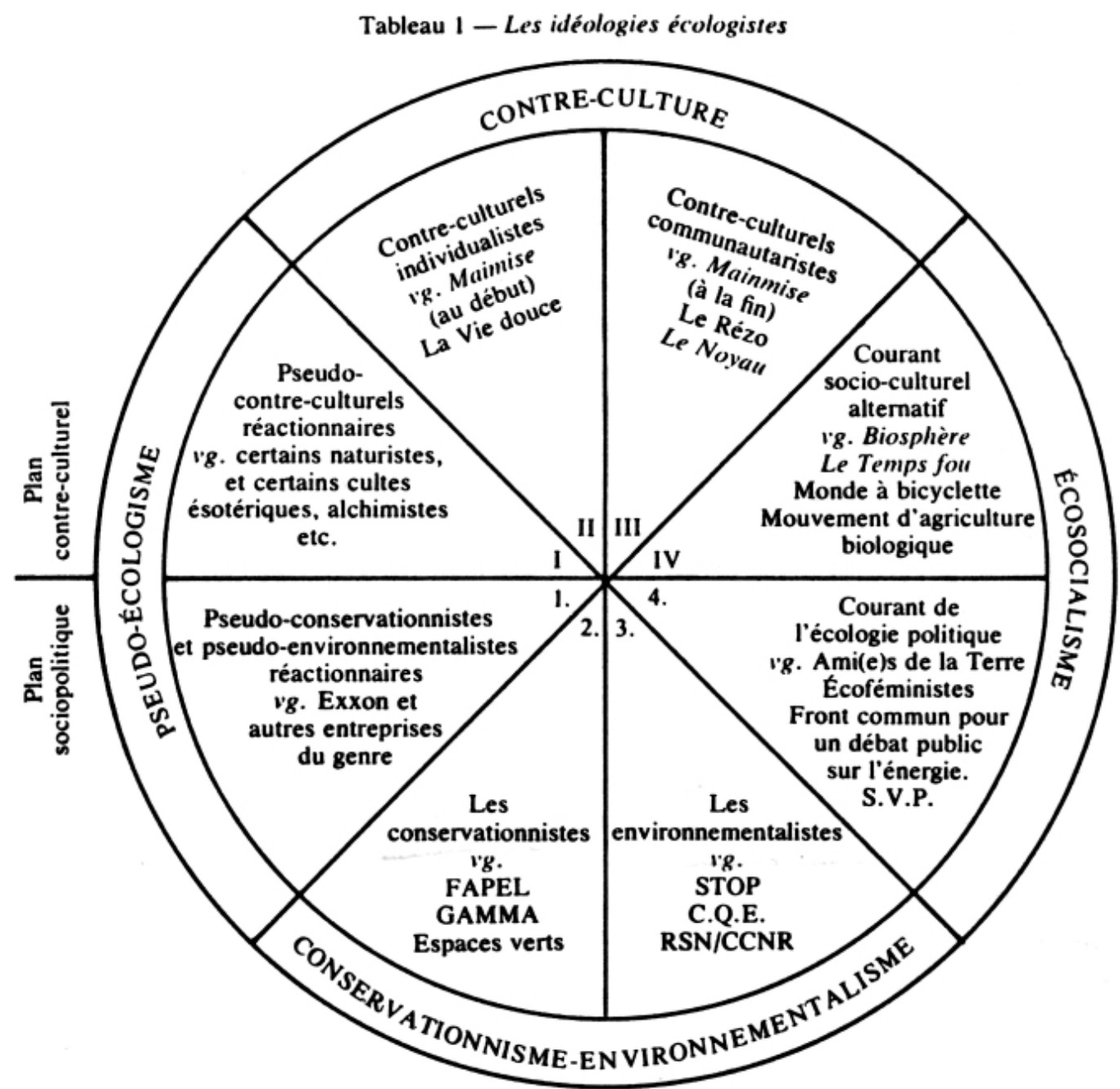

$\underline{\text { Retour à la table des matières }}$

tion réactionnaire sur le plan contre-culturel. C'est l'idéologie contreculturelle réactionnaire qu'on rencontre chez les contre-culturels d'extrêmedroite, chez certains naturistes, chez ceux qui ont sombré dans divers genres de pensée magique, de sadomasochisme, d'érotismes, de culte des drogues, d'occultisme, de mysticisme mystifiant. Comme le pseudoconservationnisme réactionnaire, cette position n'est pas vraiment écologique, mais représente plutôt une forme de pseudo-écologisme, et même, à la limite, d'écofascisme. 
Ce que j'ai dit jusqu'ici du mouvement écologique québécois pourra sembler un peu trop descriptif et pas suffisamment analytique, même si je me hasarde à théoriser un peu avec ma classification, surtout quand je l'utilise pour tenter d'indiquer dans quelle direction le mouvement écologique et les associations qui en font partie ont évolué ces dernières années. Il est peut-être plus intéressant en sociologie de tester des hypothèses, et de pousser dans le sens de l'explication et de l'interprétation, mais dans un domaine aussi neuf et aussi peu étudié que celui-ci, il me semble qu'il faut d'abord tenter d'établir les faits avant d'échafauder des schémas explicatifs et des prédictions. J'ai préféré retracer dans ses grandes lignes le cheminement récent du mouvement écologique québécois et des principaux groupes qui en font partie, et à partir de là établir un modèle classificatoire pouvant être utile pour comprendre non seulement les grandes lignes de son développement, mais aussi sa configuration actuelle et sa diversité, puisque malgré l'émergence et l'accroissement de tendances nouvelles, les tendances plus anciennes et plus conservatrices continuent à exister et même à croître.

\section{Spécificité et originalité des associations écologiques québécoises}

\section{$\underline{\text { Retour à la table des matières }}$}

À la lumière de tout ce que nous avons vu jusqu'ici sur les groupes écologiques québécois, je ne crois pas qu'il soit légitime de dire comme le font Julien, Lamonde et Latouche dans leur livre Québec 2001 : une société refroidie que leur action a été «très ponctuelle, sans grand impact et surtout largement symbolique 42 ». On peut probablement dire que leur action a été « très récente », mais on ne peut certainement pas affirmer comme ils le font qu'elle a été «surtout très éphémère 43 », même en ne tenant compte que de la période d'avant 1977. Dans une section de leur chapitre sur l'organisation sociétale du Québec, ces auteurs

\footnotetext{
42 Pierre-André Julien, Pierre Lamonde et Daniel Latouche, Québec 2001 une société refroidie, Québec, Boréal Express, 1976, p. 144-150.

43 Loc. cit.
} 
tentent de décrire le mouvement écologique québécois entre 1970 et 1976 et de prédire la dynamique de son développement futur. Mais comme les données sur lesquelles ils basent leur tentative d'explication sont insuffisantes et dans certains cas inexactes, il n'est pas surprenant que même leur description soit erronée et que leurs prédictions soient en train de s'avérer fausses. En effet, comment peut-on affirmer sérieusement que le discours des écologistes québécois est un « discours apolitique... » ou affirmer que c'est « la règle de la pensée magique et du discours incantatoire 44 ? " C'est à ce genre de conclusion qu'on aboutit quand on ne se base que sur un maigre dossier de presse et sur quelques ouvrages américains pour asseoir les faits.

Dans un texte plus long écrit à peu près à la même époque (été 1976) et qui constitue une des seules tentatives d'analyse explicative du mouvement écologique québécois, ces trois mêmes auteurs essaient d'expliquer le soi-disant retard du mouvement écologique québécois et le « caractère éphémère et très récent d'une prise de conscience écologique chez les Québécois francophones 45 », sans même avoir bien réussi à démontrer qu'il y avait eu effectivement « retard » et « sousdéveloppement » de ce mouvement. Ils invoquent toute une série de raisons pour ce « retard », par exemple, la nature utilitaire et les perspectives globalisantes de l'action et de l'idéologie des associations écologiques, la grande préoccupation des Québécois avec la question nationale et avec la croissance économique, l'isolement culturel et le bas statut socio-économique et éducationnel des Québécois, le carcan législatif et le sentiment anti-fédéraliste qu'on trouve au Québec (le fédéral ayant, selon eux, pris l'initiative dans la lutte contre la pollution, cela pousserait les Québécois à négliger cette lutte).

Si cette analyse des raisons pour lesquelles l'action du mouvement écologique québécois serait récente, éphémère et de peu d'envergure, semble bien peu convaincante, c'est sans doute parce que les faits qu'elle tente d'expliquer ne sont

44 Ibid., p. 148.

45 Daniel Latouche, Pierre-André Julien, Pierre Lamonde, avec la participation de Diane Poliquin-Bourassa, Perspective socio-économique du Québec, 1re étape. Sous-système des valeurs (6). Dossier technique (6.2): Valeurs et idéologies post-industrielles au Québec, t. II, Québec, Office de planification et de développement du Québec, 1978, p. 516. 
pas du tout établis. Ce n'est pas tellement d'un retard qu'il s'agit, à mon avis, mais d'un développement en partie différent de ce qui s'est passé ailleurs. Ce développement a été spécifique au milieu québécois, et probablement tout aussi important qu'ailleurs. Si au lieu de se demander pourquoi le mouvement écologique québécois est en retard sur le mouvement écologique américain ou français, en le mesurant à l'aune de ces derniers, on examine plutôt comment le mouvement écologique québécois est né et s'est développé, avec ses particularités propres et sa spécificité, on arrive à une toute autre conclusion. On s'aperçoit alors qu'il n'est pas possible de parler d'un « retard », et qu'il est donc oiseux d'essayer d'expliquer ce soi-disant retard, et de faire des prédictions du genre: «La société postindustrielle que nous avons décrite aux deux chapitres précédents n'a donc rien à craindre du mouvement écologique. Déjà aux États-Unis, ce dernier a été en bonne partie récupéré. Cette tendance ne pourra que s'accentuer au cours des années 1975-2001 46. »

Même si les développements les plus considérables du mouvement écologique québécois ont eu lieu à partir de 1977, donc après la rédaction des deux ouvrages de nos trois futurologues, il n'en reste pas moins qu'avant cela, si on regarde attentivement, il y avait eu un développement suffisamment imposant, même si c'était forcément sous une forme légèrement différente de celle que ce mouvement a prise ailleurs, pour qu'il fut possible d'éviter des affirmations à l'emporte-pièce comme celles qu'on trouve dans ces deux écrits.

Si le mouvement écologique québécois ne s'est pas développé comme en France et aux États-Unis, malgré de grandes ressemblances venant de l'influence chez nous des écrits et des luttes des écologistes de ces pays, et de la similarité de certains problèmes écologiques d'ici et de là-bas, c'est probablement d'abord parce que les problèmes écologiques québécois sont en bonne partie spécifiques à l'environnement québécois. Les associations écologiques québécoises se sont développées en réponse à des problèmes concrets de caractère local. Si l'anti-nucléaire est moins développé au Québec qu'aux États-Unis et en France, c'est sans doute que l'électronucléaire y est plus développé là-bas qu'ici. C'est moins le nucléaire que toute la question de la politique énergétique qui a attiré l'attention ici, ce qui

$46 \quad$ Julien et al., Québec 2001 : une société refroidie, p. 149. 
n'est pas encore tout à fait le cas dans le mouvement écologique en France et aux États-Unis. De plus, notre vaste réseau de coopératives d'alimentation naturelle, qui est une des composantes importantes et même une source de recrutement pour le mouvement écologique québécois, fait l'envie de certains écologistes français, bien que les agriculteurs biologiques soient bien plus nombreux et mieux organisés là-bas qu'ici. La sensibilisation contre la pollution de l'eau, et plus récemment contre les pluies acides et même contre les déchets toxiques, semble plus grande ici qu'aux États-Unis et en France, peut-être parce que ces problèmes sont plus aigus chez nous. Et si nous avions eu dans le Saint-Laurent une marée noire de l'envergure de celles qui sont apparues à Santa Barbara ou en Bretagne, ou si nous avions eu un Three Mile Island à Gentilly, ou si le territoire du Québec était saupoudré de centrales nucléaires, peut-être aurions-nous eu nous aussi des manifestations monstres pour protester contre la pollution par le pétrole et contre l'énergie nucléaire. Le mouvement de conservation et de récupération se développe rapidement au Québec actuellement, mais c'est probablement parce que nous gaspillons plus qu'en France, et peut-être aussi parce que nos gouvernements sont plus préoccupés par ces problèmes que ne le sont le gouvernement des Etats-Unis et de la France. Notre climat, nos grands espaces, notre économie basée sur l'exploitation de ressources naturelles ont aussi eu une influence sur la façon dont s'est développé le mouvement écologique québécois.

Il faudrait aussi tenir compte, en examinant la spécificité du mouvement écologique québécois, du rôle particulier qu'ont pu jouer chez nous des chercheurs engagés comme Pierre Dansereau, Michel Jurdant, Michel Maldague, le groupe GAMMA, entre autres, et celui des différents paliers et agences des gouvernements, ainsi que de la relation entre chercheurs et gouvernements. En comparaison avec les États-Unis et la France, on peut dire que le gouvernement fédéral, de même que le gouvernement du Québec à partir de 1970 avec le ministre Goldbloom, ont eu une certaine préoccupation pour les questions écologiques, spécialement pour la question de la conservation de l'énergie. L'État a ainsi réussi à coopter et à drainer bien des ressources humaines dans ses programmes de changements prudents et modérés. Beaucoup des efforts qui ailleurs sont allés dans des manifestations sont récupérés ici dans des programmes gouvernementaux, et dans les mémoires, les pétitions et d'autres genres de pressions pour affecter ces programmes. Des écologistes comme Tony Lesauteur et Michel Jurdant auraient 
peut-être été en France ou aux États-Unis des permanents à plein temps de groupes écologiques militants, alors qu'ici ils sont allés travailler au gouvernement pour essayer de faire passer leurs idées dans les officines du pouvoir plutôt que dans la rue et dans des contre-médias. Quand l'État prend en main certaines revendications des écologistes, même en les édulcorant, le mouvement écologiste n'est pas toujours tout à fait perdant. De plus, notre système électoral, contrairement à ce qui se passe en France, ne favorise pas l'éclosion d'un parti ou de candidatures écologistes, ni l'influence politique des militants des associations écologiques.

Par ailleurs, parce qu'il est perçu comme un mouvement social important, et à cause de son interdépendance avec les autres mouvements sociaux québécois, (le film et le livre La Fiction nucléaire illustrent bien cette interdépendance dans le cas du mouvement de libération nationale contre l'impérialisme américain), le mouvement écologique québécois a une influence considérable. Quand on retrouve la tendance d'écologie politique parmi des nationalistes, des féministes, des socialistes, des contre-culturels, des anarchistes, des libertaires, des militants étudiants, des agriculteurs, des gens qui mènent les luttes urbaines pour le logement, le transport en commun, la santé, la défense des consommateurs et la qualité de la vie en général, on hésite à déclarer comme le font les prophètes de la société refroidie : «ce n'est donc pas de ce côté que viendra une mise en question de la société post-industrielle. Tout au plus, cette préoccupation pour l'environnement servira-t-elle à réorienter les relations des individus avec le système et asseoir la survie de ce dernier sur des fondements différents et peut-être plus valides 47 ».

C'est aussi au niveau de sa production scientifique et idéologique que le mouvement écologique québécois se différencie des mouvements français et américain. Les écologistes québécois, si on les compare par exemple aux français et même aux américains, produisent moins de travaux scientifiques et en général moins d'écrits, bien que la production de petits journaux, de bulletins, de revues et de pamphlets soit impressionnante, quand on se donne la peine de la dénicher. $\mathrm{Si}$ l'écologie est moins visible au Québec, c'est peut-être aussi parce que la pseudoécologie des multinationales y est moins diffusée qu'aux États-Unis, et parce qu'à

47 Julien et al., Québec 2001 : une société refroidie, p. 150. 
cause de la faible densité de la population et de l'abondance des ressources naturelles, les problèmes écologiques apparaissent moins pressants.

Dans les secteurs où les problèmes sont effectivement graves, par exemple ceux de la pollution des lacs, des déchets toxiques, des pluies acides, du transport urbain, de l'alimentation, de l'énergie, les associations écologiques québécoises sont très actives et elles ne donnent pas l'impression d'être en voie d'être récupérées par le système. Au contraire, la conscientisation et la radicalisation continuent de bon train, de sorte qu'il n'est plus possible de parler sérieusement, surtout depuis quelques années, d'un retard quelconque de ce mouvement par rapport à ce qui se passe ailleurs. On n'a qu'à lire les divers manifestes et les publications des différents groupes écologiques et participer un peu à leurs activités militantes ou scientifiques pour se rendre compte que ce mouvement existe bel et bien, qu'il se développe normalement, et qu'il pose les problèmes importants, comme celui des politiques énergétiques et de l'écosociété. Le mouvement écologique québécois est fortement influencé par les mouvements écologiques français et américain, mais à bien des points de vue, il n'a rien à leur envier car il est en passe de devenir un des plus importants mouvements sociaux au Québec. D'après l'observation que j'ai pu en faire, c'est un mouvement qui semble trouver de plus en plus ses appuis parmi les jeunes, les travailleurs, les femmes, les étudiants, les enseignants, les animateurs sociaux, les techniciens, les scientifiques et de moins en moins parmi les mieux nantis, car ce mouvement a des implications très radicales au plan socio-économique et politique. Il tend à s'opposer en fait aux mêmes adversaires que le mouvement ouvrier, c'est-à-dire aux grandes entreprises multinationales et aux technocrates à leur service. Il commence à converger avec les éléments les plus ouverts dans le mouvement ouvrier et dans le mouvement socialiste, ainsi qu'avec l'aile progressiste du mouvement des femmes, du mouvement pour la démocratie de base, et du mouvement anti-impérialiste et pro libération nationale, c'est-à-dire, en somme, qu'il est en voie de devenir un véritable mouvement d'écologie politique. Il semble bien que c'est seulement à cette condition qu'il réussira à avoir l'impact nécessaire pour arriver à vraiment pouvoir transformer la société québécoise ${ }^{48}$. De fait, il me semble qu'aucun des mouvements que je viens de men-

48 Le sociologue américain Charles A. Anderson affirmait il y a quelques années : «Pour être vraiment efficace, le mouvement écologique doit faire par- 
tionner ne peut y arriver tout seul, ce qui laisse croire que les divisions et oppositions ou tout simplement l'absence d'alliances entre eux ne fait que contribuer à faciliter le retour en force du conservatisme qui est une caractéristique importante de la conjoncture actuelle. C'est donc dire que si ces mouvements continuent de sortir de leurs ghettos respectifs pour essayer de trouver les points de convergence sur lesquels ils peuvent travailler pour des revendications égalitaires, démocratiques et respectueuses de l'environnement, leur influence sera bien plus grande. Si la tendance progressiste à l'intérieur de ces mouvements s'organisait et se structurait sous forme de mouvement social et politique, ce qui ne veut pas nécessairement dire, à cause des particularités de notre système électoral, comme parti politique électoraliste, ce mouvement aurait des chances de renverser le courant conservateur actuel.

Il y a, comme nous l'avons vu, des contradictions et des différences à l'intérieur du mouvement écologique québécois, et surtout entre le mouvement écologique québécois et les autres mouvements sociaux que j'ai mentionnés. Il ne faut donc pas tout attendre du mouvement écologique, ni des autres mouvements sociaux d'ailleurs. Il faut sans doute, pour que croisse leur influence une relativisation réciproque de leurs exigences contradictoires pour les rendre compatibles entre elles, et assez de réalisme pour qu'ils soient capables de faire converger leurs luttes non seulement pour éviter le pire (C'est un départ) mais pour maximiser les chances du changement dans la direction des besoins réels de la population.

tie d'un mouvement politique établi sur une base large et orienté vers une reconstruction économique fondamentale. C'est seulement alors que l'assaut contre l'environnement pourra être renversé. » Charles A. Anderson, The Sociology of Survival, Social Problems of Growth, Homewood, III, The Dorsey Press, 1976, p. 138. 
Mouvement écologiste, énergie et environnement.

Essais d'écosociologie.

Première partie . Descriptions et analyses

\title{
Chapitre 6
}

\section{“Les Québécois ont-ils besoin du nucléaire? \\ Le point de vue des groupes anti-nucléaires québécois.”}

Texte publié dans le bulletin De toute urgence, août 1981, vol. XII, no 2, p. 231243

\author{
par Jean-Guy Vaillancourt *
}

Introduction

Retour à la table des matières

Dans les sciences sociales, le concept de besoin est l'un des plus difficiles à cerner, l'un des plus ambigus et des plus complexes qui soient, parce qu'il renvoie à de multiples aspects de la vie des personnes et des groupes, et parce qu'il doit tenir compte du contexte socio-économique, politique, culturel et psychologique en même temps que d'un environnement physique et d'une époque historique donnés ${ }^{49}$. Le problème ne se posait pas en des termes aussi compliqués qu'aujour-

* Je tiens à remercier sincèrement Rachel Desrochers, étudiante au doctorat au Département de sociologie de l'Université de Montréal, qui m'a assisté dans la recherche qui a conduit à la production de ce travail. La rédaction du texte, cependant, implique ma seule responsabilité.

49 I.F. Cortesi, «La notion de besoin : essai de conceptualisation théorique », Recherches sociologiques, vol. IX, no 2, 1978, p. 179. 
d'hui quand l'humanité était au stade de la cueillette ou de la chasse, ou même de l'agriculture. Les besoins étaient alors beaucoup plus limités, centrés qu'ils étaient sur la survie physique et sur une organisation sociale et culturelle relativement simples. Mais avec l'avènement de l'ère industrielle, qui engendra tellement de produits et de moyens nouveaux et, par conséquent, de désirs inédits, la situation commença à changer radicalement. Pour satisfaire ces nouveaux besoins, l'homme occidental, grâce à la science et à la technologie, s'érigea peu à peu en maître absolu de la planète, pensant qu'il pouvait puiser sans limite parmi les ressources disponibles pour répondre à ses besoins accrus et parfois artificiels en nourriture, en eau, en vêtements, en logement, en chauffage, en transports, en santé, en communications, en loisirs, en connaissances, en expression de soi, en relations sociales, etc., alors que la majorité des hommes et des femmes de la planète, surtout dans l'hémisphère sud, n'arrivent pas à rencontrer les plus fondamentaux de leurs besoins 50 .

Il y a un rapport étroit entre le progrès scientifique et technologique, l'industrialisation et l'urbanisation d'une part, et l'utilisation de quantités de plus en plus grandes de matières premières et de ressources énergétiques d'autre part. En ce qui concerne ces dernières, l'humanité est passée d'une société basée sur l'utilisation de l'énergie humaine et animale, du bois, de la force du vent et des cours d'eau, à une société de plus en plus basée sur l'utilisation généralisée du charbon puis du pétrole. Le capitalisme comme système mondial est un mode de production qui en est venu à susciter des besoins sophistiqués de plus en plus nombreux et de plus en plus complexes et, il faut bien le dire, de plus en plus factices dans une partie privilégiée de la population mondiale, alors qu'une autre partie n'arrivait même pas à se nourrir et à se loger convenablement. L'offre a stimulé la demande, la production a engendré de faux besoins dont l'assouvissement chez certains prive les autres du nécessaire. Par exemple, les États-Unis, avec 6\% de la population mondiale, utilisent de 30 à $40 \%$ des matières premières de la planète ${ }^{51}$.

50 Voir les chapitres 1 et 2 de Nord-Sud, un programme de survie, rapport de la Commission indépendante sur les problèmes de développement international, sous la présidence de Willy Brandt, Paris, Éditions Gallimard, 1980.

51 Thomas Sieger Derr, Ecology and Human Need, Philadelphie, The Westminster Press, 1975, p. 117. 
Certains sociologues nous disent qu'au-delà de l'ère industrielle s'ouvre maintenant une période qu'on pourrait appeler postindustrielle, technologique ou programmée ${ }^{52}$. Dans cette nouvelle société dans laquelle nous entrons, nous faisons face à une stimulation encore plus grande des désirs, ce qui amène beaucoup de nouveaux besoins, dont la plupart ne sont pas essentiels ou fondamentaux. Ceci conduit rapidement à l'épuisement des matières premières et, en premier lieu, des sources d'énergie fossile. La crise qui s'annonce est telle que nous nous rendons compte qu'il faut diminuer nos pseudo-besoins en énergie et trouver de nouvelles sources d'approvisionnement, ou redécouvrir d'anciennes sources inépuisables pour éviter la catastrophe et arriver à un développement et à un bien-être plus égalitaires et plus généralisés. Tout le monde est d'accord sur le fait qu'il faut le plus rapidement possible s'acheminer vers la conservation énergétique et vers une certaine diversification de nos sources d'énergie, et qu'il faudra tôt ou tard faire surtout appel aux multiples formes d'énergie solaire. Le problème qui demeure pour plusieurs, et qui constitue le sujet d'une controverse mondiale, C'est de savoir si durant la difficile période de transition vers le solaire, il faudra faire appel ou non à la fission nucléaire, avec tous les dangers et les coûts que comporte cette voie énergétique. La question se pose de façon particulièrement aiguë dans plusieurs pays industrialisés qui ont peu de ressources énergétiques traditionnelles à leur disposition. Dans le cas du Québec, qui est bien pourvu en énergie hydroélectrique, mais qui importe beaucoup de pétrole pour le chauffage et le transport, la question se pose avec moins d'acuité qu'ailleurs, mais elle se pose quand même depuis une dizaine d'années. « Avons-nous vraiment besoin du nucléaire ? »

Avant son arrivée au pouvoir en 1976, par opposition au Parti libéral qui misait sur l'énergie électrique de la Baie James, le Parti québécois répondait « oui » à cette question. Depuis lors, ce parti a décidé d'accepter un moratoire sur la question du nucléaire. Le Premier ministre Lévesque n'a pas parlé du nucléaire quand il a mentionné les options énergétiques actuelles du Québec dans son discours d'ouverture de la session d'automne, mais plusieurs militants anti-nucléaires craignent qu'avec le départ de Guy Joron, la tendance pro-nucléaire ne risque peut-

52 Alain Touraine et al., La Prophétie anti-nucléaire, Paris, Seuil, 1980, p. 314-316. 
être de refaire surface dans ce parti. Quant au Parti libéral du Québec, il vient de se ranger du côté de l'option nucléaire en faisant élire Pierre Fortier, président de Canatom et grand " pusher » du nucléaire, comme candidat ministrable dans Outremont. C'est donc dire que d'ici un an, y compris durant la campagne électorale qui s'annonce, le débat sur le nucléaire a de bonnes chances de reprendre plus fort que jamais, d'autant plus que plusieurs groupes vont faire de 1982 une année de discussions et de débat sur la question énergétique.

En se servant de Pierre Fortier pour se débarrasser en même temps de Jérôme Choquette et de Robert Bourassa, Claude Ryan a sans doute cru qu'il faisait d'une pierre (ou d'un Pierre) deux coups. Mais il se peut fort bien, si les stratèges du Parti québécois savent profiter de l'occasion en or qui se présente à leur parti, que le Parti libéral ait fait là une gaffe monumentale en s'aliénant beaucoup de Québécois opposés au nucléaire. En effet, s'il prenait nettement position contre le nucléaire en fermant définitivement la « centrale citron » qu'est Gentilly I, en refusant l'ouverture de Gentilly II et la construction de Gentilly III, et en étendant le moratoire pour un autre cinq ans, le Parti québécois, à notre avis, ferait un coup de maître et irait se chercher de nouveaux appuis non seulement chez les écologistes militants qui laisseraient alors tomber leur projet de créer un parti qui ne ferait qu'enlever des votes au PQ, mais chez la majorité de la population qui est très préoccupée actuellement par l'environnement. Beaucoup d'anglophones, de femmes, de jeunes, d'étudiants, de travailleurs qui sont présentement plutôt tièdes visà-vis du PQ, seraient probablement stimulés à l'appuyer activement surtout si le Parti libéral fait de Pierre Fortier son porte-parole en matière d'énergie.

Même si personnellement je suis de plus en plus convaincu qu'il faut répondre « non » à la question de savoir si le Québec a besoin du nucléaire, mon intention n'est pas d'essayer de répondre directement ici à cette question en évaluant si les projections d'Hydro-Québec basées sur les taux de consommation énergétique passée et présente sont adéquates, ni d'essayer de calculer de combien il est possible de diminuer la consommation en énergie en accélérant les programmes de conservation, en diversifiant nos sources d'énergie, et en diminuant nos besoins à leur plus simple expression. 
En tant que sociologue, je préfère mettre pour un bref instant mes préférences entre parenthèses, et prendre un cheminement plus classique dans ma discipline, celui de l'analyse de la production idéologique d'un ensemble de groupes et d'organisations. Je me limiterai dans le présent exposé aux groupes écologiques qui ont pris position officiellement contre le développement de l'énergie nucléaire au Québec. J'essaierai de voir quels sont ces groupes et quelles sont les réponses qu'ils apportent à la question de nos besoins énergétiques, spécialement de nos besoins, réels ou imaginaires, en énergie nucléaire. En somme, nous ferons ensemble un petit tour d'horizon pour essayer de comprendre les raisons pour lesquelles le mouvement anti-nucléaire québécois s'oppose à l'implantation de centrales nucléaires au Québec, tout en tentant de nous faire une idée de la composition et de l'ampleur de ce mouvement. Nous essaierons donc de répondre à l'une des questions posées par Cortesi dans son article sur la notion de besoin, à savoir : «Quel est l'impact des mouvements sociaux et politiques sur la dynamique des besoins 53 ? »

Le mouvement anti-nucléaire québécois est né, un peu comme aux États-Unis et dans plusieurs pays d'Europe, de la convergence entre la critique de scientifiques, de pacifistes, d'écologistes et de populations locales préoccupés par les dangers de la radioactivité ${ }^{54}$. En juillet 1975, est né à Montréal le Regroupement pour la surveillance du nucléaire, sous l'impulsion de scientifiques opposés au nucléaire comme le Dr. Gordon Edwards et le professeur Fred Knelman de l'Université Concordia, auteur du livre Nuclear Energy: the Unforgiving Technology ${ }^{55}$. C'est un groupe pancanadien qui réunit maintenant plus de 200 groupes de citoyens de toutes les régions du pays, mais comme ses locaux sont à Montréal, et qu'il y a beaucoup de Québécois d'impliqués dans ce regroupement, nous examinerons ses positions au même titre que celles des groupes qui se limitent au contexte québécois. Il faut d'abord remarquer que ce regroupement ne se définit pas de prime abord comme étant anti-nucléaire, bien qu'il le soit effectivement,

$53 \quad$ Ibid, p. 180.

54 Voir mon article intitulé « Lettre à un militant anti-nucléaire », Possibles, vol. 2, no 4, été 1978, p. 99-110, où je traite des origines du mouvement anti-nucléaire québécois.

55 Fred H. Knelman, Nuclear Energy: the Unforgiving Technology, Hurtig, Edmonton, 1976. 
mais comme un front commun exigeant une plus grande surveillance, et un meilleur contrôle du nucléaire. Ce groupe a présenté à la Commission parlementaire des ressources naturelles du Québec, le 11 février 1977, un mémoire qui comprend une section importante sur toute la question du nucléaire ${ }^{56}$. Ce document demandait que le gouvernement ne construise pas Gentilly III, à cause des problèmes techniques, économiques et moraux impliqués et dont certains apparaissaient tout à fait insolubles aux auteurs du document.

Le RSN croit que le Québec n'a pas besoin d'énergie nucléaire, puisque la demande réelle en électricité diminue, et que le Québec possède d'abondantes réserves hydro-électriques qui, avec une stratégie énergétique rationnelle de conservation, et d'exploitation de sources d'énergie renouvelables, pourront satisfaire les besoins québécois en électricité, pour bien au-delà de 50 ans. Selon les membres de ce regroupement, les coûts du nucléaire sont exorbitants, et l'entreposage des déchets, les accidents de fonctionnement, la prolifération des armes atomiques, le terrorisme et le despotisme sont des dangers tels qu'il faut éviter de se lancer dans le nucléaire.

La position du RSN s'est radicalisée ces dernières années : le groupe exige maintenant un arrêt complet de toute l'industrie nucléaire au Québec. Dans un de ses récents pamphlets, le RSN pose directement la question : « A-t-on vraiment besoin de l'énergie nucléaire ? » et répond de la façon suivante :

On peut se demander si ces énormes montants investis dans l'énergie nucléaire n'auraient pas pu être mieux utilisés ailleurs. Des études faites par le Conseil des sciences du Canada démontrent qu'une utilisation plus rationnelle de nos ressources énergétiques actuelles pourrait nous faire épargner plus d'énergie d'ici l'an 2000 que l'industrie nucléaire pourra en produire durant cette période. S'il y avait encore quelque argent de disponible dans le budget consacré à la recherche sur l'énergie - effectivement la presque totalité de ce budget va au nucléaire - nous pourrions consacrer le dernier quart de siècle à développer des moyens permettant de puiser à même les réserves inépuisables d'énergie du soleil ainsi que de toute autre

56 Dorothy Hénaut, Dorothy Rosenberg, Dr. Gordon Edwards, De l'Énergie, mémoire à la Commission des ressources naturelles du Québec, CNR/Regroupement pour la surveillance nucléaire, 11 février 1977, 69 pages. 
source énergétique sûre et non polluante. Et ceci ne tient pas compte de l'énergie qu'on pourrait épargner si on apprenait à vivre en consommant moins.

La Société pour vaincre la pollution, un groupe entièrement québécois et plus ancien que le RSN, s'est aussi prononcée à maintes reprises contre le nucléaire. Ce groupe, créé pour lutter contre les différents types de pollution, est un des groupes écologiques les plus actifs au Québec. Lui aussi s'est sensiblement radicalisé depuis sa fondation, en 1970. Le Comité Énergie-Environnement de la SVP a publié en 1975 une brochure intitulée Tout ce que vous aimeriez ne pas savoir sur l'énergie nucléaire et que l'on ne voudrait pas non plus vous dire, brochure qui s'oppose au nucléaire pour des raisons de sécurité et à cause des coûts économiques et sociaux d'une telle option. Dans son mémoire de février 1977 à la Commission parlementaire sur l'énergie, la SVP est revenue à l'attaque avec un plaidoyer sur les dangers et les coûts du nucléaire et sur les avantages de la conservation de l'énergie, de l'utilisation des ressources renouvelables, des technologies douces, du recyclage, de l'optimisation du système actuel, de la recherche, de la décentralisation et du développement d'une. autosuffisance maximale ${ }^{57}$. La SVP a demandé aussi, à ce moment-là, un moratoire sur l'implantation de centrales nucléaires au Québec et a lancé l'idée d'un vaste débat public sur l'énergie.

En collaboration avec d'autres groupes écologiques préoccupés par la question du nucléaire (le Comité Ste-Croix de Lotbinière et celui de Grondines, le Mouvement pour l'agriculture biologique, le Monde à bicyclette, ContactConservation, le Projet banque d'information, le Groupe écologique de Maisonneuve, le Regroupement québécois pour la protection de l'environnement, Sauvons Montréal, STOP, la Librairie populaire d'Alma, etc.), la SVP a aidé à lancer le Front commun anti-nucléaire durant l'été de 1977. La déclaration de principe distribuée à la conférence de presse du 20 septembre 1977 parla des conséquences négatives du choix nucléaire, aux plans économique, politique, environnemental et social, et s'opposa à l'implantation de nouveaux réacteurs nucléaires au Québec, à cause de la menace qu'ils font peser sur tout l'écosystème, sur l'eau, l'air, le sol,

57 Pierre Lacombe, Solange Vincent, Michel Belleau, Mémoire présenté par la Société pour vaincre la pollution à la Commission parlementaire sur l'énergie, février 1977, 65 pages. 
les aliments, sur notre santé, nos emplois, et notre liberté. Il fut aussi question du gaspillage énergétique, des coûts exorbitants, de la prolifération des armes nucléaires, et de la nécessité de créer une nouvelle société conviviale basée sur l'équilibre avec la nature, la non-violence, la conservation et la qualité de la vie, en somme, une écosociété autogérée et décentralisée. La déclaration exigea enfin un moratoire sur le nucléaire, et des fonds pour la conservation, pour la recherche d'alternatives douces et sécuritaires, et pour les programmes d'information des groupes anti-nucléaires. Un mois plus tard, le 22 octobre 1977, Le Front commun anti-nucléaire tint une manifestation à Gentilly, avec près de 800 personnes. Le 19 novembre, une cinquantaine de membres du Front commun se réunirent à Montréal pour former le Comité écologique anti-nucléaire qui publia ensuite, au début de 1978, une lettre-manifeste aux 6 millions de Québécois, qui reprenait les thèmes déjà soulevés dans le manifeste et dans les documents de la SVP, mais avec une insistance particulière sur la nécessité de la lutte au gaspillage et sur l'utilité de l'information pour arriver à bannir le nucléaire du Québec.

Les 11 et 12 février 1978, le Comité organisa une session de formation à Montréal. Les cent personnes présentes décidèrent de créer l'Alliance Tournesol, un mouvement écologique anti-nucléaire décentralisé, basé sur des cellules locales autonomes reliées entre elles autour de centres régionaux. L'Alliance Tournesol a été, depuis ce temps, grâce au travail de quelques permanents bénévoles appuyés par de nombreux autres militants, une des plaques tournantes de l'activité anti-nucléaire au Québec. Il serait trop long d'analyser ici toute la production de l'Alliance Tournesol : lettres aux élus et aux journaux, conférences de presse, manifestations, bulletins de liaison, macarons, vidéo, diaporamas, programme à Radio Centre-Ville, conférences, sessions d'information, banque d'information avec livres, films, revues et documents, etc. Le message est toujours sensiblement le même : le Québec n'a pas besoin de se lancer dans la production d'énergie nucléaire, car le bilan économique, énergétique, social et politique du nucléaire est un bilan négatif, et il y a moyen de se tirer de l'impasse actuelle sans le nucléaire, qui ne ferait qu'empirer la situation. Considérant la pollution radioactive comme l'une des plus insidieuses et des plus durables qui soient, l'Alliance Tournesol veut apporter le plus de lumière possible sur les implications néfastes d'une industrie qui menace gravement l'homme et son environnement. Sa vocation première, selon elle, est de publiciser les graves dangers du nucléaire de façon que la popula- 
tion bien informée puisse décider le plus tôt possible de rejeter le nucléaire, afin que plus rien ne subsiste de ce cauchemar, et pour que puisse se bâtir dans la paix une société alternative, une société conviviale. Consciente des liens entre le nucléaire civil et le nucléaire militaire, l'Alliance Tournesol est aussi un mouvement qui milite en faveur du désarmement, affirmant que l'humanité doit mettre fin à la guerre et détruire tout armement sinon «c'est la guerre qui mettra fin à l'humanité ». Une société écologique non nucléaire ne pouvant naître que dans la nonviolence, cette dernière est àla base du mouvement que tente de développer l'Alliance Tournesol.

Dans son manifeste du 28 février 1980, l'Alliance Tournesol revient sur les dangers du nucléaire, et sur la nécessité de réduire la demande d'énergie en éliminant le gaspillage, et d'utiliser les énergies douces et décentralisées pour répondre aux besoins énergétiques réels. Ce groupe fait présentement circuler une pétition contre le nucléaire 58 et se prépare à entreprendre des actions au printemps.

Il y a toute une série d'autres groupes québécois qui se sont prononcés contre le nucléaire. Au plan local, il y eut d'abord le Comité de protection de l'environnement de Lotbinière, qui présenta une pétition à Hydro-Québec en 1974 contre l'implantation d'une centrale dans la région, et qui envoya un mémoire à la Commission Joron au début de 1977, sous le titre Centrales nucléaires : aventure technique coûteuse, dangereuse et inutile. Ce groupe s'est surtout préoccupé d'informer la population locale sur la pollution nucléaire et il a réussi à empêcher la construction d'une centrale sur son territoire. Au même moment, de l'autre côté du fleuve St-Laurent, dans le village de Grondines, un autre groupe anti-nucléaire travaillait aussi contre le projet d'une centrale nucléaire. En parlant des groupes locaux, il faudrait mentionner également les Protons de Trois-Rivières, qui ont eu un certain impact il y a quelques années dans la région de Gentilly et de TroisRivières. Des membres de ce groupe ont fait circuler dans cette région un tract intitulé À propos du nucléaire sur les dangers et les répercussions sociales et politiques du nucléaire, et l'un des auteurs du tract a aussi publié par la suite un amu-

58 Le libellé de la pétition se lit comme suit : « Nous, soussignés, demandons pour le présent et pour le futur un monde sans nucléaire. Nous demandons l'arrêt de la construction de Gentilly II et la mise à l'écart de tout Projet futur mettant en danger la population du Québec. » 
sant petit livre de 60 pages sur le nucléaire sous le titre Les neutrons s'affolent. Ce pamphlet, écrit dans un style très original, insiste sur les coûts économiques, politiques et sociaux prohibitifs du nucléaire et sur la nécessité de la non-violence et de la convivialité.

Le Groupement écologique de Maisonneuve est un autre groupe écologique très impliqué dans la lutte anti-nucléaire. Ces cégépiens ont préparé un court document intitulé Nous n'avons pas besoin d'énergie nucléaire, qui porte sur les problèmes techniques, politiques, économiques et moraux du nucléaire, et ils ont organisé beaucoup de rencontres avec films, vidéos et conférences sur ce sujet. Selon eux, le développement des centrales s'accompagnera d'un développement sans précédent des contrôles policiers, et amènera en fin de compte très peu d'emplois ; plusieurs des emplois dans le cycle du nucléaire, d'ailleurs, sont des emplois très dangereux pour la santé et la sécurité des travailleurs et pour la population avoisinante. Ce groupe exige donc, comme la plupart des autres groupes écologiques anti-nucléaires d'ailleurs, un véritable moratoire et un débat public sur le nucléaire.

Parmi les nombreux autres groupes écologiques qui ont pris position contre le nucléaire, on pourrait mentionner aussi le Monde à bicyclette, qui publie régulièrement des articles sur cette question dans son journal et qui participe à toutes les actions anti-nucléaires. Il y a aussi les Amis de la Terre de Québec dont le fondateur, Michel Jurdant, s'est souvent prononcé dans les colloques et les mass media pour une éco-société d'où serait banni le nucléaire. Un autre membre des Amis de la Terre de Québec, Solange Vincent, a publié un livre intitulé La Fiction nucléaire, qui est rempli de données tendant à démontrer que le Québec n'a pas besoin du nucléaire. Solange Vincent a aussi aidé le réalisateur Jean Chabot de l'ONF, d'abord comme recherchiste pour la réalisation du film anti-nucléaire intitulé aussi La Fiction nucléaire, puis dans la préparation d'un document d'accompagnement pour le film. Ce film et ce document s'efforcent de démontrer de façon fort convaincante que le Québec non seulement peut, mais doit se passer du nucléaire, et que les Québécois produisent beaucoup trop d'électricité pour les Américains et pour les grandes compagnies. Hélène Lajambe, économiste du groupe HélioQuébec, une militante écologique de la première heure qui a été très active depuis le début à la SVP, a publié en novembre 1979 une brochure de 60 pages intitulée 
L'autonomie énergétique du Québec dans une perspective écologique. Elle y montre comment le Québec peut éviter le nucléaire et arriver à l'autonomie énergétique dès 2025 par une meilleure utilisation des ressources existantes (hydroélectricité, isolation, électrification des transports en commun, économies d'énergies, biomasse, éolienne, solaire, tourbe, hydrogène, etc.) et par l'élimination du gaspillage, et cela avec moins de chômage et plus de prospérité. Il faudrait aussi parler du livre Face au nucléaire, dans lequel bon nombre de journalistes scientifiques prennent position contre le nucléaire.

Enfin, il y a le Conseil québécois de l'environnement qui s'est prononcé contre le développement du nucléaire au Québec à son 3e symposium en mars 1975, puis dans son mémoire présenté à la Commission parlementaire de février 1977. La demande moratoire pour suspendre toute utilisation de l'électro-nucléaire au Québec faite dans ce mémoire a sans doute eu une influence sur le gouvernement du Québec, puisque c'est dans les termes presque identiques à ceux du mémoire que ce gouvernement a proclamé un moratoire quelque temps après.

Dans un communiqué de presse en date du 18 novembre 1977, publié dans la revue De toute urgence en décembre 1977, le CQE s'est opposé à la construction de Gentilly III. Le CQE a aussi suggéré, dans le numéro de la revue De toute urgence de mars 1978, qu'un débat soit ouvert sur les risques de l'utilisation de l'énergie atomique, et sur les avantages de l'utilisation des énergies douces. Un appel fut alors lancé pour accélérer les efforts pour la recherche et contre le gaspillage. "Information, recherches et développement de nouvelles voies, lutte contre le gaspillage énergétique et modification du comportement, tels sont les secteurs essentiels où des actions doivent être engagées et amplifiées », lit-on dans D.T.U. de mars 1978, p. 43. La position anti-nucléaire du CQE a été réitérée en 1980, et à l'assemblée générale de 1980, le CQE s'est engagé à participer activement au Front commun pour un débat sur l'énergie et à entreprendre ses efforts de l'année 1981 dans le domaine de l'énergie en collaboration et en consultation avec le Front commun pour un débat sur l'énergie.

En examinant les positions anti-nucléaires de divers groupes écologiques québécois, on a pu se rendre compte du fait qu'ils insistent surtout sur la nécessité d'un débat public sur l'énergie. De fait, en 1979, la lutte anti-nucléaire québécoise 
a pris un tournant important avec la création d'un grand Front commun pour un débat public sur l'énergie, qui regroupe une centaine de groupes québécois, et qui est devenu le fer de lance de la lutte anti-nucléaire au Québec, puisque le Front commun demande que durant la durée du débat publie, il y ait un moratoire sur le développement de l'énergie nucléaire au Québec, c'est-à-dire un arrêt de la remise en service de Gentilly II et de l'usine d'eau lourde de La Prade, et un arrêt des travaux de planification de Gentilly III. Le Front commun a organisé un colloque sur l'énergie et l'information, qui aura lieu du 16 au 22 février 1981 à l'UQÀM, dans le but de contribuer à établir quels sont les besoins énergétiques des Québécois et pour déterminer quelles seront les grandes orientations et politiques énergétiques que le Québec devrait adopter pour les années et les décennies qui viennent.

Les militants anti-nucléaires québécois ne prétendent pas avoir le monopole de la vérité sur les questions énergétiques. En somme, ce qu'ils disent, c'est que les Québécois n'ont pas besoin d'autant d'énergie que les technocrates et les marchands du nucléaire essaient de le faire croire, et que les Québécois n'ont pas du tout besoin du nucléaire étant donné les dangers et les coûts de cette option. Ils exigent un grand débat public pour discuter de ces questions, parce qu'ils veulent discuter ouvertement de ces problèmes entre eux, avec le grand publie, et avec ceux qui planifient l'avenir énergétique du Québec et du Canada.

Des technocrates et des experts, des relationnistes et des vendeurs de nucléaire affirment que les Québécois auront besoin de plus en plus d'énergie pour maintenir et améliorer leur bien-être et leur confort actuels. Les besoins que définissent les appareils technocratiques se transmettent dans les programmes énergétiques de nos gouvernements. Le nucléaire risque toujours de devenir un des éléments de ces politiques au plan provincial, et de le rester au plan fédéral.

Les écologistes et les anti-nucléaires affirment au contraire qu'on peut bien vivre avec moins de production et de consommation d'énergie. Il suffit, selon eux, d'éliminer le gaspillage et les inégalités, de foncer sans tarder vers les énergies nouvelles, de bien gérer ce qui reste de gaz, de pétrole et de charbon, de conserver et de recycler. Ils espèrent que la population rejettera la création de pseudobesoins et la programmation de ces besoins par la publicité et les appareils, qu'elle définira elle-même ses besoins réels, et que l'énergie nucléaire ne fera pas partie 
des énergies auxquelles on fera appel dans les années 80 et au-delà. En somme, le mouvement écologique anti-nucléaire québécois essaie d'agir sur la dynamique des besoins eux-mêmes, pour convaincre les gens que la crise de l'énergie serait surmontable si seulement ils acceptaient de se débarrasser de certains de leurs besoins non essentiels, et que dans toute éventualité, le nucléaire, par les coûts et les dangers de toutes sortes qu'il amène, ne répond pas à un besoin réel mais amplifie plutôt les problèmes au lieu d'y apporter une solution acceptable. 
Mouvement écologiste, énergie et environnement.

Essais d'écosociologie.

Première partie . Descriptions et analyses

\section{Chapitre 7}

\section{"Le mouvement écologiste et anti- nucléaire face aux gouvernements : le cas du débat public sur l'énergie au Québec et au Canada.”}

Texte présenté au 2e Colloque sur la réforme et le changement en administration publique, Montréal les 27-28-29 avril 1982.

\section{Par Ronald Babin et Jean-Guy Vaillancourt *}

\section{Introduction}

$\underline{\text { Retour à la table des matières }}$

Un des cas très importants (et à notre avis peut-être aussi parmi les plus intéressants) du rapport actuel entre les organisations publiques et les gouvernements d'une part, et les mouvements sociaux et les groupes populaires d'autre part, est la question du débat public sur l'énergie. Le mouvement écologiste et anti-nucléaire exige ce débat avec beaucoup d'insistance depuis quelques années, tant au Québec qu'au Canada, tandis que nos gouvernements à Québec et à Ottawa ne semblent pas encore prêts à accepter qu'un tel débat soit lancé.

Je tiens à remercier François Benoît et Chantal McAviney qui m'ont aidé à faire la traduction française du texte original anglais. 
Dans le bref exposé qui suit, nous nous proposons de décrire et d'analyser ce rapport entre le mouvement écologiste et anti-nucléaire d'une part, et les instances responsables des questions énergétiques au gouvernement du Québec et à Ottawa d'autre part, en nous basant sur des recherches que nous menons depuis quelques années sur ces problèmes. Au plan méthodologique, nos conclusions s'appuient sur l'analyse documentaire, sur des interviews, et sur l'observation participante. Ces recherches ont déjà conduit à la rédaction de la thèse de doctorat de Ronald Babin à l'École des hautes études en Sciences sociales de Paris sur l'industrie nucléaire et sur le mouvement anti-nucléaire, et à un article de Ronald Babin sur la lutte anti-nucléaire au Canada publié l'an dernier dans Sociologie et Sociétés 59, ainsi qu'à des articles sur le mouvement écologiste québécois, sur les antinucléaires québécois, et sur le débat public sur l'énergie par Jean-Guy Vaillancourt dans les revues Sociologie et Sociétés, De toute urgence et Possibles 60. Nous avons aussi publié conjointement, avec des militants anti-nucléaires de l'Alliance Tournesol et du Regroupement pour la surveillance du nucléaire, depuis un an environ, une série de trois articles dans Le Devoir sur ces questions d'énergie ${ }^{61}$.

Ici, nous verrons comment la lutte du mouvement écologiste et anti-nucléaire pour obtenir des gouvernements un véritable débat public sur l'énergie n'a pas encore atteint son but, mais a contribué quand même à étendre dans la population le désir de démocratiser les décisions qui affectent notre avenir énergétique.

59 Ronald Babin, «La lutte anti-nucléaire au Canada », Sociologie et Sociétés, vol. XIII, no 1, avril 1981, p. 131-145.

60 Jean-Guy Vaillancourt, « Évolution, diversité et spécificité des associations écologiques québécoises : de la contre-culture et du conservatisme à l'environnementalisme et à l'écosocialisme », Sociologie et Sociétés, vol. XIII, no 1, avril 1981, p. 81-98 ; "Les Québécois ont-ils besoin du nucléaire ? Le point de vue des groupes anti-nucléaires québécois ", De toute urgence, vol. XII, no 2, août 1981, p. 231-243 ; «Le débat public sur l'énergie aura-t-il lieu ? », Possibles, vol. 5, no 3-4, 1981, p. 277-288.

61 «La politique québécoise de conservation de l'énergie », Le Devoir, 10 février 1981 ; "Pour un débat public sur l'énergie », Le Devoir, 5 octobre 1981 ; « Contre le nucléaire », Le Devoir, 23 novembre 1981. 
Nous aborderons d'abord la question de l'évolution de la lutte anti-nucléaire au Canada et au Québec qui a abouti à la revendication d'un débat public sur l'énergie. Après avoir parlé de l'action du Front commun pour un débat public sur l'énergie et de la promesse non tenue du gouvernement du Québec à cet égard, nous décrirons la nouvelle régionalisation de cette lutte au Québec, et analyserons ce qui s'est passé au fédéral dans ce domaine.

En conclusion, nous indiquerons comment la lutte pour un débat public est en train de s'étendre et comment le mouvement écologiste et anti-nucléaire est actuellement un mouvement d'écologie politique qui cherche à opérer un rapprochement avec d'autres forces sociales.

\section{L'évolution de la lutte anti-nucléaire}

$\underline{\text { Retour à la table des matières }}$

La montée de la contestation anti-nucléaire s'est opérée plutôt rapidement au Canada et en quelques années un vaste réseau de groupes anti-nucléaires s'est établi à divers niveaux à travers l'ensemble du pays. L'évolution idéologique de ces groupes a été rapide elle aussi. Durant cette première phase de la lutte, on a vu une critique d'abord essentiellement orientée contre les dangers de l'énergie nucléaire se transformer en une critique plus fondamentale, dirigée contre le mode de représentation démocratique et contre l'orientation socio-économique générale qui nous ont conduit à l'impasse nucléaire.

L'action en cette première période de la lutte se situe surtout au plan du témoignage : le mouvement identifie et dénonce certains états de faits dans la société.

D'abord le mouvement anti-nucléaire dénonce les conséquences sociales de l'industrie nucléaire qui mène à la concentration du pouvoir dans les mains de technocrates. Mais peu à peu, en se politisant, le mouvement anti-nucléaire s'éloigne de ce déterminisme technique et fait plutôt ressortir que c'est la domination technocratique elle-même qui fait choisir la voie dure de l'énergie nucléaire et des 
autres mégaprojets à haute teneur technologique, afin de mieux asseoir son pouvoir. Après un rejet initial du nucléaire basé sur la peur, la lutte passe à la contestation du mode de développement que cherche à imposer la technocratie. L'adversaire social est reconnu et désigné, et sa stratégie devient de mieux en mieux comprise et de plus en plus âprement combattue. Le mouvement ne se bat pas contre l'avenir et pour le passé mais plutôt pour une modernisation différente de la société, une modernisation dans laquelle la. population en général joue un rôle plus important dans la détermination des choix qui engagent l'avenir. Le mouvement anti-nucléaire saisit l'enjeu commun de la lutte qui unit et sépare à la fois les pro-nucléaires et les anti-nucléaires, à savoir le contrôle de la modernité, et la gestion et l'orientation du changement social. Toutefois, bien que la prise de conscience soit grande, il n'en demeure pas moins qu'il manque encore au mouvement anti-nucléaire une définition claire de ceux qu'il représente. Cette carence au plan de l'identité affaiblit quelque peu le potentiel de cette lutte en la privant d'une base sociale sur laquelle le mouvement pourrait s'appuyer. Cette faiblesse devient surtout apparente à partir de 1978, suite à la démobilisation survenue après des victoires mais aussi des échecs qu'ont vécus une partie des populations locales, qui sont la composante la plus directement concernée par l'exploitation du nucléaire et dont la réunion avec le mouvement anti-nucléaire dans son ensemble avait permis la grande percée de 1974-1978.

Depuis quelques années, le mouvement cherche à s'engager plus directement dans une action politique organisée pouvant déboucher sur un programme d'action centré sur des objectifs politiques généraux. Une réflexion en ce sens est engagée depuis 1977, notamment au Québec. Cependant, ce changement d'orientation de l'action s'opère lentement, au même moment le mouvement traverse une période d'essoufflement qui traduit l'épuisement des premières formes de lutte.

Le tournant s'opère après l'accident de Three Mile Island, au moment où la contestation générale est relancée, non pas du côté de la peur et du danger du nucléaire, mais plutôt du côté des responsabilités sociales et du débat publie. En effet, l'action anti-nucléaire entre dans une deuxième phase. Elle adopte de nouvelles formes de lutte guidées par la préoccupation de mieux définir sa base sociale, d'élargir sa démarche politique, et de chercher une plus grande efficacité. Partant de la constatation que la lutte anti-nucléaire porte en elle beaucoup de thèmes 
communs à d'autres luttes sociales, le mouvement anti-nucléaire et écologiste cherche donc, à partir de ce moment-là, à créer des liens et à s'allier avec d'autres forces sociales telles les syndicats, les divers groupes populaires, les féministes, les autochtones...

La deuxième phase voit donc se diversifier la protestation qui se rapporte à des considérations plus larges touchant plus directement toute la société. Le mouvement cherche alors à aller au-delà de la seule question énergétique et nucléaire pour faire ressortir la domination qu'impose le système technocratique et pour parler de ce fait au nom de ceux à qui l'on demande de subir les décisions prises par d'autres. Le mouvement cherche à élargir le champ politique afin de susciter une participation plus considérable et plus directe de la population et de la faire réfléchir sur les rapports de classes, tout en se donnant une nouvelle capacité d'agir. La façon idéale d'atteindre ces buts est vite apparue comme étant la mise en marche d'un vaste débat parmi la population sur l'ensemble de la question énergétique.

\section{Pour un débat public sur l'énergie}

$\underline{\text { Retour à la table des matières }}$

L'idée d'un débat public sur l'énergie est très tôt présente dans les revendications du mouvement anti-nucléaire. Déjà, en 1975, lors de sa formation en tant que coalition nationale, le Rassemblement pour la surveillance du nucléaire (RSN) avait parmi ses objectifs d'agir de manière à lancer un débat national sur la question nucléaire semblable à celui qui avait eu lieu en Suède en 1973. Un nouveau pas est fait dans cette direction avec la présentation en février 1977 d'un mémoire devant la Commission parlementaire sur l'énergie à Québec par la Société pour vaincre la pollution (SVP-Montréal). Après avoir présenté un plaidoyer classique contre le développement de l'énergie nucléaire, le mémoire exige un moratoire sur l'implantation de centrales nucléaires au Québec et il lance l'idée 
d'engager un débat public sur l'énergie durant cette période, sans toutefois en préciser la forme ni le contenu 62.

C'est à partir de 1979 qu'une priorité est donnée à la lutte autour du thème du débat public et ceci dans un contexte très significatif. L'accident d'Harrisburg venait de confirmer que les nombreuses inquiétudes exprimées par le mouvement anti-nucléaire étaient justifiées. Cependant, la relance de l'action ne s'est pas faite sous le signe de la peur du nucléaire mais a plutôt été caractérisée par un appel pressant à la nécessité de tenir un véritable débat public sur l'ensemble des questions énergétiques. Cette lutte a été amorcée durant l'été de 1979 par la SVP. Elle a conduit à la formation en novembre 1979 d'un vaste Front commun pour un débat public sur l'énergie de plus de 80 groupes et associations représentant un large éventail des mouvements populaires québécois. Parmi ceux-ci, on trouve des groupes écologiques et anti-nucléaires, des coopératives d'habitations, des associations de défense des consommateurs, des syndicats, des associations de professeurs et d'étudiants, des regroupements de femmes ainsi que divers comités de citoyens. Malgré certaines divergences mineures inévitables, tous s'accordent sur l'essentiel, à savoir l'élargissement nécessaire du processus décisionnel en matière d'énergie, accompagné d'un accès total aux informations. Il est à noter que le débat réclamé dépasse les seules préoccupations nucléaires pour poser des questions sur l'ensemble de la politique énergétique québécoise.

Comme première tâche et pour y voir plus clair, ce nouveau regroupement définit ce que pourraient être l'objectif et les modalités d'un tel débat publie. L'ensemble est contenu dans une proposition-cadre dont voici les grandes lignes 63 :

- la création d'une commission sur l'énergie, indépendante des producteurs d'énergie, qui contrôlerait, arbitrerait et animerait le débat public ;

62 Pierre Lacombe, Solange Vincent et Michel Belleau, Mémoire présenté par la Société pour vaincre la pollution à la Commission parlementaire sur l'énergie, février 1977, p. 53.

63 Pierre Lacombe, « Débat public sur l'énergie au Québec : état de la situation », L'Environnement, vol. 8, no 1, 1981, p. 1. 
- le financement du débat public à partir des fonds initialement prévus pour l'usine d'eau lourde de La Prade ;

- une durée minimum de deux ans pour le débat lui-même ;

- un support financier et technique pour les groupes et personnes qui veulent intervenir et qui n'ont pas les moyens pour le faire ;

- un moratoire sur tous les projets énergétiques majeurs qui ne sont pas déjà en cours durant toute la durée du débat public ;

- la mise sur pied d'une structure de consultation permanente après la phase intensive du débat public ;

- le débat public sur l'énergie déboucherait sur le choix des grandes orientations énergétiques du Québec, lesquelles serviraient de cadre aux futures politiques énergétiques du gouvernement du Québec.

Il ressort de ceci que le Front commun exige que soient mis à la disposition de la société les moyens et les institutions par lesquels elle serait en mesure de surveiller et de contrôler le développement énergétique, afin d'en définir les objectifs ainsi que les moyens de les atteindre et la vitesse de leurs réalisations. Cette campagne lancée par la SVP constitue une nouvelle orientation de la lutte, le mouvement anti-nucléaire et écologiste cherchant à rendre ses revendications plus directement politiques. Elle exprime le besoin de changer de mode de décision et d'inventer des formes nouvelles de démocratie plus directe, la démocratie parlementaire ayant fait défaut puisque les choix de développement technologique se font en dehors d'elle.

La deuxième étape a été de faire pression auprès du gouvernement pour qu'il initie une telle réflexion collective sur l'avenir énergétique du Québec. Devant les demandes pressantes du Front commun, le ministre de l'Énergie de l'époque, Yves Bérubé, annonce en mai 1980 sa décision de mettre sur pied une nouvelle commission parlementaire sur l'énergie plutôt qu'un véritable débat publie. Le Front commun refuse d'emblée cette commission aussi peu conforme à son idée de débat public approfondi, n'y voyant qu'un semblant de démocratie, une mise en scène destinée à désamorcer la contestation et à maquiller le fait que les citoyens ont bien peu de poids dans les décisions prises à leur insu. Cette prise de position découle de l'expérience des groupes membres ayant participé à la Commission parlementaire sur l'énergie mise sur pied par le ministre Guy Joron en 1977. Ceux-ci 
ont gardé l'impression d'avoir été écoutés poliment sans qu'il ait été tenu compte de leurs demandes. Au contraire, le gouvernement s'est plutôt servi de leur participation pour cautionner des politiques énergétiques décidées à l'avance par Hydro-Québec.

\section{La Semaine de l'énergie}

Retour à la table des matières

Non seulement le Front commun pour un débat public sur l'énergie, mais aussi la quasi-totalité des groupes écologistes ont décidé de boycotter toute activité de ce genre. Le Front commun S'est plutôt lancé dans une action concrète en vue de donner plus de poids à la demande d'un débat publie. C'est ainsi que le Front commun a entrepris d'organiser une manifestation d'envergure sous forme d'une semaine sur J'énergie au Québec, du 16 au 22 février 1981, à l'Université du Québec à Montréal. Tout en réclamant la tenue d'un véritable débat publie, le colloque de trois jours qui a clôturé cette semaine sur l'énergie a permis de faire un bilan de la situation énergétique au Québec et de contribuer ainsi à la discussion et à la réflexion sur les avenirs énergétiques possibles au Québec.

Cette étude était devenue d'autant Plus importante qu'Hydro-Québec avait Publié en décembre 1980 son plan décennal intitulé « Une stratégie pour la décennie 80 ». Son plan d'investissement de 55 milliards de dollars (récemment porté àplus de 70 milliards de dollars à cause de l'inflation et des taux d'intérêts élevés) est fondé sur un postulat invraisemblable du doublement de la production en énergie primaire au cours des dix prochaines années. Les calculs d'Hydro-Québec sont basés sur des prévisions très contestables de l'accroissement de la demande en électricité estimé à 6,2\% par an alors que l'augmentation de la population par exemple ne sera que de 0,6\% par année durant cette même période. De plus, le ministère de l'Énergie, des mines et des ressources à Ottawa prévoit jusqu'à l'an 2000 une augmentation annuelle de la demande de 3,8\% pour le Québec, de 2,8\% 
pour l'Ontario et de 3,3\% pour l'ensemble du Canada ${ }^{64}$. Aux sommes déjà mentionnées, il faut ajouter une dépense supplémentaire de quelques 40 milliards de dollars pour l'entretien du réseau actuel et près de 50 milliards de dollars pour l'achat d'énergie, principalement sous forme de pétrole et de gaz naturel.

Cette valse des milliards représente une part considérable des capitaux qui circulent dans le système économique où actuellement les seuls investissements d'Hydro-Québec représentent 25\% de tous les capitaux investis au Québec. C'est donc dire qu'ils ont un impact important sur la vie économique et sociale des Québécois, le nombre et les types d'emplois créés, la santé de la population, et la qualité de l'environnement et de la vie en général. C'est cette prise de conscience de l'importance des décisions énergétiques pour notre avenir collectif, associée à la volonté d'un nombre croissant de citoyens d'orienter le changement selon les besoins réels de la population, qui anime l'action du Front commun.

La semaine sur l'énergie a permis de rassembler des témoignages manifestant l'intérêt des citoyens pour les questions énergétiques et de faire valoir que ces dernières concernent l'ensemble de la population et non les seuls experts en ce domaine. C'est ce qu'exprime le thème "À nous de choisir ", qui met l'accent sur la volonté de ceux qui subissent les politiques de participer aux décisions sur les grandes orientations dans le domaine énergétique. Ce point a été défendu durant le colloque et exprimé comme suit à l'intérieur d'un atelier :

Les choix énergétiques d'aujourd'hui vont façonner la société de demain. Il est donc nécessaire de s'engager dans un débat pour l'orienter sinon ceci sera fait par d'autres qui ont des orientations bien précises qui ne sont pas celles de la population 65 .

L'organisation du colloque a été faite de façon à favoriser l'émergence d'une analyse plus étendue et plus approfondie de la situation énergétique permettant, voire encourageant un débordement des seules questions énergétiques pour mieux

64 Rapport ER 81-2F, Aperçu de la politique nucléaire. Documents d'information, p. 10.

65 Inverview avec Solange Vincent. 
faire ressortir leurs liens avec des problèmes socio-économiques plus généraux 66 . Ce souci est mis en évidence lorsqu'on considère les quatre thèmes généraux suivants qui ont servi à organiser les discussions :

1) Énergie : inventaire, besoins et choix,

2) Énergie et économie,

3) Énergie, équité et environnement,

4) Énergie et débat public.

Chacun de ces thèmes était lui-même subdivisé en ateliers de discussions où étaient abordés des points plus particuliers.

Les écologistes cherchent à lancer une grande campagne d'information et de discussion pour que la population soit en mesure de débattre et de choisir librement en connaissance de cause non seulement entre telle ou telle politique énergétique mais un certain type de développement socio-économique pour l'avenir. Ils ont tenté de faire de la Semaine de l'énergie le point de départ, la première étape d'un véritable débat sociétal et une démonstration concrète de ce qui peut être fait dans l'immédiat en ce sens. Cette volonté et cette démarche n'ont pas suscité un grand enthousiasme de la part du gouvernement québécois, mais celui-ci s'est vu placé dans une position où il lui était impossible d'ignorer ce nouveau développement.

\section{Une promesse électorale...}

$\underline{\text { Retour à la table des matières }}$

66 Cette manifestation, par son appel à la responsabilité du publie, contraste avec le premier Salon national de l'énergie tenu à Montréal en septembre 1981, sous le thème « Vers la maîtrise de l'énergie », où il était plus question d'épater la galerie par le biais d'une exposition technique et scientifique éclatante accompagnée de brochures publicitaires, que de fournir une information pertinente sur la diversité des moyens disponibles dans le secteur énergétique et où il n'était aucunement question de demander l'avis des gens. 
La semaine et le colloque du Front commun se sont donc révélés efficaces comme moyen de pression auprès du gouvernement. L'actualité des questions énergétiques et l'intérêt qu'ils ont suscité dans les mass média ont contribué à en faire des événements qui ne sont pas passés inaperçus. Cette mise en relief, conjuguée à la décision de boycotter la Commission parlementaire sur les investissements d'Hydro-Québec, tenue quelques jours après le colloque, a affecté la crédibilité de ce type de consultation au point que le ministre Bérubé a accepté, lors de cette même Commission, le principe d'un débat publie. Quelques jours plus tard, le ministre promettait de faire tenir par une future Régie de l'énergie un débat public itinérant qui aboutirait à la tenue d'un sommet sur l'énergie ${ }^{67}$. De plus, un financement public devait être disponible pour des groupes indépendants.

Il s'agissait là d'un pas important dans la direction voulue par le Front commun. Cependant la démarche demeurait encore incomplète et c'est dans son mode de réalisation qu'on pouvait deviner l'intention du gouvernement de ne pas aller aussi loin que souhaité par le Front commun. Suite aux élections québécoises de 1981 et à la réélection du Parti québécois, la nomination d'un nouveau ministre de l'Énergie, Yves Duhaime, en est une première indication. Très vite, celui-ci atténue, sans les démentir, les propos de son prédécesseur et il indique qu'il n'est pas acquis d'emblée à l'idée d'une telle consultation populaire. Par la suite, il procède à la mise sur pied d'un Comité d'étude chargé d'évaluer l'opportunité de tenir un débat public sur l'énergie.

Ce comité entreprend ses travaux durant l'été et l'automne de 1981. Ses objectifs sont d'abord de déterminer la nature et le contenu possible d'un débat en tenant compte du contexte actuel, à savoir que le gouvernement doit faire des choix pour l'horizon 2000-2020 sur les divers aspects de sa politique énergétique et, ensuite, de montrer qu'un débat public serait l'occasion de le faire ${ }^{68}$. Le Comité d'étude a donc entendu divers intervenants sur ces sujets mais, fait assez remarquable, ce comité chargé d'élaborer les mécanismes d'un débat public a siégé de

67 « Bérubé donne son appui à un débat sur l'énergie », Montréal, La Presse, 3 mars 1981.

68 Explications fournies par M. Girard, Président de la Commission, lors d'une communication personnelle avec Ronald Babin en octobre 1981. M. Girard est également Directeur des communications au ministère de l'Énergie. 
façon non publique. Bien plus, cet organisme a choisi de ne pas consulter officiellement le Front commun qui est pourtant le requérant initial d'un tel débat. L'argument justificatif avancé est que la position du Front commun étant suffisamment connue, des rencontres formelles ne sont pas jugées nécessaires. On devine en réalité une gêne manifeste devant l'étendue des revendications du Front commun, associée à un désir de ne pas légitimer une organisation qui favorise un mécanisme de prise de décision en matière d'énergie qui serait lié au résultat d'un débat publie, et qui exige la mise sur pied d'une structure permanente de consultation auprès des citoyens. Sans doute le gouvernement préférerait faire de ce débat un simple mécanisme de consultation et ceci pendant une période de temps limitée.

Il est probable que le gouvernement québécois va chercher à adapter ses techniques de participation publique devant la nouvelle réalité que pose le Front commun. Après avoir été débordé et placé dans une position défensive, le gouvernement va probablement créer une structure de « débat public » susceptible d'intéresser individuellement les groupes membres du Front commun. Il cherchera au moyen de cette structure à se placer à la pointe de l'évolution sociale pour mieux l'anticiper et mieux l'orienter dans le sens de ses propres objectifs. Rappelons que ceux-ci vont surtout dans le sens d'un renforcement des pouvoirs centraux de l'État québécois dont un moyen privilégié d'action est le développement accéléré du secteur énergétique. Ceci est clair si l'on en juge par les investissements massifs dans ce secteur et par les récentes décisions (la loi 16), visant une plus grande prise de contrôle étatique sur ce secteur. Il est donc possible qu'il y ait création d'un nouvel appareil de consultation dans l'esprit des recommandations qui seront mises de l'avant par le Comité d'étude, en somme, une réforme du cadre institutionnel de consultation afin de pouvoir structurer et orienter les questions de façon à limiter l'éventail des réponses possibles. Par l'introduction de limites de ce genre, le Comité cherchera à enfermer le débat dans des considérations économiques, plus faciles à justifier en termes techniques inéluctables, sans toucher les finalités qui, elles, sont plus directement liées à des choix politiques et donc plus facilement contestables. Ainsi le choix de ne pas consulter le Front commun apparaît comme un effort pour déradicaliser des choix collectifs. En effet, la coalition demande à participer à la définition des finalités plutôt qu'une simple participation par objectifs, même si ceux-ci pourraient être élargis pour comprendre l'ensemble 
de la politique énergétique. Le Front commun cherche à lancer un vaste débat public non seulement sur la politique énergétique du Québec mais aussi sur le type de développement que celle-ci commande, en mettant l'accent sur les conséquences socio-économiques des diverses options possibles. Le débat voulu par le Front commun s'ouvrirait donc directement sur une critique des rapports entre les classes sociales dans la société québécoise et canadienne et même des rapports entre gouvernements et entre États. En questionnant le développement économique et social, il touche à la légitimité du pouvoir et contribue à ramener en surface les contradictions du système social tout entier. Le gouvernement redoute cette situation puisque tous les éléments d'une confrontation directe avec les citoyens sont là en puissance. Il n'est donc pas étonnant de voir le ministre de l'Énergie agir pour éviter un tel affrontement de classe ainsi que la politisation du débat énergétique, en cherchant à canaliser le débat autour d'objectifs économiques (les choix pour l'horizon 2000-2020) et en tentant d'isoler le Front commun pour qu'il ne puisse pas prétendre être le représentant principal du bien commun en cette question.

Depuis la Semaine sur l'énergie de février 1981, des pressions ont été maintenues sur le gouvernement pour qu'il mette fin à ses « consultations » et qu'il introduise au plus tôt le débat public promis. Afin de sensibiliser la population à ses demandes, le Front commun cherche à faire sentir sa présence sur la scène énergétique en demeurant proche de l'actualité et en réagissant aux déclarations officielles. Ceci se fait par l'intermédiaire des mass média, généralement sous forme de lettres et d'articles dans les journaux, mais aussi en réponse à des demandes d'informations de quelques postes de radio et de télévision, ainsi que par des interventions dans les CÉGEP et les universités. Le ton de ces interventions est celui de l'explication qui cherche davantage à convaincre, à construire une analyse et à encourager la réflexion qu'à provoquer une mobilisation populaire pour une cause. Le Front commun cherche à montrer que le choix d'une politique énergétique est l'affaire de tous et, dans cet esprit, il invite les citoyens et les consommateurs à réclamer la tenue d'un débat public pour choisir une stratégie de l'énergie et du développement pour le Québec. 


\section{La nouvelle régionalisation de la lutte}

$\underline{\text { Retour à la table des matières }}$

L'organisation de la lutte en ce sens se veut exemplaire et en accord avec les fins recherchées. Elle privilégie l'émergence d'une démocratie de base. Dans un effort de décentralisation du Front commun, une réunion a eu lieu en août 1981 à l'île du Repos (Lac Saint-Jean). À cette occasion, un Comité de coordination a été mis sur pied avec comme objectif de favoriser l'élargissement du réseau et spécialement le développement de groupes régionaux. Le premier groupe régional a été créé au Lac Saint-Jean. Éventuellement, un groupe devrait se former à Québec ainsi que dans la région de l'Outaouais. Cette démarche a pour but de montrer qu'un débat démocratique doit être décentralisé sur une base régionale, et doit aboutir à l'élaboration de plans énergétiques régionaux guidés par le souci d'autonomie locale et du plus grand contrôle par les populations des ressources énergétiques du milieu.

On voit ainsi prendre forme une nouvelle tendance qui pourrait prendre de l'importance durant cette deuxième phase que traverse actuellement la lutte antinucléaire et écologique. Pendant la première phase, les groupes locaux et régionaux se sont réunis en coalitions et en regroupements plus larges afin d'adresser une critique globale à l'ensemble de la politique nucléaire et énergétique. Les rassemblements ainsi formés ont eu un certain impact sur cette politique, vu la nature fondamentale des critiques qu'ils faisaient et dans la mesure où ils bénéficiaient d'un soutien populaire résultant de la grande montée de la contestation entre 1974 et 1978. La participation de nombreux groupes écologiques et anti-nucléaires aux diverses commissions d'enquêtes durant la période 1977-1979 et le constat de l'échec de l'action sur ce terrain ont été le début d'un certain découragement et d'une démobilisation chez quelques-uns de ces groupes. Pour d'autres, il s'agit d'une indication des limites des premières formes d'action ; une prise de conscience s'amorce donc à l'effet qu'un changement d'orientation de la lutte s'impose. Cette opération est rendue d'autant plus importante que la stagnation et le déclin de l'activité de certains groupes en 1978-79 ont privé la contestation générale 
d'une partie de son assise sociale. Peu après Three Mile Island, la deuxième phase de la lutte anti-nucléaire et écologique commence à s'amorcer alors que la relance de l'action se fait dans la direction inverse de celle de la première phase et est marquée par une volonté des coalitions de retourner à la région, voire éventuellement à des unités locales encore plus restreintes que la région. Cette action décentralisante vise à reconstruire une base sociale sur laquelle le mouvement puisse s'appuyer et au nom de laquelle il puisse agir.

\section{Le débat public sur l'énergie au niveau fédéral}

$\underline{\text { Retour à la table des matières }}$

L'action du Front commun pour un débat public sur l'énergie au Québec offre pour le moment l'exemple le plus visible de cette volonté de réorienter la lutte anti-nucléaire et écologique. Cependant, elle existe aussi au niveau plan canadien de la lutte anti-nucléaire puisqu'une tentative pour organiser l'action autour du thème du débat public a aussi eu lieu. Rappelons qu'un tel débat au plan canadien constitue l'une des principales revendications de la coalition anti-nucléaire canadienne, le Regroupement pour la surveillance du nucléaire (RSN) dont le nom anglais est la Canadian Coalition for Nuclear Responsibility (CCNR). Peu après l'accident de Harrisburg, le RSN a entrepris de faire pression sur le gouvernement fédéral pour qu'il mette en marche un débat national sur l'ensemble de la question nucléaire par la création d'une Commission d'enquête indépendante à vocation itinérante, telle que déjà réclamée par la coalition en mai $1977{ }^{69}$. Pour appuyer sa demande et afin de définir un mandat réellement efficace pour une telle commission d'enquête, le RSN a organisé deux congres successifs à Toronto, l'un en mai 1979, avant les élections fédérales, et l'autre en juin 1979, après la victoire des Conservateurs. Plus de 50 organisations canadiennes se sont associées à cette démarche. Il y avait là des groupes écologistes et anti-nucléaires à côté d'associations professionnelles, de syndicats et de groupes religieux et pacifistes.

69 Time to Stop and Think, a brief to P.E. Trudeau, Prime Minister of Canada, RSN/CCNR, 27 mai 1977, 26 p. 
Ces congrès ont eu l'effet recherché, qui était de faire pression sur le chef du Parti conservateur fédéral, Joe Clark, d'abord en prévision de son élection, puis à la suite de sa victoire électorale du 22 mai 1979. Le deuxième congrès devait lui rappeler sa prise de position, exprimée par sa signature apposée à la pétition lancée par le RSN, en faveur de la tenue d'une vaste enquête publique sur l'énergie nucléaire. Peu après son élection, le nouveau Premier ministre annonçait la mise sur pied d'un comité d'étude chargé de déterminer la forme qu'une telle enquête nationale pourrait prendre. Tout comme au Québec et pour les mêmes raisons, les travaux de ce comité se sont déroulés à huis clos et sans consultation des diverses organisations qui réclamaient depuis longtemps une telle enquête. En septembre 1979, suite aux appels répétés du RSN, le gouvernement fédéral a laissé filtrer les premières indications officielles concernant le cadre prévu pour cette enquête. Le ministre de l'Énergie, des mines et des ressources a donc dévoilé la décision de tenir une enquête parlementaire selon des modalités qui n'étaient pas encore définies et non pas une enquête judiciaire comme le réclamaient les groupes. Aucun moratoire sur les décisions ne devait accompagner cette enquête, et de plus Ottawa prévoyait tenir compte des travaux déjà accomplis par les diverses commissions d'enquêtes provinciales.

Autant dire que rien de fondamental n'allait changer. Cette réponse du gouvernement fédéral a été un facteur déterminant dans l'organisation d'une grande manifestation anti-nucléaire nationale tenue à Ottawa le 13 octobre 1979. À cette occasion, les groupes venus d'un peu partout à travers le Canada ainsi que trois membres du parlement canadien, ont dénoncé l'enquête parlementaire et réclamé la tenue d'un véritable débat national, tout en insistant longuement sur la nécessité de suspendre toutes les ventes de technologie nucléaire à l'étranger. L'insistance sur ce dernier point visait à faire pression sur le Parti conservateur, au sein duquel se trouvaient de nombreuses personnes influentes appuyant l'idée d'un moratoire sur l'exportation de technologie nucléaire canadienne. Elle visait également à frapper le coeur de l'industrie nucléaire, puisque la survie de cette dernière ne peut être assurée que dans la mesure où elle réussit une percée sur le marché international. 
L'évolution vers un genre d'enquête élargie, quoique jugée insuffisante par les écologistes, n'a pas abouti car les Libéraux de Pierre Trudeau revenaient au pouvoir lors des élections anticipées de février 1980. Trudeau refusa d'emblée la solution de l'enquête publique et le 2er mai 1980 il se prononça plutôt en faveur d'une étude gouvernementale interne. Ce modèle était privilégié par le lobby pronucléaire et en réalité il était destiné à trouver les moyens de sauver l'industrie nucléaire de la faillite vers laquelle elle se dirige inexorablement. La consultation gouvernement-sociétés de la Couronne entreprises nucléaires fut tenue essentiellement secrète. Peu d'informations ont filtré de ces rencontres jusqu'en juin 1981 alors qu'Ottawa annonçait officieusement dans un climat de fuites d'information, une politique d'aide financière aux provinces et aux pays importateurs de réacteurs CANDU afin de stimuler artificiellement une relance de l'industrie nucléaire. Bien qu'aucune politique officielle en ce sens n'ait encore été définie, ni encore moins adoptée, tout se passe comme si ce l'était. Une offensive du gouvernement fédéral et de l'industrie nucléaire est en cours dans un ultime effort pour pousser à l'achat de réacteurs, et ceci tant à l'intérieur du Canada qu'à l'étranger. Que l'on songe aux voyages d'affaires entrepris par le Premier ministre Trudeau accompagné de dirigeants de l'EACL, en Corée du Sud (septembre 1981), au Mexique (janvier 1982) et au Koweit (janvier 1982). De même, l'important colloque « Le nucléaire au Québec » parrainé par l'Association nucléaire canadienne et tenu à Trois-Rivières en mai 1982 a évidemment été organisé dans l'espoir de réhabiliter l'image ternie du nucléaire au Québec. Ce ne sont là que quelques indications récentes parmi les plus visibles, auxquelles il faut sans doute ajouter le relâchement accru des normes anti-proliférations exigées par le Canada de la part des acheteurs éventuels.

\section{Conclusion}

$\underline{\text { Retour à la table des matières }}$

Les actions entreprises par les groupes écologistes et anti-nucléaires pour la tenue de débats publics financés à même les fonds publics québécois et canadiens n'ont pas encore donne les résultats souhaités. Aucun débat véritable n'a eu lieu à ce jour sur les grands problèmes énergétiques qui nous assaillent. Toutefois, ces 
idées ne sont pas abandonnées pour autant. Elles continuent d'être une revendication majeure du mouvement écologiste et anti-nucléaire, une revendication d'autant plus importante que ces idées ont tendance à se répandre dans l'opinion publique à mesure que les préoccupations énergétiques prennent plus d'importance dans la vie quotidienne des gens. Les gouvernements peuvent retarder la tenue d'un débat public par toutes sortes de mesures dilatoires, mais ils ne pourront probablement pas refuser indéfiniment de le mettre sur pied, d'autant plus que l'appui populaire pour un tel débat ne cesse de croître.

Entre-temps, bien que beaucoup d'efforts aient été orientés pour obtenir ce débat plus large et mieux financé et organisé, l'action anti-nucléaire récente ne s'est pas limitée à la question du débat publie. Certains groupes écologistes et antinucléaires se sont aussi engagés activement dans la création de liens avec d'autres forces sociales, par exemple le mouvement ouvrier, le mouvement féministe, le courant indépendance et socialisme, en vue de favoriser l'émergence d'un grand front d'opposition rejoignant les syndicats, le mouvement des femmes et les divers groupes populaires.

En somme le problème du débat sur le mode de développement énergétique, et de la lutte contre le nucléaire a des potentialités politiques considérables. En effet, il pose des questions fondamentales sur le type d'avenir que nous projetons. Surtout, il permet la construction d'une large coalition de ceux qui veulent orienter le développement de la société dans le sens de la convivialité et de l'autogestion, en opposition à la domination des technocrates qui tentent d'organiser l'avenir au nom de la pseudo-nécessité économique et de la fausse rationalité technologique. 


\section{Mouvement écologiste, énergie et environnement.}

Essais d'écosociologie.

Première partie . Descriptions et analyses

\section{Chapitre 8 \\ "Le mouvement écologiste québécois des années 80.”}

Texte à paraître dans Changer de société, Serge Proulx et Pierre Vallières (sous la direction de), Québec-Amérique, Montréal, 1982.

\section{Par Jean-Guy Vaillancourt}

Il faudra quelques bonnes initiatives, dans le contexte de la crise naissante (à nouveau !) du système capitaliste en vue de faire surgir la coalition de l'avenir humain ; celle du Travail et de la Culture, des mouvements syndicaux et de la Femme, des luttes contre la pollution et la guerre nucléaire, des mouvements d'égalité et de libération nationale.

Stanley Bréhaut-Ryerson, " Mouvement ouvrier et question nationale », Conjoncture politique au Québec, no 1, hiver 1981-1982, p. 93.

$\underline{\text { Retour à la table des matières }}$

Il est toujours bien tentant, lorsqu'on a étudié un tant soit peu un phénomène social quelconque, de se lancer dans les prévisions et les prédictions à son sujet. Néanmoins, je n'ai pas l'intention de jouer ici au futurologue, de me lancer dans un exercice de prospective, ni encore moins de faire des prophéties concernant le mouvement écologiste québécois des années à venir. Mon but est plus modeste, et plus prosaïque à la fois. J'aimerais tout simplement décrire la situation actuelle de ce mouvement telle que je l'entrevois aujourd'hui, tout en indiquant quelques-unes des voies possibles dans lesquelles il semble en train de s'acheminer à court ter- 
me, compte tenu de la conjoncture économique et politique que nous traversons actuellement au Québec. Depuis une couple d'années, le mouvement écologiste québécois paraît prendre un nouveau virage qui risque de le rendre méconnaissable pour ceux qui seraient portés à l'examiner uniquement à la lumière de ce qu'ils ont entrevu ici et ailleurs au début des années $70{ }^{70}$. Je pense donc qu'il vaut la peine d'essayer de faire le point sur cette transformation en cours, en tentant de déceler la direction dans laquelle ce mouvement semble se réorienter présentement.

Le mouvement écologiste québécois est un ensemble disparate d'associations, de groupes et d'individus qui ont surtout été intéressés, depuis une douzaine d'années, par les problèmes de la pollution de l'air, de l'eau et des sols, par la question du gaspillage et de la pénurie des ressources naturelles (surtout énergétiques), par le danger de la contamination radioactive, et, plus récemment, par les problèmes des déchets toxiques et des pluies acides, en somme, par les questions fondamentales de la qualité de la vie et de plus en plus de la simple survie de l'humanité 71 .

Des gens se sont organisés pour se défendre et pour défendre le grand public contre les appareils technocratiques et bureaucratiques et contre les entreprises économiques qui sont les principaux responsables de la crise qui menace l'équilibre écologique de notre coin de la planète. Ce mouvement veut jeter les bases d'une vie sociale différente, où le respect de la nature et des autres, où la convivialité, la démocratie et la justice sociale, seront considérés comme plus importants que la programmation de faux besoins, le productivisme aveugle, la consommation à outrance, la course effrénée aux privilèges, et la domination et l'exploitation de la nature et des humains.

70 La crise de croissance que traversent actuellement la SVP et plusieurs autres groupes écologistes québécois témoigne de cette transformation.

71 Jean-Pierre Rogel, à la suite de Michel Bosquet, utilise l'expression « la nébuleuse écologique » pour décrire cette faune et cette flore bigarrée qu'est le mouvement écologiste québécois. Voir Jean-Pierre Rogel, Le Paradis de la pollution, Montréal, Éditions Québec-Science, 1981, p. 126-130. Le titre de cet excellent ouvrage vient sans doute de Ralph Nader, défenseur des consommateurs et leader écologiste qui a traité le Québec de « paradis de la pollution » lors d'une manifestation anti-pollution à Montréal à l'occasion du Jour de la terre en mai 1981. 
Il existe au Québec un mouvement écologiste original, très diversifié, et dont les origines lointaines remontent, comme c'est le cas pour les mouvements écologistes français et américain, aux préoccupations conservationnistes de certaines élites sociales et scientifiques de la première moitié du XXe siècle. Toutefois, c'est vers la fin des années 60 et au début des années 70, suite à une prise de conscience assez généralisée face à la crise de l'environnement (songeons aux premiers écrits du Club de Rome en 1968, au Jour de la terre en 1970, au Congrès de 1972 à Stockholm), que le mouvement écologiste québécois a réussi à démarrer. C'est en 1970 que l'on voit naître des groupes environnementalistes comme STOP (Society to Overcome Pollution), la SVP (Société pour vaincre la pollution), et le CQE (Conseil québécois de l'environnement), et des revues comme QuébecScience, le bulletin De toute urgence et la revue Québec-Écologie (qui est malheureusement morte après une seule parution). Les groupes Sauvons Montréal et Espaces verts naîtront l'année suivante et le Conseil consultatif de l'environnement sera créé par le gouvernement du Québec en 1972. L'opinion publique deviendra elle aussi de plus en plus consciente des menaces que l'incurie des pollueurs et des gouvernements fait peser sur l'écosphère. Enfin, un mouvement communautaire fortement imprégné d'écologisme s'est développé lui aussi au début des années 70 parmi les contre-culturels urbains et ruraux, par exemple à travers le vaste réseau de coopératives d'alimentation naturelle. Le Répertoire québécois des outils planétaires date de cette époque.

Avec la crise du pétrole de 1973, certains de ces groupes environnementalistes ont pris un second souffle et se sont radicalisés davantage. De nouveaux groupes écologistes, souvent plus populaires et plus activistes que les premiers, ont surgi, tels Le Mouvement pour l'agriculture biologique, le Monde à bicyclette, et les Amis de la terre de Québec. La question du nucléaire suscita la naissance de divers groupes locaux (à Lotbinière et à Trois-Rivières entre autres) et de vastes coalitions telles le Regroupement pour la surveillance du nucléaire (1975), et, en 1977, le Front commun anti-nucléaire, puis le Comité écologique anti-nucléaire qui se transforma au début de 1978 en l'Alliance Tournesol. J'ai déjà décrit et analysé assez longuement ailleurs l'origine, l'histoire et les caractéristiques de ces divers groupes écologistes et anti-nucléaires, ainsi que leurs tentatives de regrou- 
pement, qui ont toujours avorté, étant donné les différences idéologiques qui les séparaient ${ }^{72}$.

C'est finalement sur la base de fronts communs, tel le Front commun pour un débat public sur l'énergie, créé en 1979, sous l'impulsion d'un comité animé par Pierre Lacombe de la SVP, que l'unité d'action s'est forgée. C'est ce Front commun qui a organisé, en février 1981, un colloque et une semaine sur l'énergie qui a finalement réussi à obtenir des Libéraux puis du PQ une promesse électorale à l'effet que le gouvernement organiserait la tenue d'un débat public sur l'énergie ${ }^{73}$. Comme le débat public n'a pas été mis sur pied après les élections, le Front commun continue à exister, à informer, et à lutter pour obtenir un tel débat.

L'année 1981 a donc été, pour le mouvement écologiste, une année de travail et de discussions sur les questions d'énergie. L’Alliance Tournesol et le Regroupement pour la surveillance du nucléaire, par exemple, ont publié, dans le but de sensibiliser la population québécoise à ces questions, une série d'articles et de lettres dans Le Devoir sur diverses facettes de la question énergétique ${ }^{74}$. Cette collaboration entre l'Alliance Tournesol, qui est francophone, et le Regroupement pour la surveillance du nucléaire, qui est surtout composé d'anglophones, continuera sans doute en 1982 et au-delà aussi longtemps que le fédéral tentera d'embarquer le Québec dans la désastreuse aventure économique des centrales nucléai-

72 Jean-Guy Vaillancourt, «Évolution, diversité et spécificité des associations écologiques québécoises : de la contre-culture et du conservatisme à l'environnementalisme et l'écosocialisme », Sociologies et Sociétés, vol. 13, no 1, avril 1981, p. 81-98, et Jean-Guy Vaillancourt, « Les Québécois ont-ils besoin du nucléaire ? Le point de vue des groupes anti-nucléaires québécois », De toute urgence, vol. XII, no 2, août 1981, p. 231-243.

Ces deux articles signalent plusieurs autres sources utiles à consulter concernant les groupes écologistes et anti-nucléaires québécois.

73 Jean-Guy Vaillancourt, « Le débat public sur l'énergie aura-t-il lieu ? », Possibles, vol. 5, no 3-4, 1981, p. 277-288.

74 Voici entre autres les articles suivants, écrits en collaboration par les membres de ces deux groupes:

« La politique québécoise de conservation d'énergie », Le Devoir, 10 février 1981, p. 9-10.

«Pour un débat public sur l'énergie », Le Devoir, 5 octobre 1981, p. 14. Contre le nucléaire », Le Devoir, 23 novembre 1981, p. 7. 
res CANDU. Pour dépanner une industrie qui est en train de couler à pie, Ottawa tente par tous les moyens d'intéresser le Québec et certains pays du Tiers-Monde à opter pour des réacteurs CANDU. Si jamais cette tentative réussissait, cela ne pourrait que réactiver un mouvement anti-nucléaire québécois que le moratoire du gouvernement du Québec avait réussi à calmer 75 .

Une partie des efforts des militants anti-nucléaires est présentement drainée vers l'opposition aux armes nucléaires que brandissent depuis plus d'un an le président Reagan et ses acolytes, parce que ce danger du nucléaire militaire est particulièrement aigu et pressant à l'heure actuelle. Avec l'accroissement de l'opposition populaire au nucléaire civil et militaire que révèlent les sondages depuis quelques années, il n'y a pas de doute que le mouvement contre les centrales nucléaires pourra redémarrer en force aussitôt que le danger de nouvelles constructions de centrales se fera plus réel. Mais la lutte contre les armes nucléaires est aussi un combat écologique, car ce qui est en jeu ici, c'est aussi la survie de la planète et de ses habitants.

Des groupes comme l'Alliance Tournesol, Projet Ploughshares et le Regroupement pour la surveillance du nucléaire travaillent actuellement d'arrache-pied pour organiser une participation québécoise aux événements qui auront lieu durant la Deuxième session spéciale des Nations unies sur le désarmement (ou SSNUD-II) du 7 juin au 9 juillet 1982 à New York, session qui aura lieu à la demande des pays non alignés et de ceux du Tiers-Monde. Une manifestation internationale géante se tiendra le 12 juin entre le siège des Nations unies et Central Park à laquelle assisteront des écologistes et des pacifistes du monde entier. On y attend 1000 pacifistes japonais. Les principaux thèmes de cette marche seront : arrêtez de produire, commencez à réduire l'arsenal nucléaire et réorientez les res-

75 Un nouveau genre de groupe anti-nucléaire a quand même été formé au début de 1981, avec une bonne participation de Montréalais. L'Organisation des personnes affectées par la radiation tente de regrouper les personnes tombées malades après avoir été exposées aux radiations dans les mines et le transport d'uranium, dans les réacteurs nucléaires et dans le domaine médical. Le groupe s'est fixé comme première tâche de retrouver les personnes qui, comme Bjarnie Paulson d'Outremont, ont été impliquées dans les accidents, et dans les « nettoyages » subséquents, aux Laboratoires de Chalk River, en 1952 ou en 1958. 
sources pour satisfaire aux besoins de l'humanité. Le 13 juin, il y aura une convocation religieuse internationale sur la paix et le 14 juin, une action de désobéissance civile devant les ambassades des pays nucléaires. Une grande Marche pour la paix, avec la participation de moines bouddhistes japonais est partie de Montréal pour New York le 3 avril 1982 pour se rendre à ces manifestations.

Ainsi, le mouvement écologiste anti-nucléaire rajoute à son opposition aux dangers des centrales une préoccupation beaucoup plus fondamentale et plus englobante, et aussi plus ancienne, pour des questions posées par une nouvelle escalade de la course aux armements. Cette réorientation des écologistes vers le pacifisme est fort compréhensible, car une guerre nucléaire serait évidemment un désastre écologique sans pareil, un génocide et un écocide absolus.

À un autre niveau, incontestablement moins politique mais tout de même très important, le mouvement écologiste s'est réorienté depuis quelques années vers une attention particulière pour les problèmes d'alimentation et de santé. La médecine préventive, la nourriture saine et naturelle, l'exercice physique et le plein air sont maintenant des axes importants dans l'idéologie et les programmes de plusieurs écologistes. Certains essaient par exemple de concilier cette nouvelle préoccupation avec des perspectives d'écologie politique ${ }^{76}$. On trouve aujourd'hui cette ouverture vers l'écosocialisme dans des groupes qui tentent de plus en plus d'allier une sensibilisation à l'égard d'une saine nutrition avec un intérêt pour les luttes des militants écologistes. On voit surgir un peu partout au Québec des restaurants et des magasins où la nourriture naturelle, les fruits et les légumes, les graines et les fèves de toutes sortes, prennent la place des aliments supertransformés et des concoctions chimiques dangereuses pour la santé ou ayant peu de valeur nutritive. De plus en plus de gens s'intéressent au végétarisme ou au moins à la diminution de la viande et de certains aliments nocifs de leur régime alimentaire, et perdent leur confiance magique dans les médicaments et les produits pharmaceutiques. Les non-fumeurs gagnent du terrain et deviennent plus militants dans leur lutte contre ceux qui rendent l'air irrespirable dans les lieux publics. Cette préoccupation pour les questions de survie que l'on rencontre dans

76 Voir par exemple la chronique hebdomadaire sur la santé par le médecinécologiste Serge Mongeau dans le journal Dimanche-Matin. 
le domaine de la santé se retrouve à un niveau plus progressiste dans les luttes qui se dessinent pour la santé et la sécurité des travailleurs.

Dans les universités et les écoles, les perspectives écologistes sont de plus en plus considérées comme acquises par plusieurs étudiants et enseignants, et elles sont en train d'y imprégner à la fois le curriculum et la vie quotidienne. Une des caractéristiques du mouvement écologiste des années 1980, c'est précisément l'émergence d'une nouvelle génération de jeunes ayant une bonne formation scientifique qui militent dans des groupes et dans les médias pour protéger l'environnement bio-physique, par l'analyse des causes et la présentation des solutions possibles à la crise actuelle. À l'Université du Québec et dans plusieurs Cégeps, il existe maintenant des groupes de militants écologistes qui combattent la pollution et s'intéressent à l'aménagement des ressources. À l'Université de Montréal, au Département de biologie, depuis quelques années, un Comité d'action pour la protection de l'environnement organise une imposante semaine de l'environnement pour conscientiser les gens. Des groupes comme Environnement-Jeunesse et les Jeunes naturalistes sensibilisent les jeunes à l'écologie de façon très concrète avant même qu'ils n'arrivent au Cégep.

Parallèlement à l'importance accrue de l'écologie et de l'environnement dans les programmes scolaires et les maisons d'enseignement à tous les niveaux, on doit mentionner aussi l'ampleur qu'a prise la couverture des questions écologiques et environnementales dans les divers médias de masse. C'est cette année que sera lancée la série de films d'une demi-heure sur l'environnement préparés pour l'enseignement et pour la télévision par l'écologiste québécois de renommée internationale Pierre Dansereau ${ }^{77}$. De plus, chaque jour, des quotidiens comme Le Devoir, La Presse et Le Soleil, entre autres, ont des articles intéressants sur l'actualité environnementale, et les programmes de radio et de télévision présentent Continuellement des nouvelles et des dossiers sur l'énergie, la pollution, le recyclage, les groupes écologistes, et les politiques et programmes gouvernementaux en matière d'environnement ${ }^{78}$. D'une certaine façon, on peut §ans doute dire que le

77 Sur Dansereau, voir l'excellente présentation de Thérèse Dumesnil, Pierre Dansereau, l'écologiste aux pieds nus, Montréal, Nouvelle Optique, 1981.

78 À Montréal, des stations de radio communautaires comme CIBL et Radio centre-ville diffusent des émissions écologiques plusieurs fois par semaine. 
mouvement écologiste, dans ce qu'il avait de plus radical et de plus flamboyant, est présentement dans une étape de repli et d'incubation, mais il est clair aussi qu'il est en train d'étendre sa base sociale dans plusieurs milieux et de diffuser ses perspectives dans les villes et les villages, dans les campagnes et les quartiers. Le travail se fait davantage en profondeur, grâce à l'école et aux médias, grâce aussi à la connaissance des enjeux qui se diffuse dans la population ${ }^{79}$.

Je ne veux surtout pas essayer de donner l'impression que le mouvement écologiste continue de croître à un rythme accéléré comme ce fut le cas à ses débuts durant les années 70. Il y a effectivement un certain essoufflement depuis quelques années. La crise économique actuelle, les coupures budgétaires et le danger d'une troisième guerre mondiale, font que la préoccupation de la qualité de la vie au plan écologique a quelque peu cédé la place à la nécessité de tout simplement survivre, de s'assurer un emploi, de sauver les meubles et la maison. Les groupes écologistes sont peut-être moins contestataires maintenant qu'il y a quelques années, mais le travail d'éducation et de sensibilisation continue. L'écologie a toujours la cote d'amour dans les sondages, et la convergence du mouvement écologiste avec les autres mouvements sociaux progressistes fait en sorte que le mouvement de ressac a pu être amorti en partie. Le mouvement écologiste québécois n'est pas fortement structuré, mais sa faible organisation est compensée toutefois par la forte implication des gens qui en font partie. Et il possède une forte capacité de mobilisation qui peut se mettre en acte rapidement dans les moments de crise.

Deux des grands problèmes en 1980 et 1981, qui resteront primordiaux en 1982 et pour longtemps par la suite, sont le problème des déchets toxiques (qui n'a pas entendu parler du procédé Stablex ?) et celui, encore plus grave et dont on parle presque chaque jour dans les journaux, des fameuses pluies acides. Le livre de Jean-Pierre Rogel, cité plus haut, et l'action de la SVP depuis plus d'un an, sont en bonne partie centrés sur ces formes par excellence de la pollution des années 80. Les pluies acides, que certains ont qualifié de «la plus grave menace qu'ait jamais connue notre continent » sont en train de devenir l'enjeu d'une lutte écologique et politique importante en Amérique du Nord. Déjà, il est question de créer

79 On peut maintenant par exemple remplir tout un rayon de bibliothèque avec de bons ouvrages québécois qui traitent d'écologie et d'environnement. 
au Québec un grand centre d'information pour sensibiliser le public sur les conséquences économiques des pluies acides. Parce que les sources de cette pollution se trouvent surtout aux États-Unis et en Ontario, cette lutte écologique a de bonnes chances de prendre une certaine coloration nationaliste, voire même antiimpérialiste, ce qui montre les possibilités d'élargissement des luttes écologiques à d'autres luttes d'avant-garde, et de formation de vastes coalitions progressistes comme le suggère Ryerson dans la citation placée en exergue du présent essai.

L'écologisme des années 80 est beaucoup plus pratique et concret que celui du début des années 70. Par exemple, certains jeunes qui ont été sensibilisés aux problèmes de l'environnement et aux solutions possibles à ces problèmes tentent depuis quelques années de se créer des emplois écologiques en se lançant dans le recyclage et la récupération, qui sont devenus par le fait même des pôles importants d'une pratique renouvelée de l'écologisme. Ces récupérateurs continuent d'essayer de mettre sur pied des petites entreprises plus ou moins autogérées, même si le bas prix actuel du papier, du verre et des métaux rend présentement les activités de recyclage difficilement rentables et extrêmement dépendantes du bon vouloir des gouvernements et des entreprises acheteuses. Le ministère de l'Environnement du Québec vient d'octroyer 600000 \$ à 12 groupes qui s'occupent de récupération des déchets. Ceci correspond à environ 130 emplois, en plus de constituer une expérience intéressante de sensibilisation du public à l'environnement, étant donné que ces groupes font appel à la population pour le tri des déchets à la source. Les résultats de ces projets serviront par la suite à l'élaboration de normes obligatoires pour ce qui est de l'uniformisation des formes des contenants et de l'utilisation de matériaux récupérés. Ces 12 groupes constituent donc une avantgarde de praticiens écologistes en ce qui concerne la prévention environnementale.

Quand on parle de l'écologisme des années 80, il ne faudrait pas oublier non plus les militants du cyclisme, surtout ceux du Monde à bicyclette qui continuent leur théâtre de guérilla et leur lutte multiforme pour des modes de transport plus écologiques que l'auto et qui viennent de remporter une grande victoire avec l'acceptation des bicyclettes dans le métro. À mon avis, l'aile « vélorutionnaire » du mouvement écologiste va continuer de s'imposer comme l'une des branches les plus dynamiques de ce mouvement durant la présente décennie, d'autant plus que 
la puissante association Vélo-Québec est en train d'assumer une bonne partie des revendications et même des moyens d'action que le Monde à bicyclette a rendus si populaires depuis un certain nombre d'années. Quant au transport en commun, qui représente l'autre possibilité écologique de remplacement du transport par auto, le groupe Transport 2000 est en voie de s'imposer comme la branche du mouvement écologiste qui le défend avec le plus d'ardeur.

Le gouvernement du Québec prépare une nouvelle politique pour les transports collectifs, surtout dans la région de Montréal, et il est évident que la pression des écologistes y est pour quelque chose.

La question du logement, tant en milieu rural qu'en milieu urbain, est rapidement devenue elle aussi un domaine clé des luttes des écologistes. En milieu rural, c'est l'autoconstruction et l'architecture écologiste qui semblent intéresser davantage les gens, alors qu'en ville, c'est surtout le problème de la hausse des coûts du chauffage et du prix des loyers et des hypothèques qui les préoccupe. À ce chapitre, mentionnons aussi les victimes de la mousse isolante d'urée-formol (MIUF) qui contestent la pseudo-aide des gouvernements en bonne partie responsables de leurs déboires, qui s'organisent en conséquence, et qui sont en voie de devenir aussi une branche nouvelle et importante de la lutte écologique dans le Québec des années 80 . On n'est pas porté spontanément à considérer ces groupes de victimes de la MIUF comme faisant partie du mouvement écologiste, mais il est évident que leur contestation de l'incurie du gouvernement fédéral dans ce dossier de l'isolation des maisons les place en plein cœur de la lutte actuelle pour la protection de l'habitat et de l'environnement.

Un des développements intéressants pour le mouvement écologiste québécois des années 80, c'est la mise en marche récente des consultations auprès des citoyens et des groupes écologistes par le Bureau d'audiences publiques sur l'environnement (le BAPE) à l'occasion de la promotion des projets d'envergure qui risquent d'avoir des impacts importants sur l'environnement bio-physique et sur les communautés humaines, et qui sont assujettis à la Loi de la qualité de l'environnement. Le BAPE invite régulièrement la population et les groupes écologistes à participer à l'évolution de ces projets de développement. 
Le processus de consultation du BAPE a lieu en trois étapes. D'abord, il doit y avoir une étude d'impact par le promoteur, une analyse des alternatives au projet proposé, et une justification des besoins auxquels le projet vise à répondre. Ensuite, il y a mise en commun de l'information générale concernant le projet, pour que le public puisse en prendre connaissance. Enfin, il y a présentation de mémoires ou d'opinions orales, à l'occasion principalement d'une audience publique si celleci est demandée. En définitive, c'est le Conseil des ministres qui décide, mais le processus public de consultation constitue une rude épreuve pour les promoteurs d'un projet. Le seul fait que tout soit public du début à la fin permet à la population et aux groupes écologistes de surveiller et de vérifier ce qui se prépare. C'est un outil parmi d'autres, une tribune idéale pour exercer des pressions, et un moyen formel et légal, utile pour aller chercher de l'information permettant de mener la lutte là et ailleurs. Il y a quelques années, les militants écologistes auraient balayé d'un revers de la main un tel cheminement, lui préférant la voie de la contestation bruyante et des manifestations de rues. Aujourd'hui, et jusqu'à ce que la preuve soit faite que ces consultations sont inutiles, plusieurs groupes écologistes demanderont qu'il y ait des audiences publiques, et ils y présenteront des mémoires. C'est seulement quand le gouvernement fait des pseudo-consultations qui ne changent rien mais légitimisent plutôt ce que lui et les promoteurs veulent, comme ce fut le cas pour les Commissions parlementaires sur l'énergie de 1977 et de 1981, que les groupes écologistes refusent de participer. Ce n'est pas encore le cas pour les consultations du BAPE, qui n'est pas encore très puissant, mais qui fait déjà trembler bien des promoteurs, puisque ceux-ci font des pieds et des mains pour être exemptés du processus. C'est donc dire que pour le mouvement écologiste, en ce qui concerne le BAPE, la chance reste au coureur.

Les avis présentés par le Conseil consultatif de l'environnement au ministre de l'Environnement suite à des études et à des consultations auprès de la population constituent une autre manifestation de la force grandissante des préoccupations écologistes parmi la population québécoise. En février 1981, le Conseil consultatif de l'environnement a émis par exemple un avis sur la pertinence des Conseils régionaux de l'environnement que le ministère de l'Environnement du Québec tente de promouvoir et d'implanter dans les diverses régions de la province. Suite à une consultation d'environ 40 groupes québécois intéressés à la conservation et à la protection de l'environnement, le Conseil a émis l'avis que le gouvernement de- 
vrait cesser d'essayer de créer des regroupements régionaux dans certaines régions comme Montréal et Québec où les groupes existants n'en veulent pas parce qu'ils sont satisfaits de leurs regroupements ad hoc sur des problèmes précis. Le Conseil veut que le gouvernement mette plutôt l'accent sur l'aide technique et financière aux groupes environnementaux existants et opérant aux niveaux local, régional et provincial, y compris les conseils régionaux déjà créés qui sont représentatifs et voulus par les régions, comme c'est le cas au Saguenay-Lac Saint-JeanChibougamau et dans l'Est du Québec ${ }^{80}$. Le Conseil a proposé aussi au ministre de l'Environnement de tripler la part actuelle de son budget consacré aux groupes écologistes à but non lucratif, laquelle se situe actuellement à 200000 \$ par an, et d'établir des guides d'éligibilité et des normes d'attribution pour minimiser la discrétion dans l'octroi de l'aide financière. Si jamais ces recommandations sont acceptées, on peut prévoir un nouvel essor au plan des programmes d'action de ces groupes dans les années à venir. On peut croire que le ministère continuera cependant à favoriser les regroupements régionaux qui existent déjà en dehors des régions de Montréal et de Québec, et que les groupes écologistes locaux et nationaux continueront de défendre leur autonomie tout en acceptant, et même en recherchant, le plus d'aide possible de Québec (et même d'Ottawa) pour leurs programmes d'action, de rencontres, et de regroupement ad hoc sur des luttes sectorielles ou régionales.

Les rapports entre le mouvement écologiste et les gouvernements ne sont pas toujours des plus harmonieux, et le fait qu'il y a une concurrence entre le fédéral et Québec dans le domaine de l'environnement rend certains groupes vulnérables aux efforts accrus de cooptation du fédéral, qui donne des fonds et les retire à sa guise. Ottawa essaie depuis quelque temps de créer un secrétariat national des groupes environnementaux à Ottawa en faisant miroiter l'appât de quelques milliers de dollars pour des rencontres «nationales » et secondairement pour des rencontres régionales comme celle qui a eu lieu près de Shawinigan à la fin de novembre 1981 pour les groupes québécois. Le but du fédéral semble être de favoriser la centralisation de l'organisation et du contrôle des groupes écologistes, et de

80 Conseil consultatif de l'environnement, Avis sur la pertinence des Conseils régionaux de l'environnement, rapport préparé pour le ministre de l'Environnement, Gouvernement du Québec, Québec, février 1981. 
développer les contacts entre des ministères fédéraux et des groupes écologistes. Certains des groupes québécois qui ont décidé de participer à ces rencontres l'ont fait surtout par curiosité, et aussi dans le but d'établir les contacts et échanger l'information avec les autres groupes québécois, bien plus que pour faire le jeu du gouvernement fédéral. Certains le font aussi pour signifier au gouvernement du Québec qu'il devrait faire davantage au plan de l'aide financière et de l'amélioration de ses politiques en matière d'environnement.

Quant aux relations des groupes avec le gouvernement du Québec et ses divers ministères qui s'occupent d'environnement, d'énergie, d'agriculture, etc., on peut dire qu'elles sont plutôt tendues, surtout depuis le refus de la plupart des groupes écologistes de participer au Mois de l'environnement en 1980 et à la Commission parlementaire sur les plans d'investissements d'Hydro-Québec à l'hiver 1981.

Le ministère de l'Environnement du Québec a actuellement comme priorité la dépollution et l'assainissement des cours d'eaux et des lacs, la question des pluies acides, et l'éducation du publie. Il y a aussi un effort de fait pour régionaliser le ministère mais une tentative s'amorce pour dispenser les requérants de permis de l'obligation d'obtenir des autorisations administratives préalables avant d'exécuter des projets mineurs potentiellement dangereux pour l'environnement. Ce démantèlement d'une partie de l'appareil préventif du ministère se ferait dans le but de faire sortir les fonctionnaires de leurs bureaux pour qu'ils puissent faire de l'inspection de projets durant et après leur exécution, ce qu'ils n'ont pas le temps de faire présentement, et au besoin de révoquer les permis, ce qu'ils n'ont pas le pouvoir de faire actuellement. Les groupes écologistes n'ont pas encore réagi à ce projet ambigu de réforme légale, mais on peut prévoir qu'ils le feront à mesure qu'ils se rendront compte de son caractère rétrograde en matière de protection de l'environnement. En effet, il n'est pas nécessaire de supprimer la prévention pour pouvoir faire du travail correctif.

Le ministère de l'Environnement du Québec n'est pas très chaud à l'égard des groupes écologistes les plus politisés et les plus revendicateurs des régions de Montréal et de Québec. L'aide financière qu'ils reçoivent est insignifiante, en comparaison avec celle que reçoivent par exemple les Conseils régionaux de l'en- 
vironnement du Saguenay-Lac Saint-Jean-Chibougamau et de l'Est du Québec, les groupes de récupérateurs, et les Comités de protection des lacs. Il y a un manque de confiance réciproque entre les groupes écologistes les plus politisés et les fonctionnaires, et même si le gouvernement et le mouvement écologiste ont parfois des buts communs (la régionalisation et l'éducation du public en matière d'environnement, la lutte contre les pluies acides, etc.), il y a peu de communication et de collaboration entre eux, et à mon avis, il y a peu de chances que cette situation puisse s'améliorer considérablement dans un avenir rapproché.

Ce n'est pas du côté du rapport avec les gouvernements et leurs fonctionnaires que le mouvement écologiste québécois des années 80 fera sa percée la plus importante. Ce qui me semble bien plus significatif à l'heure actuelle, c'est le rapprochement grandissant entre le mouvement écologiste québécois et divers autres mouvements sociaux, comme le mouvement des femmes, le mouvement ouvrier et syndical, et le mouvement socialiste naissant.

Depuis quelque temps, on a vu apparaître à l'intérieur de divers groupes écologistes une tendance écoféministe, qui est encore peu organisée mais qui s'affirme de plus en plus. Cette conjonction entre le mouvement écologiste et le mouvement des femmes est fort compréhensible, quand on considère le haut degré de participation des femmes dans le mouvement écologiste et la similitude de plusieurs des revendications de ces deux mouvements sociaux.

Tous les deux veulent une société plus humaine et sont préoccupés par les atteintes faites à la vie par les technocrates, qui sont bien souvent aussi des phallocrates.

Un sondage SORECOM récent a indiqué que parmi les jeunes, les deux mouvements sociaux considérés comme les plus importants pour les années à venir sont le mouvement écologiste et le mouvement féministe. Des revues comme $L e$ Temps fou et La Vie en rose expriment assez bien l'alliance qui est en train de s'opérer entre ces deux mouvements. Le mouvement écologiste est l'un des seuls mouvements québécois, à l'exception bien sûr du mouvement des femmes, où les femmes jouent actuellement un rôle de premier plan, égal à toutes fins pratiques à celui des hommes, malgré les relents de chauvinisme et de sexisme qu'on y ren- 
contre, et qui s'exprime par le fait que les hommes sont portés à prendre la vedette tandis que les femmes font plus souvent qu'à leur tour le travail plus obscur et plus ingrat.

Il y a aussi un rapprochement qui est en voie de se forger entre le mouvement québécois de solidarité internationale et le mouvement écologiste. Des organismes comme le Centre international de solidarité internationale, Développement et Paix, SUCO, Atelier Tiers-Monde, et Carrefour international par exemple manifestent de fortes préoccupations écologistes dans leur travail d'aide au TiersMonde. Il existe même une coalition canadienne de groupes intéressés par le rapport entre environnement, énergie et Tiers-Monde, qui s'appelle le Projet énergie pour le développement, auquel participent des groupes québécois. Quant aux groupes écologistes, ils sont de plus en plus sensibilisés aux problèmes de la faim dans le monde, de la surpopulation, du pillage des ressources des pays pauvres, de l'échange inégal. Tout récemment, la SVP, qui fait partie du Projet énergie pour le Tiers-Monde, a organisé un colloque sur les énergies douces dans le Tiers-Monde après avoir envoyé une délégation à la conférence de l'ONU sur les énergies nouvelles à Nairobi, au Kenya en août 1981. De plus, un intérêt grandissant se dessine au Québec pour ce qu'on appelle l'écodéveloppement, c'est-à-dire le développement écologique par les technologies appropriées et la lutte contre l'exploitation éhontée des ressources du Tiers-Monde par les pays riches.

On rencontre aussi une préoccupation semblable de rapprochement entre le mouvement écologiste d'une part, et le mouvement autogestionnaire d'autre part. La revue Possibles, par exemple, ainsi que la revue Our Generation, publient des articles favorables à l'écologisme, alors que plusieurs des écologistes de leur côté se disent aussi autogestionnaires et socialistes libertaires, partisans de l'État minimum. Certains en viennent même à définir l'écologisme comme étant la technologie douce plus la recherche de l'autogestion.

Le rapprochement entre contre-culturels et écologistes est trop bien connu pour qu'il soit nécessaire d'y insister de nouveau ici. Par ailleurs, on voit aussi se dessiner depuis quelque temps une convergence avec les chrétiens engagés de plus en plus actifs dans les luttes écologiques anti-nucléaires. Il y a même eu récemment la publication d'un document-choc sur l'environnement par les évêques 
du Québec ${ }^{81}$, qui se sont signalés dans le passé récent par leur appui à la lutte très importante pour la protection de nos forêts et surtout de ceux qui y travaillent.

Une autre caractéristique frappante du mouvement écologiste québécois des années 80, c'est son implantation solide dans les diverses régions du Québec, et ses rapports de collaboration grandissante avec les mouvements régionalistes qui se développent sur le territoire québécois. Montréal, à cause de sa population, reste sans contredit le centre le plus important pour ce qui est du mouvement écologiste, mais il existe maintenant une multitude de groupes actifs en province. Seulement ces derniers mois, il y a eu le Colloque des écologistes à Sainte-Luce sur Mer près de Rimouski, la rencontre des groupes écologistes du Québec au camp Minogami près de Shawinigan, les mardis de l'écologie à Alma, les mercredis de l'environnement à Sherbrooke, et j'en passe. Il existe même un village écologique et quasi-autosuffisant à Saint-Lin, et dans tous les coins du Québec, on peut trouver un nombre considérable de praticiens de l'écologisme qui vivent sur des fermes dont ils essaient de tirer leur subsistance.

Quant aux rapports du mouvement écologiste avec le mouvement syndical et ouvrier, c'est à travers le Sommet populaire Il de Montréal, organisé conjointement par les groupes populaires et par les syndicats de la région de Montréal, que la jonction est en train de s'opérer. Ce Sommet populaire II de Montréal a eu lieu les 2-3-4 avril 1982. Trois des 10 comités ou fronts de lutte ont traité de façon plus immédiate des questions d'environnement: le comité Transport, le comité Logement et aménagement urbain, et surtout le comité Écologie, énergie et plein emploi. Ce dernier comité a suggéré qu'une industrie québécoise à technologie appropriée, faisant appel aux énergies alternatives, pourrait permettre aux Québécois d'accéder à une meilleure qualité de vie dans une société moins polluante qui assurerait de l'emploi à plus de monde. Pour atteindre ce but, ce comité a proposé une plate-forme de revendications centrée sur les quatre grandes lignes suivantes : la santé et la sécurité au travail, J'amélioration de la qualité de la vie, les conversions industrielles et agricoles, et enfin, l'information et la sensibilisation. Il y a des revendications qui s'adressent au gouvernement, et d'autres qui sont faîtes aux

81 «Les Chrétiens et l'environnement», Le Comité des affaires sociales de l'Assemblée des évêques du Québec, Secrétariat de l'AEQ, Montréal, 1981. 
employeurs ${ }^{82}$. L'atelier exige une politique de santé et de sécurité qui éliminerait à la source les risques d'intoxication et d'accidents, la transformation des industries polluantes et des industries militaires, le développement d'un programme global de santé préventive, le droit individuel et collectif de cesser tout travail jugé dangereux pour soi ou pour la collectivité (sans pénalité), le droit d'inspection et d'enquête syndicale et le droit au médecin de son choix. Au plan de l'amélioration de la qualité de la vie, l'atelier demande un revenu minimum garanti pour tous, une politique de plein emploi, l'arrêt des coupures d'assurance-chômage, le droit à un environnement sain, la construction et la rénovation de logements qui ne gaspillent pas l'énergie, la réduction du temps de travail et le contrôle du temps supplémentaire, et un mois de vacances annuelles payées. Quant aux conversions industrielles et agricoles, l'atelier demande une politique énergétique, industrielle et agricole basée sur les besoins réels, dans une perspective d'autonomie et non d'exportation, le plein emploi et la création de nouveaux emplois dans les domaines du recyclage, des énergies alternatives, de la conservation, du transport en commun, de l'information et de l'organisation communautaire de l'habitation et de la santé, la mise sur pied d'un organisme anti-fermetures, responsable aussi des conversions industrielles et agricoles, et l'institution de cours sur la santé-sécurité intégrés au temps de travail. Enfin au plan de l'information et de la sensibilisation, l'atelier exige des cours d'écologie dès le primaire, et l'accès du public aux dossiers gouvernementaux.

La question de l'emploi est un terrain de rencontre idéal pour le mouvement ouvrier et le mouvement écologiste, car il apparaît de plus en plus évident que se préoccuper des questions de dépollution et d'économie d'énergies et d'énergies douces créera plus d'emplois et des emplois plus sécuritaires et plus intéressants que le développement des énergies d'origine fossile ou nucléaire.

La décision prise durant le Sommet populaire II de créer une organisation conjointe permanente réunissant des militants des syndicats et des groupes populaires augure bien pour la continuation de la collaboration entre le mouvement

82 Stuart Stilitz, «Le monde syndical : le RSN voudrait avoir votre avis », Transitions, vol. 5, no 1, hiver 1981-1982, p. 15. Voir aussi Jean-Guy Vaillancourt, "Sommet populaire II de Montréal », De toute urgence, vol. XII, no 3, décembre 1981, p. 404-405. 
écologiste, qui était présent en force au Sommet populaire, et le mouvement syndical.

En somme, du côté du mouvement écologiste, depuis la publication du manifeste écologique du Regroupement écologique québécois en novembre 1978, qui a identifié le système de domination et d'exploitation capitaliste comme étant la principale cause du pillage de notre environnement, et qui proposait aux écologistes de collaborer plus activement avec le mouvement syndical et les autres mouvements progressistes, la prise de conscience de la nécessité de faire converger le mouvement écologiste et le mouvement ouvrier n'a pas cessé de s'accentuer à travers plusieurs projets communs.

Dans le mouvement écologiste québécois actuel, il n'est pas question pour l'instant de créer un parti écologiste qui mènerait des luttes électorales partisanes, mais plutôt de continuer le travail d'éducation et de sensibilisation, de créer des alliances et des coalitions, et de jouer un rôle dans certains des groupes politiques de gauche qui existent actuellement au Québec. Il y a cependant un phénomène important qui est en train de se produire au plan électoral aux Etats-Unis parmi les groupes conservationnistes et environnementalistes puissants comme le Sierra Club, et qui pourrait avoir un impact au Québec dans les années à venir. Ces groupes américains ont décidé de commencer à appuyer certains candidats indépendants ou des partis existants, qui sont favorables aux revendications écologistes. Il se peut donc, comme ce fut le cas dans le comté d'Outremont où le Parti libéral présentait le pro-nucléaire notoire Pierre Fortier, que les groupes écologistes fassent un effort considérable pour combattre les candidats les plus antiécologiques dans les élections futures.

En général, les groupes et les partis de la gauche la plus orthodoxe et dogmatique tels les marxistes-léninistes, les trotskystes et les staliniens, ont de la difficulté à concilier leur marxisme avec les nouvelles exigences anti-productivistes mises de l'avant par le mouvement écologiste. Mais même là, on sent que les luttes de ce mouvement sont perçues de plus en plus comme étant importantes et même progressistes, alors qu'il y a quelques années, tout le mouvement écologiste était considéré par eux comme quelque chose de réactionnaire. 
Dans les écrits des deux groupes socialistes québécois qui attirent beaucoup d'intérêt depuis un an, le Regroupement pour le socialisme et le Mouvement socialiste, la question écologique prend une place très importante. Le dernier chapitre d'un livre publié par quatre des leaders du Regroupement pour le socialisme se termine par une section sur le Front écologique qui se clôt sur les interrogations suivantes :

Mais en fait, les revendications écologiques ne posent-elles pas un problème gigantesque au capitalisme, particulièrement dans la conjoncture de crise structurelle actuelle du système (modernisation, dépenses, recyclage, etc.) ? Jusqu'à quel point la problématique écologique ne constitue-t-elle pas ces années-ci un front privilégié pour affaiblir le capitalisme ? D'autre part, en jonction avec des organisations inscrites dans une lutte sociale plus globale (syndicale ou politique), le mouvement écologique ne pourrait-il pas apporter aux militants syndicaux et politiques une vision nouvelle plus large de la société à construire ? Une société dans laquelle la conservation de la vie, la qualité de la vie ne seraient pas des expressions creuses, une société critique face au productivisme, à l'idéologie de la croissance 83 .

Quant au Mouvement socialiste, quoi qu'en disent certains, lui aussi accorde une place importante à la lutte écologiste, à côté des quatre axes (socialisme, démocratie, indépendance, et égalité des sexes) qui caractérisent son option de base.

Dans un article au Devoir, l'écologiste bien connu Michel Jurdant reproche au Manifeste du Mouvement pour un Québec socialiste, indépendant, démocratique et pour l'égalité entre les hommes et les femmes, de n'être point suffisamment écologiste. Même si les militants écologistes qui ont participé à la rédaction de ce manifeste n'ont pas insisté pour ajouter l'axe écologique comme cinquième dimension dans le nom du mouvement et dans le titre du manifeste, les préoccupa-

83 Marielle Désy, Marc Ferland, Benoît Lévesque et Yves Vaillancourt, La Conjoncture au Québec au début des années 80 : les enjeux pour le mouvement ouvrier et populaire, Libraire socialiste de l'Est du Québec, Rimouski, 1980, p. 85. 
tions écologiques furent très présentes dans les discussions de l'ex-Comité des Cent, et jusque dans la version finale du Manifeste.

Je voudrais ici relever les principales références écologistes qu'on rencontre dans le Manifeste, pour montrer comment la critique de Michel Jurdant me semble injuste et incomplète.

Dès le deuxième paragraphe du Manifeste, dans le diagnostic sur la crise mondiale actuelle, il est fait mention de la course aux armements, de l'exploitation, de la misère et de la faim dans le Tiers-Monde, et au droit des peuples à disposer de leurs ressources naturelles. Une phrase lapidaire y résume la situation présente : « Le gaspillage et la détérioration de l'environnement s'accroissent 84 ».

Un peu plus loin, il est question aussi de la santé et de la sécurité des travailleurs qui sont affectés par le travail en continu et le travail de nuit, par un manque de période de repos et un manque d'espace, par « de la machinerie bruyante, du froid, de la chaleur trop élevée, des produits dangereux [...] Ces détériorations constantes des conditions de travail se répercutent de façon plus globale sur la qualité de vie en général, de telle sorte que la très grande majorité des Québécois perdent leur vie à la gagner 85 ».

Quelques pages plus loin, dans l'analyse des causes de la crise, il est fait mention des compagnies qui « encouragent la surconsommation et le gaspillage. Elles sont les principaux responsables de la pollution de l'air et des eaux, de l'épuisement des sols et des ressources 86 ». Cette partie du manifeste mentionne aussi le « scandaleux pillage de nos richesses naturelles qu'on transporte aux États-Unis pour les transformer en produits finis, lesquels on viendra par la suite nous revendre au gros prix 87 »

84 Le Comité des Cent, Pour un Québec socialiste, Manifeste du Mouvement pour un Québec socialiste, indépendant, démocratique et pour l'égalité des hommes et des femmes, Montréal, Mouvement socialiste, 1981, p. 5. [Texte disponible dans Les Classiques des sciences sociales. JMT.]

85 Ibid., p. 9-10.

86 Ibid., p. 17.

87 Ibid., p. 23. 
Après avoir posé les questions : "Qui décide des besoins de la population, de la répartition des ressources [...], des politiques énergétiques [...] ? Quel contrôle avons-nous sur nos vies, notre environnement, nos quartiers, nos villages et nos villes 88 ? », le Manifeste en vient à citer en exemple de résistance, de combativité et de solidarité des classes ouvrière et populaire, « [...] les luttes et revendications du mouvement écologique » qui contribuent à l'élaboration "d'un projet d'une société radicalement nouvelle et affirment de plus en plus la nécessité d'une transformation en profondeur de la société québécoise dans le sens de leurs intérêts et de leurs espoirs collectifs 89 ».

L'accent qui est mis sur la socialisation plutôt que sur l'étatisation, sur les débats publics et les choix démocratiques plutôt que sur la planification autoritaire et centralisée, sur le contrôle à la base et les besoins réels plutôt que sur l'organisation hiérarchique et les rapports de domination, indique très bien aussi que les préoccupations des signataires du Manifeste sont assez proches de celles des écologistes politiques et des écosocialistes. Le passage suivant par exemple, représente un genre de critique qu'on rencontre constamment dans les écrits de ces écologistes :

Ce n'est pas une minorité de capitalistes se cachant derrière de pseudo-lois du marché, ni une minorité de technocrates et de ministres se couvrant du voile mystérieux de leurs expertises mais l'ensemble du peuple travailleur qui doit décider à travers des mécanismes démocratiques qu'il faudra élaborer collectivement [...] des choix dans le domaine de l'énergie, des orientations du développement, bref de l'ensemble de ces décisions qui, plus que toutes les autres, déterminent les conditions de vie et de travail 90 .

Accuser le Comité des Cent d'avoir sombré dans l'économisme, le productivisme et le marxisme orthodoxe parce qu'il utilise l'expression « classe ouvrière et

88 Ibid., p. 25.

89 Ihid., p. 30-31.

$90 \quad$ Ibid., p. 36-37. 
classes populaires » et qu'il parle de socialisation des moyens de production relève de la plus haute fantaisie. D'ailleurs, les groupes marxistes orthodoxes lui reprochent précisément le contraire, c'est-à-dire d'abandonner le rôle de leadership de la classe ouvrière et du parti et les concepts de lutte de classe et de dictature du prolétariat.

Comme on l'a vu, ce manifeste représente un effort réel pour tenir compte des revendications des écologistes et pour les conjuguer avec les demandes des autres mouvements progressistes qui luttent actuellement au Québec pour un changement de société. Il est donc pour le moins exagéré de prétendre que le mouvement socialiste n'est pas ouvert aux luttes environnementales. Ce manifeste vient peutêtre 25 ans en retard et il pourra sans doute être amélioré au plan écologique dans les années à venir, mais on peut au moins dire à son sujet : mieux vaut tard que jamais !

Au lieu de constamment chercher à opposer entre eux les mouvements sociaux progressistes, on devrait plutôt, il me semble, chercher à les unir, comme le font actuellement certain(e)s écologistes qui militent avec le mouvement syndical au sommet populaire et à la CSN. En effet, ceux qui veulent créer un parti écologiste, un parti féministe, un parti indépendantiste, des partis régionalistes, un parti anarchiste, ou même un parti socialiste qui ne tiendrait pas compte des autres luttes progressistes, ne font que diviser les forces face à des adversaires passablement unis.

Une véritable convergence entre le mouvement ouvrier et la gauche d'une part, et le mouvement écologique et les autres nouveaux mouvements sociaux d'autre part, ne pourrait qu'avoir des effets bénéfiques pour eux tous, non seulement parce que «l'union fait la force », mais aussi parce qu'une telle coalition progressiste serait avantageuse au plan du raffinement de l'idéologie, et de sa diffusion sur une base plus large, au plan de l'accroissement du radicalisme et de l'action directe, et au plan du rajeunissement des participants et de la revitalisation des tactiques et des stratégies de combat. Le mouvement écologiste, comme la plupart des autres mouvements sociaux d'ailleurs, a un apport très important à apporter à la lutte pour la transformation de la société dans une direction plus humaine, car il ne se meut pas uniquement dans la sphère de la production économique, dans celle du 
combat politique ou dans celle de la culture, mais il oeuvre à tous ces niveaux tout en résistant en plus contre ce qui attaque les bases organiques de la vie humaine. Stanley Ryerson, dans l'interview qu'il a donnée à la revue Conjoncture et dont j'ai cité un extrait au tout début de cet article, avait donc raison de l'inclure dans la future coalition de l'avenir humain. 
Mouvement écologiste, énergie et environnement.

Essais d'écosociologie.

\section{Deuxième partie}

Interventions

et prises de position

$\underline{\text { Retour à la table des matières }}$ 
Mouvement écologiste, énergie et environnement.

Essais d'écosociologie.

Deuxième partie . Interventions et prises de position

\section{Chapitre 1}

\section{"Localisation de lignes de transport d'énergie."}

Texte publié dans le Rapport du Comité d'experts sur l'environnement : analyse méthodologique, Direction Environnement, Hydro-Québec, Projet Canton Mousseau-Chénier, Montréal, janvier 1976 ; et reproduit dans le Mémoire pour le rejet du projet de ligne électrique de $735 \mathrm{Kw}$ dans la région de Saint-Jean-de-Matha, mémoire du Comité des citoyens de Saint-Jean-de-Matha, Saint-Jean-de-Matha, 14 février 1978, p. 122-135.

\section{par Jean-Guy Vaillancourt}

Le présent rapport porte surtout sur le projet Canton Mousseau-Chénier, même si certaines références seront faites à des projets déjà plus avancés (Projet 1696 : Chénier-Châteauguay) ou moins avancés (Carignan). En tant que sociologue de l'environnement (J'enseigne la sociologie des organisations et l'écologie humaine à l'Université de Montréal), je voudrais insister surtout sur les implications sociales et écologiques des choix des tracés tels qu'effectués par HydroQuébec et ses consultants. Plus particulièrement, je voudrais insister sur la nécessité d'améliorer le processus de consultation et de décision utilisé par HydroQuébec dans la sélection finale de ses tracés. 
Je n'ai pas la prétention que j'apporterai une contribution bien originale à cette question, étant donné que ce dossier n'a été porté à mon attention que depuis quelques mois, et que je n'ai malheureusement pas pu assister à la réunion synthèse du 13 novembre 1975. Mais à la suite des demandes des Consultants du Groupe Lavalin, j'ai accepté de présenter quand même quelques remarques et suggestions sur ce qui m'apparaît être le problème le plus important à considérer dans toute cette question fort épineuse du transport de l'énergie de la Baie James vers les grands centres de consommation d'électricité. Même si je crois que dans le cas de la ligne Canton Mousseau-Chénier, il n'y a pas grand chose à reprocher au choix du tracé lui-même, je pense qu'il y a quand même des critiques graves à faire au processus utilisé par Hydro-Québec pour arriver au choix final de ses tracés.

Je dois d'abord souligner que j'ai l'impression que le comité d'experts dont je fais partie (et qui a été formé en septembre dernier) a été créé dans le but d'apporter un léger surcroît de légitimation à un processus de décision déjà fort avancé, et non pour apporter une contribution substantielle à la sélection finale du tracé Canton Mousseau-Chénier. C'est pourquoi mes observations critiques visent les projets qui viennent après Canton Mousseau-Chénier bien plus que les diverses possibilités de tracé pour cette ligne. Le comité d'experts est arrivé trop tard dans l'élaboration de ce projet précis pour y apporter autre chose qu'une bénédiction ou un non-placet à une décision déjà faite.

En d'autres mots nous n'avons pas été consultés mais plutôt informés. Pour être en mesure d'apporter une contribution sérieuse, un comité d'experts doit avoir en main plus d'éléments concrets que nous n'en avions et participer dès les premières étapes au processus d'analyse et de sélection des corridors et tracés. De plus, je ne suis pas certain que la contribution d'experts et de consultants en environnement soit aussi importante que celle des gens à la base qui seront touchés par ces lignes, et que celles des divers spécialistes d'Hydro-Québec qui ont pour tâche de faire les recherches et l'analyse concrète (à condition bien sûr qu'ils le fassent selon des critères professionnels sans être indûment influencés ou contredits ensuite par les pressions politiques partisanes qui peuvent jouer aux niveaux où sont prises les décisions ultimes). 
Pour ce qui est de la ligne Canton Mousseau-Chénier, je dois avouer que j'ai été frappé de voir le sérieux avec lequel Hydro-Québec et ses consultants ont effectué leur travail d'inventaire et d'analyse. Je ne pense pas que le même effort a été fourni pour la ligne Chénier-Châteauguay, surtout en ce qui a trait à la consultation des gens sur place, tant ceux d'Hydro que ceux qui représentent la population au plan local. Il me semble qu'il n'est pas trop tard pour corriger le tracé dans le cas de cette première ligne, ce qui pourrait avoir pour effet de rassurer la population affectée par les autres lignes qui viendront ensuite.

Si Hydro-Québec s'obstine à passer outre aux préoccupations légitimes que soulève la controverse autour du projet Chénier-Châteauguay, les gens auront l'impression que le même type d'erreur a pu se glisser dans les projets subséquents. Il ne semble pas que le tracé Canton Mousseau-Chénier soulèvera beaucoup d'objections, car il y a eu un peu plus de consultation auprès des intéressés et le tracé choisi pose un minimum de problèmes au plan technique, au plan social et au plan écologique.

Dans le projet Canton Mousseau la question des fermes est bien moins importante que celle de la villégiature, mais on a heureusement trouvé un endroit de passage où le dommage sera minimum. Contrairement à Chénier-Châteauguay, la région n'est pas déjà traversée par plusieurs corridors de transport et les questions de la protection des forêts et des ravages de chevreuils sont les seules qui pourraient causer un peu d'alarme dans le publie. En somme, même si la consultation du public a été limitée et la contribution des experts en environnement faite uniquement pro forma (pour parer à l'accusation qu'on n'a pas tenu compte du Conseil consultatif de l'environnement), je crois que ça ira passablement bien, parce que le tracé ne semble pas poser tellement de problèmes. Il est loin d'être sûr que ce sera le cas pour les prochaines lignes où, à mon avis, les retombées du projet Chénier-Châteauguay risquent d'exacerber les problèmes.

D'où la nécessité de ne pas se leurrer et de croire qu'une consultation bidon et une campagne d'information ex post facto seront suffisantes dans la relation avec la population et les organismes intéressés. Il faut qu'il y ait, dès le début, un input réel produit ouvertement par la population et les organisations intéressées, en plus d'une consultation auprès des ministères et des représentants élus au plan local. Il 
me semble que le ministère de l'Agriculture, le ministère de l'Environnement, des organismes comme le Conseil consultatif de l'environnement, l'UPA, etc., devraient avoir leur mot à dire eux aussi et devraient pouvoir exiger qu'Hydro tienne compte davantage des aspects écologiques et sociaux quand ceux-ci sembleront avoir été trop négligés.

En plus d'accepter d'ouvrir le dossier et de rectifier le tracé s'il y a lieu dans le cas de Chénier-Châteauguay, je crois qu'Hydro-Québec doit améliorer sensiblement le processus de consultation et de décisions pour les projets qui s'annoncent après Canton Mousseau-Chénier. Les projets Carignan et Canton de l'Est surtout, et même la ligne Lac Saint-Jean s'annoncent comme étant encore plus propices à la controverse que le projet Chénier-Châteauguay. En effet, il ne suffit pas de faire appel aux ingénieurs et experts d'Hydro-Québec, aux maisons privées de consultants, au personnel d'Hydro-Québec qui vit et travaille dans la région affectée et de faire évaluer le tout vers la fin par un comité d'experts et quelques représentants du gouvernement et du publie. Ce qui est le plus important, à mon avis, c'est qu'il y ait aussi, dès le début, une large consultation de la population, par des sondages et surtout par des rencontres et par des échanges d'information avec les organismes publics, les corps intermédiaires, les groupes populaires, les représentants de municipalités et autres personnes intéressées, spécialement avec celles qui risquent d'être affectées d'une façon ou d'une autre par ces lignes à haut voltage. Dans le cas des trois lignes qui viendront après Canton Mousseau-Chénier, surtout la ligne Carignan qui doit passer à travers de très bonnes terres arables, il faudra avant tout laisser la parole aux groupes comme l'UPA qui représentent les intérêts des cultivateurs. Si un tel effort avait été fait dans le cas de ChénierChâteauguay, le tracé aurait tout probablement été bien meilleur, il y aurait eu moins d'opposition, et à longue échéance, on se serait rendu compte que le point de vue écologique et le point de vue socio-économique peuvent souvent se rencontrer au lieu de s'opposer.

Pour ce qui est de Canton Mousseau-Chénier, il y a eu un sondage plutôt insatisfaisant de fait au début, mais cela ne suffit pas comme processus de consultation d'autant plus que les personnes interviewées ne savaient même pas qu'on les questionnait pour avoir leur opinion sur les lignes de transport d'énergie. Il ne faudrait pas que l'on néglige de faire des sondages pour les lignes à venir. C'est 
peut-être moins important pour la ligne Carignan, où la population touchée et le type de sol traversé sont assez homogènes, mais dans le cas de la ligne des Cantons de l'Est, où les élevages sont nombreux (fermiers/villégiateurs, anglophones/francophones), je pense qu'une bonne enquête par sondage et interviews s'impose.

Les études d'impact social et écologique ont été beaucoup plus approfondies, mais la participation du public et de ses représentants aux processus de consultation et de décision a été presque aussi déficiente que dans le cas de ChénierChâteauguay. Hydro-Québec devrait donc à l'avenir éviter les écueils qui ont fait que le tracé Chénier-Châteauguay devrait peut-être être modifié et que les autres projets devront peut-être être retardés, et ne pas s'imaginer que le processus légèrement amélioré mais encore déficient utilisé pour Canton Mousseau-Chénier sera suffisant à l'avenir.

Le choix d'un tracé de ligne n'est pas uniquement un problème technique pouvant être résolu par des spécialistes. C'est une question de valeurs, d'intérêts, de perspective qui doit être résolue dans le concret par ceux qui tracent, en collaboration avec ceux chez qui l'on trace. La nécessaire pondération doit tenir compte de l'apport de ceux qui sont touchés bien plus ou tout autant que de l'apport des ingénieurs et des écologistes.

Les gens acceptent facilement le fait qu'il est nécessaire de créer des corridors pour transporter l'électricité du Grand Nord vers les grandes agglomérations urbaines, et que les lignes doivent nécessairement passer quelque part sur le territoire. Ils acceptent aussi le fait que le choix de tracé devra tenir compte de multiples valeurs et intérêts parfois contradictoires et que par conséquent les décisions ne seront pas faciles à prendre. Par ailleurs, ils acceptent difficilement qu'HydroQuébec soit juge et partie et que dans la mesure où elle est partie, elle ne soit pas contrebalancée par d'autres instances représentant des intérêts, des valeurs et des points de vue différents, plus généraux, et plus près des préoccupations des gens à la base, au plan local. Je pense que la solution à laquelle on pourra arriver après une campagne de consultation et d'information faite dès le début des inventaires, et après de sérieux échanges avec les parties intéressées, sera moins arbitraire que 
si l'on ne consulte et informe qu'après que la décision a été prise avec les seules lumières des gens d'Hydro et de leurs consultants.

Fondamentalement donc, ma recommandation est que ce type de décision est trop important pour être laissé aux politiciens, aux bureaucrates, aux technocrates et aux experts. Même si l'acte de "décision-taking » doit rester dans les mains de la Commission, je pense que le processus de « décision-making » doit être surtout confié aux ingénieurs du Service chargé des études de tracés des lignes travaillant avec le Service de l'environnement, des consultants et des experts, et surtout en collaboration avec les organismes publics et privés et la population locale, et ce dès le début du processus d'inventaire et d'analyse des corridors et des tracés. La création d'un organisme consultatif formé de gens d'Hydro, de consultants, d'experts, et de représentants de divers organismes serait peut-être une façon de rendre le cheminement plus ouvert et moins susceptible d'être faussé par les intérêts particuliers ou des points de vue limités, à condition bien sûr qu'un tel comité mixte vienne complémenter et non supplanter une large consultation de divers organismes et représentants du publie. Un tel comité aurait pour fonction de veiller à ce qu'on tienne vraiment compte, dans la décision finale, des solutions qui ont émergé dans le processus de consultation comme étant les plus dignes d'être retenues, afin que les idées et désirs des gens pratiques à la base ne soient pas négligés par ceux qui sont mandatés pour prendre la décision finale. En effet, la multiplicité des alternatives qui émergent dans un vaste processus de consultation et parmi les experts risque de n'être pas plus satisfaisante qu'une série d'options limitées présentées par des consultants et des spécialistes, à moins qu'un comité avec un certain degré d'indépendance vis-à-vis d'Hydro-Québec ne puisse veiller à ce que l'on tienne compte de ce qui a été apporté par les spécialistes et par les personnes et groupes concernés. 
Mouvement écologiste, énergie et environnement.

Essais d'écosociologie.

Deuxième partie . Interventions et prises de position

\title{
Chapitre 2 \\ "Le manifeste écologique et la croissance du mouvement au Québec.”
}

Texte publié dans la revue Our Generation, vol. 13, no 4, automne 1979, p. 5-7.

\author{
par Jean-Guy Vaillancourt
}

Retour à la table des matières

Le manifeste écologique que les rédacteurs de la revue Our Generation ont traduit, reproduit et commenté dans ce numéro, a été préparé par la section montréalaise du Regroupement écologique québécois, une coalition plutôt souple de groupes écologiques progressistes et d'individus conscientisés aux problèmes de l'environnement. Ce regroupement fut créé en juin 1978, durant une importante rencontre de trois jours au Lac Saint-Joseph près de Québec. Ce mouvement décentralisé et régionalisé a été fondé à partir d'une coalition de nombreux groupes écologiques québécois qui avait été formée en un front commun anti-nucléaire moins d'un an auparavant. Sa création constitue un signe de la revitalisation des mouvements écologique et anti-nucléaire au Québec.

Durant les années 70, plusieurs groupes ont été actifs sur la scène écologique au Québec. Un effort fut tenté en mai 1976 pour créer une fédération de ces groupes, mais cela n'a pas réussi, en partie parce que le RQPE (Regroupement québé- 
cois pour l'environnement) avait une base trop large en termes de l'orientation politique de ses groupes constituants (quelques-uns par exemple étaient des groupes apolitiques de fervents de la nature), et en partie à cause du manque de leadership et de l'absence d'intérêt de la part des groupes membres. Les dirigeants du RQPE avaient discuté de la possibilité de rédiger un manifeste écologique, mais l'idée est demeurée à l'état de projet, chaque groupe étant alors trop pris par ses propres préoccupations.

C'est la question nucléaire qui a été finalement le déclencheur du nouveau regroupement. Les groupes écologiques les plus actifs, tels la Société pour vaincre la pollution, le Mouvement pour l'agriculture biologique, le Monde à bicyclette, STOP (Society to Overcome Pollution), Sauvons Montréal et quelques autres groupes ayant une base régionale (à Lotbinière, Trois-Rivières, Grondines et Alma) ont décidé durant l'été de 1977 de créer une coalition anti-nucléaire pour s'opposer aux centrales de Gentilly I, II et III et à l'usine d'eau lourde de La Prade. Le 20 septembre 1977, le Front commun anti-nucléaire fut lancé simultanément à Montréal, à Alma et à Trois-Rivières. Il y eut ensuite une manifestation très réussie avec plus de 800 participants, le 22 octobre à Gentilly. Le 19 novembre, le Front commun anti-nucléaire s'est réuni de nouveau à Montréal pour faire deux choses : d'abord pour former une organisation anti-nucléaire semblable à celles existant aux États-Unis et en Europe (ceci fut réalisé les 11 et 12 février 1978, quand l'Alliance Tournesol est née), et ensuite pour créer un nouveau regroupement des associations et des militants écologiques du Québec (la rencontre du Lac Saint-Joseph fut la réalisation de cette seconde décision). Quatre comités furent mis sur pied pour actualiser ces décisions : un comité anti-nucléaire, un comité sur les structures, un comité du manifeste, et un comité d'organisation de la rencontre de juin.

Une lettre fut envoyée par le comité organisateur de la rencontre de juin à 180 groupes écologiques et à des centaines d'individus actifs dans le mouvement écologique, pour les inviter à la fin de semaine du Lac Saint-Joseph. Le paragraphe qui suit, qui est tiré de cette lettre d'invitation, est un bon indicateur de l'esprit qui animait les organisateurs de cette rencontre : 
Ce colloque sera les assises d'un grand Mouvement Écologique Kébécois (à baptiser), décentralisé mais unifié dont le but sera de créer une force socio-politique qui révolutionnera globalement et radicale ment la société productiviste, hiérarchique et destructrice dans laquelle nous vivons, en contestant les choix et les valeurs sous-jacentes de son orientation actuelle et en proposant les alternatives d'une société écologique en harmonie avec l'écosphère de la planète Terre. Les chapitres locaux de ce mouvement pourront canaliser l'activité des aspirants soit vers les groupes écologiques déjà existants soit vers le développement d'un chapitre local ou régional qui favorisera la polyvalence des préoccupations écologiques selon les priorités locales et/ou nationales.

Un second envoi postal comprenait des documents sur la structure organisationnelle proposée pour le nouveau regroupement (on suggérait une forme très décentralisée et très égalitaire), ainsi qu'une première ébauche de manifeste préparée, entre autres, par Michel Jurdant, l'écologiste bien connu de Québec. Le manifeste était présenté sous la forme d'un questionnaire, pour que chacun puisse y ajouter ses commentaires et ses suggestions sur ce qu'il faudrait y ajouter ou $\mathrm{Y}$ retrancher.

Les organisateurs avaient décidé que les discussions sur le manifeste seraient la principale activité durant la rencontre de trois jours, mais les animateurs d'ateliers, qui tinrent une réunion préparatoire à leur arrivée le vendredi après-midi décidèrent que la question des structures était plus pressante. C'est donc cette dernière question qui accapara presque tout le temps durant ces trois jours. Les participants insistèrent pour qu'un nouveau regroupement soit créé, sur une base régionale, avec un minimum de coordination nationale (à l'échelle du Québec), et un maximum d'activités sur une base régionale. Quant à l'ébauche de manifeste, il fut décidé qu'elle était trop générale et pas assez concrète, et qu'elle devrait servir comme texte de discussion que les divers groupes régionaux pourraient utiliser pour préparer leurs propres manifestes. On décida en plus de continuer le travail sur le manifeste, avec plus de consultation sur une base régionale. Un manifeste global pour le Regroupement pourrait donc venir plus tard, mais seulement après que les groupes régionaux auraient eu la chance de produire leur propre texte. Une seule section régionale à part Montréal, à savoir la région des Laurentides, a rédigé un tel manifeste, même si le groupe de Québec, qui s'est transformé en une 
section des Amis de la Terre, a produit des documents de très haut calibre dans ses publications.

Il y eut deux rencontres inter-régionales du Regroupement après le rassemblement au Lac Saint-Joseph, l'une à Victoriaville le 29 juin et l'autre à Upton du 22 au 24 septembre 1978. Cette dernière rencontre, qui fut annoncée comme un grand « Pawa » écologique, insista sur l'idée que le nouveau Regroupement interrégional devrait être un réseau contre-culturel de communication de personnes rejetant la société de consommation, plutôt qu'un front politique de groupes écologiques activistes.

Par ailleurs, la section montréalaise du Regroupement qui s'est réunie plusieurs fois durant l'été de 1978, créa un comité du manifeste qui commença rapidement à préparer un document inspiré en partie par la version antérieure rédigée par Jurdant et par d'autres pour la rencontre de juin au Lac Saint-Joseph. Après plusieurs rencontres du comité du manifeste et de l'assemblée générale de la section montréalaise du Regroupement, à la fin de l'été et au début de l'automne de 1978, le manifeste fut adopté et commença à circuler en novembre de cette même année. Il fut diffusé largement au Québec comme base idéologique de la section montréalaise du Regroupement.

Depuis la publication de ce manifeste, il y a eu plusieurs développements intéressants dans le Regroupement, qui s'est défini lui-même au début de 1979 comme « un groupe décentralisé qui croit à l'autonomie locale, et à la coopération des forces populaires travaillant pour une écosociété participative et égalitaire, et qui présente une alternative à la droite et à la gauche centralisatrice et doctrinaire »(Convocation pour la réunion du 20 janvier 1979). À cette réunion, à laquelle 14 groupes étaient représentés, six comités furent créés ou réactivés :

1. le comité de la radio, qui a pris en charge une émission d'une heure par jour, cinq jours par semaine à Radio Centre-Ville. Divers groupes écologiques montréalais prennent chacun une heure, chaque semaine ou deux fois par mois, pour présenter leurs idées sur les développements en cours sur la scène écologique. Ceci est une des activités les plus réussies du Regroupement ; 
2. le comité du journal, qui fut lent à démarrer, mais qui a réussi à sortir un excellent premier numéro ;

3. le comité du 1er mai, qui a jeté les bases de la participation des écologistes aux fêtes du 1er mai à Montréal ;

4. le comité énergie, qui étudie les politiques énergétiques du gouvernement du Québec, et qui prépare des réponses à ces politiques. Ce comité a réussi à lancer une vaste campagne pour obtenir un débat public sur l'énergie. Ce débat aurait pour but de pousser le gouvernement à créer une commission populaire sur l'énergie, et d'obtenir un moratoire véritable et complet sur l'utilisation de l'énergie nucléaire au Québec ;

5. le comité sur les alternatives, qui a pris comme mandat la question de la promotion du recyclage, du compostage, des énergies de substitution ;

6. finalement, le comité du manifeste, qui ayant rempli son mandat initial, décida de s'attaquer au problème de la santé et de la sécurité des travailleurs. Le 18 septembre 1979, ce comité présenta un mémoire à Québec à la Commission parlementaire sur la loi 17 sur la santé et la sécurité des travailleurs.

Quelques-unes de ces activités représentent une nouvelle orientation pour le mouvement écologique québécois. La participation aux fêtes du 1er mai et la préoccupation du problème de la santé et de la sécurité des travailleurs constituent des efforts pour relier le mouvement ouvrier et le mouvement écologique. Il y a une prise de conscience croissante dans les divers groupes écologiques du fait que les travailleurs, les écologistes, les groupes communautaires, les femmes et les nationalistes progressistes ont souvent des intérêts en commun et des adversaires communs. De même, les militants dans d'autres mouvements sociaux sont de plus en plus conscients de l'importance de la question écologique et de ses implications radicales. 
Pour Alain Touraine, que Michel Bosquet (alias André Gorz) a récemment qualifié de "prophète des nouveaux mouvements sociaux » dans un très intéressant article dans Le Nouvel Observateur du 8 janvier 1979, le mouvement écologique anti-nucléaire est probablement le plus important des nouveaux mouvements sociaux. Sa lutte contre l'énergie nucléaire est une des premières manifestations de l'opposition aux appareils technocratiques privés et publics du pouvoir qui dominent de plus en plus la société contemporaine ${ }^{91}$. S'il a raison, alors les individus et les groupes qui ont produit le manifeste écologique ne sont pas un groupe nostalgique de fervents de la nature désireux de faire reculer les roues de l'histoire, mais plutôt les précurseurs d'un nouveau mode de développement et d'une nouvelle lutte sociale qui rejettent la course effrénée vers le progrès technique, la production centralisée, et la grosseur pour la grosseur, afin de construire une société plus démocratique et plus fraternelle dans laquelle les gens vivront davantage en harmonie entre eux et avec la nature.

91 Alain Touraine, Mort d'une gauche, Paris, Galilée, 1979, p. 207. 
Mouvement écologiste, énergie et environnement.

Essais d'écosociologie.

Deuxième partie . Interventions et prises de position

\section{Chapitre 3}

\section{“Manifeste écologique du Regroupement écologique québécois.”}

Texte terminé le 22 novembre 1978, et distribué sous forme de pamphlet.

par des militants de la région de Montréal

Introduction

\section{$\underline{\text { Retour à la table des matières }}$}

Notre monde part à la dérive : la pollution, les guerres, l'inflation, le chômage sont ses nouvelles coordonnées. La machine est emballée et on se demande si on va pouvoir la maîtriser. Il semble qu'il faille trouver autre chose que les remède classiques. Devant la complexité et l'envergure des problèmes, l'immobilisme du système en place, l'action arbitraire et destructive de ceux qui sont aux postes de commande, que pouvons-nous faire ? Que pourraient apporter les écologistes et l'écologie?

Elle est révolue l'époque où l'écologiste limitait son action à protéger les plantes et les animaux et où il se sentait presque obligé de s'opposer à toute forme de développement. La principale cause de la crise écologique nous paraît être la logique du profit et de l'accumulation du capital, amenant la surproduction de biens inutiles, ou souvent inadaptés à nos besoins réels. 
L'humanité évolue déjà de façon catastrophique. On ne peut plus se permettre de jouer la survie d'un grand nombre sur une série de paris dont certains sont stupides, comme celui de la prétendue sécurité de la filière électro-nucléaire. Il nous apparaît nécessaire de réorienter l'évolution de la société vers une intégration des activités humaines au milieu naturel, supposant un nouveau mode de vie, une restructuration sociale et une réorientation de la technologie vers nos besoins réels, assurant ainsi un équilibre durable des cycles vitaux de la nature dont l'espèce humaine ne peut se dissocier. Une écosociété implique la fin d'un système de domination-exploitation imposé à l'humanité et à la nature. C'est une option de survie autant qu'un réel progrès qualitatif visant à résoudre les problèmes qui se posent à une société devant se réadapter aux conditions nouvelles qu'elle a ellemême créées.

Face à la crise écologique, des milliers de Québécois et de Québécoises, réunis dans de nombreuses organisations, ont formé le « Regroupement écologique québécois ». Un réseau de militants, regroupés régionalement à travers le Québec, veut élaborer des choix et des stratégies de lutte. Ensemble, nous tenterons d'établir cette nouvelle société, en harmonie avec nous-mêmes et avec notre environnement.

Ce manifeste parle au nom du Regroupement. Mais les militants écologistes sont convaincus qu'il parle aussi au nom des millions d'autres Québécoises et Québécois qui subissent tous les jours les conséquences des problèmes actuels. Ce manifeste, qui sonne l'alarme sur un aspect de notre vie trop ignoré dans le passé, veut réussir à rallier des milliers voire des millions de Québécois dans la lutte pour une écosociété faite par nous, à notre mesure et en fonction de nos besoins.

Partout dans le monde naissent de tels mouvements. Ces luttes se coordonneront un jour car c'est à l'échelle de la planète que la société écologique doit s'établir. 


\section{Qui sont les écologistes ?}

$\underline{\text { Retour à la table des matières }}$

À la fin des années soixante, au Québec, on n'entend guère parler des écologistes. Bien sûr, on reçoit depuis quelques années déjà des échos des luttes amor-

cées aux États-Unis, au Japon et en Europe, mais il n'y a pas encore de groupes écologistes bien constitués dans notre province. La prise de conscience de nos problèmes écologiques est cependant rapide et, dès 1970, sont créées des associations importantes comme la SVP (Société pour vaincre la pollution), le STOP (Society to Overcome Pollution) et le CEQ (Conseil québécois de l'environnement). Ces associations s'attaquent à la tâche d'informer la population sur les problèmes écologiques et à celle d'impliquer l'État dans la solution de ces problèmes. C'est ainsi, pour ne citer qu'un cas, que la SVP s'est occupée depuis 1970 de questions aussi variées que la fluoruration des eaux, le traitement des eaux usées, l'aménagement du Saint-Laurent (projet « Un fleuve, un parc »), la protection des écosystèmes de la Baie James, la pollution de l'air à Montréal, les épandages d'insecticides, la pollution des eaux par le mercure et les hydrocarbures, les questions d'énergie et, surtout, la diffusion d'informations par tous les moyens possibles.

Dans les usines, les travailleurs prennent de plus en plus conscience des effets néfastes de leur environnement immédiat ; les syndicats revendiquent des conditions de travail adéquates. Des citoyens mettent sur pied des comités pour défendre leurs logements. On s'organise contre la vie chère en créant des comptoirs alimentaires. Les mouvements de femmes prennent de l'ampleur, revendiquant l'égalité.

La conscience écologique créée par ces associations a eu rapidement un impact positif. Partout, au niveau de toutes les régions du Québec, ont surgi de petites associations, des rassemblements de citoyens, permanents ou temporaires, qui se sont levés pour défendre leurs droits et la qualité de leur environnement. Il n'est plus rare de voir au Québec des citoyens jeter un oeil critique sur des projets comme l'établissement d'une ligne de transport d'énergie, l'implantation d'une 
usine dans leur région ou sur la pollution d'un cours d'eau et faire des revendications et des propositions pour protéger leur environnement et leurs conditions de vie. Sans la vigilance de ces écologistes, notre milieu serait encore en bien plus mauvais état qu'il ne l'est aujourd'hui.

Les écologistes se regroupent aussi autour d'un ensemble de projets qui annoncent et illustrent certaines dimensions d'une société écologique. Plusieurs centaines d'artisans de techniques agricoles saines sont membres du mouvement pour l'agriculture biologique ; tous s'appliquent à leur façon à répandre des techniques qui sont la seule alternative au maquillage alimentaire actuel. Le Québécois rural a connu jusqu'à tout récemment un mode de vie qui a respecté la plupart des lois écologiques. Une grande partie de cette tradition est entretenue et on se plaît à la redécouvrir. Les écologistes ajoutent à ces connaissances du passé des connaissances nouvelles dans tous les domaines et en particulier dans le domaine de l'agriculture. Un cadre scientifique s'est articulé dans les manières de cultiver la terre, on appelle cette agriculture, biologique, car elle respecte la vie du sol au lieu de lui nuire.

Parallèlement à ce mouvement, s'est développé un réseau de coopératives d'alimentation dans toutes les régions du Québec, groupes animés par une volonté d'alimentation végétarienne et d'approvisionnement local.

Dans plusieurs villes, on retrouve un nombre grandissant de membres du Monde à bicyclette qui favorisent l'adoption d'autres modes de transport que l'automobile et qui démontrent dans la vie de tous les jours l'efficacité de la bicyclette.

D'autres groupes, comme l'Alliance Tournesol, s'attachent davantage à trouver des alternatives en matière d'énergie. Partout enfin, des citoyens posent des gestes qui développent de plus en plus la conscience écologique au Québec. Le chemin de cette conscientisation est encore long à parcourir mais les écologistes du Québec ont une cause solide à défendre qui ne peut pas rester sans réponse. Des premiers travailleurs qui se sont soulevés contre leurs milieux nocifs de travail aux populations entières de quartiers urbains et de villages qui ont réclamé un envi- 
ronnement sain, il y a toujours le même appel à l'abandon de la logique productiviste aveugle de ses conséquences, pour créer une écosociété.

\section{Les problèmes et leur cause}

$\underline{\text { Retour à la table des matières }}$

Nos conditions de vie se détériorent. Pendant qu'on nous pousse, en entretenant notre insécurité, à une hyperconsommation maladive qui devrait nous apporter le bonheur, beaucoup, même parmi nous, ne peuvent se procurer une nourriture de qualité, un logement décent, des loisirs qui leur conviennent. La technologie qui était apparue comme un outil de libération sert maintenant à concentrer le pouvoir et la richesse dans les mains de quelques uns.

Ici au Québec, les rivières servent d'égouts à ciel ouvert. On y déverse les eaux usées des villes, riches en bactéries et en virus, les déchets des animaux d'élevage (la pollution de l'eau due à l'élevage des pores au Québec équivaut à celle d'une population de 35 millions de personnes ; celle due aux pâtes et papiers à une population de 18 millions d'humains) et on y jette aussi les eaux industrielles, chargées de produits toxiques et même cancérigènes. La rivière l'Assomption reçoit chaque année des millions de gallons d'insecticides répandus sur les cultures de tabac dans la région de Lanaudière ; et son eau sert àla consommation. La technologie a permis l'apparition dans notre milieu de poisons nouveaux, qui ne sont pas détruits dans l'environnement. Ces produits non biodégradables, tels de nombreux insecticides, avec le mercure (responsable de la maladie de Minamata qui affecte maintenant les Inuits à Lebel sur Quévillon), le plomb, les virus même, passent souvent de l'eau aux êtres qui y vivent, se concentrent dans les fruits de mer ou les poissons qu'on nous vend au marché. Ils affectent le plus souvent notre cerveau, leurs effets s'additionnent ou même se renforcent. De la même façon, les plantes qui servent de nourriture au bétail et à nous-mêmes concentrent des poisons répandus sur le sol. La valeur nutritive de nos aliments diminue aussi car pour accroître les gains, on sélectionne sans se soucier de leur qualité alimentaire, des variétés à croissance rapide, faciles à manipuler et plaisantes à l'oeil du consommateur. On met en marché de plus en plus d'aliments transformés, altérés. 
On y ajoute des colorants, aux effets souvent inconnus. On publicise la consommation de viande en sachant qu'elle est déjà trop forte. Les prix montent et ce ne sont pas les fermiers qui s'enrichissent. Au contraire, ils doivent souvent abandonner leur terre.

L'air que nous respirons, comme l'eau et les aliments que nous consommons, contient des poisons qui s'accumulent parfois dans notre organisme et le détériorent. L'automobile, une importante cause de mortalité, est aussi un facteur de stress ainsi que la principale source de monoxyde de carbone (CO) dans les villes. Ce gaz, qu'on ne peut déceler à son odeur, passe à travers les murs des maisons, nous asphyxie, nous affaiblit et cause même la confusion de nos idées. Le monoxyde de carbone empêche l'élimination par notre organisme du cholestérol en excès et cause des maladies cardiaques. Dans l'air des villes, la combustion de l'huile à chauffage, les industries et les automobiles libèrent aussi le dioxyde de soufre (S02) qui attaque nos poumons : jusqu'à 800 tonnes par jour sont rejetées dans l'air de Montréal (140 tonnes en moyenne par jour par les raffineries). À Shawinigan, la pollution est telle que les malformations congénitales sont augmentées. Dans la région de l'amiante, la poussière affecte les poumons non seulement des mineurs mais aussi ceux des autres citadins. À Arvida, les fluorures et l'anhydride sulfureux rejetés par l'Alcan ont le même effet.

La logique du système capitaliste pousse à la consommation effrénée et au gaspillage. Au lieu de stimuler l'utilisation de déchets comme source de fertilisants organiques, le pouvoir capitaliste encourage l'utilisation de fertilisants synthétiques. Ceux-ci, délavés par la pluie, iront engraisser les plantes des lacs et des rivières, qui se transformeront en mares, pendant que nos déchets de table seront brûlés et nos eaux d'égouts pollueront encore davantage au lieu de retourner à la terre comme nourriture pour les plantes utiles. Deux millions de tonnes de déchets par an sont à toutes fins utiles perdues sur l'île de Montréal. À Limoilou, l'incinérateur de la communauté urbaine de Québec ajoute sa fumée polluante à celle des usines environnantes. Seulement sept pour cent des eaux usées sont traitées avant d'être déversées dans le Saint-Laurent. On pense aux égouts de Montréal mais il faut aussi penser à toutes les villes jetant leurs eaux usées dans les affluents du fleuve, Sherbrooke par exemple dans le Saint-François. Dans l'Outaouais seul, l'industrie des pâtes et papiers déverse par jour 190 tonnes de solides en suspen- 
sion. Cette industrie rejette chaque jour 632 millions de gallons d'eau usée dans le Saint-Laurent ou ses tributaires. L'eau soi-disant potable est contaminée. C'est le cas de façon scandaleuse sur la Côte Nord. Mais partout les virus, les produits non biodégradables et les sels minéraux s'infiltrent jusque dans les puits artésiens qui risquent de devenir sous peu contaminés pour des dizaines d'années. Quant à l'eau puisée dans les rivières, elle est traitée contre les microbes mais pas contre les poisons qu'elle contient.

De grandes parties de nos forêts sont coupées « à blanc », ne se renouvelant qu'après des décennies, dans les meilleurs des cas, ou tout simplement jamais, dans les régions où le gel empêche toute repousse. Les coupes «à blanc » favorisent aussi la prolifération de la tordeuse des bourgeons de l'épinette.

Les équilibres biologiques sont brisés. De nouveaux équilibres s'établiront. Mais ils ne seront pas nécessairement à notre avantage. Et plus des espèces animales ou végétales disparaîtront, plus nous avancerons vers une rupture générale de l'équilibre dans lequel nous avons pour le moment une place.

Déjà certains sont affectés par la situation actuelle. On se rappelle les cas de thyphoïde de Saint-Grabriel de Brandon. Certains meurent d'asthme, des suites de bronchite chronique, d'arthériosclérose, de cancer. Beaucoup meurent aussi de maladies industrielles et il ne faut pas oublier qu'une grande partie de l'industrie contemporaine est une industrie de guerre. On connaît les méfaits de l'amiantose, on connaît les cas d'empoisonnement au monoxyde de carbone dans les industries (par exemple à la Great Lakes Carbon de Berthierville), les cyrrhoses, les empoisonnements par le plomb (à la Carter White Lead de Montréal), par le sélénium, le benzène et les accidents de travail augmentés par le stress, on connaît aussi l'augmentation graduelle des cancers, surtout chez les travailleurs d'usines. Les cancers sont, dans la plupart des cas, nettement attribuables à des facteurs de l'environnement. Les radiations atomiques, en plus de produire des mutations et des maladies héréditaires, sont une cause de cancers. N'oublions pas qu'en refusant l'utilisation de sources recyclables d'énergie, la logique du système capitaliste nous entraîne vers l'acceptation de l'énergie nucléaire, paravent à la fabrication de bombes et outil de pouvoir centralisateur. 
La pollution est un phénomène généralisé dans notre société. Pour le moment, ses effets catastrophiques n'apparaissent que localement. Mais la rupture d'un équilibre est une rupture brusque. La logique du système capitaliste est que les plus faibles mourront pour les plus forts. De la même façon que les pays où on souffre le plus de la faim sont des exportateurs de nourriture, les femmes laissées sans soutien suffisant de l'État sont incitées à faire des enfants, les chômeurs sont tenus responsables du chômage, les malades de leur maladie et les consommateurs de la pollution : on nous dit de ne pas jeter nos papiers dans la rue et on construit des autoroutes devant nos balcons.

La technologie aveugle est le fait de la course au profit ; elle est au service du pouvoir capitaliste. Un appareil policier de plus en plus puissant la protège. Nous dépendons de plus en plus d'elle et elle nous enlève tout pouvoir. Il nous faut la reprendre en mains, collectivement et la faire servir nos besoins.

\section{Une société écologique}

Retour à la table des matières

Une société écologique serait radicalement différente de celle que nous connaissons aujourd'hui. Les différences pourraient Se manifester de multiples façons et à divers niveaux. Ainsi, l'avènement de la société écologique coïncidera avec des modifications profondes dans les domaines de la technologie, de l'économie et de la politique. Ces changements impliqueront l'apparition d'un nouveau mode de vie, d'une valorisation authentique des notions de vie humaine et de qualité de cette vie humaine. La société écologique sera une société construite par tous et pour tous également. Elle ne pourra atteindre son plein développement qu'à l'échelle planétaire.

Une société écologique, telle que nous l'édifierons, reconnaîtra d'abord le fait que l'humanité fait partie de l'écosystème et qu'à ce titre l'espèce humaine doit s'intégrer harmonieusement aux mécanismes régulateurs de son environnement naturel. De plus, les membres de la société écologique insisteront tout autant sur l'importance de leur intégration en tant que participants de plein droit à un envi- 
ronnement culturel où chacun doit pouvoir trouver les moyens concrets de réaliser pleinement son développement tant physique, qu'intellectuel et affectif. Cette conscience de l'équilibre vital entre nous et notre milieu devra se traduire dans la pratique par des choix lucides et collectifs sur les moyens à prendre pour produire, distribuer et préserver les biens et les services que nous jugerons essentiels ou désirables pour notre épanouissement d'êtres humains.

Sur le plan technologique, la société écologique se souciera de la salubrité des processus de production employés ; elle évaluera les implications de l'utilisation alternative ou complémentaire de ressources naturelles et verra à les recycler afin d'assurer leur permanence. Cela signifie que dans la société écologique, il ne saurait être admis ou toléré que la production de biens destinés à la consommation humaine, ou que les techniques employées pour réaliser cette production, ou que la consommation de ces biens, entrainent des risques pour la santé des travailleurs de cette industrie, des résidents qui habitent à proximité du lieu de production ou à plus grande distance, des consommateurs de ce bien ou de tout autre individu ou groupe concerné. Ainsi, les activités de production polluantes qui dégradent l'environnement naturel ou social seront abandonnées ou alors elles seront modifiées afin que disparaissent ces conséquences inacceptables.

Quant à savoir ce qui devra être produit, la société écologique insistera d'abord pour que soit garantie une sécurité économique à tous ses membres. Cela veut dire qu'une planification de la production verra en premier lieu à ce que chacun soit assuré de manger à sa faim une nourriture saine et pleinement nutritive, que chacun soit vêtu, logé, soigné et éduqué adéquatement, et à ce que chacun ait accès aux autres biens et services qui, sur le plan social, sont jugés essentiels à la valorisation humaine.

La décentralisation et la participation de tous les citoyens concernés au processus de décision seront des caractéristiques marquantes de cette nouvelle société. Le cadre de la démocratie formelle, parlementaire et consultative, sera dépassé, de telle sorte que tous seront des décideurs, des façonneurs du milieu collectif, des préservateurs de l'environnement naturel. La démocratie écologique aura aboli le caractère hiérarchique du pouvoir politique de notre société. Elle prônera la coopération plutôt que la compétition entre les individus. 
Une société écologique ne saurait être une société de classe dans sa réalisation finale, c'est-à-dire qu'elle ne saurait reposer sur un accès différentiel à la propriété ou au contrôle des moyens de production. De même, elle ne saurait tolérer que subsiste une diffusion inégale de l'information nécessaire à la prise des décisions politiques et économiques conscientes qu'implique ce contrôle, ce pouvoir sur l'environnement humain, qu'il soit naturel ou social.

La société écologique sera donc une société participative et égalitaire où l'individu, conscient qu'il exerce un pouvoir réel de décision sur son milieu, sera appelé à donner la pleine mesure de ses talents et de son dynamisme pour que se réalisent enfin nos aspirations à un monde plus juste et meilleur.

\section{Plan d'action}

$\underline{\text { Retour à la table des matières }}$

La société écologique idéale, participative et égalitaire, exige bien sûr une vision internationale. Elle n'a pas de sens à une échelle restreinte, ceci pour trois raisons principales. D'abord, les problèmes de pollution ne sont pas uniquement des problèmes locaux : les mers sont polluées, des régions se désertifient, la terre entière risque d'être affectée. Ensuite, la société écologique égalitaire implique la cessation de l'exploitation de nations par d'autres : nous n'entendons pas demander l'expulsion des industries polluantes vers des pays où le pouvoir politique le permet, ni encore la baisse des prix des denrées importées de pays où règne la malnutrition. La troisième raison pour laquelle la société écologique doit avoir une ampleur internationale est sa nature participative : nous ne voulons pas d'une société imposée des pays capitalistes développés, dont nous sommes, aux pays exploités mais bien d'une société où tous, hommes et femmes de tous âges et de toutes nationalités auront leur mot à dire dans un choix collectif.

Pourtant, l'action que nous proposons ici, dans une optique de transition, est une action locale : c'est l'action que nous pouvons nous-mêmes entreprendre et 
c'est bien sûr une action visant aussi à combattre le pouvoir étatique brimant les libertés individuelles et celles des autres nations.

Notre première tâche sera de favoriser l'expérimentation d'alternatives qui pourront ensuite être diffusées. Les premiers noyaux de vie écologique à la campagne sont des centres d'apprentissage qui ne demandent pas mieux que de témoigner de leurs réalisations aux groupes de la société soucieux d'expérimenter des façons de vivre en harmonie avec l'environnement. Notre société y gagnerait de beaucoup en prévention des maladies et en diminution des besoins artificiels si on encourageait ces groupes marginaux et favorisait la diffusion de leurs apprentissages.

Une seconde tâche vers la recherche d'une société participative et égalitaire sera une tâche d'information. Combattre la manipulation, permettre l'information maximale est nécessaire pour que chacun puisse se libérer et effectuer des choix conscients.

Notre troisième tâche en sera une de revendication et de mobilisation. En plus d'expérimenter des alternatives et de veiller à la circulation de l'information, il faut également faire face à la dure réalité du pillage actuel de l'environnement. Nous devons donc forcer l'État et les entreprises privées à arrêter ce pillage. Pour cela, il faudra organiser des mobilisations de masse. Concrètement, nous réclamons des gouvernements :

- $\quad$ des canaux d'information communautaire contrôlés par le peuple ;

- $\quad$ la limitation des budgets publicitaires des compagnies ;

- $\quad$ de la publicité visant à renseigner sur la valeur véritable des biens offerts ;

- $\quad$ un programme de diffusion des alternatives écologiques ;

- $\quad$ la mise sur pied immédiate des cours d'écologie annoncés par le ministre de l'Environnement dès le niveau primaire dans les écoles. Ces cours devront avoir un contenu majoritairement pratique et être aussi offerts dans les programmes d'éducation des adultes. 
L'information libre est nécessaire mais insuffisante pour nous libérer du système actuel. Nous devons poursuivre les luttes entreprises sur tous les plans et en élaborer d'autres. Il est particulièrement urgent d'attaquer les problèmes du travail ainsi que des maladies et de la pollution industrielles, de l'agriculture et du zonage des terres agricoles et celui de l'énergie nucléaire.

En ce qui concerne le travail ainsi que les maladies et la pollution industrielles, nous réclamons :

- le revenu minimum garanti pour tous ;

- l'insertion dans le code du travail de quatre articles :

1) tout travailleur, ou tout groupe de travailleurs, peut cesser un travail jugé par lui dangereux, à court ou à long terme, sans risque de congédiement et sans perte de salaire. Ceci implique le droit pour les travailleurs de mesurer le degré de pollution ;

2) tout travailleur exerçant un métier dangereux aura droit à au moins quatorze heures de repos entre chaque période normale de travail (d'un maximum de dix heures), ceci pour diminuer les risques d'accident ;

3) nul ne pourra employer des travailleurs à la pièce ;

4) la semaine de travail sera portée à trente heures sans réduction de salaire et sans augmentation de tâche. Cette mesure vise à combattre le chômage.

Nous réclamons aussi :

- $\quad$ une compensation adéquate aux accidentés du travail et à ceux qui sont atteints de maladies industrielles ;

- des hausses des normes de sécurité au travail ;

- l'installation obligatoire d'équipements antipollution, y compris des équipements pour traiter ou recycler les déchets industriels qui ne devront plus être libérés dans l'atmosphère ni dans les eaux courantes. Les dépenses impliquées devront être aux frais des compagnies (qui ont retiré plusieurs fois la valeur de leur investissement aux dépens de la santé des employés et de la population en général). Un tel plan inclura le versement du plein 
salaire aux travailleurs en cas de fermeture temporaire. Ces mesures s'appliquent également à la « pollution psychologique » causée par un travail aliénant : le travail, dans tous les domaines, devra être réorganisé pour répondre aux besoins psychologiques des travailleurs, à leur dignité humaine ;

- l'accessibilité du sol à ceux qui veulent le cultiver ;

- $\quad$ une politique de contrôle de l'utilisation des pesticides ;

- l'arrêt immédiat de l'épandage d'herbicides toxiques le long des routes et des voies ferrées par le ministère des Travaux publics ;

- l'interdiction des additifs alimentaires inutiles (colorants par exemple) ou dont l'innocuité est soit non prouvée, soit mise en doute lors de combinaison avec d'autres substances. (La même règle devrait s'appliquer aux produits pharmaceutiques et on devrait obliger les fabricants à mentionner les effets secondaires des médicaments.)

En ce qui concerne l'énergie nucléaire, nous réclamons :

- que les centrales I et II à Gentilly et l'usine d'eau lourde en construction à La Prade soient démantelées. On devra employer à cette fin les mêmes travailleurs qui y sont déjà ;

- qu'aucune autre centrale nucléaire ne soit construite ;

- que des subventions soient octroyées pour l'installation de capteurs solaires sur les maisons, assurant au moins le chauffage de l'eau ;

- la construction de nouvelles unités de logement, conçues de façon à profiter du soleil pour le chauffage. La mise en marche de tels projets à une échelle massive fournira des emplois utiles.

Quant aux autres luttes déjà amorcées, les principales revendications en sont les suivantes :

- le développement de réseaux de transport en commun urbains et interurbains à prix modique et éventuellement gratuits. Nous nous opposons à l'automobile privée comme moyen de transport principal en milieu urbain ; 
- la création de pistes cyclables aménagées de façon à permettre l'accès à tous les lieux, partout au Québec et prioritairement dans les villes ;

- la préservation des espaces verts dans les villes et l'aménagement de nouveaux espaces accessibles aux citadins dans les campagnes, pour un usage collectif ;

- que l'appui gouvernemental se fasse sans ingérence dans les petites coopératives, alimentaires ou autres ;

- des investissements dans un programme de santé préventive, par exemple dans le sport non compétitif, l'alimentation équilibrée et saine, la dépollution (et l'arrêt de pollution) de l'air et de l'eau, la diminution des situations stressantes plutôt que dans une pharmacopée de plus en plus envahissante ;

- le contrôle de la teneur en soufre des carburants ;

- le compostage obligatoire des boues d'égouts et des déchets recyclables des villes, avec possibilité de récupération du méthane libéré. Les industries ne devront évidemment plus jeter aucun produit toxique dans les égouts. Le compostage pourrait aussi s'appliquer aux déchets de certaines usines (laiteries, par exemple) et au purin.

Enfin nous appuyons toutes les luttes contre la concentration du pouvoir et pour la sécurité économique pour tous, nationalement et internationalement. Mentionnons le droit à l'autodétermination des nations amérindiennes, qui est un droit politique à la vie collective sur les territoires où elles vivent.

Nous avons les moyens de nous offrir une société juste, à l'échelle mondiale, sans austérité. Qu'on regarde simplement les budgets consacrés aux armées nationales et on comprendra. 


\section{Conclusion}

$\underline{\text { Retour à la table des matières }}$

Le pillage désastreux de notre environnement doit cesser. La seule façon de l'arrêter est de combattre la base matérielle et sociale qui le soutient : le système de production capitaliste basé sur l'impératif du profit. Notre objectif ultime est de bâtir une société où les gens vivront et travailleront en harmonie avec leur environnement et avec eux-mêmes, sans rapports d'exploitation, d'oppression ou de domination.

La crise écologique a poussé des Québécois à se regrouper. Les événements ont jeté de nombreux militants et militantes écologistes dans le feu de l'action. Mais le mouvement écologique québécois reste à construire avec l'appui et l'engagement de milliers, voire de millions, d'autres Québécois. La lutte écologique doit se poursuivre partout où des gens se trouvent réunis, entre autres dans et par les syndicats, les groupes populaires, les associations d'étudiants, de chômeurs et d'assistés sociaux, les mouvements de femmes, les comités de lutte pour l'égalité des minorités, les organisations politiques progressistes.

Nos revendications sont nombreuses et ambitieuses, et absolument nécessaires. Mais elles ne sont qu'une étape vers la création de l'écosociété de l'avenir, égalitaire et Participative. Chaque victoire partielle diminue la monopolisation du pouvoir et nous fait faire un pas vers la société écologique que nous voulons. 
Mouvement écologiste, énergie et environnement.

Essais d'écosociologie.

Deuxième partie . Interventions et prises de position

\section{Chapitre 4}

\section{"La politique québécoise de conservation de l'énergie.”}

Texte publié dans Le Devoir, 10 février 1981, p. 9-10.

par Gordon Edwards, Francine Ruvinsky, Stuart Stilitz, Ronald Babin, Paul Berleur, Jacques Boucher, Claude Champagne et JeanGuy Vaillancourt

\section{$\underline{\text { Retour à la table des matières }}$}

La présente est une contribution de groupes anti-nucléaires au « débat public éclairé » concernant le document « Une stratégie pour la décennie 80 » rendu public par le président de l'Hydro-Québec, le 16 décembre dernier. Notre réflexion embrasse aussi le projet de loi 9, projet qui a trait à « l'économie de l'énergie dans le bâtiment ». Les groupes anti-nucléaires concernés ici sont Alliance Tournesol (Montréal) et la Canadian Coalition for Nuclear Responsibility/Regroupement pour la surveillance du nucléaire (CCNR).

Nous voulons nous joindre à de nombreux citoyens qui ont réagi positivement au projet de loi no 9, présenté par M. Bérubé. Par les dispositions de cette loi, les Québécois sont encouragés à économiser l'énergie par l'isolation de leurs bâtiments. Cette isolation sera financée à même les économies d'énergie qui seront réalisées, en sorte que, non seulement le citoyen n'aura pas à s'endetter pour faire 
l'isolation d'un bâtiment mais, à court terme, l'opération signifiera également pour lui une économie intéressante. Voilà un plan concret et important de conservation de l'énergie qui peut inspirer une démarche plus importante pour trouver des solutions à l'ensemble de la question énergétique au Québec.

Une telle démarche contraste avec le projet exposé par l'Hydro-Québec dans « Une stratégie pour la décennie 80 », où il est question d'investir 55,5 milliards de dollars (soit l'équivalent d'un million de maisons unifamiliales) durant les dix prochaines années, pour construire de nouvelles unités de production d'électricité (hydro et autres). Le plan d'investissement de l'Hydro-Québec prend pour acquis que la demande en électricité va continuer de croître à un rythme annuel moyen de 6,2\%. Cependant, à y regarder de plus près, il y a de bonnes chances qu'une fois installées les unités de production en construction ou projetées, il n'y ait pas de marché pour l'électricité qui sera alors produite. Si tel était le cas, l'HydroQuébec pourrait bien être en train de conduire le Québec à la banqueroute.

Le marché de l'électricité en Amérique du Nord est présentement saturé. L'Hydro-Ontario, en dépit d'une capacité de production dépassant de 35\% la demande de pointe, a connu une croissance zero dans ses ventes d'électricité (sur son territoire et à l'extérieur), durant les neuf derniers mois de 1980. Le Manitoba et le Nouveau-Brunswick exportent tous deux de l'électricité à un coût moindre que le prix coûtant. Selon le ministère de l'Énergie des États-Unis, les unités de production électrique vont avoir une capacité trop grande au-delà des années 1990 et ceci, même si tous les projets de centrales nucléaires étaient immédiatement annulés.

Une question se pose donc devant le projet de l'Hydro-Québec d'investir 55,5 milliards de dollars pour produire d'ici 1996, deux ou trois fois plus d'électricité qu'actuellement : toute cette électricité pourra-t-elle être vendue ? L'HydroQuébec parie que oui, en présumant, premièrement, qu'elle pourra vendre de l'électricité aux États-Unis et, deuxièmement, que les Québécois vont passer du chauffage à l'huile au chauffage à l'électricité. Ces présomptions sont-elles sages ?

C'est un fait que la Nouvelle-Angleterre est présentement une des deux seules régions américaines sous-équipées en électricité. Cependant, il est impensable que 
le Québec puisse lui venir en aide d'une façon substantielle, du seul fait que la demande en électricité en Nouvelle-Angleterre et au Québec est semblable : en effet, c'est en hiver, au moment des grands froids, que la demande est la plus forte, à la fois au Québec et en Nouvelle-Angleterre. Le Québec n'a donc pas de surplus à vendre à la Nouvelle-Angleterre au moment où celle ci en aurait vraiment besoin, à moins que le Québec ne devienne partie du réseau de base de la Nouvelle-Angleterre et ne consente à construire des barrages, à grands frais et à grand endettement pour le Québec, de façon à pouvoir répondre aux besoins des Américains. Ce n'est pas là le mandat de l'Hydro-Québec et nous nous objectons fortement à ce que ça le devienne. D'ailleurs, d'autres États américains sont également intéressés à vendre de l'électricité à la Nouvelle-Angleterre, vus leurs surplus. Seule la conurbation de New York présente une demande de pointe pendant l'été, alors que l'Hydro-Québec a des surplus et, déjà, les échanges nécessaires ont été contractés.

Examinons maintenant la seconde présomption de l'Hydro-Québec, suivant laquelle les Québécois vont se convertir au chauffage tout-électrique. Si le prix de l'électricité double ou triple d'ici 5 ou 10 ans, il est logique de penser que les gens vont plutôt se tourner vers des solutions moins coûteuses (amélioration de l'isolation et des systèmes de chauffage, recours à l'énergie solaire, récupération de la chaleur dans l'industrie, le commerce et au niveau domestique, etc.). Les investissements actuels de l'Hydro-Québec sont déjà très lourds à supporter : le remboursement des intérêts de sa dette gruge àlui seul environ $87 \%$ de ses revenus actuels. Est-il sage de se lancer dans une aventure de 55,5 milliards de dollars ? ? ? Nous croyons que non. Il serait préférable d'investir de façon plus diversifiée et au niveau local, afin de générer des activités économiques et de créer une multitude d'emplois. De toutes façons, c'est une question trop grave et trop engageante de notre avenir pour que la décision en soit laissée à l'Hydro-Québec et même au Conseil des ministres. C'est une question qui regarde l'ensemble des citoyens du Québec.

Quant à nous, nous proposons premièrement qu'un programme de conservation de l'énergie beaucoup plus vaste soit entrepris ; deuxièmement, que les alternatives énergétiques de type décentralisé soient vraiment prises au sérieux ; troi- 
sièmement, que la question du nucléaire soit enfin débattue en public dans tous ses aspects.

« Économisez l'énergie », c'est devenu un mot d'ordre passe-partout et ça nous coûte des millions en publicité. Le résultat est plutôt mince et le tout reste au niveau des bonnes intentions. Des mesures nombreuses, efficaces, doivent être prises, tant au niveau de l'industrie et des organismes publics qu'au niveau des particuliers. Le gouvernement du Québec fait la cour aux industries qui sont de grosses consommatrices d'électricité, si bien que l'industrie avalera 17723 mégawatts en 1996, soit 37\% de ce qui sera alors produit, ou presque l'équivalent de l'ensemble de la production actuelle de l'Hydro-Québec, et ceci pour une population de 7 millions d'habitants. Il nous semble qu'ici il y a du cynisme à parler d'économie d'énergie aux citoyens. On pourrait probablement s'exempter deux ou trois LG2 d'ici 1996, si l'on faisait le tri dans le secteur industriel. S'il veut vraiment conserver l'énergie, le Québec doit faire en sorte que les activités économiques sur son territoire, tout en employant le maximum de Québécois, n'épuisent qu'au minimum ses ressources énergétiques. Or, c'est le caractère particulier des industries grandes consommatrices d'énergie de ne fournir que très peu d'emplois par dollar investi, vu leur caractère généralement très mécanisé et technologiquement raffiné.

Après le tout-électrique, il est temps de passer à une situation du strict nécessaire, tant dans les maisons que dans les édifices publics et les industries. Les tarifs à l'usager ne pourraient-ils pas être prévus pour encourager ceux qui consomment le nécessaire et pour faire payer la surconsommation : le coût de l'électricité pourrait être moindre, jusqu'à un certain palier de consommation basé sur le strict nécessaire et, au-delà de ce palier, les tarifs seraient sensiblement plus élevés, de façon à décourager la surconsommation. Combien d'appareils ménagers dont on devrait se passer et qui devraient être retirés du marché, suivant un échéancier précis! Combien de produits, comme l'aluminium, devraient être recyclés ou, comme le papier, devraient être régis par un code d'éthique de conservation et de lutte au gaspillage ! Plutôt que de céder aux mythes de la croissance exponentielle, il nous semble que l'Hydro-Québec devrait viser à la croissance zéro et pourrait, avec le potentiel énergétique dont elle dispose, non seulement répondre aux besoins essentiels, mais encore, jouer un rôle moteur pour améliorer 
la qualité de la vie des Québécois. Les 55,5 milliards de dollars prévus pour les dix prochaines années ne risquent-ils pas d'être le plus grand gaspillage de notre histoire?

Passons aux alternatives énergétiques, en constatant qu'elles ne sont pas prises au sérieux par l'Hydro-Québec. Pourtant, elles existent ces alternatives. Après une isolation adéquate, le chauffage des maisons par collecteurs solaires, c'est possible et ça représenterait une sécurité infiniment plus grande pour les citoyens d'une ville comme Montréal que le fait de dépendre d'un énorme réseau de lignes à haute tension, aussi complexe que délicat, vulnérable et difficile à protéger. Imaginons un instant que seulement 5 milliards de dollars soient consacrés à l'installation de collecteurs solaires au Québec d'ici 1996. À 10000 \$ par logement (ce qui est beaucoup, car la production en série pourrait rapidement en faire baisser le coût), on pourrait en équiper 500000 logements. Le financement de telles installations pourrait être réalisé par des procédures semblables à Celles proposées par la loi 9, en ce qui a trait à l'isolation des bâtiments. Des régions entières, comme celles de la Côte Nord et de la Gaspésie, pourraient s'alimenter à de petites éoliennes pour la satisfaction de leurs besoins en électricité. Elles pourraient trouver dans des concessions forestières gérées communautairement et écologiquement une source d'appoint pour le chauffage. Les maisons pourraient, par des digesteurs, convertir leurs déchets en méthane. L'Hydro-Québec parle d'énergies nouvelles sous forme de biomasse utilisée de façon industrielle (par exemple, la combustion de la tourbe). Quant à nous, notre option est en faveur des énergies nouvelles décentralisées et écologiquement acceptables. La stratégie de l'HydroQuébec consiste à mystifier la population, en lui disant : « Ne bougez pas ; avec nos milliards, nous allons répondre à vos besoins. » Notre avenir, selon nous, ne pourra se bâtir qu'en impliquant l'ensemble des citoyens dans des campagnes de conservation de l'énergie et d'aménagement de moyens autogérés de production.

Et encore au chapitre des énergies nouvelles, il faudrait reconsidérer toute la question du transport. L'ère des autoroutes et de l'automobile individuelle n'arrivet-elle pas à son terme ? Ici, c'est plus qu'une question de carburant et d'automobile électrique. Ne serait-il pas possible de réaménager la vie économique de telle sorte qu'on n'aurait pas à avoir recours à tant de déplacements ? Comment allonsnous gérer notre mobilité et quelles valeurs vont guider nos choix ? 
Souhaitons enfin que la question du nucléaire soit vraiment débattue dans tous ses aspects. Sur ce point, le document de l'Hydro-Québec non seulement se contente de quelques vagues allusions, mais prend implicitement pour acquis que la construction de centrales nucléaires va aller de soi. D'après l'Hydro, ce sera devenu en 1996 la façon économique de faire face à nos besoins : le coût de l'électricité sera 4 fois moindre que celui de l'hydro-électricité des nouveaux projets. Pour notre part, nous croyons que nous pouvons et que nous devons nous passer du nucléaire. Nous le pouvons, en arrêtant de prendre nos désirs pour la réalité et de définir nos besoins selon le mythe de la croissance exponentielle. Nous le pouvons, en prenant le moindrement en considération les alternatives en énergies douces.

Nous le devons, si nous nous arrêtons le moindrement à considérer les dangers de la radioactivité et les coûts, exponentiels, ceux-là, dont les générations futures vont hériter lorsque, dans trente ans, elles auront à gérer nos centrales désaffectées, ainsi que des tonnes de déchets radioactifs et des monceaux de matériel contaminé. Comme groupes anti-nucléaires, nous croyons que l'Hydro-Québec n'a pas le droit de cacher la moitié du paysage aux citoyens qu'elle invite à participer à « un débat public éclairé ». Nous demandons en outre qu'une enquête publique conduite par un groupe d'experts indépendants (tel que ça s'est produit en Suède) soit menée sur la sécurité de Gentilly II (sa conception, la structure du bâti, les procédures de contrôle du carburant, lors du fonctionnement, et des déchets, les plans d'évacuation et de sécurité dans et hors de l'usine, etc.). Dans le contexte actuel, les Québécois ne sont-ils pas profondément induits en erreur quand on les invite (en parlant du nucléaire) à " prendre des risques », parce que, dans la vie, c'est normal de prendre des risques ? Prendre des risques individuellement, c'est autre chose cependant que d'engager une population entière dans une aventure comportant des risques incalculables. Il doit y avoir information détaillée des dangers du nucléaire, consultation de la population et audiences publiques, avant que tout autre projet nucléaire soit entrepris au Québec (Gentilly III, tokamak sur la fusion à Varennes, ou tout autre projet)...

En terminant, nous invitons nos concitoyens à s'exprimer sur le projet de 55,5 milliards de dollars de l'Hydro-Québec. Les enjeux sont trop importants pour que 
nous gardions le silence. Malgré les réalisations remarquables de l'Hydro-Québec, on doit se méfier. La danse des milliards risque de nous aveugler tous et de servir le prestige d'une institution plutôt que le bien des citoyens. Comme l'ont fait des millions de citoyens des États-Unis, des autres parties du Canada et de plusieurs autres pays, il est important que nous prenions part à ce qui va être décidé, que nous participions à l'élaboration de programmes de conservation de l'énergie et d'implantation des énergies décentralisées et inépuisables et que, pour ce, nous ayons toute l'information nécessaire. Nous vous invitons à écrire à vos députés et ministres, et à en parler dans votre milieu, afin d'éviter une aventure financière au moins 55 fois et demie plus grave et plus engageante que celle des Jeux Olympiques... 
Mouvement écologiste, énergie et environnement.

Essais d'écosociologie.

Deuxième partie . Interventions et prises de position

\section{Chapitre 5}

\section{"Le débat public sur l'énergie aura-t-il lieu ?”}

Texte publié dans la revue Possibles, vol. 5, no 3-4, 1981, p. 277-288.

par Jean-Guy Vaillancourt

$\underline{\text { Retour à la table des matières }}$

Le Front commun pour un débat public sur l'énergie a organisé une semaine sur l'énergie à l'UQAM, du 16 au 22 février dernier. Quelques jours plus tard se tenait à Québec la Commission parlementaire sur les plans d'investissement d'Hydro-Québec pour la décennie 80. Chaque jour depuis des mois, les journaux nous parlent de pétrole et d'électricité, de solaire et de nucléaire, de gaspillage et d'économies d'énergie. La question de l'énergie prend ainsi une ampleur de plus en plus grande. À mesure que nous sommes assaillis par des informations compliquées et souvent contradictoires sur notre avenir énergétique, une réflexion collective commence péniblement à s'amorcer.

Au Québec, région riche en ressources hydro-électriques, les problèmes liés à l'énergie se posent peut-être d'une façon moins aiguë que dans la plupart des pays du monde, mais ils se posent quand même avec une certaine gravité, étant donné que nous avons une des plus hautes consommations énergétiques au monde et que nous sommes très dépendants à l'égard du pétrole importé. Les deux tiers de la 
demande québécoise en énergie est satisfaite actuellement par le pétrole, et il n'est pas possible dans la plupart des cas de remplacer ce pétrole par de l'électricité. Et là où c'est possible, par exemple pour le chauffage des bâtiments, ce n'est pas toujours la solution la plus désirable. Au plan des coûts, le gaz naturel, par exemple, s'avère sans doute une source d'énergie préférable à l'électricité, même si à longue échéance, il faut songer à autre chose.

Depuis la crise du pétrole de 1973, et surtout depuis que l'Alberta a fermé ses robinets de pétrole au Québec, nous nous trouvons dans une passe bien difficile. La confusion règne dans beaucoup d'esprits, entretenue par des intérêts économiques et politiques colossaux qui, du jour au lendemain, parlent de surplus puis de pénurie, d'autonomie puis de dépendance, de la nécessité d'importer puis de celle d'exporter, de la banqueroute possible puis de milliards de profit en perspective. C'est à n'y rien comprendre. Il y a tellement de variables qui bougent tout à coup sur tous les fronts en même temps, tellement de voies possibles qui s'ouvrent devant nous, qu'il est difficile d'y voir clair. Faut-il accélérer le développement hydro-électrique, économiser encore davantage de cette énergie que l'on gaspille toujours si allègrement, accroître plus rapidement la pénétration du gaz naturel, opter au plus tôt pour la fission ou pour la fusion nucléaire, s'orienter définitivement vers la biomasse, le solaire et les autres énergies nouvelles ou redécouvertes ? Voilà autant de possibilités non exclusives les unes des autres, et dont chacune peut prendre des formes multiples. La question du dosage de ces diverses options est extrêmement complexe, et les solutions possibles sont d'autant plus difficiles à choisir que l'on joue ici avec du très long terme et beaucoup d'imprévisible. Les politiques qui seront adoptées auront en plus des répercussions sérieuses dans une foule de secteurs de l'activité humaine.

Voilà pourquoi plusieurs Québécois en sont arrivés à la conclusion qu'il fallait à tout prix exiger du gouvernement du Québec la mise en marche d'un vaste débat public sur la question énergétique dans son ensemble. L'énergie est quelque chose de trop important pour qu'on laisse les politiciens, les producteurs privés, les soidisant experts d'Hydro-Québec en discuter uniquement entre eux, et prendre tout seuls les décisions cruciales qui s'imposent. Plusieurs groupes et individus déjà sensibilisés au problème exigent d'être informés clairement et objectivement, tiennent absolument à prendre part à un débat démocratique sur la question, et 
veulent exercer leur droit de participer activement aux prises de décisions difficiles qui s'imposent dans ce domaine. Lors de la Commission parlementaire sur l'énergie en février 1977, par exemple, plusieurs groupes présentèrent des mémoires dans lesquels cette demande d'un débat véritable sur l'énergie fut mise de l'avant. En 1979, la Société pour vaincre la pollution, l'une des plus actives des associations écologiques québécoises, mettait sur pied le Front commun pour un débat public sur l'énergie, pour tenter d'obtenir du gouvernement un débat large et ouvert sur les enjeux énergétiques qui s'offrent à la société québécoise. Ce Front commun, qui comprend maintenant plus de 80 groupes et associations de toutes sortes, voudrait que ce grand débat public soit orchestré par une commission paragouvernementale indépendante des producteurs d'énergie, pour que tous les groupes et les citoyens intéressés puissent s'exprimer au grand jour et librement, afin d'aider à trouver les meilleures solutions aux grands problèmes énergétiques actuels et futurs. Pour que la population puisse participer aux discussions et aux décisions dans ce domaine, il faudrait, selon le Front commun, beaucoup plus d'information, et une information de qualité, que les producteurs d'énergie et les gouvernements sont souvent réticents à fournir. Il faudrait aussi des moyens financiers et techniques pour faire des recherches et en diffuser les résultats. Audelà de la question énergétique, c'est celle de la création d'une écosociété alternative qui se dessine, avec ses scénarios de convivialité, de technologie douce et de décentralisation.

En réponse aux demandes pressantes du Front commun, le ministre Bérubé répondit dans une lettre du 6 mai 1980 qu'il avait décidé de tenir une autre commission parlementaire, plutôt qu'un débat publie. Le Front commun rejeta d'emblée l'utilisation d'un outil aussi inadéquat et aussi inaccessible pour les groupes de citoyens intéressés, l'expérience malheureuse des groupes présents à la Commission parlementaire sur l'énergie en 1977 ayant été probante à cet égard. En effet, les groupes ont l'impression que l'on n'a pas tenu compte de leurs demandes de 1977 et, qu'au contraire, on a utilisé leur participation pour cautionner des politiques énergétiques inacceptables. De plus, avec un mois d'avis a peine, et avec un thème aussi limité et délirant que le programme d'investissement de 55 milliards de dollars d'Hydro-Québec pour la décennie 1980-1990, faut-il se surprendre que presque aucun groupe faisant partie du Front commun ne se soit présenté à la Commission parlementaire des 24-25-26 février derniers ? 
Le Front commun a donc préféré boycotter la commission parlementaire de février, pour pouvoir consacrer toutes ses énergies (c'est le cas de le dire) à réaliser sa semaine sur l'énergie. Celle-ci n'était pas prévue comme devant être le débat public désiré, comme certaines personnes l'ont cru, à tort, mais comme un point de départ pour amorcer ce grand débat public qui devra se dérouler dans toutes les régions du Québec. C'était tout au plus une manifestation d'envergure d'une semaine entreprise pour revendiquer la tenue du débat lui-même, qui, lui, devrait durer au moins deux ans. Il s'agissait de faire un bilan initial de l'information énergétique pour permettre de lancer la discussion et la réflexion sur l'avenir énergétique du Québec. À cet égard, la semaine fut un franc succès, car l'information sur l'énergie y fut très abondante et généralement d'excellente qualité. En plus des conférences, des panels et des ateliers, il y eut plusieurs kiosques, expositions et îlots d'information où une trentaine de groupes ont présenté des instruments d'information et de travail. Il y eut même deux séminaires pratiques sur l'énergie solaire et ses applications concrètes, l'un par Roger Camous, ingénieur-architecte à la Faculté d'aménagement de l'Université de Montréal, l'autre par Nick Nicholson, architecte-constructeur et pionnier du solaire au Québec. On a pu aussi participer à un panel-discussion sur le projet Archipel et sur le projet Ashapmouchouan, avec des représentants des groupes d'opposants à ces projets hydroélectriques.

La première moitié de la semaine fut surtout consacrée à la projection de films et de vidéos. On a pu y voir entre autres, Gens d'Abitibi de Pierre Perrault, Three Mile Island de Joan Harvey, Québec à vendre de Raymond Garceau, Soleil d'hiver de Jean Rivard, Les Douces d'Alain Chartrand, Sun, Wind and Wood et Alchimie nouvelle de Dorothée Henault, Paul Jacobs and his nuclear gang de Paul Jacobs, La Fiction nucléaire de Jean Chabot, De la tourbe et du restant de Jean Frappier, Les Hydro-Québécois (ou un débat qui n'a pas lieu) de Coop Video et SVP, Si l'on s'y mettait de Guy Parent et du Monde àbicyclette et Ninan Nitassinan d'Arthur Lamothe. La plupart de ces films et vidéos (et d'autres encore) ont été montrés à deux reprises durant la semaine pour permettre à plus de gens de les voir.

Le lundi soir, le théâtre Petit à Petit présenta une intéressante pièce écologique De plus en poubelles, et le mardi soir le public a pu venir discuter avec des per- 
sonnes-ressources sur des questions très concrètes d'économies d'énergie : chauffage, isolation, hausse des prix de l'essence, de l'électricité et du gaz. Le colloque proprement dit débuta vraiment le mercredi soir, avec un panel-discussion sur la politique énergétique du Québec, avec deux invités de marque : Yves Bérubé, ministre de l'Énergie, et Pierre Fortier, ex-président de Canatom, actuel député d'Outremont et critique de la politique énergétique pour le Parti libéral du Québec. Le ministre Bérubé, à mon avis, l'emporta de justesse sur son adversaire dans ce combat oratoire, en manifestant une plus grande compétence et un plus grand souci écologique. Par ailleurs, Fortier, que tout le monde perçoit comme un pronucléaire farouche, a quand même marqué un point important quand il s'est engagé à tenir un débat public sur l'énergie, alors que Bérubé prenait plutôt une position très technocratique et ostensiblement moins démocratique, en disant qu'il ne voulait pas d'un grand débat public avant d'avoir reçu plus d'information de la part des experts sur ce qui est techniquement et économiquement possible. Deux semaines plus tard, à la suite de la Commission parlementaire et probablement pour éviter que le PQ ne paraisse moins ouvert que le Parti libéral de Ryan, le ministre Bérubé a promis de faire tenir par la future régie de l'Énergie un débat public avec mission itinérante (un peu comme la Commission Berger), avec en plus un financement public des groupes indépendants. Le tout serait couronné par un sommet sur l'énergie. C'est bien mieux donc que ce que promet Fortier, car il semble que pour ce dernier, un débat public serait avant tout un débat entre producteurs. De toute façon, il est clair que si Fortier est venu en politique, c'est surtout pour donner un coup de pouce au secteur de l'énergie nucléaire qui est en perte de vitesse ici comme ailleurs dans le monde.

Durant toute la matinée du jeudi 19 février, les participants au colloque purent discuter du développement énergétique du Québec (sources, équipements et besoins) avec le journaliste scientifique Jean-Marc Carpentier, du programme d'équipements d'Hydro-Québec pour 1980-1990, avec l'écologiste Solange Vincent et avec Jacques Ruelland du Bureau de l'économie des énergies (qui remplaçaient l'économiste Hélène Lajambe absente pour cause de maternité), des alternatives et de l'autonomie énergétique avec l'économiste David Brooks, coordonnateur d'Energy Probe et des Amis de la Terre du Canada. Ce panel-discussion a constitué un très bon bilan de la situation énergétique actuelle, et a permis de lancer le débat sur les besoins et sur les choix possibles pour l'avenir. 
Hélène Lajambe, auteur d'une excellente brochure sur « L'Autonomie énergétique du Québec dans une perspective écologique », publiée par Hélio-Québec, dans son texte lu par Solange Vincent, a fustigé Hydro-Québec pour ses stratégies douteuses de surendettement et d'électrification à outrance. Une politique sérieuse d'économie d'énergie, et le développement de sources diversifiées, renouvelables et écologiquement plus adaptées, comme l'énergie du soleil et de la biomasse, seraient autrement plus rationnels, d'après Lajambe. David Brooks, quant à lui, a insisté particulièrement sur les économies d'énergie, qui pourraient nous éviter le recours au nucléaire et même au charbon.

La conférence du jeudi soir par Yvon Soucy, d'Environnement Canada, a porté sur les incidences environnementales de l'énergie de remplacement du pétrole. Selon lui, les économies d'énergie sont la source d'énergie la plus intéressante pour l'environnement. Viennent ensuite les sources d'énergie renouvelables comme l'énergie solaire, éolienne, marémotrice, hydro-électrique, et de biomasse, qui pourraient satisfaire environ le tiers de la demande canadienne anticipée pour l'an 2000. Si à ces deux stratégies on en ajoute une de diversité et de multiplicité des sources, utilisées en fonction des régions et des technologies appropriées, on peut alors s'en tirer.

La journée du vendredi a été consacrée à l'étude des impacts économiques et politiques des choix énergétiques sur la population québécoise. Dans le paneldiscussion du matin, Solange Vincent aborda la question du continentalisme énergétique, qui est déjà bien plus avancé que les gens ne se l'imaginent quand ils entendent Reagan le proposer comme solution à la crise énergétique des États-Unis. Ensuite, Colette Provost, biologiste (et candidate écologiste dans la circonscription de Saint-Louis aux élections du 13 avril) fit une intervention remarquée sur l'énergie et l'agriculture, alors que l'écoféministe Claire Morissette du Monde à bicyclette nous a entretenu des problèmes énergétiques reliés au transport. Le quatrième paneliste, Gérald Larose, organisateur communautaire et président du Conseil central de Montréal de la CSN, et des travailleurs forestiers en grève, ont ensuite lancé un débat stimulant sur le rapport entre l'énergie et l'emploi, qui a démontré la possibilité et même la nécessité d'une convergence entre les luttes des 
travailleurs et les luttes des écologistes pour donner des emplois aux Québécois et sauvegarder leur environnement.

Dans la soirée de vendredi, il y a eu deux conférences importantes, la première par le mathématicien Gordon Edwards, coordonnateur du Regroupement pour la surveillance du nucléaire et contre-expert sur le CANDU, et la seconde par le célèbre défenseur des consommateurs, Ralph Nader. Tous les deux ont parlé abondamment du nucléaire, montrant une fois de plus que la fission nucléaire, à cause des coûts astronomiques et des dangers mortels qu'elle comporte (prolifération, déchets, accidents, état policier, etc.), constitue une entreprise risible et stupide, pour ne pas dire insensée et criminelle. Avec des économies d'énergie, une meilleurs utilisation de l'hydroélectricité existante (par l'aplatissement des périodes de pointe et la production d'hydrogène en période creuse), par le développement du solaire sous toutes ses formes, et par une gestion intelligente des énergies fossiles qui restent, le Québec peut éviter le nucléaire, qui de toute façon n'est pas rentable et cause bien plus de problèmes qu'il n'en résout. Ralph Nader s'est permis aussi de donner d'excellents conseils aux militants écologistes présents concernant la création d'instruments organisationnels solides et durables, surtout au plan financier, pour développer la lutte écologique et accroître la protection des consommateurs.

Samedi après-midi, ce fut une autre série de conférences, sur les impacts écologiques et sociaux des choix énergétiques. Michel Jurdant, écologiste bien connu par ses interventions sur l'écosociété dans Le Devoir, a touché au thème de l'électronueléaire, Paul Charest, anthropologue de Laval, a abordé la question de l'hydroélectricité, François Bregha, analyste énergétique, a traité du pétrole et du gaz, et enfin André Delisle, ingénieur-journaliste, nous a parlé des économies d'énergies et des énergies alternatives. Ce panel-discussion fut immédiatement suivi par des ateliers parallèles sur chacun des quatre sujets abordés par les panelistes.

La journée du dimanche, dernier jour du colloque, a été consacrée au thème du débat public sur l'énergie. Pierre Lacombe, coordonnateur du Front commun et Nicole Forget, ex-présidente de l'Association des consommateurs du Québec, firent chacun un exposé sur le cadre et les modalités d'un débat public sur l'énergie. Pierre Lacombe, au nom du Front commun, réitéra la demande pour un véritable 
débat public sur l'énergie, cogéré par les citoyens et l'État, et pour lequel les groupes recevraient des ressources pour mieux préparer leur participation. Nicole Forget parla du débat publie, mais en se plaçant du point de vue des consommateurs qu'elle représente au Conseil d'administration d'Hydro-Québec. Michel Nadeau, éditorialiste au Devoir, parla ensuite du droit du public à une information abondante et scientifiquement valable. Selon lui, il faudrait créer au Québec des centres de recherche et d'information sur l'énergie, pour alimenter le débat public et aider à la prise des décisions.

Dans la discussion qui s'ensuivit, un responsable des relations publiques d'Hydro-Québec vint sommer les trois panelistes de créer un tel centre d'information dès le lendemain matin. Malgré l'importance qu'ils accordent à l'information, le Front commun et les autres personnes qui veulent débattre de l'énergie et participer aux discussions et aux décisions sur les politiques énergétiques, sont réticents à se limiter exclusivement au rôle de disséminateurs d'information, surtout quand cette demande de se saborder comme groupe de pression pour un débat public leur vient du responsable des relations publiques d'une entreprise qui est extrêmement avare quand vient le temps de donner de l'information franche et ouverte au grand public sur les enjeux énergétiques. En effet, le président d'Hydro-Québec a refusé de venir parler au colloque ou d'y envoyer ses experts, et c'est son conseil d'administration qui a finalement décidé de donner un octroi symbolique de 5000 \$ pour aider à l'organisation du colloque.

Lors du bilan final du colloque durant l'après-midi, un point qui est revenu à quelques reprises fut le peu d'intérêt manifesté par certains media d'information pour le colloque, ce qui n'eut pas l'heur de plaire à un journaliste présent qui se défendit en disant qu'il n'avait rien appris de neuf et de digne de faire l'objet d'un article dans ce qu'il venait tout juste d'entendre. Et pourtant, durant cette semaine sur l'énergie, il me semble qu'il s'est passé des choses tout aussi intéressantes et importantes que la déclaration de Ralph Nader à l'effet que l'indépendance du Canada était menacée par le président Reagan, et celle du ministre Bérubé à l'effet qu'il y a danger d'une pénurie de pétrole l'automne prochain au Québec.

Par ailleurs, il me semble que les personnes impliquées dans l'organisation du Front commun ont tendance à ne pas se rendre compte de l'impact important 
qu'elles ont dans les mass media, dans l'opinion publique, et auprès des preneurs de décisions dans le domaine énergétique. J'ai rarement vu un événement de ce genre recevoir autant de publicité qu'en a reçue cette semaine sur l'énergie et, à mon avis, d'après mon expérience de semblables rencontres, la participation du public a été excellente, compte tenu du fait que les gens se déplacent difficilement pour les événements de ce genre, malgré leur importance. Il y a quand même eu plus de 200 personnes inscrites en plus des centaines d'autres qui ont été touchées par les kiosques, les vidéos et les autres activités comme les conférences publiques. Les articles de journaux et de revues, les programmes de radio et de télévision qui ont découlé de cet événement d'une semaine sont aussi des conséquences importantes de celui-ci. Et si le rapport du colloque voit finalement le jour sous forme de publication, ce sera encore là un impact important quoique difficilement mesurable de ce colloque sur l'énergie.

Le gouvernement et Hydro-Québec sont de plus en plus obligés de tenir compte de la force que représente le Front commun pour un débat public sur l'énergie. Sans le Front commun, sans son colloque et sa semaine sur l'énergie qui ont vraiment amorcé un véritable débat public sur la question, et sans son boycott de la Commission parlementaire du ministre Bérubé, je doute que ce dernier se serait senti obligé de promettre de tenir un débat public sur l'énergie, à l'instar des libéraux et sous une forme bien plus acceptable que celle proposée par ceux-ci.

En somme, le débat public sur l'énergie aura lieu, grâce en bonne partie au Front commun. Bien plus, ce débat a déjà commencé, et je ne crois pas qu'il se termine avant que la question n'ait été complètement vidée. Bien sûr, ce n'est qu'un début, les ressources financières et organisationnelles de ceux qui veulent continuer ce débat sont insuffisantes, mais les questions soulevées sont si fondamentales, les groupes et les individus impliqués sont si convaincus, et les critiques que ceux-ci font des soi-disant politiques officielles du gouvernement et d'HydroQuébec sont si pertinentes, qu'il ne sera plus possible de les faire taire.

L'importance cruciale d'un débat public découle du fait que les gens ordinaires et les groupes de citoyens sont souvent aussi bien, sinon mieux placés que les spécialistes et les entreprises intéressées pour comprendre et résoudre les problèmes qui les concernent. Nous avons tous à faire chaque jour de nombreuses déci- 
sions qui touchent à l'utilisation de l'énergie. Ces décisions sont trop importantes, trop politiques, et peut-être même trop simples pour qu'on s'en décharge sur des producteurs et des marchands d'énergie, et sur des bureaucrates et des technocrates qui nous ont fait la preuve à maintes reprises que leurs statistiques abstraites et leurs prévisions farfelues n'avaient qu'une mince relation avec la réalité vécue des gens et l'étoffe concrète de l'histoire. Un débat public complètement ouvert est la meilleure assurance que nous ayons que les erreurs faites dans le passé dans le domaine énergétique ne se répéteront pas. 
Mouvement écologiste, énergie et environnement.

Essais d'écosociologie.

Deuxième partie . Interventions et prises de position

\title{
Chapitre 6
}

\section{"Pour un débat public sur l'énergie.”}

Texte publié dans Le Devoir, le 5 octobre 1981, p. 14.

\author{
par Ronald Babin, Paul Berleur, Gordon Edwards \\ et Jean-Guy Vaillancourt.
}

\section{$\underline{\text { Retour à la table des matières }}$}

Avant les élections, M. Yves Bérubé, à l'occasion d'une commission parlementaire sur les investissements d'Hydro-Québec, avait formellement promis un débat public sur l'énergie, réclamé depuis longtemps par plus d'une soixantaine d'organisations regroupées dans le «Front commun pour un débat public sur l'énergie ».

Il semble bien que ce n'était là qu'une simple promesse électorale que le PQ a faite pour ne pas être débordé par le nucléocrate, Pierre Fortier, député libéral d'Outremont. Depuis les élections d'avril dernier, des décisions engageant notre avenir se prennent tous les jours dans le domaine de la production d'électricité et ce, sans que le gouvernement permette à l'ensemble de la population, qui aura de toute évidence à payer les conséquences de ces décisions, d'en discuter démocratiquement. Au lieu d'un vrai débat, on nous informe qu'il y aurait un «comité 
d'étude » chargé d'évaluer l'opportunité d'un débat public sur l'énergie. Quant à nous, nous croyons que la situation actuelle requiert ce débat publie.

Dans Le Devoir du 12 septembre, Lise Bissonnette commentait très judicieusement la récupération de l'idée de Robert Bourassa « d'exporter de l'électricité de base aux États-Unis » par le gouvernement du Parti québécois. Le rêve que le «Québec pourrait devenir l'OPEP de l'électricité », l'image qui veut que « nos rivières coulent pour rien, en pure perte » et l'espoir d'une richesse à portée de main venant de la vente de notre électricité aux Américains : tout cela mérite au moins d'être réexaminé par la population. Quant à nous, nous voulons rappeler le mandat d'Hydro-Québec : fournir de l'électricité aux Québécois au meilleur coût possible. Pourquoi changer ce mandat sans débat comme se propose de le faire le projet de loi 16 ? De plus, nous croyons que le Québec risque de se mettre dans une position de faiblesse et de dépendance s'il précipite les choses dans le domaine de l'exportation. Il serait le fournisseur d'une ressource naturelle qu'il aurait payée très cher en investissements de base. Imaginons un instant que les USA, comme demandeurs, se retirent du jeu. Ils mettent le Québec au bord de la faillite avec une énorme dette. Des milliards en investissement pour l'exportation, ça crée des emplois chez nos voisins du sud, pas chez nous ; ça crée un lourd endettement chez nous, pas chez nos voisins.

Une fois engagé dans la vente d'électricité aux USA, le Québec pourra-t-il se retirer au moment où il aura besoin de cette électricité pour lui-même ? Les USA comme prêteurs de capitaux n'auront-ils pas les moyens d'empêcher un tel retrait ? Le Québec serait alors forcé de se lancer dans le nucléaire.

L'autre hypothèse est celle d'une baisse de la consommation aux USA, baisse due à la volonté de réduire leur dépendance énergétique et aux programmes de conservation de l'énergie. Ceci laisserait le Québec avec des stocks d'électricité non vendue.

Sommes-nous d'accord pour payer deux fois plus cher l'électricité d'ici 1985 ? Voilà une question à laquelle nous répondons par la négative et, pourtant, HydroQuébec et le gouvernement mettent tout en place pour que ça devienne réalité : 
investissements disproportionnés et projet de faire d'Hydro-Québec une «société à actions dont le principal actionnaire est le gouvernement ».

Les investissements d'Hydro-Québec sont prévus en fonction d'un taux de croissance de $6 \%$ à un moment où Hydro-Ontario prévoit 3,1\% d'augmentation moyenne d'ici à la fin du siècle et où le ministère de l'Énergie, des mines et des ressources prévoit pour la même période 3,8\% d'augmentation pour le Québec. De plus, on sait que les mêmes investissements seraient moins coûteux et créeraient beaucoup plus d'emplois s'ils étaient mis dans un programme de conservation de l'énergie. Des études menées aux USA ont démontré qu'un programme de conservation réduit à la fois la consommation d'électricité et de pétrole.

Quant au projet de faire d'Hydro-Québec une société à actions avec le gouvernement comme principal actionnaire, il mérite au moins un débat. Si les profits d'Hydro-Québec servent à renflouer les déficits du gouvernement plutôt qu'à maintenir nos factures d'électricité à un coût modéré, ne sommes-nous pas, comme citoyens, victimes d'un nouvel impôt déguisé ? Ça aussi vaut d'être l'objet d'un débat.

Le gouvernement du Parti québécois, après avoir réaffirmé son moratoire nucléaire pendant la dernière campagne électorale, va-t-il céder aux pressions d'Ottawa, à ses offres alléchantes et se lancer dans la construction des quatre réacteurs de Gentilly III à un moment où il n'en a pas besoin ? Nos craintes vont dans le sens affirmatif et c'est pourquoi nous revenons à la demande d'un débat public sur l'énergie. Actuellement, pour sauver l'industrie nucléaire canadienne principalement située en Ontario (très peu de retombées économiques en termes d'emplois et investissements venant de cette industrie concernant le Québec), Ottawa met le paquet pour que le Québec construise Gentilly III et le Nouveau-Brunswick, Lepreau II. C'est la conclusion d'une étude réalisée par le ministère de l'Énergie, des mines et des ressources et présentée en juin 1981. Selon le Fédéral, si le Québec veut avoir des centrales nucléaires après 1990, il est nécessaire d'en construire dès maintenant pour empêcher que l'industrie nucléaire ne s'effondre. Qu'importe le fait que nous n'ayons pas besoin de l'électricité qui sera ainsi produite. Le nucléaire « inévitable », c'est une invention des technocrates et des marchands du nucléaire qui veulent protéger leurs emplois et leurs intérêts. Quant à nous, nous 
croyons qu'un débat public où toutes les options auraient le droit de parole et les moyens de diffuser leurs points de vue est la seule voie pour mûrir de bonnes décisions sur une base démocratique. Autrement, ne risquons-nous pas de nous faire avoir par les promoteurs de la technologie nucléaire ? 
Mouvement écologiste, énergie et environnement.

Essais d'écosociologie.

Deuxième partie . Interventions et prises de position

\section{Chapitre 7}

\section{“Contre l'énergie nucléaire.”}

Texte présenté par l'Alliance Tournesol et le Regroupement pour la surveillance du nucléaire, publié dans Le Devoir, 23 novembre 1981, p. 7.

par Chantal Hamel, Marie Vincent, Jean-Guy Vaillancourt, Ronald Babin, Paul Berleur, Jacques Boucher, Gordon Edwards, Alain Pontbriand et Stuart Stillitz

$\underline{\text { Retour à la table des matières }}$

Le Québec peut et doit s'organiser sans le nucléaire. Il n'a aucun intérêt à s'engager dans une voie qui risque de conduire à un désastre économique et écologique sans précédent.

Rappelons d'abord le coût exorbitant des centrales nucléaires, en soulignant à la fois leur coût officiel et leurs coûts cachés. Au départ, le coût estimé de Gentilly II était de 300 millions de dollars. Après de nombreux retards, l'entrée en opération est annoncée pour 1982, à un coût qui dépassera 3 milliards de dollars. Dans Le Devoir du 5 novembre dernier, Gilles Provost fait état de nouveaux dommages subis cet été à Gentilly II, qui ne sont pas encore complètement réparés, et dont les coûts ne sont pas encore connus. Le fédéral s'était engagé à défrayer la moitié du coût de la centrale, mais il refuse maintenant de verser plus de la moitié de la somme initiale. Ce sont les contribuables du Québec et les clients 
d'Hydro-Québec qui devront assumer les frais de ce cadeau du fédéral et qui devront payer une partie de la note des réparations.

Quant à Gentilly III, avec ses quatre réacteurs de 850 mégawatts, il devrait coûter de 7 à 8 milliards de dollars, selon les estimations actuelles d'HydroQuébec. Mais selon Hydro-Ontario, le coût des quatre réacteurs de Darlington, identiques à ceux de Gentilly III, sera plutôt de 11 milliards de dollars. HydroQuébec estime que ces coûts seraient raisonnables, une fois répartis sur les 30 années de fonctionnement de la centrale. Mais fonctionnera-t-elle durant 30 ans ? Avant l'accident de Harrisburg, le réacteur avait fonctionné seulement 3 mois. Plusieurs réacteurs devront être fermés aux USA parce que les radiations ont causé des fissures dans les cuves du réacteur. En Ontario, tous les réacteurs en opération seront fermés car on doit en rebâtir le coeur. Personne ne connaît le coût ni les risques de cette opération. Gentilly I, notre centrale-citron, n'a pas fonctionné plus de 200 jours en 10 ans.

Il faut ajouter aux coûts officiels les dépenses cachées que la collectivité est obligée d'absorber. Le gouvernement canadien a récemment épongé une dette de 825 millions de dollars de ]'Énergie atomique du Canada Ltée (EACL). Notre usine d'eau lourde à La Prade, qui a coûté 650 millions de dollars n'a jamais démarré parce qu'il y a surproduction d'eau lourde, et qu'Ottawa a favorisé celle de Bruce, en Ontario. La Prade ne pourra jamais fonctionner à cause de problèmes techniques dorénavant insurmontables. Dans ce seul dossier, le Québec a donc perdu des centaines de millions de dollars.

Trente-deux générateurs de vapeur défectueux ont été vendus à Hydro-Ontario par Babock et Wilcox dont la compagnie-mère a construit les réacteurs de Harrisburg. Hydro-Ontario doit maintenant débourser 10 millions de dollars pour les réparations, 400 millions pour les coûts de remplacement de l'électricité, et environ un milliard à cause du délai de construction. Des générateurs de vapeur défectueux identiques ont aussi été vendus à Hydro-Québec pour Gentilly II.

Aux coûts déjà encourus, il faut ajouter les coûts cachés qui s'annoncent pour l'avenir. Une fois la centrale hors d'usage, il faudra la démanteler, au coût de 30 à 40 millions de dollars par réacteur selon Hydro-Québec, mais une étude du 
congrès américain conclut que le coût de démantèlement d'un réacteur peut en venir à égaler son coût de construction. Il faudra aussi régler le problème des déchets radioactifs qui demeureront dangereux pour des milliers d'années. Et à quel coût ? Nul ne le sait. Selon des géologues canadiens, il n'y a aucune preuve scientifique qu'une solution existe au problème du stockage àlong terme de ces déchets extrêmement dangereux. Et si la centrale en vient à faire défaut, ce sont encore d'autres coûts imprévus. À Harrisburg, on évalue que le coût du nettoyage sera de 1 à 1,8 milliard de dollars, et on ne sait pas s'il est vraiment possible de faire ce nettoyage. Si le coeur du réacteur avait fondu, le coût aurait pu dépasser 10 milliards de dollars. Au Canada, les propriétaires des réacteurs nucléaires voient leurs obligations de dédommagement des personnes et des propriétés affectées par un accident limitées à 75 millions de dollars. Le reste du dédommagement retombe sur les épaules du fédéral, bref sur nos impôts. De plus, dans nos polices d'assurance, il y a une clause qui indique que nous ne sommes pas couverts, advenant un accident impliquant des contaminations radioactives.

Ceci nous amène à la conclusion qu'au plan économique, J'aventure nucléaire risque d'être catastrophique. Il faut donc faire pression pour que le moratoire sur le nucléaire soit maintenu et même étendu afin d'y inclure Gentilly II et Gentilly III. De plus, il faut que cessent l'exploitation de l'uranium et le transport de celui-ci (en particulier, vers et à partir du port de Montréal). Nous savons que l'EACL est prête à financer 75\% du coût final de Gentilly III, et ce, dans le but d'empêcher la faillite de l'industrie nucléaire canadienne, car celle-ci n'a pas réalisé de vente depuis 1978. Alors que le nucléaire semblait prometteur au Canada, le fédéral en faisait l'implantation en Ontario. Seulement 10\% des 5,7 milliards de dollars dépensés par Ottawa pour promouvoir le nucléaire entre 1945 et 1979 ont été investis au Québec. Aujourd'hui que la situation s'est détériorée pour cette industrie, Ottawa veut à tout prix en refiler les coûts au Québec, à la Corée du Sud et à l'Argentine. Le nucléaire ne sert pas les intérêts du Québec. Il est trop coûteux, nous n'en avons pas besoin et il est impératif de nous organiser sur le plan énergétique pour développer des choix réalistes aux énergies non renouvelables et polluantes.

Du point de vue écologique, il est indubitable que les centrales nucléaires sont dangereuses. Il ne se passe pas une semaine sans qu'ici ou à l'étranger, un accident 
n'arrive. Des études récentes font état des dangers de cancer dus aux faibles émissions de radioactivité d'un réacteur en fonctionnement normal. Les réacteurs CANDU produisent 30 fois plus de tritium, et 20 fois plus de carbone 14 que les réacteurs américains, et presque tout ceci est libéré dans l'air et dans J'eau durant le fonctionnement normal du réacteur. Les centrales nucléaires canadiennes produisent des tonnes de plutonium (deux fois plus que les réacteurs américains), en plus de 200 autres substances radioactives dont on ne sait que faire. Les dangers pour la santé sont si considérables que l'Association médicale de la Colombie britannique a affirmé qu'il était irresponsable de la part d'Ottawa d'octroyer des permis de fonctionnement pour les réacteurs nucléaires aussi longtemps que le problème des déchets radioactifs ne sera pas réglé. De plus, une commission royale en Ontario a recommandé qu'un moratoire soit imposé si on ne trouve pas une solution au problème des déchets d'ici 1985.

Avec le plutonium, nous entrons dans le processus de prolifération des armes atomiques. Le rapport Ford-MITRE sur la politique nucléaire américaine a révélé que le CANDU est le réacteur le plus apte à produire du plutonium de la qualité nécessaire à la fabrication des bombes atomiques. On connaît le cas de l'Inde qui, en 1974, a fabriqué sa bombe atomique a partir d'un réacteur expérimental canadien. Rappelons qu'Israël, qui a l'arme atomique, a bombardé récemment une centrale expérimentale française que l'Iraq construisait pour avoir elle aussi sa bombe. Quand les nucléocrates tentent de nous rassurer sur la sécurité des centrales nucléaires, comment les croire ? Quand les pro-nucléaires nous disent, comme Pierre Fortier (député libéral et ex-président de CANATOM), que « dans la vie, il faut prendre des risques », nous refusons cette logique insensée parce que ce sont nos vies et celles des générations futures qui sont en jeu.

D'après les calculs de l'EACL, le taux de risque est d'un sur quatre pendant les présumées 30 années de vie d'un réacteur CANDU pour qu'arrive un accident semblable à celui de Harrisburg. Personne ne sait à quel moment cela pourrait se produire, ni quelles conséquences un tel accident pourrait avoir.

En conclusion, rappelons l'importance d'un débat public sur l'énergie. Collectivement, nous devrions prendre deux ou trois ans pour examiner tous les enjeux impliqués dans cette question. Nous savons, et un grand nombre d'études le dé- 
montrent, que les programmes d'économies d'énergie et le développement des énergies nouvelles créeraient beaucoup plus d'emplois, de sécurité et d'autonomie locale que toutes ces installations nucléaires ruineuses et dangereuses. Il existe des voies non nucléaires qui feraient un meilleur usage de nos ressources énergétiques, financières et humaines. En Suède et en Allemagne de l'Ouest, il est interdit d'installer dans un édifice un chauffage électrique avant d'avoir mis en place un système de stockage de chaleur, ceci afin d'éviter l'utilisation de l'électricité en période de pointe. Une fois le système de stockage installé, quoi de plus logique que de faire appel à des collecteurs solaires, possiblement couplés d'une pompe à chaleur? Voilà un exemple parmi des centaines d'autres qui nous indique quelle est la voie à suivre. Au delà de l'utilisation plus efficace des ressources énergétiques disponibles, il y a aussi les combustibles fluides dérivés des matériaux organiques, la co-génération industrielle, l'énergie solaire et éolienne et l'utilisation plus rationnelle du bois. L'indépendance énergétique est de ce côté, et non sur la voie qui nous mène à l'impasse atomique. Un débat social s'impose... 
Mouvement écologiste, énergie et environnement.

Essais d'écosociologie.

Deuxième partie . Interventions et prises de position

\section{Chapitre 8}

\section{Les interventions du groupe Écologie humaine d’Hydro-Québec}

Texte publié dans L'Intervention sociale : Actes du colloque annuel de l'ACSALF, (sous la direction de Micheline Renaud-Mayer et Alberte Le Doyen), Éditions coopératives Albert Saint-Martin, Montréal, 1982, p. 245-255.

\section{par Jean-Guy Vaillancourt}

\section{$\underline{\text { Retour à la table des matières }}$}

Les organisatrices de ce panel m'ont demandé de commenter brièvement l'exposé des membres du groupe Écologie humaine de la direction Environnement d'Hydro-Québec, afin d'aider à lancer le débat. Je me limiterai donc dans mes commentaires à discuter du type d'intervention que font les sociologues et les autres spécialistes des sciences humaines du groupe Écologie humaine, ainsi que du genre d'interventions qu'ils pourraient et devraient peut-être faire. Je dirai auparavant quelques mots sur l'exposé lui-même, et je ferai aussi quelques remarques sur les projets et les programmes d'Hydro-Québec, notamment sur divers projets de lignes à haute tension et sur le projet d'harnachement de l'Ashapmouchouan.

Tout d'abord, avouons qu'il ne doit pas être facile de travailler à la direction Environnement d'Hydro-Québec, quand on a des préoccupations écologiques et environnementales le moindrement sérieuses, et quand on a des exigences per- 
sonnelles et professionnelles en ce qui concerne la participation et le pouvoir réels des citoyens dans les décisions qui les affectent. Bien entendu, ce doit être quand même plus facile de travailler là que d'être responsable des questions environnementales chez Domtar, à l'Alcan, ou à Noranda Mines. Les vingt personnes du groupe Écologie humaine de la direction Environnement, et plus particulièrement les quelques sociologues parmi eux, ne représentent probablement pas un poids très lourd en termes d'influence sur les grands projets énergétiques et sur les décisions d'investissement et de financement, dans ce milieu d'ingénieurs et de technocrates qu'est Hydro-Québec, mais au moins, ils sont là et ils peuvent à l'occasion se faire entendre. Les critiques que l'on peut et que l'on doit faire à l'égard d'Hydro-Québec ne devraient donc pas, à strictement parler, s'adresser seulement à eux, mais bien plus à ceux qui les encadrent et à d'autres services et directions de l'entreprise, avec lesquels ils doivent sans doute être plus souvent en conflit qu'à leur tour. Cependant, ils travaillent à Hydro-Québec, et ils doivent souvent défendre publiquement les politiques et les actions de leur employeur. Pour cette raison, je pense qu'il est normal qu'on puisse leur adresser certaines critiques et certaines suggestions dans l'espoir d'infléchir un peu si possible les orientations actuelles et futures de leur service et de leur entreprise.

Je dois d'abord reconnaître que la communication qui vient de nous être présentée constitue un document sérieux et intéressant, et même si on doit la considérer avant tout comme un effort de relations publiques, elle manifeste toutefois passablement d'ouverture et même de courage, étant donné la position précaire des sociologues et des écologistes, et à fortiori des sociologues de l'environnement, à Hydro-Québec. Il n'a pas dû être très facile pour eux de faire accepter le principe, puis le contenu, d'un tel exposé par leurs patrons, même si à plusieurs d'entre nous, ce qu'ils disent peut sembler assez modéré et plutôt inoffensif. Coincés comme ils le sont entre le marteau des contestataires et l'enclume patronale, ils ont quand même opté ici pour l'ouverture et la franchise, tout en maintenant une certaine loyauté, pour ne pas dire une loyauté certaine, à l'égard de leur employeur.

Ce qui ressort du texte des membres du groupe Écologie humaine, c'est que le rôle de ce groupe dans la planification, dans les étapes préliminaires des projets, et dans l'aménagement du territoire, est bien secondaire et limité. Quant aux étu- 
des sociales, spécialement les études sociologiques qu'ils entreprennent, leur cadre apparaît aussi comme étant fortement restreint. Elles portent surtout sur les projets d'aménagement d'équipement de production et de transport, plutôt que sur des questions plus larges et plus fondamentales comme celles de la prévision de la demande en électricité, des besoins énergétiques en général, et des choix alternatifs qui s'offrent aux Québécois. On touche aux questions d'emploi pour montrer les retombées positives des projets, mais on en néglige les aspects négatifs comme les problèmes sociaux posés par les dangers à la sécurité des travailleurs et à leur bien-être, dans des chantiers isolés et temporaires où il est très difficile de vivre normalement et de façon sécuritaire. On parle de consultation publique, et de facilitation de la participation du public aux études et aux prises de décision, mais il s'agit bien plus en fait de séances d'information où les avis recueillis ont peu de chances de renverser des décisions déjà passablement amorcées. Les études que font les chercheurs du groupe Écologie humaine ne seraient-elles pas, pour ceux qui décident vraiment à Hydro-Québec, qu'une étape tardive, encombrante et malheureusement devenue obligatoire, pour mieux faire accepter ce qui est déjà décidé ou en voie de l'être?

À l'autocritique intéressante mais bien mitigée qu'ils font de leurs possibilités d'intervention, il faudrait donc ajouter aussi ce fait qu'Hydro-Québec tient peu compte finalement de l'avis des citoyens et des groupes populaires que les enquêtes du groupe Écologie humaine peuvent rassembler. On demande aux gens ce qu'ils pensent du fait qu'une ligne à haute tension passera à tel ou tel endroit, mais on se garde bien de remettre en question les options plus fondamentales, à savoir si le projet lui-même est désirable, si on doit produire autant d'électricité au Québec, si la structure des tarifs est équitable, si le maintien de l'option hydroélectrique à outrance est souhaitable, si la voie nucléaire est acceptable, s'il ne serait pas plus désirable de favoriser le solaire, les économies d'énergie et même le gaz naturel. On cherche à mieux connaître les populations affectées par les projets, non pas pour réviser ces derniers, mais pour mieux pouvoir les faire passer. On cherche à convaincre du bien-fondé du projet tel que conçu en insistant sur les retombées économiques éventuelles, plutôt que d'accepter un vrai débat sur le projet et sur les options qui le sous-tendent. 
C'est un fait bien connu que la technocratie hydro-québécoise est bien cachottière et très avare d'information. La politique d'interaction avec ses publics qu'Hydro-Québec s'est donnée en 1978 et « qui vise à intégrer dans son processus décisionnel le résultat de ses communications avec la population », et les lois qui l'obligent à rendre publics les résultats des études d'avant-projets, ont rarement amené l'entreprise à modifier quoi que ce soit, à l'exception de quelques choix d'emplacements de postes ou de tracés de lignes. Hydro-Québec tient de plus à garder secrets les projets de transactions financières et commerciales, même après leur conclusion, et les délibérations des comités du conseil d'administration en plus de celles du Conseil d'administration lui-même, et veut que les personnes et les groupes paient les frais de la transmission de l'information demandée.

Au colloque du Front commun pour un débat public sur l'énergie qui a eu lieu à l'UQÀM en février 1981, il n'y a pas eu de participation réelle et officielle d'Hydro-Québec, sauf une aide symbolique de 5000 \$ qui a été arrachée de justesse au Conseil d'administration suite à un refus de la direction. Il y a bien eu quelques participants d'Hydro-Québec qui sont venus à titre individuel, par exemple la personne qui au Conseil d'administration représente les consommateurs. Par ailleurs, un responsable des relations publiques d'Hydro est intervenu à partir de la salle pour sommer le Front commun pour un débat public sur l'énergie de se transformer dès le lendemain du colloque en centre d'information sur les questions énergétiques, plutôt que de continuer à fonctionner surtout comme groupe de pression pour obtenir un débat Publie sur l'énergie. Venant d'un service d'Hydro-Québec qui est passablement avare en information, cette invitation au Front commun pour qu'il se saborde afin de remplir une fonction que ce service lui-même devrait remplir mais ne remplit pas, donnait toutes les apparences d'une provocation, Les membres du groupe Écologie humaine qui étaient présents dans la salle et qui manifestement auraient pu faire entendre un autre son de cloche ont préféré garder le silence. Il me semble que c'est dans des rencontres comme celle-là, autant que durant les colloques de l'ACSALF au congrès de l'ACFAS, que le groupe Écologie humaine devrait se manifester.

En tant que professeur de sociologie de l'environnement et de sociologie des organisations, et en tant que chercheur quelque peu militant dans le domaine des politiques énergétiques et des mouvements écologiques depuis déjà presque dix 
ans, j'ai eu l'occasion à quelques reprises de jeter un coup d'oeil sur les façons de procéder d'Hydro-Québec dans certains dossiers énergétiques. Un séjour de plus de deux semaines dans la région du Saguenay et du Lac Saint-Jean, et plus spécialement à Saint-Félicien où la rivière Ashouapmouchouan se déverse dans le lac Saint-Jean, m'a donné récemment l'occasion d'approfondir, avec des gens impliqués dans les problèmes écologiques de la région, le dossier sur le projet d'harnachement qu'envisage Hydro-Québec sur cette rivière sauvage et majestueuse. De plus, je suis présentement engagé avec divers groupes écologiques québécois dans une évaluation critique des politiques énergétiques gouvernementales et de l'action d'Hydro-Québec dans le domaine de l'énergie ${ }^{92}$.

La première fois que je suis venu en contact avec les gens du service Environnement à Hydro-Québec, c'était il y a 6 ans. À ce moment-là, en 1975 et en 1976, j'ai fait partie d'un petit et éphémère comité d'experts, constitué par une firme de consultants engagée par Hydro-Québec, et qui « avait pour mandat général d'étudier, d'analyser et de formuler des critiques constructives concernant l'approche générale, la méthode, les inventaires et le schéma d'interprétation des dossiers préparés aux fins de localisation de la ligne Canton Mousseau-Chénier. Il était entendu que [nos] critiques seraient utilisées pour améliorer la qualité des travaux à venir 93 ».

Comme d'habitude, les experts ne furent pas d'accord entre eux, d'autant plus que ce problème du choix des tracés est toujours extrêmement complexe. Mais les deux d'entre nous qui avons osé dépasser le cadre étroit qui nous avait été imposé

92 Jean-Guy Vaillancourt, «Les Québécois ont-ils besoin du nucléaire ? Le point de vue des groupes anti-nucléaires québécois », De toute urgence, vol. XII, no 2, août 1981, p. 231-243 et Jean-Guy Vaillancourt, « Le débat public sur l'énergie aura-t-il lieu ? », Possibles, vol. 5, no 3, 1981.

Voir aussi les articles que j'ai écrits en collaboration avec divers membres des groupes anti-nucléaires Alliance Tournesol et Regroupement pour la surveillance du nucléaire, dans Le Devoir du 10 février 1981, « La politique québécoise de conservation de l'énergie », du 5 octobre 1981, « Pour un débat public sur l'énergie », et du 23 novembre 1981, « Contre le nucléaire ».

93 Rapport du Comité d'experts sur l'environnement. Analyse méthodologique, Direction Environnement, Hydro-Québec, Rapport Canton MousseauChénier, Dossier 030411-10, janvier 1976. 
et qui avons eu l'audace d'affirmer dans nos textes qu'il nous semblait que nous avions été mobilisés pour une opération de relations publiques plutôt qu'à cause d'une préoccupation réelle envers l'environnement et envers les opinions de la population affectée, avons eu droit chacun à une rebuffade de la part de l'auteur du rapport général de notre comité. Il s'agissait, pour Hydro-Québec et pour la firme de consultants, à mon avis, de montrer, face aux critiques qu'adressait alors à Hydro-Québec le Conseil consultatif de J'environnement, que cette entreprise pouvait aussi faire appel à des experts en environnement, indépendants et crédibles.

En 1977, mon texte de 1976 a été publié de nouveau, cette fois par le Comité de citoyens de Saint-Jean-de-Matha, dans un mémoire soumis aux Services de protection de l'environnement, pour tenter d'obtenir le rejet du projet de ligne électrique de 755 kilowatts dans la région de Saint-Jean-de-Matha. Selon ce comité de citoyens, les gens d'Hydro-Québec leur avaient dit que leurs critiques concernant la participation des citoyens étaient trop nouvelles pour qu'il soit possible d'en tenir compte. C'est à ce moment-là que le Comité avait déniché mon texte de 1976 et avait décidé de s'en servir pour montrer que les mêmes critiques avaient été faites l'année précédente dans un rapport officiel, et qu'Hydro-Québec n'avait pas cru bon d'en tenir compte.

Les critiques que je faisais en 1976 me semblent encore pertinentes et valables aujourd'hui. Je disais alors qu'Hydro-Québec devrait améliorer le processus de consultation et de décision utilisé dans la sélection de ses tracés de lignes à haute tension, et dans ses projets en général. Je parlais de «la nécessité de ne pas se leurrer et de croire qu'une consultation bidon et une campagne d'information ex post facto seraient suffisantes dans les relations avec la population et avec les organismes intéressés ».

Comme la ligne Canton Mousseau-Chénier elle-même posait en somme assez peu de problèmes écologiques et humains sérieux, j'avais débordé légèrement le cadre étroit du mandat du comité d'experts pour aborder la question de la ligne antérieure Chénier-Châteauguay, suggérant qu'Hydro-Québec devrait accepter de rouvrir ce dossier et même de rectifier le tracé choisi s'il y avait lieu, à la lumière 
des nouveaux « inputs »introduits sur le tard dans le débat par les citoyens et les groupes impliqués.

J'ai surtout à ce moment-là fait des suggestions pour le processus de consultation pour les tracés des lignes venant après Chénier-Châteauguay et après Canton Mousseau-Chénier, qui à mon avis s'annonçaient comme étant encore plus problématiques et plus propices à la controverse que ces deux projets. Ce qui me semblait le plus important, c'était « qu'il y ait aussi, dès le début, une large consultation de la population, par des sondages et surtout par des rencontres et par des échanges d'information avec les organismes publics, les corps intermédiaires, les groupes populaires, les représentants de municipalités et autres personnes intéressées qui risquent d'être affectées d'une façon ou d'une autre par ces lignes à haut voltage ».

Et je terminais en disant que les gens « acceptent difficilement qu'HydroQuébec soit juge et partie et que dans la mesure où elle est partie, elle ne soit pas contrebalancée par d'autres instances représentant des intérêts, des valeurs, et des points de vue différents, plus généraux, et plus près des préoccupations des gens à la base, au plan local. Je pense que la solution à laquelle on pourra arriver après une campagne de consultation et d'information faite dès le début des inventaires, et après de sérieux échanges avec les parties intéressées, sera moins arbitraire que si l'on ne consulte et informe qu'après que la décision a été prise avec les seules lumières des gens d'Hydro et de leurs consultants. Fondamentalement donc, ma recommandation est que ce type de décision est trop important pour être laissé aux politiciens, aux bureaucrates, aux technocrates et aux experts ».

J'ai insisté sur ces recommandations faites en 1976, non pas pour dire aux gens d'Hydro: «Je vous l'avais bien dit », mais pour qu'on puisse mesurer le chemin parcouru en six ans. On consulte un peu plus, et un peu plus tôt dans le processus du choix des tracés de ligne en 1981, on a fait un certain chemin depuis 5 ans, mais on ne tient pas beaucoup plus compte de l'avis de la population, des intéressés, et des experts de l'extérieur. Dans le cas de l'Ashouapmouchouan, on offre un choix entre deux projets, alors que ce sont les projets eux-mêmes et même la politique énergétique globale d'Hydro qui doivent être mis en question, et non l'un ou l'autre des deux projets proposés. La stratégie des gens d'Hydro est de 
circonscrire l'opposition potentielle à l'intérieur d'un cadre étroit dont les options générales sont considérées comme acquises. Les représentants de la direction Environnement ne peuvent alors fonctionner que comme des agents d'information et de relations publiques, parfois même comme des espions ou des soupapes de sûreté, auprès de la population. Si par hasard ils s'avisent d'être trop critiques ou même trop tièdes vis-à-vis des projets préparés indépendamment d'eux, ou s'ils établissent une relation d'ouverture trop grande et surtout de support envers les groupes ou envers l'environnement affectés par ces projets, ils risquent d'être ostracisés ou même mutés. Dans le cas de l'Ashouapmouchouan, on a établi une consultation publique avant que les décisions finales ne soient prises, mais rien n'indique qu'on tiendra compte de l'opposition presque générale et sans cesse grandissante au projet tel qu'il a été formulé. Même les quelques chambres de commerce et conseils municipaux locaux qui sont favorables au harnachement de cette rivière, le sont en posant des exigences telles (par exemple des tarifs réduits pour l'industrie locale, ou une participation locale aux investissements, ce qui équivaudrait à une dé-nationalisation de l'électricité) que leur appui équivaut en pratique à une forme de refus. Les supporteurs inconditionnels du projet sont tellement rares et si visiblement intéressés par des gains à court terme qu'on peut dire que le projet est jugé inacceptable par la population consultée. Et pourtant, Hydro-Québec continue à engloutir des millions dans la préparation de ce projet comme si la population s'était prononcée favorablement.

Aujourd'hui, avec cinq ans de recul, ma critique des interventions d'HydroQuébec va bien plus loin que celle que je formulais en 1976. Hydro-Québec a beau consulter les gens tôt dans le processus, si elle ne tient pas compte de l'avis de la population ou ne donne de choix qu'entre deux modalités quasi-équivalentes d'un même projet, la consultation demeure de la pseudo-consultation. La méthode s'est raffinée, mais elle n'a pas changé substantiellement. En un certain sens, c'est pire, car on donne l'impression aux gens que leur opinion aura un certain poids, mais quand ils ne sont pas d'accord avec les plans d'Hydro-Québec, on ne tient pas compte de leur opposition. Et le groupe Écologie humaine, qui a acquis un certain statut dans l'entreprise, malgré sa position toujours précaire, ne semble pas capable de dépasser sensiblement la fonction de caution et de légitimation qu'on lui assigne, pour assumer des positions critiques à l'égard des orientations officielles de l'entreprise, et un rôle d'appui véritable à ceux qui demandent un débat pu- 
blic sur l'énergie afin de préparer l'avenir énergétique à long terme de notre société.

Pourquoi le groupe Écologie humaine ne pourrait-il pas, de l'intérieur, travailler pour un moratoire sur les nouveaux projets grandioses qui s'amorcent, aider à la diffusion de l'information sur l'énergie, élaborer des scénarios et des courbes de demandes réalistes, entreprendre des études de rentabilité tenant compte des coûts sociaux, économiques et environnementaux, étudier la question des pratiques commerciales et de la tarification qui apparaissent inéquitables envers le petit consommateur, évaluer la part de l'électricité dans la consommation globale, proposer des stratégies d'établissement de bilans énergétiques, d'économies d'énergie et de décentralisation-diversification du système énergétique québécois ?

Un véritable débat, tout comme une consultation honnête et ouverte ne doit pas préjuger des conclusions, mais doit mettre en contact des experts et des représentants des citoyens et des groupes intéressés par le bien commun. Le domaine énergétique n'est pas aussi complexe que les experts veulent bien le faire croire, même s'il comprend des décisions multiples à divers niveaux allant de l'individu à l'État. Les risques d'erreurs sont grands, dans ce domaine, mais plusieurs des pires erreurs (l'addition pétrolière, l'embardée nucléaire, La Prade, l'encouragement au gaspillage électrique d'il y ,a quelques années, la dette grandissante d'HydroQuébec et son récent programme d'investissement) auraient pu être évitées ou mitigées si des esprits clairvoyants à Hydro-Québec avaient assumé leurs responsabilités et consulté le public au lieu de se contenter d'être de bons experts hydroquébécois. Amory Lovins avait bien raison, à mon avis, de dire : « Les aspects fondamentaux d'une stratégie énergétique sont loin d'être complexes pour le public en général, mais ils sont trop simples pour les bureaucrates et les technocrates $»$.

On l'a vu à la Commission parlementaire sur l'énergie en 1977, où les groupes de citoyens demandèrent plus d'information et exigèrent un débat publie, en plus d'offrir des amorces de solution qui s'avèrent aujourd'hui beaucoup plus adéquates que celles proposées par Hydro. La plupart des groupes ont refusé de participer à la Commission parlementaire de février 1981 durant laquelle Hydro-Québec proposa un programme d'investissement d'environ 100 milliards de dollars pour les 
années 80. Ce plan prévoit un accroissement de demande de 6,2\% par année et un pourcentage de $45 \%$ du bilan énergétique global pour l'électricité en 1996, c'est-àdire presque le double de ce qu'il est aujourd'hui. Beaucoup de gens mettent en question ce programme et ces prévisions farfelues basées sur des présupposés inacceptables et qui risquent de nous acheminer à la banqueroute. Avons-nous vraiment besoin de toute cette électricité ? Peut-on vraiment se fier à HydroQuébec pour gérer des programmes d'économie et d'efficacité énergétique d'énergies nouvelles, et écologiquement bénignes, qu'hier encore cette entreprise considérait comme irréalisables et ridicules. Peut-on demander à Hydro-Québec d'encourager le chauffage au gaz naturel et le solaire actif et passif, la décentralisation et la diversification du réseau énergétique, et même de tenir compte de l'impact négatif de ses projets sur la nature et sur la population?

Il me semble que ce sont des questions de ce genre dont devraient s'occuper les sociologues de l'environnement et les autres spécialistes des sciences sociales du groupe Écologie humaine, plutôt que de se laisser utiliser uniquement pour sonder ou pour convaincre les gens affectés par les projets grandioses des ingénieurs et des technocrates qui ne songent qu'à produire de plus en plus d'électricité.

Il faudrait, il me semble, que les sociologues de l'environnement fassent pénétrer à Hydro-Québec les idées de Lovins sur les voies énergétiques douces, ainsi que celles d'Hélène Lajambe, de Solange Vincent et du Front commun pour un débat public sur l'énergie. Il faudrait qu'ils travaillent à ouvrir les écluses de l'information dont le public et les groupes ont besoin. Ce qu'ils livrent, parcimonieusement, ce sont les conclusions générales d'études secrètes et les résultats de modèles dont les données et les présupposés de base restent cachés. Il faudrait qu'ils soient à l'écoute des groupes écologiques, qu'ils assument leurs demandes valables. En somme, il faudrait qu'ils se branchent avec la population et les groupes écologiques plutôt qu'avec les technocrates et les industriels du kilowatt, qui nous préparent une deuxième Baie James pour le plus grand bien des fournisseurs et des consultants d'Hydro-Québec, et qui veulent construire des centrales nucléaire, même s'ils n'en parlent pas beaucoup afin de ne pas effrayer la population. Mais lorsqu'on lit attentivement certains documents qu'Hydro a rendu publics, on s'aperçoit que le nucléaire reste une option importante pour cette entreprise. Il y a 
présentement 63 millions de dollars de prévus pour de la recherche sur un programme nucléaire minimal qui, selon Hydro-Québec, « est susceptible d'assurer éventuellement de façon économique la relève de l'hydraulique ». Les 12012 qui nous poussaient il y a quelques années à surconsommer l'électricité se sont convertis bien tardivement et douloureusement (et à moitié) aux économies d'énergie et aux énergies nouvelles, mais ils louchent quand même vers une deuxième Baie James et vers de nouvelles centrales nucléaires. Je sais qu'il n'est pas facile pour des sociologues à Hydro-Québec de tenir front aux ingénieurs, mais après le fiasco de La Prade, et la construction des centrales citrons de Gentilly dont Hydro-Québec risque de devenir la propriétaire, il me semble qu'il leur serait possible, sinon d'infléchir le rapport de force à l'intérieur d'Hydro, du moins de fournir, discrètement s'il le faut, des informations et des appuis plus substantiels aux groupes écologiques et anti-nucléaires, et aux autres citoyens et groupes populaires qui luttent pour une politique énergétique sensée et rationnelle. HydroQuébec n'a-t-elle pas intérêt, à long terme, même d'un strict point de vue économique, à tenir compte des points de vue exprimes par la population, par les groupes écologiques et par les associations de protection des consommateurs.

Toute la question des surplus d'électricité, de la vente de ces surplus éventuels aux Américains, et du prix et des concessions qui seront exigés pour cette exportation, doit aussi être clarifiée. De même, ces 100 milliards environ pour le programme d'investissement de 10 ans, et les hausses exorbitantes de tarifs, est-ce que ça ne devrait pas être discuté publiquement, et pas seulement dans des commissions parlementaires de quelques jours ? Ces investissements correspondent à presque 50000 \$ par famille québécoise ! Et maintenant que la crise économique pousse le gouvernement à restreindre les projets d'Hydro-Québec et à exiger une partie des profits, est-ce que les coupures vont être faites aux bons endroits, ou est-ce qu'on ne sera pas tenté de sabrer dans les programmes d'économie d'énergie et les projets d'énergies nouvelles. Le groupe Écologie humaine ne pourrait-il pas essayer d'intervenir dans ces questions, puisqu'elles impliquent à la fois des aspects humains et des aspects écologiques?

Il faudra bientôt amorcer au Québec, dans le domaine de l'énergie et surtout de l'énergie électrique, une planification plus souple que celle que nous préparent les technocrates d'Hydro-Québec, et je pense que la seule façon d'y arriver, c'est 
d'impliquer la population dans un vaste débat public sur l'énergie comme celui qu'exigent des centaines de groupes et que le PQ avait promis de tenir s'il gagnait les élections. Je crois que le groupe Écologie humaine, qui joue déjà un rôle indispensable à Hydro-Québec, a une contribution importante à faire pour que ce grand débat public ait lieu, et ensuite pour qu'il se fasse dans les meilleures conditions possibles. Michel Nadeau, dans un éditorial du 18 décembre 1980 sur les investissements d'Hydro-Québec, affirmait : «Un véritable débat démocratique présuppose une connaissance à peu près égale des informations pertinentes. Cette fois-ci, Hydro-Québec doit ouvrir toutes les lumières autour de la table. Autrement l'opinion publique pourrait fort bien un jour couper le courant. » Ceux qui luttent pour ce débat démocratique et pour l'accès à l'information peuvent-ils compter sur les sociologues du groupe Écologie humaine, ou devront-ils se contenter de les voir continuer de faire le genre d'interventions, utiles certes, parfois, mais insuffisantes, dont ils nous ont entretenu ici aujourd'hui ? Je suis sûr que la plupart des sociologues qui travaillent au groupe Écologie humaine, tout comme les autres sociologues qui sont dans d'autres services à Hydro-Québec, sont conscients depuis longtemps de la plupart des choses que nous leur disons actuellement. Il ne s'agit donc pas de les écraser sous les opprobres, de faire des gorges chaudes et de les condamner. Ils ont bien plus besoin de notre appui et de notre compréhension, étant donné qu'ils oeuvrent dans un contexte institutionnel délicat et difficile. Mais ils ont aussi besoin de nos suggestions et de nos critiques. C'est ce que nous devrions tenter de faire aujourd'hui. 
Mouvement écologiste, énergie et environnement.

Essais d'écosociologie.

Deuxième partie . Interventions et prises de position

\title{
Chapitre 9 \\ “L'électricité et le nucléaire.”
}

Texte publié dans La Presse, 6 mai 1982, p. A7.

\begin{abstract}
par Ronald Babin, Pascal Baudoux, Jean-François Beaudet, Paul Berleur, Jacques Boucher, Gordon Edwards et Jean-Guy Vaillancourt
\end{abstract}

$\underline{\text { Retour à la table des matières }}$

À la veille des élections d'avril 1981, lors des séances tenues par la Commission parlementaire chargée d'étudier la stratégie d'investissements d'HydroQuébec pour les années 80, le ministre Yves Bérubé faisait la promesse de tenir un débat public sur l'énergie. Pendant que nous continuons d'attendre ce débat, des décisions nombreuses se prennent qui engagent notre avenir.

Des événements importants ont eu lieu dernièrement qui appellent une réflexion de tous les citoyens : la signature d'un important contrat de vente d'électricité à l'État de New York, venant à la suite d'une prise de conscience que le Québec dispose d'importants surplus d'électricité ; l'annonce de la mise à l'écart temporaire du projet Gentilly III ; l'annonce de la création d'un Centre de recherches à Varennes pour produire des combustibles nucléaires artificiels tel l'uranium 233 ; la campagne internationale du ministre Marc Lalonde pour vendre des réacteurs CANDU et sa menace de dépenser unilatéralement une bonne partie des 200 millions de dollars destinés à l'usine d'eau lourde de La Prade pour le développement 
au Québec du secteur nucléaire (par exemple, 50 millions de dollars pour la remise en fonctionnement de la centrale-citron Gentilly 1).

De tous ces faits, celui qui a retenu l'attention du public est certainement le contrat de plusieurs milliards que M. René Lévesque a signé avec l'État de New York pour la vente d'électricité. À première vue, il s'agit d'une affaire très profitable. Dans cet article, nous allons poser quelques questions sur cette vente et sur les orientations d'Hydro-Québec. Nous profiterons de la mise entre parenthèses de Gentilly III pour réclamer à nouveau un débat public sur l'énergie. N'est-ce pas, en effet, une occasion unique de faire vraiment le point non seulement sur le nucléaire, mais aussi sur l'ensemble de la question énergétique ? Nous voulons surtout mettre en garde nos concitoyens : pendant qu'ils risquent d'oublier le nucléaire, une offensive tous azimuts est organisée par l'industrie nucléaire pour le réintroduire sous diverses formes.

La vente d'électricité aux États-Unis nous rapportera quelques milliards : c'est positif à première vue. Mais les choses ne sont pas si simples. Le Québec va se trouver en situation de compétition avec l'Ontario, le Nouveau-Brunswick et plusieurs États américains qui tous ont d'imposants surplus d'électricité. Est-on sûr que la demande et le prix de l'électricité vont se maintenir ? Si nous investissons à outrance dans de nouveaux barrages et dans la construction de lignes destinées uniquement à l'exportation, quelle garantie avons-nous que nos coûteux investissements vont rapporter ? Qu'arrivera-t-il s'ils rapportent peu ? Si le Québec sort perdant du différend qui l'oppose à Terre-Neuve au sujet des chutes Churchill, pourra-t-il honorer ses contrats de vente ? Le Québec, dans toute cette histoire, ne risque-t-il pas de connaître le sort peu enviable des pays qui sont des fournisseurs de matières premières ?

Le 27 novembre 1981, le conseil d'administration d'Hydro-Québec annonçait sa décision « de surseoir aux études d'avant-projet de Gentilly III, ne reconnaissant pas l'urgence de réaliser une telle centrale nucléaire ». On a vite interprété cette annonce comme un moratoire qui reporte après l'an 2000 le développement du nucléaire. Pourtant telle n'est pas la réalité. 
La centrale Gentilly II sera mise en fonctionnement en 1983. On procède actuellement à son chargement en combustible. Il y a cependant plusieurs problèmes relatifs à cette centrale qui requièrent une discussion publique avant qu'il ne lui soit accordé un permis d'opération : des fissures sur la paroi interne de l'édifice de retenue ont été découvertes et le bureau de contrôle d'Énergie atomique reconnaît que ça n'est pas permis selon les spécifications du plan original ; un document interne d'EACL (Énergie atomique du Canada Limitée) révèle que plusieurs devis relatifs à la résistance aux tremblements de terre n'ont pas été adéquatement conçus : le générateur de vapeur s'est révélé dangereux pour le réacteur lors des essais de novembre 1981 ; les normes pour l'octroi des permis d'opération ont été changées par l'EACL sans consultation publique; la couverture des assurances (300 millions de dollars) est tout à fait inadéquate en cas de dommages causés par des accidents ; les plans d'urgence et les secours médicaux en cas d'accidents ne sont planifiés que d'une façon rudimentaire.

Quelques jours après l'annonce d'Hydro-Québec à l'effet que Gentilly III serait mis entre parenthèses, l'EACL a, de son côté, annoncé la création d'un bureau régional québécois qui sera dirigé par l'ex-directeur de l'Institut de génie nucléaire de l'Université de Montréal, M. Laurent Amyot. De plus, l'EACL projette de construire à Varennes un centre de recherches sur la fabrication de combustibles nucléaires artificiels. Selon M. Amyot, il est nécessaire de parer à la rareté éventuelle de l'uranium naturel. L'uranium 233 qui n'existe pas à l'état naturel servirait de substitut. La question, c'est que l'uranium 233 est un matériel stratégique qui peut être utilisé immédiatement pour fabriquer une bombe atomique. Ceci entraînerait des dispositifs de sécurité nationale très importants qui toucheraient la région de Varennes et les travailleurs du centre de recherches. Comme Québécois, devons-nous permettre que le gouvernement central fasse une telle intrusion chez nous ? Nous croyons que c'est inacceptable.

Dans cette orchestration qui vise à sauver l'industrie nucléaire de la faillite, nous avons pu contempler les efforts déployés par M. Marc Lalonde et M. Pierre Trudeau pour vendre le CANDU outre-mer et ce, à des conditions « avantageuses » pour les acheteurs, ce qui devrait coûter quelques millions aux contribuables canadiens. Un prêt de 6 milliards de dollars à 7 1/2\% a été offert au Mexique pour qu'il puisse acheter notre technologie. M. Lalonde menace de dépenser 50 mil- 
lions de dollars pour ressusciter Gentilly I. Cette action comme la création d'un bureau régional d'EACL au Québec ne font-elles pas partie d'une offensive pour imposer le nucléaire chez nous ? Nous le croyons et le colloque « Le nucléaire au Québec » organisé à Trois-Rivières par l'ordre des ingénieurs du Québec les 12, 13 et 14 mai prochains va dans le même sens.

Nous terminons en invitant les Québécois à ne pas se laisser imposer le nucléaire et donc à demander qu'un débat public soit tenu, non seulement sur le nucléaire, mais sur toute la question énergétique. À un moment où la crise économique nous rend plus vulnérables aux promesses d'investissements liées aux mégaprojets, il nous faut redoubler de vigilance. Le nucléaire crée peu d'emplois par rapport à d'autres formes d'investissements pour la production énergétique et il comporte des risques humanitaires et écologiques qui sont tout à fait inacceptables. 
Mouvement écologiste, énergie et environnement.

Essais d'écosociologie.

Deuxième partie . Interventions et prises de position

\title{
Chapitre 10
}

\section{"Pourquoi prendre les risques de Gentilly II ?’}

Texte publié dans Le Devoir, 14 juin 1982, p. 13 et 14.

\author{
par Roger Julien, Paul Berleur, Jacques Boucher, \\ Jean-Guy Vaillancourt et Gordon Edwards
}

Retour à la table des matières

Si Hydro-Québec a le feu vert, le réacteur nucléaire de la centrale Gentilly II démarrera au début de juillet et il atteindra l'étape de criticité en septembre. La production d'électricité commencera au début de 1983. Le chargement de combustible a déjà été fait. Tout est prêt.

Comme d'habitude, le peuple du Québec n'a pas eu voix au chapitre. La mise en marche du réacteur nucléaire est considérée comme allant de soi, comme s'il n'existait aucune autre possibilité. Pourtant, en Autriche, on a vu la population, il n'y a pas si longtemps, voter à 51\% pour que le premier réacteur nucléaire reste inopérant et ce, malgré le fait qu'il soit déjà construit. Ici au Québec, aucune consultation publique n'a été prévue sur la mise en opération de Gentilly II.

Le 14 mai dernier, Hydro-Québec a admis, par la voix de M. Joseph Bourbeau, que le nucléaire ne serait pas une source d'énergie avantageuse économi- 
quement d'ici à la fin du siècle et qu'il n'était pas question de répéter l'aventure de Gentilly II dont le coût final dépassera d'un milliard l'estimation initiale. Néanmoins, Hydro-Québec argumente que la centrale Gentilly II lui assurera un minimum d'expertise dans le nucléaire et qu'après avoir tant investi, on ne pouvait se permettre d'attendre plus longtemps la mise en opération.

Dans la foulée d'une telle logique, on pourrait aussi conclure que les USA et l'URSS n'ont pas le choix et qu'après avoir dépensé des milliards pour fabriquer des armes atomiques, il serait dommage de ne pas s'en servir. Mais l'absurdité de cet argument saute aux yeux, car le coût humain et matériel venant de l'utilisation de ces armes serait infiniment supérieur à celui de leur construction.

Dans un domaine moins dramatique, nous voulons démontrer que le coût entrâné par la mise en marche de Gentilly II risque d'être plus élevé que celui de sa construction. Nous avons un exemple qui illustre bien ceci en Gentilly I. Cette centrale-citron draine les fonds publics depuis plus de dix ans sans avoir a ce jour apporté quoi que ce soit au Québec. Un autre exemple est celui du réacteur nucléaire de Three Mile Island. Il a produit de l'électricité pendant environ trois mois et voici que la réparation du réacteur endommagé a déjà coûté 300 millions de dollars et qu'elle dépassera probablement les 2 milliards de dollars. Les propriétaires sont au bord de la faillite et il leur en aurait coûté beaucoup moins de ne jamais mettre ce réacteur en opération même un fois construit.

L'accident de Three Mile Island est techniquement connu comme le bris d'un petit tuyau du système de refroidissement. Selon les concepteurs, la probabilité qu'un tel accident arrive à Gentilly II pendant les 30 ans de vie du réacteur est plus que de 1 sur 4. Face à ceci, Hydro-Québec est couvert par une assurance de 300 millions de dollars, à peine de quoi payer la réserve d'eau lourde qui serait perdue, mais insuffisamment pour réparer les dégâts et nettoyer la centrale. Des accidents plus graves peuvent survenir qui contamineraient des espaces importants. Les Québécois ne peuvent se couvrir d'assurances pour de telles éventualités. Chaque propriétaire a sur son assurance une clause qui exclut les dommages causés par la contamination radioactive. 
Notre argument est celui-ci : pourquoi les Québécois devraient-ils accepter les risques de l'opération de ce réacteur ? Est-ce que l'erreur de jugement faite par Hydro-Québec au moment de prendre la décision de construire est une raison suffisante ? Et puisque les Québécois ont à prendre les risques liés à l'opération de ce réacteur, n'ont-ils pas droit à un débat ouvert sur la question avant que la licence d'opérer ne soit accordée à Gentilly II ?

Le gouvernement du Québec s'est depuis longtemps engagé à ce qu'un débat public sur l'énergie nucléaire soit tenu. Il a même déclaré un moratoire en 1977, moratoire « qu'il n'est pas question de lever pour plusieurs années à venir », a déclaré le ministre, M. Yves Duhaime, le 12 mai 1982. La construction de Gentilly II s'est cependant continuée pendant ce temps et Hydro-Québec prépare la mise en opération sans que les pour et les contre aient apporté leurs arguments. La décision de mettre en marche le réacteur nucléaire de Gentilly II est essentiellement politique et elle ne doit pas être laissée aux mains des ingénieurs et des bureaucrates qui ont bâti la centrale.

Certes, ne pas opérer Gentilly II va nous coûter de l'argent et Hydro-Québec comme les gouvernants et les citoyens trouvent qu'on a assez dépensé. Il est possible cependant qu'il nous en coûte davantage du fait de la mise en opération et ce, qu'il survienne ou non un accident.

Considérons, par exemple, les coûts liés à la disposition des déchets radioactifs en provenance de Gentilly II. Personne ne sait jusqu'où ça peut aller. Si l'Ontario refusait d'accepter les déchets en provenance d'un réacteur québécois, le Québec serait obligé d'aménager son propre site d'enfouissement sécuritaire et ce, au coût d'un milliard ou plus. Et si les relations entre Québec et Ottawa continuent de se détériorer, le Québec peut devoir reprendre à son compte toute la recherche sur cette question d'enfouissement des déchets radioactifs.

Parmi les coûts d'un réacteur nucléaire, il faut aussi compter ceux de son démantèlement et de son vieillissement prématuré. Le démantèlement et la garde des restes radioactifs risquent d'être aussi coûteux que ceux de la construction. Quant au vieillissement prématuré, il faut bien l'envisager. Car si le réacteur a été pensé comme un investissement devant rapporter pendant 30 ans et qu'après 10 ou 15 
ans de fonctionnement, on doive le fermer parce que devenu non sécuritaire, ce sont d'autres coûts qui interviennent. Plusieurs centrales nucléaires américaines en sont actuellement à ce stade.

Ce n'est un secret pour personne que l'industrie nucléaire canadienne est au bord de la faillite. Dans ce contexte, il est tout à fait réaliste de poser la question du coût de l'entretien du réacteur au cas où, après la faillite, des pièces feraient défaut et l'expertise deviendrait rare.

Une autre inconnue, c'est le prix de l'uranium naturel et la certitude d'approvisionnement. Dernièrement, M. Amyot, vice-président d'Énergie atomique du Canada Ltée, a admis qu'on risquait de manquer d'uranium dès le début du 21e siècle et qu'on devrait aller vers le plutonium ou vers les combustibles artificiels. C'est donc dire que le coût de l'uranium risque d'être marqué par la rareté et que la centrale Gentilly Il risque d'être démodée avant la fin de sa vie de 30 ans.

Le bilan de cet examen sommaire nous amène à la question : ne vaut-il pas mieux laisser Gentilly II inopérante plutôt que de la mettre en opération ? Notre conclusion, c'est qu'il en coûtera moins cher d'en faire un musée que de l'opérer même si l'on doit déplorer là une perte sèche énorme.

Sur la base de ces données économiques, nous faisons appel à nos concitoyens pour qu'ils demandent que Gentilly II ne soit pas mise en marche sans qu'au minimum un examen plus approfondi n'ait été fait et sans qu'un débat public n'ait été tenu.

Plus important que les coûts financiers, n'oublions pas le coût en vies humaines. On a découvert récemment chez les hommes qui ont été exposés à la radiation à Chalk River dans les années 50, un taux de cancer six fois plus élevé que la normale. Pourtant, ils n'ont été exposés qu'à la norme « acceptable pour les travailleurs du secteur atomique ». En 1979, le syndicat américain des travailleurs unis de l'uranium au Canada, déclarait :

La recherche du pouvoir nucléaire a déjà coûté un prix inacceptable en termes de santé et de vies de nos mineurs de l'uranium. 
La population est, elle aussi, exposée à la radioactivité provenant des sites miniers et des centrales nucléaires. Le réacteur de Gentilly II produira 30 fois plus de tritium (hydrogène radioactif) et 20 fois plus de carbone-14 (aussi radioactif) qu'un réacteur américain de même taille fonctionnant à l'eau légère. Ces substances radioactives vont être au fil des opérations de routine rejetées dans l'environnement sous forme d'eau et de dioxyde de carbone. À la différence des autres particules radioactives, le tritium et le carbone-14 peuvent être directement incorporés par l'ADN des cellules vivantes, pouvant ainsi causer sur une large échelle des dommages au potentiel génétique.

Un comité de la législature ontarienne a recommandé que des études d'urgence soient entreprises pour déterminer les effets biologiques à long terme de ces contaminations radioactives. Il soulignait que :

Le carbone-14 et le tritium sont préoccupants pour les mêmes raisons. D'abord, ils ont tous deux une longue demi-vie : 5730 années pour le carbone-14 et 12,3 années pour le tritium. Cette longue demi-vie leur permet de s'accumuler dans l'environnement autour des centrales nucléaires et dans la biosphère facilement au tissu humain. Le carbone-14 est incorporé dans le carbone qui représente $18 \%$ du poids total du corps, incluant les tissus adipeux, les protéines et l'ADN. Le tritium est incorporé dans toutes les parties du corps qui contiennent de l'eau.

Les expériences en laboratoire ont confirmé que le tritium donné à une souris enceinte va traverser le placenta vers le foetus. Le tritium a causé des mutations mortelles et d'autres non mortelles aussi bien que des difformités chez les embryons, sans qu'aucun seuil sécuritaire n'ait été établi pour parer à de tels effets.

Bien sûr, dans l'éventualité d'un accident nucléaire, l'exposition à la radioactivité sera plus immédiate. Les jeunes enfants et les embryons sont les plus touchés. Est-ce que les mères de Trois-Rivières et de la région ont été assez renseignées pour passer au lait en poudre en cas d'accident nucléaire en sorte que leurs enfants ne reçoivent pas d'iode radioactif dans leur corps? Est-ce que les parents et les enseignants de la région savent, pour protéger leurs personnes et jusqu'à un certain point leurs enfants, comment obtenir et utiliser contre cet iode les comprimés 
de potassium ? Est-ce que les médecins et les infirmières de la région savent comment traiter les patients contaminés par la radioactivité ? Est-ce que les résidents de la région comprennent les plans d'urgence pour l'évacuation ?

De telles questions ne peuvent rester sans réponse et nous invitons la population à demander qu'une enquête publique soit faite sur tous ces points. Que des commissions indépendantes de l'industrie nucléaire et d'Hydro-Québec puissent éclairer le publie, commissions formées de biologistes, de physiciens, de médecins, d'environnementalistes... Nous avons le droit de savoir avant que la décision d'opérer Gentilly II ne soit prise et surtout avant que l'irréparable ne soit accompli.

À court terme, c'est-à-dire pour 5 ou 10 ans, on y gagne à opérer Gentilly II le plus tôt possible. A moyen terme (10 à 15 ans) et à long terme (15 ans et plus), nous sommes certainement perdants et nos enfants le seront aussi. Ils auront à faire face à une pollution coûteuse, à un démantèlement improductif et peut-être à des pots cassés qui vont requérir d'eux beaucoup d'énergie. Soyons responsables, sachons reconnaître l'erreur monumentale qu'a été la construction de Gentilly II et n'allons pas plus loin.

Mettre en marche Gentilly II, c'est aussi encourager l'industrie nucléaire canadienne qui sème ses CANDU à travers le monde et qui contribue d'une façon irresponsable à la prolifération des armes nucléaires. Ceci, nous ne le voulons pas, pas plus que nous ne voulons, comme ça a été le cas pour la centrale nucléaire de Chalk River, voir les déchets radioactifs de Gentilly II être acheminés vers les usines de retraitement des USA et être intégrés à la filière de l'armement atomique. 


\section{Mouvement écologiste, énergie et environnement. \\ Essais d'écosociologie.}

\section{Troisième partie}

Perspectives critiques 


\section{Mouvement écologiste, énergie et environnement.}

Essais d'écosociologie.

Troisième partie . Perspectives critiques

\section{Chapitre 1}

\section{“L'encerclement selon Barry Commoner."}

Texte publié dans la revue Études internationales, vol. 5, no 1, mars 1974, p. 168170.

\section{par Jean-Guy Vaillancourt}

Retour à la table des matières

Barry Commoner, biologiste de l'Université Washington à St-Louis, est l'un des mieux connus des écologistes contemporains. L'Encerclement 94 est la traduction française de son livre The Closing Circle, qui, dès sa parution chez Knopf en 1971, a eu un impact extraordinaire dans les milieux savants et dans le grand publie. Certains sont même allés jusqu'à dire que c'est le meilleur livre d'écologie jamais écrit.

Partant du concept clef de l'écosphère, cette peau de notre planète, Commoner essaie de comprendre les causes profondes de la crise écologique qui a brisé le cercle de la vie. Il nous décrit les ravages que l'homme fait subir à son environnement, analyse l'origine des problèmes écologiques et fournit des ébauches de

94 Commoner, Barry, L'Encerclement, problèmes de survie en milieu terrestre, Éditions du Seuil, 1972. 
solutions qui permettront à l'humanité d'éviter le suicide collectif vers lequel elle s'achemine. Rejetant certaines causes (et solutions) unilatérales qui sont offertes par exemple les théories qui centrent uniquement l'attention sur les taux d'accroissement de la population -Commoner affirme que ce sont les façons nouvelles d'utiliser la technologie dans le processus de production, ainsi que certaines forces économiques, sociales et politiques qui sont responsables de l'écocide qui menace cet être vivant qui est la planète Terre.

Au lieu de s'intégrer dans les cycles naturels du grand cercle de la vie, les hommes et leurs entreprises basées sur le profit privé ont spolié l'héritage commun. Plutôt que de participer en tant qu'éléments dans un ensemble, ils ont exploité leur environnement de façon linéaire, sans souci des conséquences sociales de leurs pratiques égoïstes. Ils ont oublié les quatre lois fondamentales de l'écologie, à savoir que tout est relié à, tout, que tout doit aller quelque part, que la nature a toujours raison, et que rien n'est gratuit. Pour survivre, l'homme doit apprendre à restituer à la nature les richesses qu'il lui arrache. Autrement, c'est la famine à plus ou moins brève échéance pour beaucoup de monde, suivie d'un effondrement complet de la civilisation et d'un retour à la barbarie.

Le coeur de l'ouvrage, les chapitres 3 à 6, sont des études de cas concrets de pollution et de destruction de l'environnement. Les problèmes nouveaux causés par J'énergie nucléaire (par exemple, les effets des retombées radioactives), le smog de Los Angeles, le sol dangereusement surchargé de nitrate dans l'Illinois, le lac Érié en train de devenir une autre «mer Morte» sont des exemples précis parmi bien d'autres, qui illustrent à merveille la thèse de Commoner selon laquelle le cercle est maintenant brisé et qu'il est déjà tard pour se mettre à la tâche de le refermer.

La détérioration de l'écosphère, nous dit Commoner, est avant tout un problème social. La science et la technologie ont été mises au service d'une production en vue de profits privés sans souci des coûts sociaux et des conséquences globales. À partir de calculs ingénieux, Commoner nous montre qu'on ne peut pas blâmer l'accroissement de la population ou la croissance économique en soi pour ce qui arrive. La cause de la crise écologique, c'est l'utilisation de technologies nouvelles de production qui ne respectent pas les lois de la nature. On a remplacé des 
choses naturelles et renouvelables (le savon, le coton, la laine, le bois, par exemple) par des objets synthétiques faits à partir de matériaux non récupérables. Les camions remplacent les trains, les autos deviennent de plus en plus grosses (les mini-autos donnent de mini-profits, disait Henry Ford II), l'agribusiness utilise engrais et pesticides synthétiques qui détruisent le sol et polluent l'eau. En somme, des technologies de production qui menacent et détruisent l'environnement ont remplacé des technologies plus en accord avec les rythmes de la vie. « La crise de l'environnement, écrit Commoner, est la conséquence inévitable de cette forme d'évolution, en contradiction avec toutes les normes de l'écologie » (p. 177).

La crise écologique est donc essentiellement une crise d'origine sociale. Ce sont les modalités de l'usage de la technologie plutôt que le progrès technologique lui-même qu'il faut blâmer. Ce sont les buts qui sont en défaut et qui doivent être changés. Par exemple, plutôt que de persister avec nos systèmes primitifs d'égouts qui polluent toutes nos eaux, il faudrait des systèmes de pipelines qui réachemineraient vers le sol, sous forme d'engrais, ce qui en a été extrait. Ceci rebouclerait le cercle de la vie, et solutionnerait non seulement le problème des égouts mais aussi celui des engrais chimiques.

Dans un avant dernier chapitre sur la signification économique de l'écologie, Commoner montre comment l'entreprise privée pollue l'environnement et gaspille les ressources non renouvelables. Ainsi, c'est la société toute entière qui se trouve à subventionner ces compagnies privées. Même si ce n'est pas tellement mieux en URSS, selon Commoner, le socialisme, en soi, a des avantages sur notre système capitaliste, à cause du fait que la planification permet à la société d'absorber certains coûts pour préserver l'environnement, ce que les assoiffées de profits que sont les compagnies ne permettront sûrement pas dans notre système.

Commoner propose des façons concrètes de s'en sortir en suggérant l'adoption de nouvelles technologies en harmonie avec l'écosphère.

Voici quelques-unes de ces recommandations : renvoyer les égouts et les vidanges dans le sol ; utiliser des matériaux renouvelables plutôt que du synthétique ; en agriculture, éviter les engrais et les pesticides artificiels, décourager les 
industries qui consomment trop d'énergie, créer un système de transport efficace qui ne gaspille pas l'énergie et le terrain ; recycler le métal, le verre et le papier ; planifier l'usage de l'espace. Et surtout que les coupables, l'entreprise privée et les pays riches nettoient les dégâts dont ils sont responsables. Que les pays industrialisés surtout paient le plein prix pour les matières premières qu'ils utilisent, de façon à permettre aux pays producteurs non industrialisés de transformer leurs ressources sur place autant que possible, pour qu'ils puissent fournir du travail à leurs populations. Commoner aimerait voir les États-Unis devenir plus dépendants des pays producteurs de matières premières, ce qui pourrait rendre les Américains plus pacifiques et plus respectueux envers les autres pays.

Pour résoudre la crise, dit-il, il va falloir éliminer la pauvreté, la discrimination raciale, la guerre et accepter les conséquences économiques des impératifs écologiques : l'écosphère étant un phénomène global et social, il faudra que l'organisation de la production soit réorientée pour être en harmonie avec cette écosphère.

Commoner croit que ce sont les valeurs d'abord qu'il faut changer. Les scientifiques doivent s'allier avec les citoyens pour changer les orientations présentes, et faire la réforme écologique de la technologie pour en éliminer les abus. Ce sont avant tout des solutions sociales et non des solutions personnelles qu'il préconise.

Leur formation et parfois leur dépendance vis-à-vis des universités, des fondations et des gouvernements qui sont souvent des appendices de la grande entreprise, empêche parfois les écologistes d'expliciter clairement leur critique du système capitaliste et de faire des propositions radicales pour s'en sortir. Mais il n'y a pas à s'y tromper. La nouvelle écologie, telle qu'elle est créée par ses théoriciens et ses praticiens les plus compétents, conduit inévitablement à une critique du système capitaliste et à la vision d'une société économique et politique nouvelle basée sur le bien commun plutôt que sur le profit privé.

Lors de sa visite à Montréal en juin 1973, Commoner a encouragé les Canadiens à ne pas céder aux demandes des États-Unis pour l'importation de nos ressources énergétiques, gaz, pétrole et électricité. C'est une façon prudente de dire que la lutte pour le contrôle et la propriété de nos ressources, la lutte anti- 
impérialiste et socialiste, est la façon la plus réaliste de faire la lutte écologique pour la protection de notre environnement. D'une pierre, deux coups, en somme. 


\section{Mouvement écologiste, énergie et environnement.}

Essais d'écosociologie.

Troisième partie . Perspectives critiques

\section{Chapitre 2}

\section{"Pierre Dansereau, écologiste humain.”}

Texte publié dans la Revue canadienne de sociologie et d'anthropologie, vol. 13, no 3, août 1976, p. 365-368.

\section{par Jean-Guy Vaillancourt}

Ce livre de Pierre Dansereau, La Terre des hommes et le paysage intérieur ${ }^{95}$, est un ouvrage remarquable qui a malheureusement été peu remarqué par ceux qui s'intéressent aux incidences sociales des questions de l'environnement. Biologiste et écologiste québécois de renommée internationale, Dansereau a réussi un tour de force surprenant en arrivant à construire, au moyen d'une approche écologique, un solide pont entre les sciences naturelles et les sciences humaines. Rares sont les savants qui parviennent à dépasser aussi heureusement que Dansereau les limites étroites de leur spécialité et de quelques disciplines connexes. Autre phénomène rare dans les ouvrages scientifiques de ce genre, le texte est d'une très haute qualité au plan littéraire. Dansereau nous livre un essai construit avec finesse, dans une langue et un style maîtrisés de façon admirable. Il réussit à unir harmonieusement

95 Pierre Dansereau, La Terre des hommes et le paysage intérieur, Montréal, Éditions Radio-Canada et Leméac, 1973. 
l'approche expérimentale et l'approche introspective dans une espèce de discours phénoménologique qui rappelle à certains égards les écrits de Teilhard de Chardin, mais sans les longues phrases truffées de parenthèses et de néologismes qui rendent la lecture du célèbre paléontologiste français légèrement indigeste. L'auteur allie une façon de voir éminemment dialectique (il nous parle des dialectiques Nature-Homme, Landscape-Inscape, Science-Sagesse, perception-implantation, connaissance scientifique-réflexion interne, paysage intérieur-terre des hommes) avec un mode d'exposition qui déroule ces relations bipolaires en une série de niveaux, de stages et de cycles.

L'ouvrage est construit de façon souple et ordonnée à la fois, sans bavures, révélant un esprit bien discipliné et d'une grande érudition. Dansereau se propose d'analyser les relations entre ce qu'il appelle le paysage extérieur (le landscape, la terre des hommes) et le paysage intérieur (l'inscape, l'univers intérieur de l'homme), en les projetant l'un dans l'autre. Cette projection se fait selon un itinéraire en six étapes, qui constituent chacune un des chapitres de l'ouvrage. Ces six chapitres déroulent l'opposition connaissance-action en suivant un cheminement qui va de l'impression sensorielle à l'intervention matérielle. Ils examinent tour à tour les six différentes étapes de cette pénétration progressive du paysage extérieur dans l'inscape humain, de cette entrée du « landscape » dans le paysage intérieur. Ces six étapes sont : 1) la perception en vue de la survivance ; 2) l'éducation pour la récupération de la connaissance ; 3) la recherche des forces de la nature ; 4) le pouvoir de transformer l'environnement ; 5) la planification ; et 6) la gestion.

Le premier chapitre examine comment l'homme perçoit la nature. L'auteur y présente une analyse des paysages très divers dominés par les minéraux (le désert, la toundra), les végétaux (la forêt tropicale, la plaine) et les animaux (les îles d'otaries, les roches aux oiseaux). Le second chapitre montre comment ces perceptions du monde matériel sont transmises par les processus de formation et d'éducation. Dansereau y insiste sur la description et l'interprétation des paysages, sur la distribution géographique des ressources minérales, végétales et animales, et sur la mise en réserve et la diffusion des connaissances sur l'environnement. Le troisième chapitre traite de l'augmentation des connaissances sur l'environnement, i.e. de la recherche écologique. Le schéma minéral-végétal-animal-homme y est de nouveau utilisé, spécialement à travers une étude du développement d'un cer- 
tain nombre de disciplines scientifiques (géologie, botanique, zoologie, sciences humaines) et de leur contribution aux recherches sur l'environnement.

À partir du quatrième chapitre, qui porte sur le pouvoir qu'a l'homme de modifier son environnement, l'auteur s'aventure davantage dans la sphère des sciences humaines. C'est dans ce chapitre que commence à se dessiner plus clairement la sociologie de l'environnement de Dansereau. Se basant sur les définitions de Tansley, Linderman, Odum et Duvigneaud, il dessine un schéma cohérent de l'écosystème. Ce qui l'intéresse d'abord, c'est le transfert d'énergie entre les différents niveaux de l'écosystème. Il vaut la peine d'entrer ici dans le détail, car le schéma que présente Dansereau constitue 1, essentiel de sa démarche écologique. Les recherches écologiques effectuées par EZAIM à Mirabel, par exemple, se sont basées sur ce modèle structuraliste de l'écosphère. Dans ce chapitre, donc, Dansereau présente ce qu'il appelle les niveaux trophiques dans l'écosystème : 1) le minéral ; 2) le végétal ; 3) l'animal herbivore ; 4) l'animal carnivore ; 5) les investissements (les ressources axées sur les fonctions à long terme) ; 6) et le contrôle (le niveau où s'exerce le pouvoir sur l'habitat dans son ensemble).

Ces six niveaux, qui vont de ce qui est plus matériel (le minéral) à ce qui l'est moins (les contrôles), ressemblent un peu aux quatre niveaux du système d'action de Parsons, tandis que les subdivisions à l'intérieur du 6e niveau nous rappellent les quatre niveaux de son système social. Pour ces six niveaux, et pour les subdivisions à l'intérieur du 6e niveau, il y a isomorphisme aussi avec le schéma infrastructure-superstructrure du marxisme. En effet, les contrôles au niveau supérieur peuvent être commerciaux, administratifs, économiques, politiques, religieux et culturels.

En partant des innovations rencontrées à chacun des six niveaux trophiques au cours de l'évolution, Dansereau distingue cinq phases cumulatives dans le développement historique de l'impact de l'homme sur l'environnement. Ces cinq phases temporelles comprennent un total de huit stages. Entre chacun des stages (sauf entre 5 et 6) comme l'illustre le tableau I, il y a une révolution qui amène le passage d'un stage à un autre. 


\section{Tableau 1}

Phase Stage Révolution

8. Échappée exobiologi-
que

E. Climatique-cosmique

7. Contrôle climatique

VI. Cosmique

V. Cybernétique

6. Urbanisation

D. Industrielle

5. Industrie

IV. Industrielle

C. D'établissement 4. Agriculture

III. Agricole

B. Nomade-pastorale 3. Paissance

II. Domestique

2. Chasse et pêche

A. Primitive

I. Instrumentale

1. Cueillette

Malgré certaines réserves sur ces typologies évolutionnistes, Dansereau croit « que les 8 stages groupés en 5 phases présentent une authentique image du pouvoir croissant de l'homme... » (P. 101). Jusqu'au stage 6, il est difficile de n'être pas d'accord. Par ailleurs, il se peut fort bien que Dansereau se trompe en faisant du contrôle climatique et de l'échappée exobiologique (voyages dans l'espace) les stages en cours de l'évolution humaine, mais il faut quand même avouer que le tout se tient assez bien d'un point de vue sociologique. En effet, comme chez la plupart des macro-sociologues, Dansereau nous présente un modèle évolutionniste de la transformation de la société humaine, modèle qui a au moins l'avantage de n'être pas trop biaisé dans le sens de l'idéalisme et du conservatisme comme celui de la plupart des sociologues, d'Auguste Comte à Talcott Parsons. 
Chez Dansereau, ce n'est pas le progrès des connaissances ou une innovation « spirituelle » qui amène la transition d'une période à une autre dans l'histoire des sociétés humaines. Dansereau suit plutôt ici certains anthropologues et macrosociologues très près du marxisme (de Morgan à Henri Lefebvre). Comme certains macro-sociologues et anthropologues, Dansereau combine cette typologie de type évolutionniste avec un modèle systématique (les six niveaux trophiques) pour produire ce que Lucien Goldmann aurait peut-être daigné appeler une espèce de structuralisme génétique.

Il serait intéressant que les sociologues qui ne sont pas d'accord avec la façon avec laquelle Dansereau décrit les deux niveaux trophiques supérieurs de l'écosystème (c'est-à-dire la distinction investissements-contrôle) et les deux derniers stages de l'évolution des sociétés humaines (contrôle climatique et échappée exobiologique), s'appliquent, non seulement à les critiquer, mais aussi à offrir des solutions plus adéquates à cette question complexe de la direction actuelle de l'évolution de la société humaine. Pour ce qui est des autres niveaux et stages, je serais surpris d'apprendre qu'ils ne rencontrent pas un degré d'adhésion presque unanime parmi les praticiens des sciences sociales. Personnellement, je crois qu'on est loin d'être arrivé à maîtriser l'évolution de nos climats et je pense que l'insistance sur une hypothétique échappée exobiologique comme solution aux problèmes de l'environnement relève d'une espèce d'eschatologisme technologique qui n'est pas sans similitude avec le culte des cargos de certains habitants des îles du Pacifique du Sud.

Enfin, dans son sixième et dernier chapitre, Dansereau examine le problème de l'aménagement et des critères. Il y montre comment l'écologie peut aider à faire prendre conscience aux hommes de leurs responsabilités. Après avoir comparé les faits et les valeurs de ce qu'il appelle les $5 \mathrm{E}$ (c'est-à-dire écologie, ethologie, économique, ethnologie et éthique), il en arrive à identifier les principales forces qui ont conduit au désordre écologique actuel. Celles-ci sont, selon lui, l'augmentation de la population, la croissance industrielle et les pratiques d'aménagement fautives.

Alors, que pouvons-nous faire ? Dansereau suggère des réformes le contrôle des naissances ; la reconsidération de la croissance économique et des pratiques 
d'aménagement ; et, enfin, au plan personnel, ce qu'il appelle une « joyeuse austérité » librement consentie et qui pousse à « faire plus avec moins », selon l'heureuse formulation de Buckminster Fuller. Ici encore, dans cette analyse des causes probables et des solutions idéales aux problèmes de l'environnement, les sociologues et les autres spécialistes des sciences sociales ne manqueront pas d'exercer leur jugement critique. A première vue, on pourrait être porté à croire que Dansereau, comme beaucoup d'écologistes américains, est un zéroiste (c'est-à-dire un partisan de la croissance démographique et économique zéro) plutôt conservateur, qui ne perçoit pas clairement les racines sociales, économiques et politiques des problèmes écologiques. Mais si on lit attentivement, on s'aperçoit que ces dimensions primordiales ne sont pas absentes de son analyse.

L'appel à la responsabilité individuelle, contrairement à ce qu'on pourrait penser, n'élimine pas chez Dansereau une préoccupation avec les aspects socioéconomiques et politiques, même si ces éléments ne sont pas clairement présents et importants dans sa pensée et son action. Quand il aborde ces questions, Dansereau devient passablement vague et ambigu. Il fait du patinage de fantaisie; mais il arrive quand même, en des termes voilés mais compréhensibles, à présenter une position passablement équilibrée, comme l'illustre bien le passage suivant : «Un partage des ressources qui permet leur renouvellement, à relativement court terme, et qui assure au moins une gratification minimum des besoins de l'homme n'est pas compatible ni avec le présent rythme auquel la population croît et les ressources sont exploitées, ni avec l'allocation actuelle des pouvoirs de les utiliser et de les accumuler » (p. 165-166).

Dansereau veut que simultanément l'on dépollue l'air, l'eau et le sol et qu'on élimine la violence, les privilèges et le gaspillage des riches. Qu'on le veuille ou non, dit-il, l'austérité s'en vient, et elle sera obligatoire pour tous. Il ne croit pas qu'on puisse miser sur les jeunes ou sur ce qu'il appelle un « groupe occupationnel » (une classe sociale ?) pour opérer ces changements. Il s'imagine que miser sur certaines catégories sociales équivaut à en éliminer d'autres : « La perte impliquée dans l'éradication ou l'inhibition d'une classe d'âge ou d'un groupe occupationnel est irréparable et laisse trop de ressources précieuses sans emploi » (p. 176). On sent percer ici un brin de naïveté unanimiste et d'optimisme libéral, un refus de voir les conflits inévitables qu'une réorientation des priorités actuelles 
amènerait. Quand il dit qu'il faut un changement radical dans l'orientation de nos buts communs, qu'il faut miser sur une joyeuse austérité librement consentie et " espérer que le Canada se lance dans une entreprise de leadership à ce point de vue »(p. 176), on voit bien les faiblesses de ses propositions concrètes. Lui-même d'ailleurs est bien conscient des limites de ses suggestions, mais il ne semble pas se rendre compte de leur ambiguïté au plan politique et socio-économique. Comme René Dumont dans La Croissance de la famille (Paris, Seuil, 1975), et Michel Bosquet dans Écologie et politique (Paris, Éditions Galilée, 1975), il aurait pu, il me semble, affirmer sans ambages que seule une transformation radicale qui nous fera passer d'un capitalisme destructeur à un socialisme qui instaurera un nouveau rapport des hommes entre eux et avec la nature, pourra assurer de bonnes chances de survie aux voyageurs du vaisseau spatial Terre. Des paroles aussi directes auraient peut-être empêché que ce livre ne remporte le prix Molson, mais ça aurait sans doute été préférable. En effet, cette marque d'honneur douteuse venant d'une entreprise destructrice de céréales et de travailleurs (les gars de la Vilas, avec leurs doigts coupés en savent quelque chose), risque de faire une mauvaise publicité à un bon livre qui ne méritait pas ce baiser de la mort de la part des magnats de la bière et du meuble. 
Mouvement écologiste, énergie et environnement.

Essais d'écosociologie.

Troisième partie . Perspectives critiques

\section{Chapitre 3}

\section{“La crise de l'énergie et les conflits mondiaux pour le pouvoir et la richesse."}

Texte publié dans la revue Études internationales, vol. 7, no 3, septembre 1976, p. 481-483.

\section{par Jean-Guy Vaillancourt}

$\underline{\text { Retour à la table des matières }}$

Quand Michael Tanzer analyse, dans The Energy Crisis, World Struggle for Power and Wealth ${ }^{96}$, la crise actuelle de l'énergie et les affrontements politiques et économiques mondiaux qui s'y rapportent, il parle en connaissance de cause. Docteur en sciences économiques de Harvard, auteur d'un autre ouvrage important sur ce sujet intitulé The Political Economy of Oil and the Underdevelopped Countries (1969), et président d'une entreprise d'experts-consultants spécialisés dans le domaine de l'énergie qui a pour clients des gouvernements de pays sousdéveloppés, il a travaillé jadis comme économiste pour la succursale afroasiatique de Exxon, la plus puissante des sept grandes compagnies de pétrole.

96 Tanzer, Michael, The Energy Crisis, World Struggle for Power and Wealth, New York, Monthly Review Press, 1974. 
Avec Harvey O'Connor et Joe Stork, il est un des auteurs américains les mieux informés sur la question des compagnies de pétrole vues dans le contexte de relations politiques et économiques internationales. Son analyse rejoint à bien des égards celle, magistrale, de J.-M. Chevalier dans Le Nouvel enjeu pétrolier (Paris, Calman-Lévy, 1973), qui montre que la crise du pétrole a été encouragée par les compagnies américaines qui veulent faire un dernier coup d'argent avec ce qui reste de pétrole avant de devenir les maîtres des nouvelles sources d'énergie.

L'intérêt majeur de ce dernier livre de Tanzer (il a aussi publié The Sick Society: An Examination en 1971, une analyse perspicace des crises des É.-U. au plan intérieur et extérieur), c'est sa concision (moins de 150 pages de texte) et sa précision. Tanzer n'alourdit pas son exposé avec une masse de détails historiques insignifiants ou avec un appareil technique obscurantiste. Utilisant des données historiques et statistiques solides et bien choisies, il va droit au but, qui est de dévoiler la véritable nature de la crise de l'énergie et de démolir par le fait même les mythes courants qui s'y rattachent, celui notamment qui essaie de faire croire que les grandes compagnies de pétrole et le gouvernement des É.-U. ont été des perdants dans les opérations de hausses du prix du pétrole décrétées depuis 1971.

Tanzer montre comment dans les pays capitalistes, l'autosuffisance énergétique qui existait autrefois avec le charbon, a fait place graduellement à la dépendance vis-à-vis du pétrole importé, à cause du bas prix payé aux pays producteurs du Proche-Orient pour leur pétrole et grâce à l'appui du gouvernement des É.-U. à l'effort de pénétration du marché mondial par les compagnies multinationales de pétrole. Parmi les sept plus grandes compagnies de pétrole, cinq (Gulf, Texaco, Exxon, Mobil, Standard of California) sont américaines, l'une est anglaise (British Petroleum) et l'une est anglo-hollandaise (Shell). L'intégration verticale (de l'exploration à la commercialisation), et l'accaparement des autres sources d'énergie (charbon, gaz naturel, énergie nucléaire), sans qu'il y ait toujours entente et conspiration, ont placé ces sept grandes soeurs dans une position monopolistique. Elles avaient donc intérêt à faire monter les prix, en jouant sur la corde de la pénurie de pétrole qui s'annonçait à plus ou moins brève échéance, ce qu'elles firent dès 1968, quelques années par conséquent avant les négociations qui renversèrent le rapport de forces entre les pays producteurs et les compagnies. Les exigences croissantes des Arabes, dues surtout à l'arrivée au pouvoir de quelques gouverne- 
ments progressistes convaincus de l'incapacité des É.-U. de s'engager dans une autre guerre comme celle d'Indochine, et à la victoire d'Israël en 1967 qui força même les régimes arabes les plus réactionnaires à faire front commun et à utiliser l'arme puissante du pétrole, fournirent une bonne occasion aux compagnies d'augmenter leurs profits considérablement, tout en permettant de jeter le blâme sur les Arabes. Le gouvernement des É.-U. avait intérêt lui aussi, au début tout au moins, à voir le prix du pétrole augmenter, non seulement à cause des profits accrus des compagnies américaines, mais aussi à cause du fait que le prix élevé du pétrole allait affaiblir les concurrents allemands et japonais. D'où le peu de résistance offerte aux exigences de l'OPEP de la part du gouvernement des É.-U., surtout de la part des consommateurs et de certaines industries touchées par la hausse des prix du pétrole (voire l'auto, le tourisme et les loisirs), mais il n'y a pas eu vraiment de crise du pétrole au sens d'une pénurie effective, pas même durant le plus fort de la crise en 1973. En ce sens, on peut dire qu'elle fut en partie un coup monté par les grandes compagnies et le gouvernement pour légitimer les hausses de prix, qui apportaient des surprofits aux compagnies, tout en augmentant le prix du charbon et des autres sources d'énergie qu'elles contrôlent. Deux autres conséquences heureuses pour les compagnies furent l'affaiblissement des contrôles écologiques au plan de l'exploration, de l'exploitation et du transport des hydrocarbures, et l'abrogation de certaines contraintes antitrust. Mais ce qui est bon pour Exxon à court terme n'est pas nécessairement bon pour la population mondiale. Les nationalisations, et les demandes de plus en plus pressantes des Arabes pour une part accrue de contrôle de leurs ressources et de la transformation et commercialisation de celles-ci, de même que l'écroulement possible des économies japonaise, allemande, italienne et anglaise, toutes sévèrement touchées par les récentes hausses de prix, risquent d'amener, d'après l'évaluation pessimiste de Tanzer, une dépression mondiale sévère, ou même une guerre pire que celles que nous avons connues en 1914 et en 1939.

Pour les pays sous-développés, surtout les Indes, la hausse des prix du pétrole fut un désastre. En comparaison, les pays communistes, et tout particulièrement la Chine, qui avaient réussi à éviter la dépendance vis-à-vis du pétrole, ont réussi à passer au travers de la crise sans grand problème. De même la France, qui a su maintenir une certaine autonomie vis-à-vis des grandes soeurs, a pu traverser la crise passablement bien. 
Au plan mondial, suggère Tanzer, il faudrait que les ressources servent l'égalité entre les personnes, y compris l'égalité entre notre génération et les générations qui viendront après nous. Il faut donc développer des moyens de transport et des sources d'énergie non polluants, conserver les ressources, et éliminer le gaspillage et l'irrationalité d'un système basé sur le profit à court terme pour un petit groupe de privilégiés. Ce qu'il faut, en somme, c'est rien d'autre qu'une « révolution sociale fondamentale qui détrône le rôle de la richesse et de l'argent et organise l'économie pour qu'elle serve les besoins réels de toute le population » (p. 152).

Il se peut fort bien que les prédictions et les prescriptions de Tanzer ne se réalisent pas dans un avenir rapproché, étant donné la fluidité de la situation et les nouveaux éléments dont il faut constamment tenir compte. Par ailleurs, sa façon de poser les problèmes en termes d'économie politique internationale, c'est-à-dire en analysant les rapports de contrôle et de dépendance entre les entreprises multinationales et les pays impérialistes, d'une part, et les pays socialistes et les pays sous-développés, d'autre part, sans négliger les rapports de classes à l'intérieur de chacun des pays, donne au lecteur une clef pour comprendre l'actualité historique et pour y intervenir avec intelligence et efficacité.

Parce que ce livre a été écrit en 1973, donc au début de la hausse des prix du pétrole, il tend un peu à minimiser l'étendue de la crise, et surtout ses implications au plan de la crise monétaire internationale. L'avantage relatif qu'obtiennent les États-Unis dans la lutte pour l'hégémonie dans le monde capitaliste, qui s'exprime par la chute récente du prix de l'or et le relèvement correspondant du dollar, est dû en bonne partie à la force apparente actuelle des États-Unis sur les fronts du pétropouvoir et surtout de l'agro-pouvoir. Pour l'instant donc, le dollar américain est dans une position avantageuse, mais il est à prévoir qu'à plus ou moins brève échéance, l'empire américain se remettra à péricliter, et la confiance exagérée accordée au dollar américain sera de nouveau ébranlée. Il suffirait, par exemple, que pour quelques années, les récoltes de céréales des États-Unis, comme ça s'annonce déjà dès 1976, soient insuffisantes, ou que les pays producteurs de ressources deviennent plus exigeants vis-à-vis de leurs spoliateurs, pour que l'euphorie de la reprise économique du début de 1976 fasse place à un retour fulgurant des angoisses stagflationnaires. Quoi qu'il arrive, une chose devient de plus en plus claire : 
le système capitaliste mondial et l'impérialisme sont plus que jamais en crise, le pétrole joue un rôle important dans cette crise, et les efforts désespérés pour éviter le désastre et rétablir l'équilibre d'hier sont voués à l'échec. 


\section{Mouvement écologiste, énergie et environnement.}

Essais d'écosociologie.

Troisième partie . Perspectives critiques

\section{Chapitre 4}

\section{"Le nucléaire militaire et le nucléaire civil."}

Texte publié dans la revue Études internationales, vol. 10, no 1, mars 1979, p. 200-201.

\section{par Jean-Guy Vaillancourt}

\section{$\underline{\text { Retour à la table des matières }}$}

L'ouvrage de Robert J. Pranger et de Roger P. Labrie sur la stratégie nucléaire et la défense nationale ${ }^{97}$ présente un ensemble de textes qui décrivent et analysent la stratégie militaire des É.-U. dans le domaine des armes nucléaires depuis la fin de la guerre du Viêt-nam. Cette nouvelle stratégie nucléaire, avec ses éléments de détente, d'alliances régionales, et surtout d'options nucléaires limitées, n'est pas tellement différente de la stratégie de «réponse flexible » de John F. Kennedy et de Lyndon B. Johnson. Les textes de cette anthologie expliquent les raisons de cette stratégie, examinent la vulnérabilité des missiles américains et la possibilité de la défense civile, et discutent de l'impact de ces questions sur les négociations en cours sur la limitation des armes stratégiques (SALT).

97 Pranger, R.J. et R.P. Labrie (éd.), Nuclear Strategy and National Security Points of View, Washington, American Enterprise Institute, 1977. 
Le livre est publié par l'American Enterprise Institute for Public Policy Research, un organisme plutôt conservateur dont le but est de produire des analyses des questions internationales et nationales pour la classe dominante américaine et pour le public américain.

Le président du projet qui a donné naissance à ce livre est Melvin R. Laird, ancien secrétaire de la Défense qui travaille maintenant comme conseiller senior pour le Reader's Digest. La plupart des options idéologiques américaines présentées dans le livre de Pranger et Labrie sont en fait celles qu'on pourrait trouver dans le Reader's Digest, même si le ton et le style sont plus près de ceux de revues conservatrices sophistiquées comme Foreign Affairs que de ceux du Reader's Digest. Il ne faut pas s'en surprendre puisque les textes de Nixon, Laird, Schlesinger, Rumsfeld, Kissinger et Brzezinski constituent plus du tiers du livre, et que plusieurs des autres textes sont écrits par des analystes à la solde des militaires, du gouvernement ou des grandes fondations des É.-U. Les quelques textes d'officiels soviétiques ne viennent qu'accentuer le ton de guerre froide du livre.

Malgré le mot «nucléaire » qui figure aussi dans le titre de la plaquette de Mueller ${ }^{98}$, il ne s'agit pas du tout d'armements nucléaires comme dans le livre de Pranger et Labrie, mais de centrales nucléaires. En 38 pages exactement, Mueller nous présente de façon succincte les principaux éléments du débat sur l'épineuse question de l'énergie nucléaire. Après un bref historique sur l'énergie nucléaire au Canada, et une description du processus de production d'énergie nucléaire et du système CANDU, Mueller analyse brièvement une dizaine des plus importants problèmes touchant le nucléaire. Malheureusement, ces questions sont abordées de façon assez superficielle, et avec un net biais en faveur du développement de l'énergie nucléaire au Canada. L'auteur transmet sans esprit critique des préjugés et des demi-vérités qui seraient beaucoup plus de mise dans la propagande officielle des marchands du nucléaire comme Énergie atomique du Canada et l'Association nucléaire canadienne que dans un rapport qui se veut objectif et désintéressé. C'est une plaquette à lire par ceux qui veulent une présentation simple et

98 Mueller, Peter G., On Things Nuclear: The Canadian Debate, Toronto, Canadian Institute of International Affairs, 1977. 
brève du débat sur le nucléaire au Canada, par un partisan de l'option pronucléaire. 
Mouvement écologiste, énergie et environnement.

Essais d'écosociologie.

Troisième partie . Perspectives critiques

\section{Chapitre 5}

\section{"Présentation du numéro spécial sur Écologie sociale et mouvements écologiques."}

Texte publié dans la revue Sociologie et Sociétés, vol. 13, no 1, avril 1981, p. 311.

\section{par Jean-Guy Vaillancourt}

$\underline{\text { Retour à la table des matières }}$

Depuis une dizaine d'années, la sociologie tente, pour la seconde fois, de se rapprocher de l'écologie. Certains sociologues remettent à nouveau de l'avant l'idée que le milieu biophysique exerce une influence considérable sur le changement social. D'autres, plus nombreux, insistent sur l'importance cruciale des agents et des facteurs sociaux dans les processus de transformations environnementales et sur la nécessité de réintégrer le monde humain dans l'histoire de la nature. La sociologie de l'environnement évolue maintenant en étroite affinité avec la nouvelle sociologie des mouvements sociaux, tout comme l'écologie humaine classique de l'entre-deux-guerres s'était développée en symbiose avec la sociologie urbaine et avait abouti à un champ nouveau auquel on donna le nom d'écologie urbaine. 
Le présent numéro reflète ces nouvelles préoccupations des sociologues qui s'intéressent aux questions environnementales. Il y est question d'abord d'écologie sociale, ce domaine de l'écologie qui s'occupe surtout des déterminants sociaux de la crise écologique et des solutions sociales qui peuvent y être apportées. Mais la plupart des dix articles inédits que nous publions ici portent plutôt sur divers aspects du mouvement écologique. L'ancienne préoccupation concernant la suprématie relative des facteurs écologiques sur les facteurs sociaux se trouve ainsi reléguée au second plan.

Déjà, les penseurs de la Grèce antique parlaient de l'influence de la nature, théâtre des dieux, puis lieu de la raison, sur les humains. Mais, certains d'entre eux avaient aussi noté l'action, parfois bénéfique, mais souvent néfaste, des hommes sur leur milieu physique. Bien avant les recherches des écologistes de l'école de Chicago, des précurseurs importants de la sociologie, comme Vico, Ibn Khaldun, Montesquieu, Malthus, Morgan, Marx, Darwin, LePlay, Geddes et, au début du XXe siècle, Durkheim et Halbwachs eux-mêmes, avec leur intérêt pour la morphologie sociale et l'étude du phénomène social total, avaient jeté les bases d'une science sociale qui tenait compte de l'environnement naturel sans toutefois sombrer dans le déterminisme absolu des facteurs matériels.

Ce sont les sociologues de l'Université de Chicago - Park, Burgess, McKenzie et Wirth entre autres - qui introduisirent vraiment la perspective écologique en sociologie par leurs travaux sur la répartition spatiale de divers phénomènes sociaux et culturels. Le recours aux concepts de communauté biotique, d'habitat, d'aire naturelle et de zone concentrique, et aux processus de compétition pour l'espace, de succession, de dominance et de coopération, permit à ces sociologues d'aller au-delà d'une simple transposition, sur un registre social, des idées de Darwin et de Haeckel. En utilisant l'environnement biophysique, avec la lutte pour la vie qui s'y déroule, comme un modèle de ce qui se passe dans la société, ils proposaient implicitement une façon non réductionniste de concevoir le rapport entre la société et son substrat matériel, mais ils devenaient aussi des apologistes et des idéologues du capitalisme de leur époque.

Secouée par les sérieuses critiques de l'approche socio-culturelle qui apparurent durant les années trente et quarante, cette écologie humaine classique fut mo- 
difiée et réaffirmée à la fois à travers les positions néo-orthodoxes de Quinn et de Hawley, qui publièrent tous les deux un livre intitulé Human Ecology en 1950. Durant les années cinquante et au début des années soixante, les débats de cette écologie humaine traditionnelle (classique, socio-culturelle et néo-orthodoxe) continuèrent dans cette branche de la sociologie urbaine que les manuels de sociologie appellent encore l'écologie urbaine, mais on a nettement l'impression que celle-ci, même dans les raffinements les plus sophistiqués de l'écologie factorielle, tourne un peu en rond et se perd de plus en plus dans la quantophrénie et l'insignifiance.

En Amérique du Nord, la réapparition d'une perspective écologique chez les sociologues est venue, non pas de l'intérieur de la sociologie, où Hauser, Duncan, Schnore et Cottrell avaient quand même maintenu une analyse intéressante des liens entre la société et le milieu biophysique, en opposition au sociocentrisme dominant, mais de l'impact de la crise de l'environnement telle qu'elle fut perçue dans ses débuts par des spécialistes des sciences de la vie comme Paul Sears, Frank Fraser Darling, Aldo Leopold, SPR Charter, Rachel Carson, Frank Egler, Barry Commoner, René Dubos, les Odum, Shepard et McKinley, et Pierre Dansereau. La préoccupation des problèmes graves qui commençaient à menacer l'écosphère au milieu des années soixante poussa des jeunes sociologues vers la nouvelle écologie humaine élaborée par les biologistes, et amena rapidement un nouvel essor de la perspective écologique en sociologie. La sociologie de l'environnement, apparue d'abord aux États-Unis comme section dans la Société de sociologie rurale, puis dans la Société pour l'étude scientifique des problèmes sociaux, devint après quelques années une section de l'Association américaine de sociologie. Les sociologues s'intéressèrent d'abord aux manifestations multiformes de la crise écologique : la pollution de l'air, de l'eau et des sols, le problème des ressources naturelles, l'accroissement de la population, les questions de l'énergie et de l'alimentation. Ils s'intéressèrent aussi à l'analyse des facteurs principaux qui contribuent à cette crise, et surtout à l'étude des acteurs associés d'une façon ou d'une autre à l'existence de cette crise.

Certains disciples américains du sociologue O.D. Duncan, tels R. Dunlap et W. Catton Jr., proposent un nouveau paradigme écologique basé sur un déterminisme biophysique (la population, l'environnement matériel et la technologie étant 
des facteurs lourds dans leur relation avec l'organisation socio-culturelle), pour remplacer ce qu'ils appellent le paradigme de «l'exceptionalisme et de l'exemptionalisme humains ». Le néo-malthusianisme à la Ehrlich ou du genre Club de Rome fait aussi des adeptes, mais certains auteurs, tels Anderson, Ridgeway, Schnaiberg et Weisberg concentrent plutôt leur attention sur le fait que c'est le système socio-économique de production basé sur la logique de la croissance, du profit et de l'optimisme technologique (l'anarchiste Murray Boockchin dira que c'est le système hiérarchique de domination), qui est responsable des problèmes écologiques actuels. Ces sociologues de l'environnement, et bien d'autres encore, comme Albrecht, Burch, Buttel, Etzkowitz, Freudenburg, Gale, Morrison, Michelson, et Nelkin, préfèrent accorder beaucoup plus d'importance à l'étude du mouvement écologique que ne l'avaient fait les écologistes humains, à tel point qu'on peut dire que la sociologie de l'environnement aux États-Unis est d'abord et avant tout une sociologie du mouvement écologique.

En Europe, et spécialement en France, l'intérêt des sciences sociales pour l'écologie et l'environnement a suivi récemment un Cheminement qui n'est pas très différent de celui qu'on a pu remarquer durant la même période aux ÉtatsUnis. Par exemple, les écrits de Jean-Pierre Charbonneau, de Jean Dorst, de Pierre George, de Pierre Aguesse insistent sur les diverses manifestations de la crise écologique selon une perspective que l'on pourrait appeler d'écologie sociale, perspective qui se rapproche beaucoup de la sociologie de l'environnement ou de ce qu'en Amérique du Nord on appelle toujours l'écologie humaine. D'autres penseurs sociaux plus politisés, tels Michel Bosquet-André Gorz, René Dumont, Brice Lalonde, Edgar Morin, Serge Moscovici, Pierre Samuel, Dominique Simonnet et Alain Touraine, invitent à briser la dichotomie artificielle entre l'homme et la nature et à développer une écologie plus proprement politique. Cette écologie politique, certains auteurs américains plus politisés préfèrent lui donner le nom d'écologie radicale ou même - c'est le cas de Bookchin - d'écologie sociale.

Pour l'écologie sociale et l'écologie politique française, comme pour la sociologie de l'environnement et l'écologie radicale américaine, le mouvement écologique, spécialement le mouvement écologique anti-nucléaire, joue un rôle central comme acteur dans les changements environnementaux et même dans les changements politiques et sociaux. Il constitue par conséquent un objet privilégié 
d'analyse. C'est pour cette raison que nous avons choisi de faire porter plusieurs des textes de ce numéro spécial sur divers aspects du mouvement écologique et du mouvement anti-nucléaire. Le choix des thèmes abordés ici témoigne ainsi de notre volonté de contribuer à un débat qui est devenu l'un des plus urgents pour l'avenir de l'humanité. Notre dossier est loin d'être exhaustif, mais il nous semble constituer un échantillon assez représentatif des nouvelles orientations de l'écologie sociale et de la sociologie des mouvements écologiques...

Dans ce numéro, nous avons essayé de couvrir un certain nombre de questions et de débats concernant l'écologie sociale et les mouvements écologiques. Nous espérons que les dix essais réunis ici contribueront à accélérer l'édification de ce nouveau champ d'analyse qu'est la sociologie de l'environnement. Cette nouvelle branche de la sociologie, qui est en train de se développer un peu partout dans le monde, se partage entre l'analyse du mouvement écologique, et spécialement du mouvement anti-nucléaire d'une part, et un débordement interdisciplinaire dans un nouveau paradigme sociologique qui tient beaucoup compte des fondements biophysiques de la société, sans cependant leur accorder un rôle complètement déterminant. Dans le premier cas, elle analyse les nouvelles luttes sociales pour la protection de l'environnement biophysique, dans le second, elle met en question l'anthropocentrisme et le culturalisme exagéré des sciences humaines. Dans les deux cas, elle participe au

renouvellement de la pensée écologique qui, depuis le début des années soixante, sous l'impact de la détérioration du milieu et de la crise des ressources naturelles, met en rapport les problèmes de l'environnement et les transformations sociopolitiques. C'est une étude de quelques aspects de cette nouvelle écologie sociale et une analyse des idéologies et des pratiques de quelques mouvements écologiques que nous proposons dans ce numéro de la revue Sociologie et Sociétés. 
Mouvement écologiste, énergie et environnement.

Essais d'écosociologie.

Troisième partie . Perspectives critiques

\section{Chapitre 6}

\section{"Société de gaspillage, société de conservation et écosociété : des scénarios à la demi-douzaine.”}

Texte publié dans L'Environnement, vol. 8, no 2, mai 1981, p. 8.

\section{par Jean-Guy Vaillancourt}

\section{$\underline{\text { Retour à la table des matières }}$}

Le mouvement écologique québécois est un ensemble relativement original et hautement diversifié de groupes et de tendances qui vont de la contre-culture au courant social alternatif, du conservationisme et de l'environnementalisme à l'écologie politique. Dans un article sur les associations écologiques québécoises paru dans un numéro spécial de la revue Sociologie et Sociétés, consacré dans son entier à l'écologie sociale et aux mouvements écologiques, je décris cette évolution, cette diversité, et cette originalité du mouvement écologique québécois ${ }^{99}$. Ici, je voudrais plutôt attirer l'attention sur un livre important pour ceux que préoccupent les problèmes graves qui se posent à l'environnement. Ce livre, qui exprime bien les idées d'un des courants principaux du mouvement écologique québécois, le

99 Sociologie et Sociétés, vol. XIII, numéro spécial sur «Écologie sociale et mouvements écologiques », sous la direction de Jean-Guy Vaillancourt. 
courant conservationniste, et qui a pour titre La Société de conservation ${ }^{100}$, a été écrit par des membres du GAMMA (Groupe associé Université de Montréal/Université McGill pour l'étude de l'avenir), une équipe interdisciplinaire de futurologues créée en 1974 sous la direction d'un économiste de l'Université de Montréal, Kimon Valaskakis. Ce groupe de prospective a reçu, en novembre 1974, une commandite de la part de 14 départements et agences du gouvernement fédéral pour une étude sur les conséquences de divers scénarios de croissance économique pour l'année 1995. Le rapport final de 1976, basé sur 18 mois de recherches, est constitué de trois volumes techniques (comprenant en tout 15 rapports traitant des aspects technologiques, institutionnels et axiologiques de la question) et un quatrième volume d'intégration et de synthèse. L'ouvrage, La Société de conservation, publié dans sa version française par les Éditions Quinze, est une adaptation moins technique de ce quatrième volume, adaptation destinée au grand publie.

Le mandat du gouvernement du Canada demandait explicitement au groupe GAMMA de définir clairement l'option politique de la société de conservation, une option du juste milieu entre l'optimisme béat (à la Herman Kahn) et l'arrêt complet de la croissance sous toutes ses formes. Les 15 professeurs et les 10 chercheurs juniors qui ont travaillé à cette recherche ont pris comme point de départ le débat ouvert par le premier rapport du Club de Rome, Limites à la croissance, mais au lieu de procéder avec des modèles mathématiques de simulation de l'avenir comme l'ont fait Meadows et autres, ils ont utilisé la méthode des scénarios. De plus, ils ont resitué le problème des limites de la croissance, qu'ils estiment mal posé par le rapport du Club de Rome, en centrant l'attention sur le comportement au niveau de la consommation et sur les conséquences des différents scénarios de croissance économique. Pour Valaskakis et son équipe, c'est moins la croissance en soi qui fait problème (car une croissance de certains services et d'un certain type de production, agricole ou artisanale par exemple, peut être désirable) mais plutôt la croissance industrielle, le cyclage à sens unique. Il existe des limites au cyclage industriel et ce sont ces limites qu'il faut respecter pour éviter que le système ne s'effondre. Selon eux, l'accumulation et la consommation effrénées

100 Kimon Valaskakis, Peter S. Sindell, J. Graham Smith et Iris Martin, La Société de conservation, Montréal, Les Éditions Quinze, 1978. 
de biens n'amènent pas nécessairement une meilleure qualité de vie, un plus grand bonheur. Les auteurs estiment qu'il est possible d'éliminer le gaspillage et même de développer l'économie en respectant les lois de l'écologie, de miser sur le long terme et de conserver les ressources sans supprimer le confort auquel les gens sont habitués. Ceci peut se faire en contrôlant les besoins artificiels et en changeant les systèmes de valeurs et les lois. Ainsi, pensent-ils, on pourra arriver à une société de conservation sélective où les gens vivent plus simplement, en harmonie avec la nature. En somme, ce qui est visé, c'est la qualité de la vie et la stabilité d'une part, et la liberté et l'équité de l'autre.

Le groupe GAMMA a élaboré trois scénarios différents de ce que pourrait être une société de conservation sélective et ils opposent ces trois utopies réalistes au statu quo et à une possible société de gaspillage. La présentation de ces cinq scénarios constitue la trame du livre. Examinons les à tour de rôle en commençant par la fin, c'est-à-dire par la société de gaspillage.

1 - La société de gaspillage (faire moins avec plus) est l'antithèse de la société de conservation. Elle est tout à fait anti-écologique, basée sur le court terme et sur l'accroissement continu de la production. C'est de l'anti-conservation à outrance. Le rapport rejette cette option, et à juste titre, comme étant la moins désirable de toutes.

2 - La seconde option possible est le statu quo, une version mitigée de la société du gaspillage dont la philosophie est de « faire plus avec plus ». C'est une société où la croissance est peu contrôlée, une société de conservation-zéro. Si cette option était retenue, ce serait la catastrophe à moyen terme plutôt qu'à court terme comme dans le cas précédent.

3 - La société de conservation sélective, version 1, vise à faire plus avec moins, c'est-à-dire à concilier la croissance avec la conservation. Cette SC 1 est, des trois types de sociétés de conservation, celle qui se rapproche le plus du statu quo. Cette société de croissance conservationniste et efficiente d'industrialisation et de recyclage est basée sur les valeurs qui rappellent l'éthique protestante de Weber. On a l'impression que c'est cette « option écossaise » que Valaskakis et ses collègues préfèrent, puisqu'elle implique un minimum de contraintes, puisque 
l'égalité s'y instaure par la croissance plutôt que par la redistribution et puisqu'on réduit le gaspillage sans changer le niveau de vie ou le système de valeurs. Les stratégies mises de l'avant pour y arriver sont la généralisation de la location et du bail des biens peu utilisés (par ex. chalets, autos, outils), la réforme des habitudes de consommation inefficientes, l'utilisation d'une technologie de conservation, de techniques améliorées et de ressources renouvelables, la fixation des prix au coût total (avec une taxe qui tient compte des coûts externes) et enfin la réglementation publique pour stimuler le recyclage.

4 - la deuxième version de la société de conservation sélective (SC 2) pourrait s'appeler l'option grecque. Elle comprend SC 1, mais va encore plus loin dans la direction de la conservation, car le cyclage y est à son optimum. Elle tente de faire « la même chose avec moins ». C'est la position modérée, celle qui gèle la création des besoins artificiels et encourage une publicité qui prône la conservation plutôt que la consommation. C'est l'option de la stabilité dans l'affluence, de la croissance industrielle zéro mais limitée à certains secteurs, de la croissance urbaine zéro dans les grandes agglomérations, et de la croissance démographique zéro. Ses prophètes sont John Stuart Mill et Ezra Mishan, son idéal, l'Europe de 1910 avec un peu plus d'égalité. On accepte de maintenir l'aisance matérielle à un niveau élevé et même de l'augmenter pour ceux qui sont défavorisés, mais on continue à pourvoir aux besoins (même artificiels) acquis et existants de ceux qui sont déjà favorisés. Dans SC 3, ces besoins seront réduits plutôt que seulement gelés.

5 - La société de conservation sélective (SC 3), c'est ce que le groupe GAMMA appelle le choix bouddhique (faire moins avec moins et faire autre chose). Celle-ci adopte la philosophie du "small is beautiful» de Schumacher, de la conservation non pas optimale mais maximale. Elle implique un minimum de moyens et une diminution de la consommation. Elle dé-industrialise et désurbanise. C'est la société de la technologie appropriée de Goldsmith, c'est l'harmonie avec la nature et la production des biens naturels qui répondent aux besoins réels. On y trouve une croissance négative des besoins artificiels et matériels. Ce type de société implique un changement de valeurs profond, mais volontaire, puisque c'est une société basée sur la démocratie, l'humanisme, la justice, la coopération, l'altruisme. Les valeurs de décentralisation, d'auto-suffisance et de permanence y 
sont à l'honneur. On y pratique beaucoup le travail manuel, spécialement l'agriculture et l'artisanat. C'est une société biocentrique plutôt qu'égocentrique, ethnocentrique ou anthropocentrique. En somme, c'est un idéal élevé, trop élevé peutêtre pour qu'il soit proposé d'emblée. Le groupe GAMMA préfère viser moins haut et proposer SC 1 et SC 2 au gouvernement comme politique à mettre en acte, quitte à proposer SC 3 comme idéal volontaire à ceux qui se sentent appelés, comme le fait Pierre Dansereau avec son appel à l'austérité joyeuse librement acceptée dans son livre de 1973, La Terre des hommes et le paysage intérieur. Cette dernière option me semble être une option environnementaliste, plutôt qu'une option purement conservationiste comme les deux précédentes, mais comme le groupe GAMMA semble hésitant à la proposer, y préférant l'option écossaise (SC 1) et l'option grecque (SC 2), je suis alors enclin à placer ce groupe parmi les conservationistes plutôt que parmi les environnementalistes.

Le livre de Valaskakis et de son groupe a été bien reçu à la fois par le gouvernement et par les militants de l'écologie de diverses tendances, ce qui pourrait surprendre. La raison de cette acceptation générale, c'est que la modération, l'absence de dogmatisme et l'irénisme manifestés par les auteurs ne donnent pas facilement prise à un rejet conservateur (qui en effet oserait se dire pour le statu quo ou pour le gaspillage) ou à une critique radicale. Même si la société de conservation sélective, dans ses versions 1 et 2, n'est pas encore l'écosociété recherchée par les écologistes radicaux, la version 3 s'en rapproche suffisamment pour attirer leur sympathie ou au moins leur silence bienveillant. En lisant, par exemple, le manifeste du Regroupement écologique québécois, section de Montréal, ou celui de l'Alliance Tournesol, ou les écrits des Amis de la Terre de Québec, de la SVP de Montréal ou des écoféministes de plus en plus nombreuses dans le mouvement écologique québécois, on s'aperçoit qu'il existe effectivement une sixième option, qui ne centre pas son attention sur le «faire » et sur " l'avoir », mais sur l'être et qui est nettement socialiste, égalitaire, et libertaire, c'est-à-dire démocratique, anti-capitaliste et anti-impérialiste, opposée à l'exploitation et à la domination. Cette sixième option, celle de l'écosociété proposée aussi par des écologistes de renommée internationale comme Murray Bookchin, Ivan Illich et Michel Bosquet, ne rencontrerait probablement pas l'assentiment de la majorité des membres du groupe GAMMA, car l'option bouddhique (SC 3) leur apparaît déjà excessive. En effet, au chapitre VI, SC 1 est comparée à une diète pour réduire le cholestérol, 
alors que SC 3 est comparée à la « chirurgie du coeur qui est plutôt une méthode radicale. En fait, ce n'est que si SC 1 échoue que l'on devrait considérer SC 2 et ainsi de suite à moins que SC 3 ne soit librement admis comme étant un mode de vie plus valable, et sans la contrainte de l'urgence » (p. 104).

Il n'est pas surprenant non plus de voir l'évaluation assez positive qui est faite dans ce livre de l'énergie nucléaire obtenue par la fission, quand on constate que le directeur de l'Institut de génie nucléaire de l'Université de Montréal fait partie de l'équipe de recherche du GAMMA. On pourrait aussi reprocher au groupe GAMMA de faire trop confiance aux autorités fédérales pour la solution des problèmes écologiques, et de ne pas suffisamment toucher au problème des inégalités sociales et internationales. J'ai sursauté par exemple quand dans un des chapitres sur SC 2, les auteurs proposent de seulement arrêter la création de besoins artificiels nouveaux : « Dans le contexte de SC 2, le 'besoin' de posséder un yacht serait satisfait si un tel 'besoin' existait déjà. Néanmoins, on devrait décourager les besoins de cette nature (p. 166). »

La méthode des scénarios présente un intérêt certain pour un gouvernement en quête de politiques rentables au plan électoral, mais il lui manque une capacité d'analyser les causes profondes des problèmes, ce qui serait en définitive la manière la plus sûre de trouver des solutions qui puissent aller à la racine du malaise et qui soient par conséquent autre chose qu'un palliatif temporaire. À cet égard, les personnes préoccupées par la crise de l'environnement, par la pollution et la pénurie de ressources, auraient intérêt à lire non seulement ce livre, mais aussi ceux d'Anderson, de Bookchin, de Bosquet, de Commoner, de René Dumont, d'Illich, de Lovins, de Ridgeway, de Schnaiberg et de Weisberg, entre autres, qui sont plus critiques vis-à-vis les grandes entreprises et vis-à-vis le système de production des pays industriels avancés, et qui proposent des alternatives plus radicales que celles envisagées par GAMMA.

Concluons. Ce livre a des lacunes au plan de l'analyse des causes de la crise écologique et par conséquent des solutions à y apporter. Et pourtant, par les réformes suggérées et le refus motivé du statu quo et du gaspillage, il apporte une contribution importante au débat écologique ainsi qu'au combat en faveur d'une gestion saine et d'une protection accrue de l'environnement. C'est un pas dans la 
bonne direction. C'est donc un livre qu'il faut connaître et dont il faut, comme strict minimum, mettre les recommandations en pratique. Ce n'est pas à partir des décombres de la société de gaspillage que pourra s'édifier du jour au lendemain l'écosociété, mais plutôt des amorces créées par les réformes limitées, mais réelles, de la société de conservation telle que proposée par GAMMA. 
Mouvement écologiste, énergie et environnement.

Essais d'écosociologie.

Troisième partie . Perspectives critiques

Chapitre 7

\section{"Relations industrielles et changements technologiques dans les mines de l'INCO.”}

Texte à paraître dans la Revue canadienne de sociologie et d'anthropologie, vol. 19, no 3, octobre-novembre 1982.

\section{par Jean-Guy Vaillancourt}

$\underline{\text { Retour à la table des matières }}$

Wallace Clement, professeur de sociologie à l'Université Carleton d'Ottawa, est l'auteur de divers ouvrages et articles sur les élites économiques et sur l'économie politique du Canada. Il est présentement considéré, bien qu'il soit encore passablement jeune, comme l'un des plus intéressants sociologues du Canada anglais. En se basant surtout sur des centaines d'interviews, faites avec des employés à tous les niveaux de la compagnie INCO, ainsi que sur la documentation écrite et de l'observation non participante, Clement a étudié le rapport entre la technologie de production et les relations de travail dans l'industrie minière canadienne, en centrant son attention sur la très puissante compagnie INCO, le plus grand producteur de nickel au monde ${ }^{101}$. Cette entreprise multinationale est bien connue

101 Wallace Clement, Hardrock Mining. Industrial Relations and Technological Changes at INCO, Toronto, McClelland and Stewart, 1981. 
du grand public comme étant une compagnie qui tente régulièrement de briser les grèves de ses employés et qui a contribué plus que toute autre compagnie canadienne au meurtre de nos lacs par les pluies acides. Avant la publication de ce livre, aucune étude sérieuse d'envergure n'avait été faite sur la structure et les activités de cette compagnie, par un spécialiste des sciences sociales. L'excellente monographie de Clement comble donc un vide important. Elle constitue aussi la première pièce d'un ensemble plus vaste de recherches que l'auteur se propose de mener dans les années qui viennent sur les transformations des classes sociales au Canada depuis la Seconde Guerre mondiale.

Clement commence son ouvrage en prenant ses distances vis-à-vis de l'approche de l'historien économique Harold Innis, un peu comme il avait distingué sa position de celle du sociologue John Porter dans son livre de 1975 intitulé The Canadian Corporate Elite. Selon lui, la formation du capital et les relations de classe qui en découlent expliquent mieux la situation dans le secteur minier que la qualité physique du minerai, comme le croyait Innis. En d'autres termes, pour Clement, le social et l'économique dominent la technologie et non l'inverse. À l'INCO, c'est donc la capitalisation qui a amené la mécanisation accrue dans les opérations sous terre, et l'automation dans le travail de surface. Celle-ci a aussi diminué la proportion et même le nombre d'emplois spécialisés, qui se trouvent déplacés vers des firmes étrangères qui produisent des machines et qui font de la recherche pour l'industrie minière canadienne. De plus, la compagnie INCO a internationalisé et diversifié ses opérations à mesure qu'elle misait davantage sur un style de production capital-intensif plutôt que travail-intensif. Ces transformations économiques et sociales ont amené des changements importants au plan des relations de travail, spécialement en ce qui a trait au genre de contrôle exercé par la partie patronale et au type de résistance offerte par les mineurs pour maximiser leurs revenus et leur sécurité et pour améliorer leurs conditions de travail. Dans le coeur de son ouvrage, après avoir décrit en détail les opérations souterraines et de surface à l'INCO, ainsi que le problème de la santé et de la sécurité des travailleurs, Clement scrute et analyse avec finesse les mécanismes anciens et nouveaux de contrôles patronaux, tant ceux qui sont utilisés sur les lieux mêmes du travail que ceux, plus généraux et, en quelque sorte, externes du lieu de travail, qui sont mis en branle par la compagnie. Clement complète cela avec le revers de la médaille, c'est-à-dire avec un chapitre sur la résistance des ouvriers à ces stratégies 
changeantes de maximisation des profits mises de l'avant par des dirigeants de l'INCO, en insistant sur le développement du syndicalisme et sur le déroulement des grèves qui ont eu lieu à l'INCO. Clement montre que la nouvelle technologie prive le travailleur de son expertise, et par conséquent de son indépendance, ce qui cause chez lui beaucoup de résistance. Enfin, l'auteur termine avec un chapitre sur l'économie politique du secteur minier, où il revient sur le problème de l'exploitation des emplois causés par les séquelles de la capitalisation et où il aborde la question centrale de l'aide de l'État (surtout à travers les subventions). Il insiste finalement sur la nécessité pour les mineurs de socialiser et de contrôler le processus de production pour que ce soient eux et non les propriétaires qui profitent des avantages qu'apportent les améliorations technologiques.

Comme on le voit, ce livre constitue un apport important à plusieurs disciplines, dont la sociologie, la science politique, l'économie politique, l'histoire et les relations industrielles. Il sera probablement utilisé dans plusieurs cours de sciences sociales comme lecture requise, et de plus, il risque de rejoindre un vaste public cultivé, car il traite d'un sujet brûlant qui intéresse beaucoup de gens. Et si l'on en juge par ce premier ouvrage de la série annoncée, l'ensemble sera une contribution imposante à la connaissance des problèmes du travail au Canada. C'est aussi un bon ouvrage empirique, qui illustre bien le processus de recherche sur une organisation économique. C'est même un modèle du genre, tant au point de vue méthodologique que théorique, car il intègre dans un cadre solide des données substantielles ramassées avec un ensemble varié de techniques de recherches adaptées au but poursuivi. On ne trouvera donc pas de fétichisme méthodologique, ni non plus de dogmatisme théorique dans cet ouvrage. Les conclusions découlent clairement des données empiriques ramassées. L'auteur touche aux questions importantes et il les aborde simplement, et de façon très juste. J'ai été particulièrement impressionné par sa façon de structurer ses dix chapitres : il y a un ordre de progression dans l'exposition qui rend le tout très agréable à lire. Les citations directes qui entrecoupent le texte en rendent aussi la lecture bien agréable, et font que le livre est facilement abordable par des lecteurs non spécialisés, même si c'est un ouvrage savant (ce qui ne veut pas dire que c'est un ouvrage pédant et rempli de redondance comme le sont malheureusement beaucoup d'ouvrages soi-disant « savants »). 
Il n'y a pas dans cet ouvrage de lacunes graves, ni d'entorses à la vérité. L'auteur a ramassé ses données de façon très objective, ce qui ne l'empêche pas d'être un sociologue engagé, ayant une perspective critique et radicale. Signalons aussi l'absence remarquable de moralisme et de préjugés idéologiques pour un ouvrage de ce genre. Même ceux qui ne sont pas d'accord avec la perspective marxisante de l'auteur, devront, en toute honnêteté, admettre que c'est un ouvrage basé sur une enquête sérieuse sur le terrain et dans la documentation écrite. Par ailleurs, on voit que l'auteur a ciselé et travaillé son texte de façon à le rendre lisible et compréhensible, contrairement à certains auteurs contemporains qui nous servent un repas mal apprêté dans une cuisine tout en désordre. En somme, en comparaison avec plusieurs autres ouvrages parus sur des entreprises ou des secteurs économiques, non seulement au Canada mais même en Europe et aux États-Unis, celui-ci apparaît d'emblée comme étant parmi les meilleurs au point de vue de l'originalité, de la solidité des données, de la présentation, de la structure, de l'intérêt, et de l'érudition. Bien peu de travaux de ce genre par exemple vont autant en profondeur, tout en utilisant abondamment de nombreux extraits verbatim d'interviews avec les acteurs impliqués.

Certains lecteurs trouveront peut-être que les descriptions détaillées des processus de production dans les chapitres 5 et 6 sont trop longues et auraient dû être abrégées. Je ne suis pas du tout de cet avis. Ces deux chapitres, malgré leur technicité, sont essentiels et méritent d'être lus. Le lecteur pressé peut toujours passer plus rapidement sur ces chapitres, mais la valeur de l'ouvrage repose en bonne partie sur cette connaissance précise que Clement démontre des aspects techniques du travail dans les mines de Sudbury et de Thompson. Ce sont ces chapitres qui montrent que ce livre n'est pas la somme des élucubrations théoriques d'un idéologue de salon, mais le résultat d'une recherche empirique basée sur l'observation minutieuse -et sur une profonde compréhension de la vie ouvrière canadienne. 
Mouvement écologiste, énergie et environnement.

Essais d’écosociologie.

\section{BIBLIOGRAPHIE SOMMAIRE}

$\underline{\text { Retour à la table des matières }}$

AGUESSE, Pierre, Clefs pour l'écologie, Paris, Seghers, 1971.

ALBRECHT, Stan L., « Legacy of the Environmental Movement », Environment and Behavior, 8, 1976, p. 147-168.

ALIHAN, Milla A., Social Ecology, A Critical Analysis, New York, Cooper Square Publishers, 1964.

ANDERSON, Charles H., The Sociology of Survival, Homewood (Ill.), The Dorsey Press, 1976.

BOOKCHIN, Murray, Pour une société écologique, Paris, Christian Bourgeois, 1976.

BUTTEL, Frederick H., "Social Science and the Environment : Competing Theories », Social Science Quarterly, 57, 1976.

CARSON, Rachel, Printemps silencieux, Paris, Plon, 1963.

CASTORIADIS, Cornélius, Daniel Cohn-Bendit et le public de Louvain-laNeuve, De l'écologie à l'autonomie, Paris, Seuil, 1981. 
CHARBONNEAU, J.-P. et al., Encyclopédie de l'écologie, Paris, Larousse, 1977.

CHARTER, S.P.R., Man on Earth : A Preliminary Evaluation of the Ecology of Man, New York, Grove Press Inc., 1970.

COMMONER, Barry, Science and Survival, New York, The Viking Press, 1966.

COMMONER, Barry, Quelle terre laisserons-nous à nos enfants ?, Paris, Seuil, 1969.

COMMONER, Barry, L'Encerclement, problèmes de survie en milieu terrestre, Paris, Seuil, 1972.

COTTRELL, Fred, Energy and Society, New York, McGraw Hill, 1955.

DANSEREAU, Pierre, Biogeography, An Ecological Perspective, New York, Ronald Press Co., 1957.

DANSEREAU, Pierre, La Terre des hommes et le paysage intérieur, Montréal, Leméac, 1973.

DOGGAN, M. et ROKKAN, Stein (édit.), Quantitative Ecological Analysis in the Social Sciences, Cambridge, Mass., 1969.

DORST, Jean, La Nature dénaturée, Paris, Delachaux et Niestlé, 1965.

DORST, Jean, Avant que nature meure, Paris, Delachaux et Niestlé, 1978.

DUBOS, René, Les Dieux de l'écologie, Paris, Fayard, 1973.

DUBOS, René, L'Homme et l'adaptation au milieu, Paris, Payot, 1973.

DUBOS, René, Choisir d'être humain, Paris, Denoël, 1974. 
DUMESNIL, Thérèse, Pierre Dansereau. L'écologiste aux pieds nus, Montréal, Nouvelle Optique, 1981.

DUMONT, René, L'Utopie ou la mort, Paris, Seuil, 1973.

DUMONT, René, La Croissance... de la famine! Une agriculture repensée, Paris, Seuil, 1975.

DUMONT, René, Seule une écologie socialiste.... Paris, Robert Laffont, 1977.

DUNCAN, Otis Dudley, «Human Ecology and Population Studies », dans Philip M. Hauser et O.D. Duncan, The Study of Population, Chicago, the University of Chicago Press, 1959, p. 678-716.

DUNCAN, Otis Dudley, "Social Organization and the Ecosystem », dans Robert E.L. Faris (édit.), Handbook and Modern Sociology, Chicago, Rand McNally, 1964, p. 36-83.

DUNCAN, Otis Dudley, «From Social System to Ecosystem », dans Michael Micklin (édit.), Population, Environment and Social Organization, Hinsdale (Ill.), The Dryden Press, 1973, p. 107-117.

EHRLICH, Paul et Anne, Population, Resources, Environment: Issues in Human Ecology, New York, W.H. Freeman, 1970.

EHRLICH, Paul et Anne, La Surpopulation, Paris, Payot, 1972.

EHRLICH, Paul, La Bombe P., Paris, « J'ai lu », 1972.

FRASER-DARLING, F. et John P. MILTON (édit.), Future Environments of North America, New York, The Natural History Press, 1966.

FRASER-DARLING, F., L'Abondance dévastatrice, Paris, Fayard, 1971. 
GEORGE, Pierre, L'Environnement, Paris, P.U.F., « Que sais-je ? », 1971.

GORZ, André-Michel BOSQUET, Écologie et politique, Paris, Seuil, 1978.

GRAFMEYER, Yves et Isaac Joseph, L'École de Chicago. Naissance de l'écologie urbaine, Paris, Éd. du Champ Urbain, 1979.

HALBWACHS, Maurice, Morphologie Sociale, Paris, Armand Colin, 1970. [Texte disponible dans Les Classiques des sciences sociales. JMT.]

HAWLEY, Amos H., Human Ecology, A Theory of Community Structure, New York, The Ronald Press Co., 1950.

LALONDE, Brice et SIMONNET, Dominique, Quand vous voudrez, Paris, Pauvert, 1977.

LEBRETON, Philippe, L'Ex-croissance, les chemins de 1'écologisme, Paris, Denoël, 1978.

LEBRETON, Philippe, L'Éco-logique, Paris, Interéditions, 1978.

LEOPOLD, Aldo, A Sand Country Almanach, New York, Ballantine Books, 1949

LLEWELYN, E. et HAWTHORN, A., «L'Écologie humaine », dans G. Gurvitch, La Sociologie au XXe siècle, Paris, P.U.F., 1947, t. 1, p. 477-510.

MCKENZIE, Roderick, On Human Ecology, Selected Writings, Chicago, University of Chicago Press, 1968.

MORRISON, Denton E., «The Environmental Movement: Conflict Dynamics », Journal of Voluntary Action Research, 2, 1973, p. 74-85.

MOSCOVICI, Serge, La Société contre nature, Paris, Union générale d'éditions, 1972. 
MOSCOVICI, Serge, Hommes domestiques et hommes sauvages, Paris, Union générale d'éditions, 1974.

MURKERJEE, R., Social Ecology, London, Longmans, Green, 1945.

NELKIN, Dorothy et POLLACK, Michael, The Atom Besieged : Extra Parliamentary Dissent in France and Germany, Cambridge, Mass., M.I.T. Press, 1980.

ODUM, Howard T., Environment, Power and Society, New York, WileyInterscience, 1971.

ODUM, Howard T. et ODUM, Elisabeth C., Energy Basis for Man and Nature, New York, McGraw-Hill, 1976.

ODUM, Eugene P., Écologie, Paris, Doin, 1976.

QUINN, J.A., Human Ecology, New York, Prentice-Hall, 1950.

RIDGEWAY, James, The Politics of Ecology, New York, E.P. Dutton, 1971.

ROGEL, Jean-Pierre, « Un paradis de la pollution, Sillery », Québec-Science, 1981.

SAMUEL, Pierre, Écologie : détente ou cycle infernal, Paris, Union générale d'éditions, 1973.

SAMUEL, Pierre et al., L'Homme et son environnement, Paris, CEPL, 1976.

SAMUEL, Pierre, Le Nucléaire en questions - Entretien avec Claude-Marie Vadrot, Paris, Editions Entente, 1977.

SCHNORE, L., « Social Morphology and Human Ecology », American Journal of Sociology, 63, 1958, p. 620-634. 
SEARS, Paul, Where Life Is. An Introduction to Ecology, New York, Dell, 1962.

SHEPARD, Paul et MCKINLEY, Daniel, The Subversive Science : Essays Toward an Ecology of Man, Boston, Houghton Mifflin, 1969.

SIMONNET, Dominique, L'Écologisme, Paris, P.U.F., «Que sais-je ? », 1979.

THEODORSON, George A. (édit.), Studies in Human Ecology, New York, Harper and Row, 1961.

WARD, Barbara et DUBOS, René, Nous n'avons qu'une terre, Paris, Denoël, 1972.

WEISBERG, Barry (édit.), Ecocide in Indochina : The Ecology of War, San Francisco, Canfield Press, 1970.

WEISBERG, Barry, Beyond Repair, The Ecology of Capitalism, Boston, Beacon Press, 1971.

WITTMAN, Jr. James S. (édit.), Selected Articles in Social Ecology, New York, MSS Information Corporation, 1973.

\section{Fin du texte}

Fin du texte 